\title{
Cost-Benefit Analysis in Practice
}

A study of the way Cost-Benefit Analysis is perceived by key individuals in the Dutch CBA practice for spatial-infrastructure projects

Niek Mouter 



\title{
Cost-Benefit Analysis in Practice
}

\section{A study of the way Cost-Benefit Analysis is perceived by key individuals in the Dutch CBA practice for spatial-infrastructure projects}

\author{
Proefschrift \\ ter verkrijging van de graad van doctor \\ aan de Technische Universiteit Delft, \\ op gezag van de Rector Magnificus prof. ir. K.C.A.M. Luyben, \\ voorzitter van het College voor Promoties, \\ in het openbaar te verdedigen op dinsdag 3 juni 2014 om 15:00 uur \\ door
}

Niek MOUTER

Meester in de Rechtsgeleerdheid, Master of Science in Economics and Business geboren te Leiden 
Dit proefschrift is goedgekeurd door de promotor:

Prof. dr. G.P. van Wee

\section{Copromotor: Dr. J.A. Annema}

Samenstelling promotiecommissie

Rector Magnificus

Prof. dr. G.P. van Wee

Dr. ir. J.A. Annema

Prof. dr. M.J.G. van Eeten

Prof. dr. ir. W.A.H. Thissen

Prof. dr. ir. L. Bertolini

Prof. drs. J.G. de Wit

Prof. dr. C.C. Koopmans

Prof. dr. H. Meurs

\author{
Voorzitter \\ Technische Universiteit Delft, Promotor \\ Technische Universiteit Delft, Copromotor \\ Technische Universiteit Delft \\ Technische Universiteit Delft, Reservelid \\ Universiteit van Amsterdam \\ Universiteit van Amsterdam \\ Vrije Universiteit Amsterdam \\ Radboud Universiteit Nijmegen
}

TRAIL Thesis Series T2014/2, The Netherlands TRAIL Research School

TRAIL Research School

PO Box 5017

2600 GA Delft

The Netherlands

T: +31 (0) 152786046

F: +31(0) 152784333

E: info@rsTRAIL.nl

ISBN: 978-90-5584-172-1

Cover design: Stephan Timmers

Copyright (C) 2014 by Niek Mouter

All rights reserved. No part of the material protect by this copyright notice may be reproduced or utilized in any form or by any means, electronic or mechanical, including photocopying, recording or by any information storage and retrieval system, without written permission from the author.

Printed in The Netherlands 




\section{Preface}

This thesis is the result of four and a half years of study. It has definitely been an exciting and inspirational time. During my Ph.D. I have met a lot of inspiring people and had the privilege of working closely together with some of them. In retrospect, they were years with a lot of highlights. Publishing my papers in Transportation Research Part A, presenting my Dutch Language book to Secretary General Siebe Riedstra, organizing national and international conferences, launching the www.mkba-informatie.nl website, winning the 'Young Planner of the year 2013' and 'Excellent example of knowledge transfer' awards were all great experiences.

Before I started my Ph.D. research I carried out small research projects for municipalities as an entrepreneur. I evaluated parking permit systems, Park \& Ride facilities, bicycle parking facilities, amongst other things. The work was great. The assignments were practical and concrete and I really had the idea that my clients used the results of my studies. However, one disadvantage of the work was that it was - in my opinion - a bit superficial. As well as answering my clients' research questions, I also came up with several new and (in my perception) even more interesting research questions during the research. I asked the clients if they would be interested in a follow-up study but, unfortunately, that was never the case. The research question was answered, the alderman was satisfied and the case was closed. I noticed 
that this did not satisfy my curiosity at all. I had the feeling that I was writing pamphlets whilst I aspired to write novels.

In March 2009 I discussed this issue with Cees-Jan Pen from the NICIS Institute (now Platform 31). Cees-Jan convinced me that I should apply for a Ph.D. position and I decided to apply for a position within the 'Design and Appraisal of Regional Visions on Land Use and Infrastructure' project, supervised by Jan Anne Annema. Jan Anne was positive about it and invited me for a job interview.

My trip to the job interview was not without difficulties. Firstly, the train was delayed because there was a dog on the track. Secondly, I had to wait because a bridge was open. I arrived half an hour late at Delft University of Technology. Because of this bad first impression, I expected that I could forget about the job. However, this was not the case at all. There was a very positive atmosphere and the last part of the job interview was taken up by Jan Anne and I cracking jokes together. The day after the job interview I received a phone call from Jan Anne in which he confirmed that I could start with my Ph.D. research.

My first day at the office was the department's section outing in Rotterdam. After traveling through Rotterdam on a scooter and a Djembe workshop we ended the day in a fast-food shop at 5 o'clock in the morning. I immediately got acquainted with one side of the Transport \& Logistics section that I really like: a bunch of very open laidback positive people with a great sense of humor. In the months that followed I got to know the other side of the section: a group of very professional, hardworking, highly intelligent people. I feel privileged that I have been, and still am, part of this section!

I would like to express my gratitude to many people (I hope I don't forget anyone). I owe lots of gratitude to Jan Anne (my daily supervisor) and Bert (my promotor)! Jan Anne, thank you for all the feedback on my ideas, for teaching me how to write scientific papers and for the fact that you are extremely easy to approach. It was and is a great pleasure to work together with you. Bert, thank you for the tons of good ideas, your infinite enthusiasm, the trust and for teaching me how to write journal papers in a structured way.

I also would like to thank my roommates: Sander, Zack, Thijs and Dimitris. Thank you very much for all the good laughs, listening to all my Cost-Benefit Analysis related ideas and giving feedback on some of them. In addition, I would like to thank Caspar - especially in the last years of my Ph.D., your ambition to strive for 'excellence' really inspired me. I also would like to thank Diana for carrying out the intercoder reality test in a very strict way and Traysi Smith for checking the English of my journal papers.

Special thanks go out to the OBRRI consortium that I was part of during the last four years (Els Beukers, Marco te Brömmelstroet, Luca Bertolini, Nick Smit, Bart van der Heijden, Fokko Kuik, Will Clerx, Bertus Postma, Coen Mekers, Eric Verroen, Johan Visser, Niek van der Heiden, Jaron Haas and Cees-Jan Pen). Thank you very much for your ideas, for giving me the opportunity to present and discuss my work and of course for financing the project 
(Amsterdam, Rotterdam, Gelderland and Platform 31). I especially want to thank the people from the University of Amsterdam for introducing me to planning literature and for teaching me how to approach a Cost-Benefit Analysis from a planner's perspective.

Of course I also want to thank the 86 people I interviewed for this thesis. I can't emphasize enough how grateful I am that 86 people with busy agendas were willing to schedule one hour of their time for an interview and that 74 people were willing to fill out an additional questionnaire. One of the respondents was Professor Piet Rietveld who sadly passed away on November $1^{\text {st }}, 2013$. With all his enthusiasm and intellect, Piet was one of the people that showed me what a great and challenging working environment academia is.

Special thanks go out to my family and friends. Mom and dad, thank you for all the love, support and everything else. Niek, Rick, Rick, Oscar, Pieter, Hubert, Sander and Quintin, thank you very much for all the love, good laughs, support and most of all for enjoying life together. Last, but certainly not least, I would like to thank Emma!! I consider myself extremely lucky to have you by my side. Thank you very much for all the fun, love and support and the fact that you like travelling as much as I do. During the last four years we have travelled through India, Nepal, Russia, Mongolia, China, New York, Lapland and Disneyland, to name just a few of the places. I consider myself privileged to share these experiences with you.

Niek Mouter, June 2014 



\section{Contents}

Preface

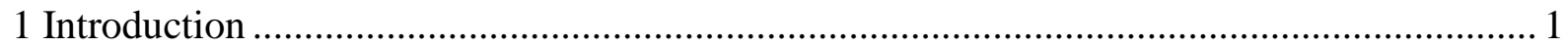

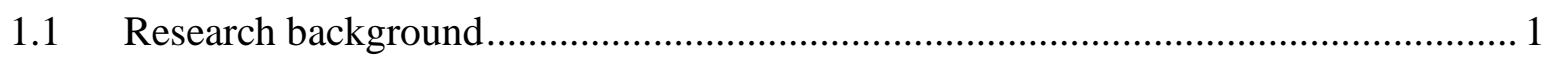

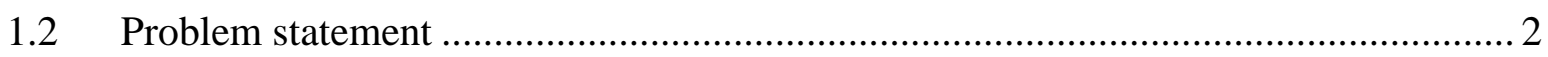

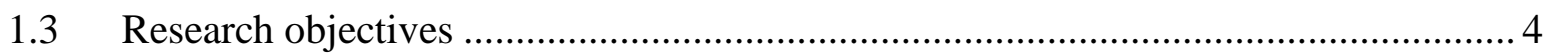

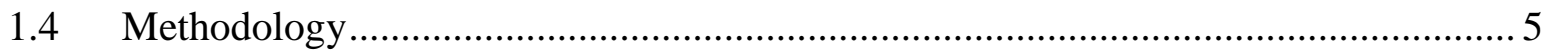

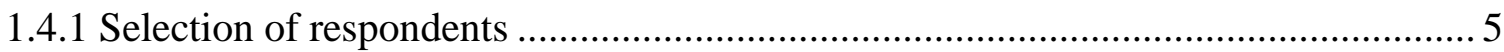

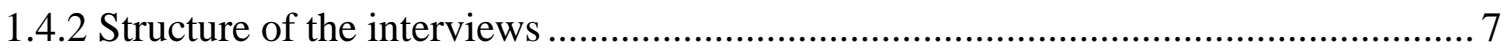

1.4.3 Characteristics of the interviewer …………………................................... 8

1.4.4 Justification of selected methods ..................................................................... 9

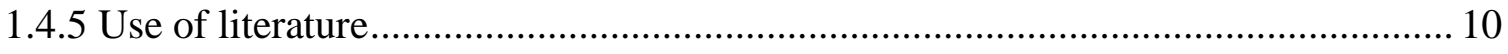

1.5 Cost-Benefit Analysis in the Netherlands .............................................................. 10

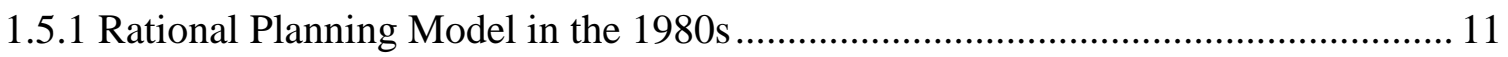

1.5.2 The interactive planning model ......................................................................... 12

1.5.3 The comeback of Cost-Benefit Analysis ............................................................ 13 


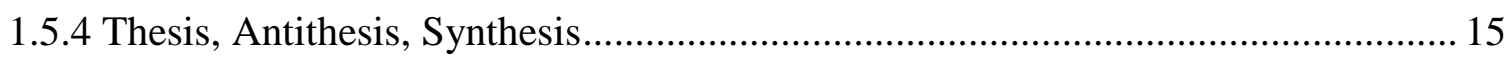

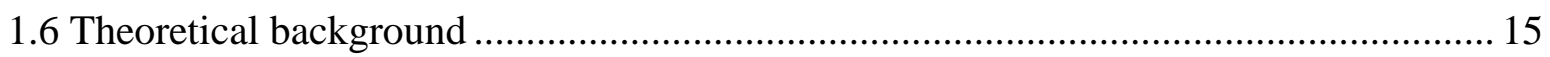

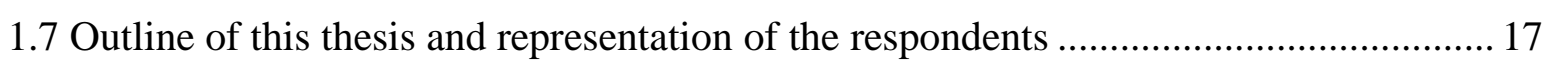

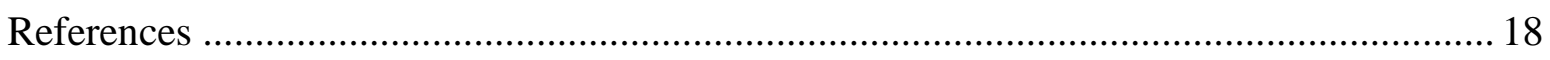

2 Ranking the substantive problems in the Dutch Cost-Benefit Analysis practice ............. 23

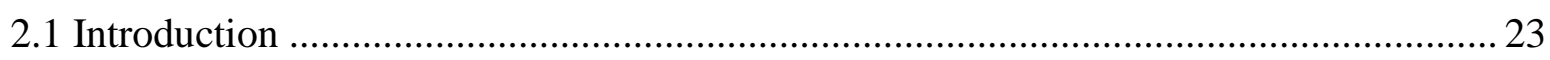

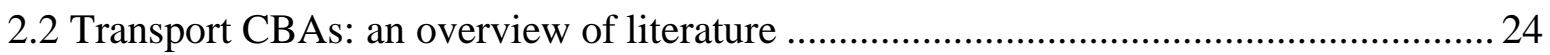

2.2.1 Seven categories of transport-related CBA literature ............................................ 24

2.2.2 Literature on (solutions for) substantive problems ............................................ 24

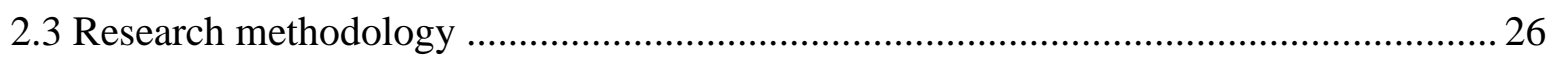

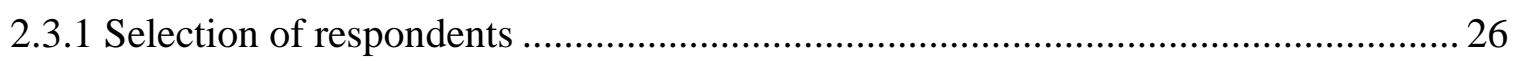

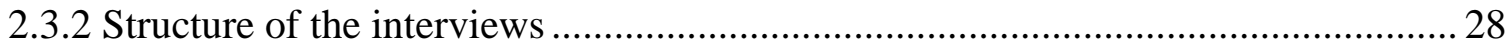

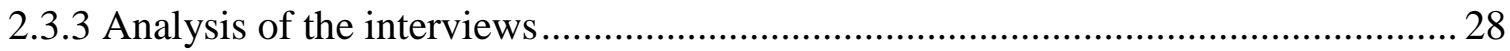

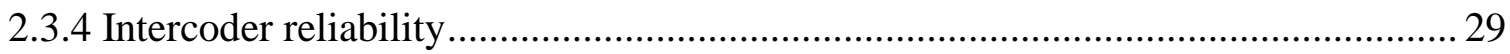

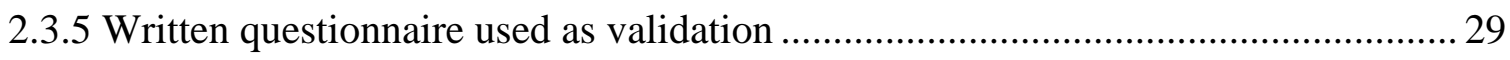

2.4 Results: ranking substantive problems in Dutch CBA practice ................................... 30

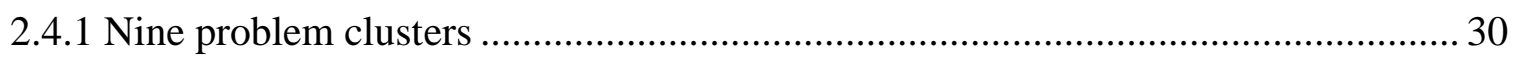

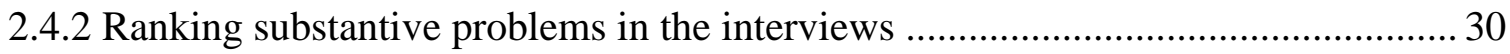

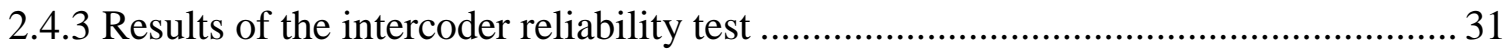

2.4.4 Ranking substantive problems in the questionnaires ............................................ 32

2.5 Interesting concrete sub-categories of problems clusters .......................................... 33

2.5.1 Problem analysis, reference case and project alternatives ................................... 34

2.5.2 Problems with the estimation of non-monetized project effects............................. 34

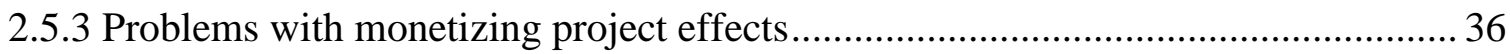

2.5.4 Problems with presentation, distributional effects and uncertainty ......................... 38

2.6 How do different groups in the Dutch CBA practice evaluate the problem clusters ..... 39

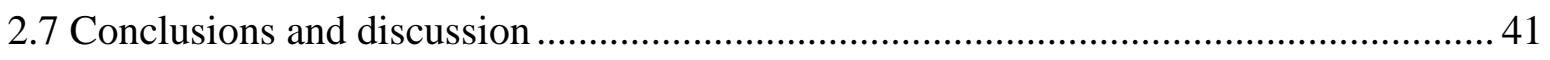

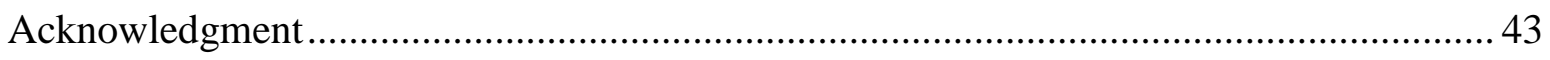

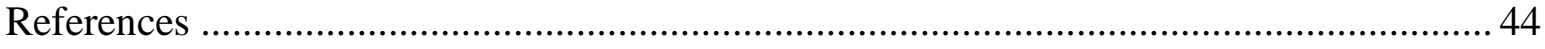

3 Attitudes towards the role of Cost-Benefit Analysis in the decision-making process for spatial-infrastructure projects: A Dutch case study ........................................................... 49

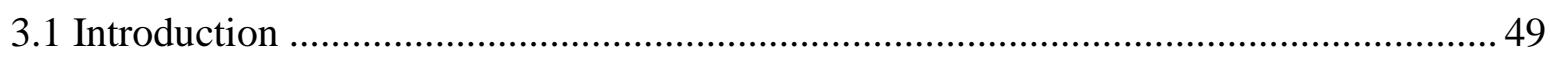

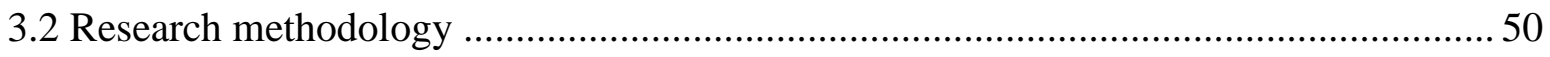

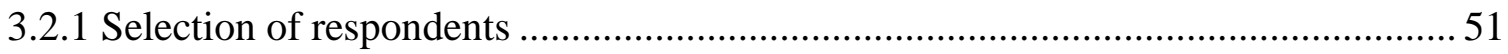




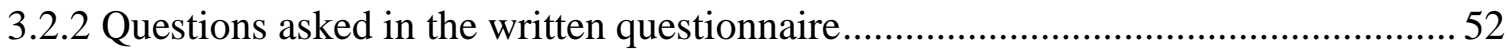

3.2.3 Analysis of the interviews with content analysis ..................................................53

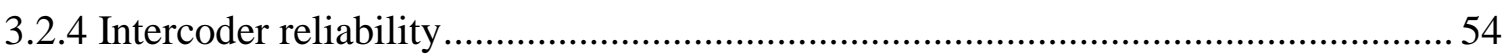

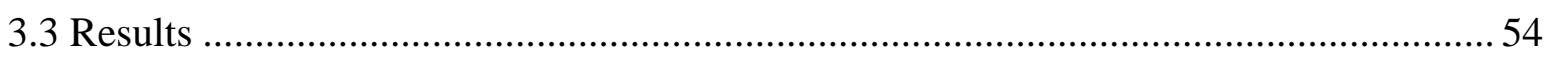

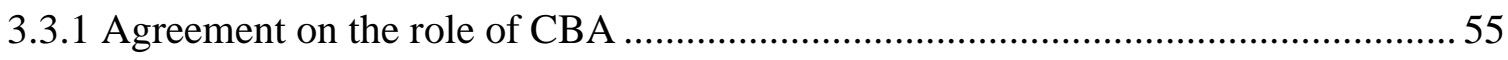

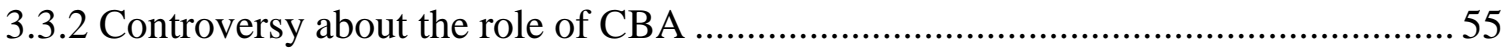

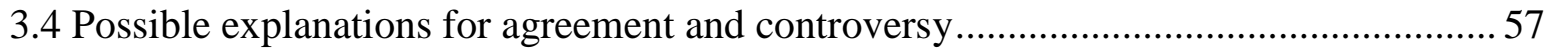

3.4.1 Actors' perceptions of CBA advantages and CBA disadvantages ..........................57

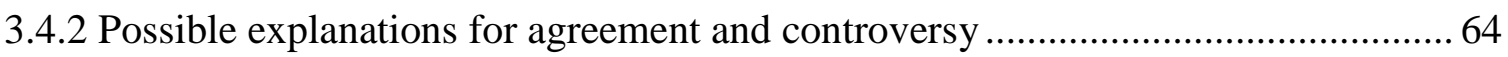

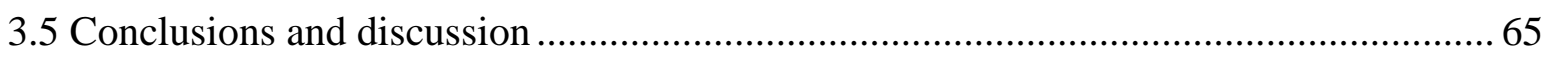

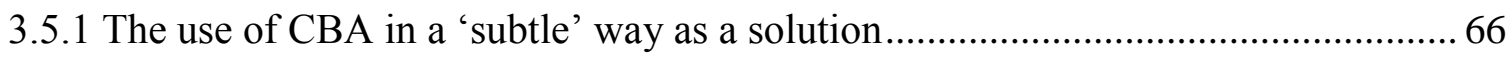

3.5.2 Further research on understanding and enhancing specific roles of the CBA ......... 68

3.5.3 Politicians underrepresented, results are limited to Dutch key actors and low

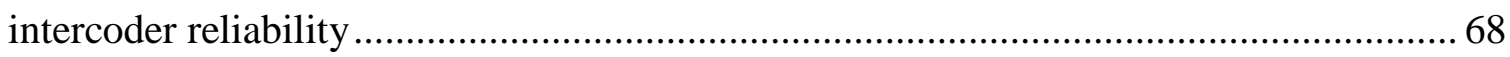

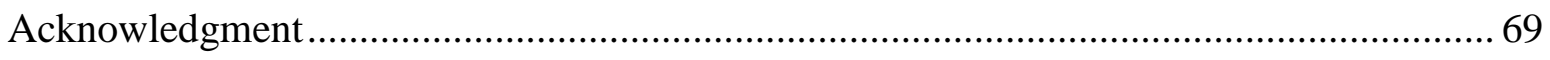

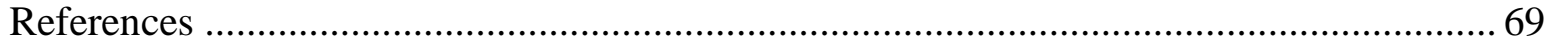

4 Solutions for substantive Cost-Benefit Analysis problems: a key actors' perspective..... 73

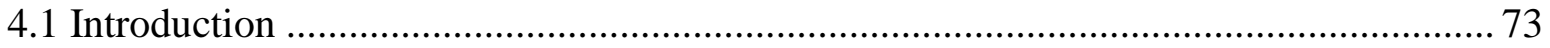

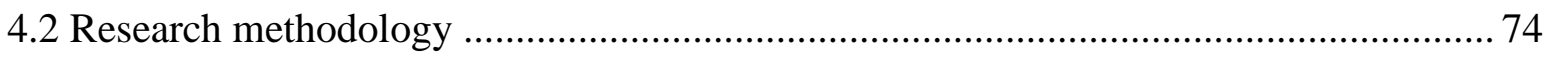

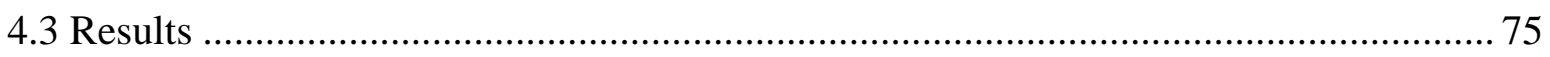

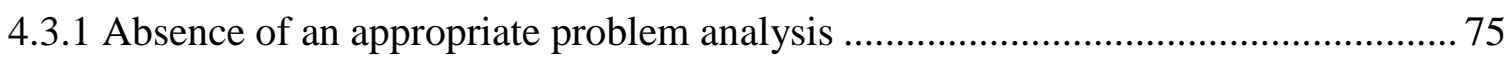

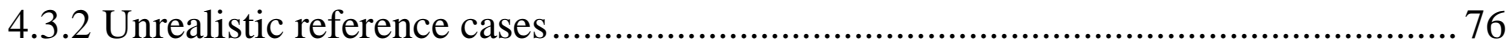

4.3.3 Lack of clarity in how to deal with spatial developments in the reference cases .... 77

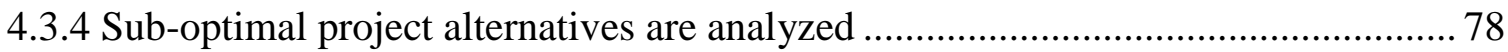

4.3.5 Several problems with the estimation of non-monetized project effects ................ 78

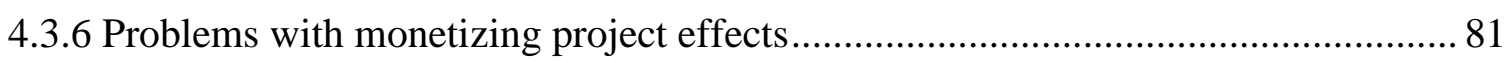

4.3.7 Discounting: two problems related to discounting ............................................. 83

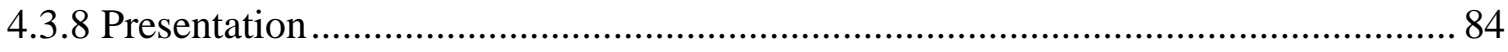

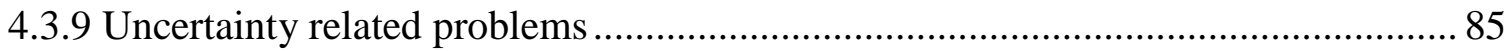

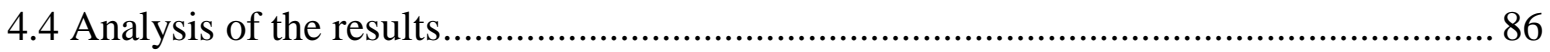

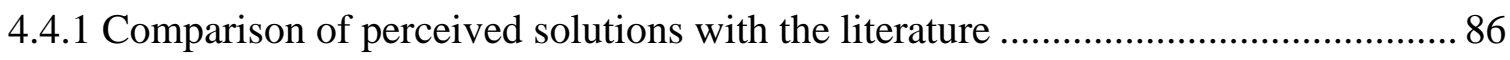

4.4.2 To which extent are solutions promising? ......................................................... 90

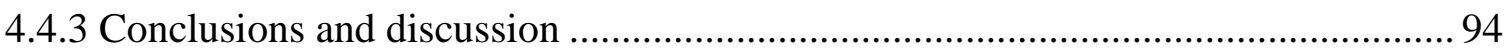

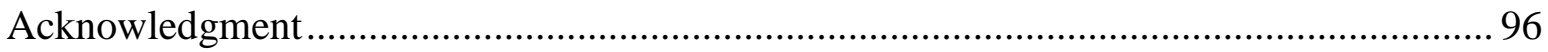


References .96

5 Managing the insolvable limitations of Cost-Benefit Analysis: results of an interview based study. 101

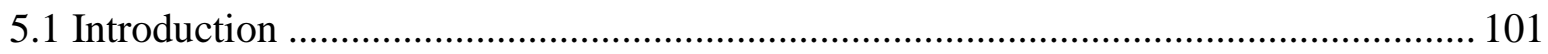

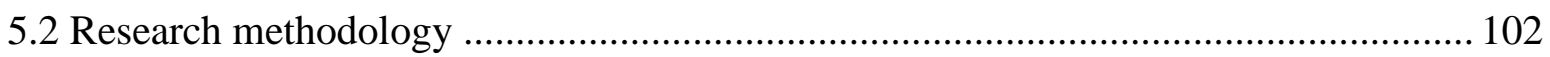

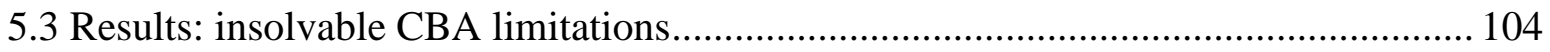

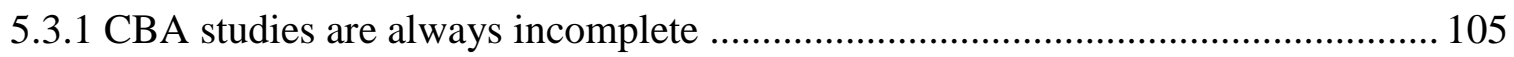

5.3.2 Outcomes of welfare effect estimations are always uncertain .............................. 106

5.3.3 Effects that are difficult to quantify/monetize have a relatively weak position..... 107

5.4 Results: when and why do respondents perceive that insolvable CBA limitations are

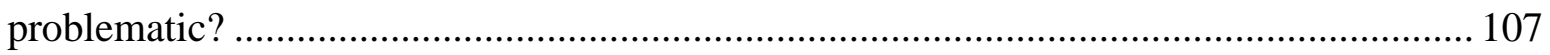

5.4.1 Why are insolvable limitations problematic? ................................................... 107

5.4.2 Why is assigning an incorrect value problematic?............................................ 109

5.5 Results: respondents' perceptions of how to manage insolvable CBA limitations ...... 110

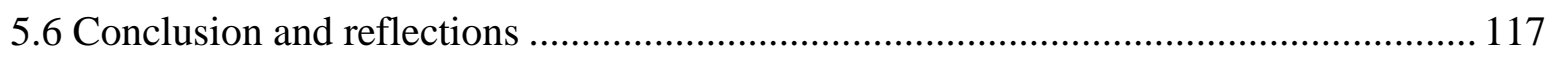

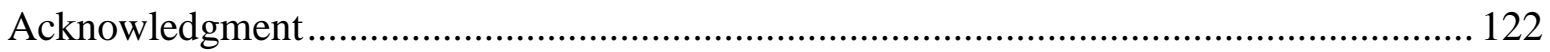

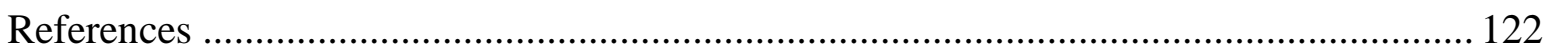

Appendix 5.1: respondents and affiliation at the time of the interview........................... 126

Appendix 5.2: number of respondents that mentioned a solution ................................... 129

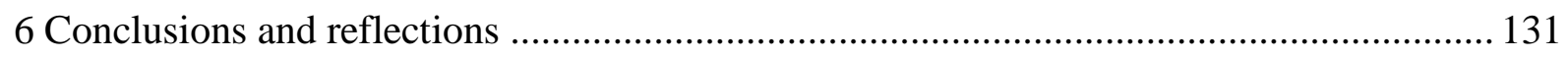

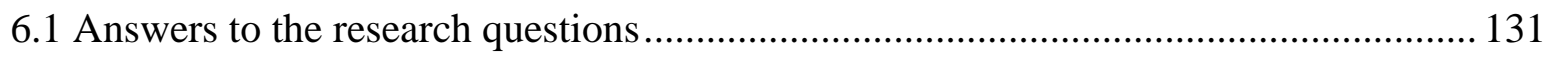

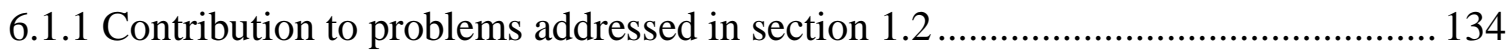

6.1.2 An analysis of individuals' perceptions or organizations' views? ......................... 134

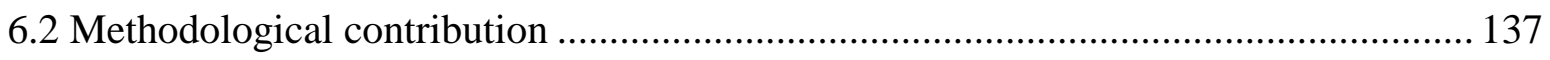

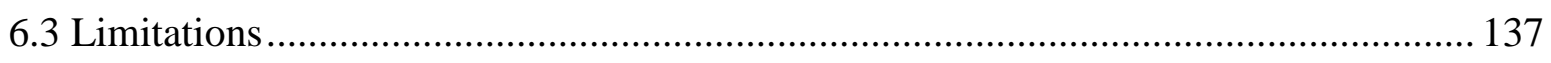

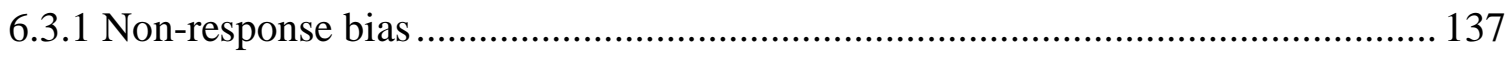

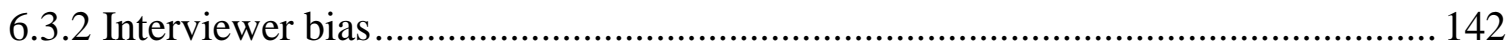

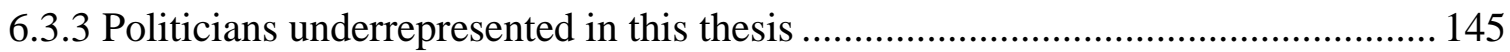

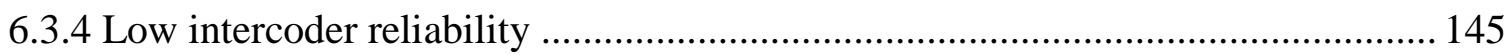

6.3.5 Limited geographical and temporal transferability ......................................... 146

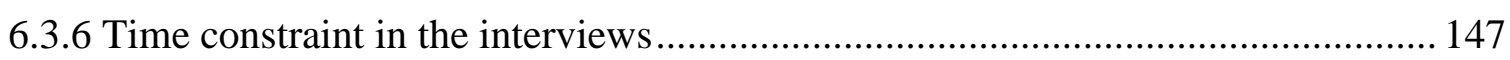

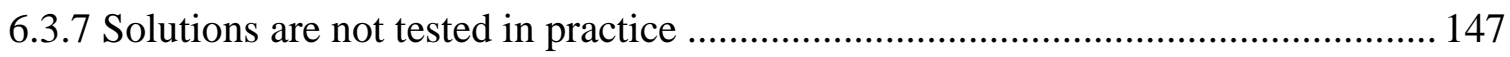

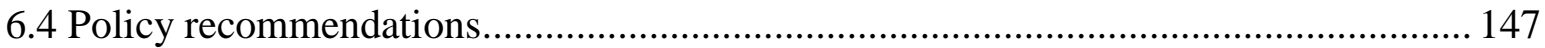


6.4.1 Maintain CBA in the appraisal process for spatial-infrastructure projects and use it

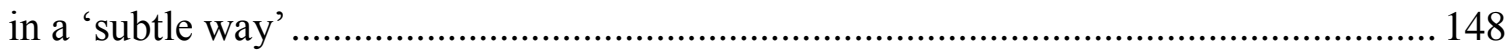

6.4.2 Design CBA research agendas based on different inputs ................................... 149

6.4.3 Prescribe clearly what a high-quality problem analysis should entail ................... 150

6.4.4 Identify whether or not a problem is a specific CBA problem ............................. 150

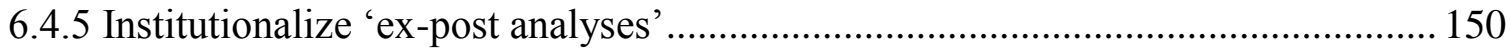

6.4.6 Make sure that CBA studies are reviewed in a second opinion........................... 151

6.4.7 Disseminate new CBA insights in the Dutch CBA practice via experts ............... 151

6.5 Possible implications for the design of a planning model for spatial-infrastructure projects

6.5.1 The importance of connecting CBA to interactive phases in the planning process

6.5.2 Recommendations for connecting CBA with the early planning process 153

6.5.3 Recommendations for connecting CBA to the planning process after the CBA ... 156

6.5.4 Usefulness of CBA in multi-actor policy settings enhances when credibility is

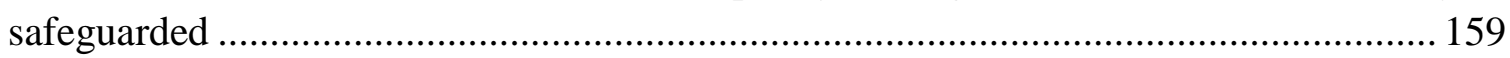

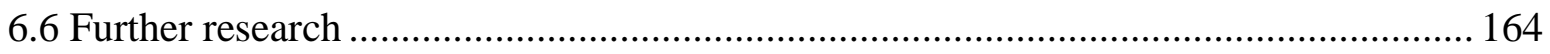

6.6.1 Enhance the quality of effect estimations ......................................................... 165

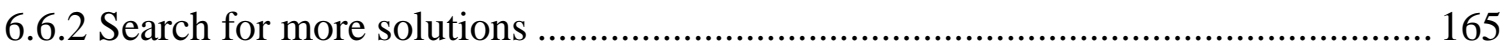

6.6.3 Further understanding of problems and solutions ............................................. 165

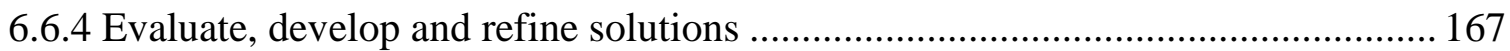

6.6.5 Organizing 'practitioners meet academics' workshops ...................................... 168

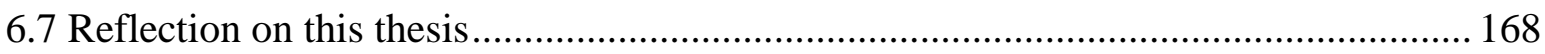

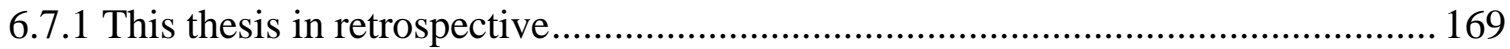

6.7.2 Reflection on scientific research in the social sciences .................................... 173

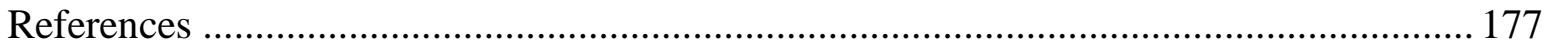

Appendix I: Towards improved handling of uncertainty in Cost-Benefit Analysis: addressing the 'price-quality' and 'communication' dilemmas .............................................................. 193

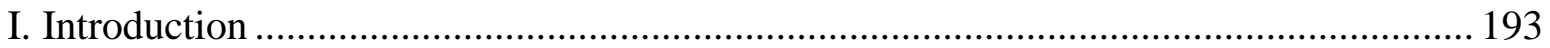

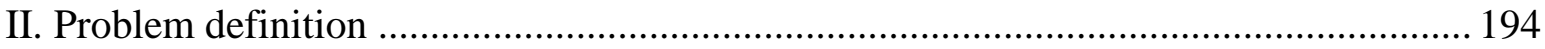

III. A first step towards solving the 'price-quality dilemma' ........................................... 195

IV. Explanations for controversy about communication of uncertainty from a psychological

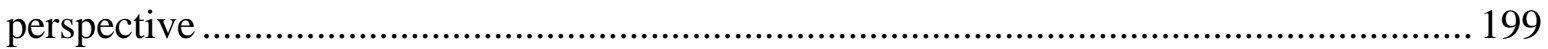

V. Prominent communication of uncertainties: problems and solutions ............................ 202

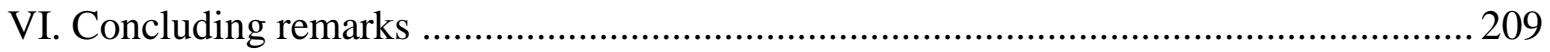




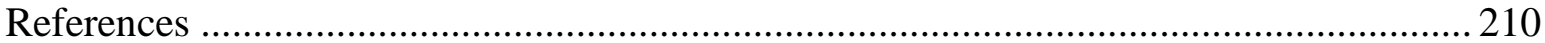

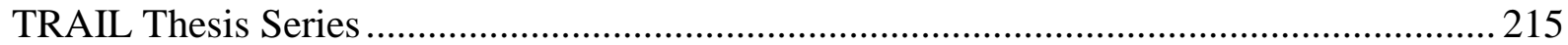




\section{Introduction}

\subsection{Research background}

"Transport is crucial for society: societies cannot function without the transport of people and goods. It enables us to participate in many activities at different locations, such as living, working, education, shopping and visiting relatives and friends" (van Wee, 2011). On the other hand, transport brings with it costs, in terms of money, time, effort and negative impacts on society, mainly due to accidents, emissions of harmful pollutants, noise and damage to nature.

For many reasons, governments are involved in transport. For example, governments finance transport infrastructure projects and carry out policies to restrict negative external effects that accrue from transport infrastructure. When governments decide to be involved in transport planning, they almost always have to outweigh the negative and positive effects of the policy option(s). For instance, the development of a new highway leads to positive travel time savings for users, but also to negative noise effects for residents and to construction costs. It is up to politicians to outweigh these effects. Hence, they frequently want to be informed about the positive and negative effects of the policy option. Often, they also like to have information about the positive and negative effects of different alternatives to the policy option (for instance, different alignments of a highway or investing in public transport instead of 
highways). Research shows that in most OECD countries Cost-Benefit Analysis (CBA) is often used to inform decision makers about the positive and negative effects for society of transport policy options, at least at some stage in the decision-making process (Hayashi and Morisugi, 2000; Mackie and Worsley, 2013; Odgaard et al., 2005; Thomopoulos et al., 2009).

Basically, a CBA is an overview of all the positive effects (benefits) and negative effects (costs) of a project. The costs and benefits are quantified and valued in monetary terms as far as possible using the notion of peoples' willingness to pay for these effects. ${ }^{1}$ Costs and benefits occur in different years within the time horizon of the CBA. To deal with this, they are presented as so-called present values, implying that - even after a correction for inflation - it is better to have one euro or dollar now than in ten years' time, for example. A discount rate is used to calculate the present values. Often, present values are aggregated to yield an indicator of the project's net impact on social welfare. Examples of indicators that are used are: Net Present Value (NPV), the Internal Rate of Return (IRR), the Benefit-Cost Ratio (BCR) or the net-benefit/investment cost ratio (NBIR).

\subsection{Problem statement}

Because CBA is applied in most OECD countries it is no surprise that the method is a popular and broad research topic in transport literature. There is, for instance, a wealth of literature that discusses theoretical and practical problems of the CBA method (e.g. Ackerman and Heinzerling, 2002; Hansson, 2007; Mackie and Preston, 1998; Naess, 2006; Sen, 2000; van Wee, 2007). There is also literature that examines solutions for these theoretical and practical problems (e.g. Mackie and Nellthorpe, 2001; Koopmans and Oosterhaven, 2011; Salling and Leleur, 2012; van Wee, 2012). Moreover, there are contributions that reflect on the role of CBA or in which the author(s) present(s) a view on the ideal role of CBA in the decisionmaking process (e.g. Frank, 2000; Lohmann, 1977; Mackie, 2010; Quinet, 2000; Sen, 2000; Sunstein, 2000). In addition, some contributions reflect on the merits of CBA compared to other ex-ante evaluation methods (e.g. Sayers et al., 2003; Tsamboulas, 2007; Tudela et al., 2006), compare different CBA practices (e.g. Bristow and Nellthorp, 2000; Hayashi and Morisugi, 2000; Mackie and Worsley, 2013; Odgaard et al., 2005) or describe a CBA practice (e.g. Lee jr., 2000; Quinet, 2000; Rothengatter, 2000).

Despite the existence of a wide range of scholarly literature arrayed across a variety of CBA related topics, the way CBA is applied and perceived by different individuals that use or carry out CBAs (e.g. consultants, policy makers, politicians) has received relatively scant attention in existing literature. There are some exceptions: Beukers et al. (2012) survey perceptions of Dutch practitioners of the CBA process; Veisten et al. (2010) scrutinize the barriers of underpinning decision making with regard to road safety measures with CBA, interviewing 83 European policy makers in road safety; Nyborg (1998) interviewed 16 Norwegian politicians about their use of CBA in the political treatment of a road investment plan. Moreover, there are contributions that study the impact of the CBA results on decision making, predominantly

\footnotetext{
${ }^{1}$ Or, vice versa, people's willingness to accept a monetary compensation when they are confronted with a negative impact.
} 
using quantitative methods (e.g. Eliasson and Lundberg et al., 2012; Odeck, 1996; Odeck, 2010). The broad picture is that these studies show that planners'/politicians' rankings of investments are to some extent influenced by CBA results and CBAs are in some cases used for enhancing project alternatives and for evaluating alternative options (for the same project) but not for making a final decision.

Although there is some knowledge that CBA is sometimes used by planners and politicians, to the author's knowledge, there are no contributions in existing literature that discuss which substantive CBA problems and CBA limitations people that use or carry out CBAs experience. Moreover, attitudes towards the role of CBA in the decision-making process of different individuals in an appraisal practice and the ideas of people that use or carry out CBAs with regard to solutions for rectifying CBA problems and minimizing CBA disadvantages have not been studied before. This thesis aims to fill these knowledge gaps because the knowledge gaps might be disadvantageous for three reasons.

Firstly, because CBA is an instrument that is applied in practice, the way the merits of CBA are experienced is important for the support of the instrument and the extent to which decision making in transport can be better informed with CBA. Despite its popularity, the role of CBA in decision-making processes for transport projects is a continuous topic of debate in countries and institutions where it is used (e.g. Hamers et al., 2012; Mackie, 2010; Sager and Ravlum, 2005; World Bank, 2010). Although scholars come up with solutions to improve CBA, they do not study why CBA is a topic of debate from the perspective of people that use or carry out CBAs. What problems and disadvantages do individuals who argue against the use of CBA perceive and how can these perceived problems and disadvantages be ironed out?

Secondly, people that use or carry out CBA studies in practice might have additional - and maybe even better - suggestions for solutions to rectify CBA problems and for improving the way CBA is used in the decision-making process besides the solutions proposed by academics that have never carried out or used a CBA in practice. Although I don't want to disqualify academics that devote their whole career to developing theories, practical problems might arise when theories are applied in practice. My point is that it seems worthwhile to also study these practical problems (and solutions to solve these problems) to enhance the probability that the theory can actually be applied in practice, and even better, can actually improve practice.

Thirdly, academics conduct a wide array of research projects with regard to CBA but it is not always clear why this research is useful and necessary. What are the urgent and less urgent problems with regard to CBA that need to be addressed relatively swiftly or, in the second case, can be postponed? To the best of my knowledge, there is no contribution in existing literature that investigates the urgency of CBA problems which can be used as a point of departure for researchers to prioritize problem areas for further research. This lack of a proper 'problem analysis' in literature is problematic because a clear rationale to guide researchers on the aspects of CBA theory and practice that should be studied is lacking in the status quo (if one assumes that 'this topic has not been studied before so it is scientifically relevant' and 
'there is funding to start this research project, so there must be an urgent problem' are not sufficient rationales to start scientific research).

To be specific, this thesis aims to fill several knowledge gaps at the interface of CBA and practice for the Netherlands. This implies that insights from this thesis are, foremost, potentially very interesting for improving the Dutch practice. Still, the Dutch practice can also give useful international insights for other CBA practices because of the extensive use of CBA in the Netherlands over the last 13 years. Mackie and Worsley (2013) state that, along with the UK and Scandinavia, the Netherlands has been a leading country in the international CBA practice for four reasons: 1) It has a strong tradition of doing transport project appraisal; 2) It has guidance manuals which constitute a clearly defined framework for appraisal that is to be followed throughout the project cycle; 3) It has a framework populated with measures and values of the impacts, which are based on evidence generated from research studies; 4) The Netherlands has a policy whereby the intention is that the results of appraisal work should have a significant influence on the case for investment. Moreover, this thesis only presents the findings which I consider to be potentially relevant for an international audience. Findings that are only relevant for the Dutch practice are presented in a Dutch language report (Mouter et al., 2012).

More detail with regard to the way CBA is embedded in the Dutch decision-making process for spatial-infrastructure projects is provided in the next chapters.

\subsection{Research objectives}

This thesis has one main objective:

To acquire a thorough understanding of the way CBA is perceived by different key individuals that use, carry out or study CBAs.

This research involves key and not all individuals in the Dutch CBA practice because I assumed that predominantly the understanding of the way CBA is perceived by key (and not all) individuals contributes to solving the problems addressed in section 1.2.

Besides the perceptions of key individuals that use or carry out CBAs I also scrutinized perceptions of academics that study CBA in this thesis because they have an important role in the Dutch appraisal practice. In the Netherlands, academics review CBA studies, contribute to the development of guidelines and participate in the debate about ex-ante appraisal of Government projects, amongst other things. Hence, I consider academics to be a relevant group of key individuals in the Dutch appraisal practice and investigate their perceptions as well in this thesis. From now on the perceptions of key individuals that use, carry out or study CBAs are labeled as 'perceptions of key individuals in the Dutch CBA practice'. 
More specifically this thesis aims to answer four research questions:

- Which substantive problems with regard to appraising spatial-infrastructure projects ${ }^{2}$ using CBA do key individuals in the Dutch appraisal practice for spatial-infrastructure projects perceive and what is the relative order of importance of substantive problems according to Dutch key individuals? (discussed in chapter 2)

- To which extent is there agreement among key individuals in the Dutch appraisal practice for spatial-infrastructure projects with regard to the role of the CBA in the decision-making process? (discussed in chapter 3 )

- What are internationally relevant solutions for substantive CBA problems as identified by key individuals in the Dutch appraisal practice for spatial-infrastructure projects? (discussed in chapter 4)

- Which insolvable CBA limitations do key individuals in the Dutch appraisal practice for spatial-infrastructure projects perceive? What are internationally relevant solutions to manage the insolvable CBA limitations as identified by Dutch key individuals? (discussed in chapter 5)

In chapters 2-5 these research questions are scrutinized. In these chapters I also go into more depth about why these research questions are relevant. This thesis does not aim to fill all the scientific gaps at the interface of CBA and practice. Topics that may be considered in further research are discussed in chapter 6.

\subsection{Methodology}

Two research methods are combined in this thesis to study the perceptions of Dutch key individuals. Firstly, key individuals in the Dutch CBA practice were interviewed in-depth on the topics outlined in the previous section. Secondly, I sent a questionnaire to these key individuals in order to validate the outcomes of the interviews and to ask some additional questions that were relevant to scrutinize the research questions. The method used to analyze the data I derived from the interviews was content analysis. Content analysis has been defined as a systematic, replicable technique for compressing many words of text into fewer content categories based on explicit rules of coding and categorizing (Weber, 1990). With the content analysis, the qualitative data was quantified, which made it possible to compare the results of the interviews with the results of the written questionnaire (Creswell, 2009). The way I applied this method is discussed in more depth in the next chapters. The data derived from the written questionnaire was analyzed using statistical analysis.

\subsubsection{Selection of respondents}

In order to investigate perceptions from Dutch key individuals that use, study or carry out CBAs of the topics discussed in the previous section, the aim of the research was to interview the entire population of key individuals. To select the key individuals it was necessary to determine the guiding principle for deciding whether an individual is a 'key' individual'. I

\footnotetext{
${ }^{2}$ Because in the Netherlands ex-ante evaluation using CBA is obligatory for all spatial-infrastructure projects (and not only transport projects) applying for co-funding by the Dutch Government, I decided to adjust my aim to this obligation.
} 
decided to use two guiding principles. Firstly, the 'objective' guiding principle: 'individuals who wrote many publications on CBA, used many CBAs for policy making or carried out many CBAs - for preferably large spatial-infrastructure projects - are key individuals'. The rationale was that it is more likely that an individual who had used fifty CBAs can be identified as a 'key' individual than an individual who used only a single CBA. However, it is possible that a person who used only a few CBAs has a very interesting and influencing opinion with regard to CBA problems, advantages or solutions to manage inherent limitations, amongst other things. Hence, 'quantity' alone was not considered decisive for identifying all the key individuals in the Netherlands and as a result I added the second 'subjective' guiding principle: 'people that are perceived as key individuals by the individuals who are identified based on the objective guiding principle are key individuals as well' ${ }^{3}$

Following the 'objective' guiding principle I contacted 10 consultants that carried out a number of important CBAs, 10 scientists/employees of assessment bureaus that reflected on important CBAs or published articles related to CBAs and 10 individuals who used the CBA results as policy makers. All 30 people were willing to participate. These 30 respondents were asked which people, in their view - besides the people that were already interviewed - were paramount in order to be certain that the Dutch population of key individuals in the Dutch CBA practice (key individuals that use, carry out or study CBAs) was interviewed for this research. Based on this survey 51 people were identified and 42 were willing to participate.

The nine people that did not participate mentioned 'lack of time' as the reason for the nonparticipation (sometimes directly, sometimes via their secretary). Some of them combined this with a statement that the added value of their interview would be marginal: 'I am very busy and I think you already interviewed the key experts in my organization with regard to CBA' or 'I have no time and I think it is better to contact 'Person A'. She is the expert in our organization with regard to $\mathrm{CBA}$ '.

To enhance the probability that I had captured the entire population of key individuals, I decided to present the list of the 72 interviewed respondents to four respondents that were often mentioned as key individuals in the Dutch CBA practice during the first 72 interviews. These respondents were asked to add to the list the names of the people that needed to be interviewed in order to make sure that all the key individuals in the Dutch CBA practice were interviewed.

In the interviews I asked the 72 respondents which 'roles' they had when they became involved with CBA in the past decade. Based on the statements made by the respondents it was possible to distinguish the following roles:

\footnotetext{
${ }^{3}$ For reasons of succinctness, the respondents that were recruited based on the objective guiding principle and the subjective guiding principle were summarized in chapters 2-5 as: 'all individuals that had an explicit and recognizable role in the Dutch CBA practice'.

${ }^{4}$ In section 6.3 I will discuss the consequences of non-participation (similar to 'non-response' when doing surveys) for my results and conclusions.
} 
1. Initiator of a plan that was assessed using a CBA (or individual who assisted these initiators);

2. Individual who decided on funding applications for project proposals and used a CBA as input for this decision (or individual who assisted these decision makers);

3. Individual who carried out CBAs;

4. Individual who reviewed the quality of CBAs;

5. Individual who studied CBA, developed CBA methodology or CBA guidelines;

6. Individual who tried to influence the decision on a spatial-infrastructure project representing an interest group.

Based on these results I realized that the category ' $\mathrm{key}$ individuals who use CBA' could be split up into three smaller groups (roles 1, 2 and 6). Hence, I decided to ask the four respondents whether they could mention the individuals that needed to be interviewed to achieve completeness with regard to each of the six 'CBA roles' mentioned above (instead of asking which individuals need to be interviewed to achieve completeness with regard to key individuals who carry out, study or use CBA).

In addition, I instructed these four respondents to check whether interviewing an individual from an organization would lead to new insights - according to them - if I already interviewed a number of individuals from an organization. I gave them an example of a civil servant from the Dutch Ministry of Infrastructure and the Environment who stated that he thought that an interview with him would not lead to any new insights, because - according to him - I already interviewed the key experts in his organization with regard to CBA.

According to the four respondents, a further 20 people needed to be interviewed to attain my objective. Finally, 14 out of these 20 respondents were interviewed. Five of these people mentioned 'lack of time' as a reason for the non-participation - sometimes combined with the 'lack of added value' argument. One respondent did not respond to several emails and phone calls.

In conclusion, 86 out of the 101 individuals contacted for this research were interviewed in the period June 2010 - April 2011 (see Appendix 5.1 for a list of the respondents). Although I consider this three-stage method as a comprehensive way to identify the Dutch key individuals, I think it is possible that I missed a few key individuals. Thus, I did not manage to interview the entire population as intended and the 86 respondents must be considered as a selection of the entire population of Dutch key individuals. The questionnaire - which was sent after all the interviews were conducted - was completed by 74 of the 86 respondents.

\subsubsection{Structure of the interviews}

The most important method I used in this thesis is in-depth interviewing (approximately one hour long). The interviews consisted of three parts. The first part predominantly focused on eliciting perceptions of respondents with regard to the most important substantive problems they experience when using CBA in the decision-making process. Moreover, in the first part of the interviews, the respondents were asked about their attitude towards the role of CBA and 
the insolvable CBA limitations they perceive. Also, I asked respondents clarifying questions (e.g. what, in your view, is the exact problem? Why do you think this is a problem? Could you give an example of a CBA where the problem occurred?). In the second part of the interview I tried to challenge the statements the respondents made, in order to sharpen the arguments they used to underpin their perception of a substantive problem. For instance, by confronting a respondent with contradicting statements made by other respondents: 'you say that this is a problem, however several other respondents argue that this is not a problem for this reason.' In the third part of the interview I pursued key individuals' perceptions of solutions for substantive CBA problems and solutions to manage insolvable CBA limitations.

To minimize 'interviewer bias' (Christensen et al., 2004) - which means that substantive problems / inherent limitations mentioned by the respondents could be influenced by the clarifying questions asked by the interviewer and the contradicting statements selected by the interviewer - I decided that when starting a new topic in the interview, the first question should be the most important for the data collection. For instance, for the topic 'substantive problems' the most important question was 'what are the five most important substantive problems you perceive with the appraisal of spatial-infrastructure projects using CBA?' After asking the question, I only started to ask clarifying questions when the respondent stopped speaking. An alternative model could have been to ask the respondent to mention the most important substantive CBA problem, then ask clarifying questions, then ask them to mention the second most important substantive problem, etc. I considered the probability of 'interviewer bias' higher with the latter model because it is plausible that the second, third, or fourth substantive problems mentioned by the respondent are influenced by the clarifying questions related to the first problem mentioned. ${ }^{5}$

\subsubsection{Characteristics of the interviewer}

All the interviews were carried out by one person (the author). The characteristics of the interviewer at the time of the interview were:

- Gender: Male;

- Age: 25-26 years old;

- Education: Master of Science in Economics and Business, Bachelor in Dutch Law;

- Level of knowledge with regard to the topic: mediocre at the time of the interviews;

- Many of the respondents had never met the interviewer personally before the interview;

- During the interviews, when possible, the interviewer sat opposite the respondent:

- The style of the interview at the beginning of each topic discussed was passive (respondents were not interrupted); at the end of each topic discussed - when asking the confronting questions - respondents were interrupted when it was considered necessary to enhance focus.

\footnotetext{
${ }^{5}$ Although I tried to minimize 'interviewer bias' in this thesis, no research that is based on open or semistructured interviews is immune to 'interviewer bias'. The consequences of this are discussed in chapter 6.
} 


\subsubsection{Justification of selected methods}

This thesis employs a mixed method strategy. Both a qualitative research method (interviews) and a quantitative research method (written questionnaire) are applied to study the research questions. Bryman (2006) concludes that the combination of interviews and a questionnaire is one of the most frequently employed mixed method strategies in practice. Below, I will discuss the motivations for using a mixed method strategy in this thesis based on the framework of Bryman (2006).

- Triangulation: cross-validating results on the same research question by using multiple methods. When results converge across different methods this enhances the probability that the results are not simply an artifact of invalidity associated with a particular method (Morgan, 1998).

- Instrument development: the results of the first method were used to develop the second method. In this thesis the statements key individuals made in the interviews were used to develop the written questionnaire.

- Illustration: in this thesis (especially chapters 2 and 3) the qualitative data were used to put 'meat on the bones' of 'dry' quantitative findings.

- Enhancement: augmenting qualitative findings by gathering data using a quantitative research method. In this thesis, the written questionnaire was used for generating information with regard to the extent that statements made by one respondent (or a group of respondents) in the interviews, is evaluated by all the respondents. For instance, in the interviews a group of respondents stated that too much value is assigned to CBA, whereas another group stated that too little value is assigned to CBA. In the written questionnaire I asked all the respondents to evaluate the value that is assigned to $\mathrm{CBA}$ in current decision-making processes.

The specific type of mixed method strategy I used in this thesis is the sequential exploratory mixed method (Creswell, 2009), which entails a first phase of qualitative data collection followed by a second phase of quantitative data collection. The most important reason for using this type of strategy is the 'instrument development' motive (see above). The written questionnaire is built on the results of the interviews (Creswell, 2009) so both methods should be carried out sequentially.

Besides interviews, other qualitative methods (for instance, Delphi studies, focus groups and Group Decision Rooms) were available. One of the interesting features of these methods is that participants can learn from each other. Interaction between participants allow for emerging insights and possibly to richer perceptions with regard to problems and solutions. However, I did not use these methods because I received two warnings from several experts in the exploratory phase of this Ph.D. research. Firstly, CBA is a highly sensitive topic in the Dutch transport policy arena. In focus groups participants might be prone to make strategic statements instead of telling what they really think. Secondly, people in the Dutch transport policy arena might reproduce each other's statements. For instance, if professor X states that 'problem A' is very problematic, other people in the Delphi study might reproduce this statement. To diminish 'group think', reproduction of statements from other people and 
strategic statements, individual in-depth interviews seemed to be the best method to arrive at a set of genuine authentic perceptions.

The reason for using a semi-structured design instead of an open design was that I felt it was important that respondents were able to prepare for the interview. For instance, I asked the respondents to mention the five most important substantive problems they experienced with CBA and assumed that it was difficult for respondents to properly answer this question without preparation. Because the questions asked in the second and third part of the interview depended on the statements made by respondents in the first part of the interview, I did not used a fully structured design for the interviews.

I considered a written questionnaire to be the most auspicious method for attaining the 'triangulation' and 'enhancement' objectives. I considered a written questionnaire a better method to triangulate the findings derived from the interviews than a Delphi study or a Group Decision Room, for instance, because respondents' answers are not influenced by another person. The extent to which the results derived from the questionnaire compare with the results derived from the interviews could be used as an indication of the extent to which the results of the interviews are influenced (biased) by the interviewer. ${ }^{6}$ Also, a written questionnaire is a cost efficient method to find out which share of the respondents is pro or against a proposition (enhancement) and a benefit of the method is that it is possible to ask respondents questions in exactly the same way.

\subsubsection{Use of literature}

For each of the topics postulated in the research questions addressed in section $1.3 \mathrm{I}$ scrutinized scientific and 'grey' literature. In chapters 2 and 3 I predominantly used the literature for distinguishing different categories of CBA substantive problems (chapter 2) and CBA (dis)advantages (chapter 3) in the content analysis. In chapters 4 and 5 I predominantly used the literature for determining the extent to which scrutinizing key individuals' perceptions of solutions (to solve substantive problems, for instance) is valuable additional input for research agendas alongside the solutions discussed in existing literature. In this thesis I did not assess the literature in a systematic literature review.

\subsection{Cost-Benefit Analysis in the Netherlands}

In this section, my aim is providing the reader with some information about the context of planning and decision support for spatial-infrastructure projects in the Netherlands. This context information could assist the reader with understanding why CBA has an important position in the planning and decision-making process for spatial-infrastructure projects in the Netherlands and, as a consequence, will then be able to put the results of this thesis in the right perspective. For reasons of succinctness my aim is not to embark on an exhaustive discussion of the planning and decision support context in the Netherlands. For further

\footnotetext{
${ }^{6}$ Christiaans et al. (2004) consider 'interviewer bias' as one of the most important disadvantages of semistructured or unstructured interviews.
} 
information regarding this topic, see de Jong and Geerlings (2003), Ministry of Infrastructure and the Environment (2010) and Huijs (2011).

\subsubsection{Rational Planning Model in the 1980s}

In the Netherlands, the views on which planning and decision support methods were most auspicious were to a great extent dominated by the views on assessment methods put forward by Professor Voogd (1983) in the 1980s. This centered on the proper use of Cost-Benefit Analysis and Multi-Criteria Analysis (de Jong and Geerlings, 2003), both of which are part of the family of classical policy analysis methods fitting well in the rational planning model. The essence of the rational planning model is the idea that decision-making consists of logical and successive steps. Using a comprehensive analysis, the problem(s) to be solved is (are) identified, objectives are formulated, favorable alternatives to rectify the problem(s) or to meet the objectives are selected and finally the desirability of the means is assessed using formal classical policy analysis methods such as Cost-Benefit Analysis (e.g. de Jong and Geerlings, 2003; Kørnøv and Thissen, 2000; Mu, 2013).

At first sight the rational planning perspective is very attractive for reasons of simplicity and effectiveness. However, the criticism about the feasibility of the model is overwhelming. For reasons of brevity I will list but a few criticisms. First of all, Rittel and Webber (1973) criticize the rational model for its claim that it is possible to unambiguously define problems in complex planning systems. They label these complex problems as 'wicked problems' and in their view - no definitive formulation is possible: 'the process of solving the problem is identical with the process of understanding its nature, because there are no criteria for sufficient understanding and because there are no ends to the causal chains that link interacting open systems. (p. 162). Checkland (1980, p.2) seems to come to more or less the same conclusion: 'In fact, the systems analyst, seeking to contribute to real-world decisions, always find himself facing, not a well-defined problem, but a problem area or situation; his problem turns out to be a nexus of problems.' In the lecture he gave when he received the Nobel Prize for Economic Science, Simon (1979) criticized the idea of the rational planning model: that the evidence on rational decision making is largely negative evidence, evidence of what people do not do. Kørnøv and Thissen (2000) state that virtually all empirical research shows that decision-making processes in practice often do not follow rational planning procedures, even in cases where significant efforts are made to improve rationality. Moreover Kørnøv and Thissen (2000) conclude that in multi-actor situations, there is often a high level of confusion and complexity. Actors often do not really know what the problem is, what to aim for, how to achieve it and least of all, what the best way is to achieve it.

The overwhelming criticisms of the rational planning model had not gone unnoticed in the Dutch planning process. In the 1990s, academics and practitioners in policy analysis, public policy and planning all claimed that the traditional planning and policy analysis methods were obsolete (de Jong and Geerlings, 2003). Hence, the consensus was that policy makers should not use traditional planning and decision support tools such as Multi-Criteria Analysis and Cost-Benefit Analysis any longer. The alternative methods for the rational planning support 
tools introduced in the Netherlands - and many other countries - were process based. The policy analysts' aim was to facilitate an interactive planning process.

\subsubsection{The interactive planning model}

Healey (1992) - one of the most important apostles of the interactive planning model defines planning as a process of collectively and interactively, addressing and working out how to act. The interactive planning model differed from the rational planning model in many respects. Planning and deciding were not an activity that could be confined to analytical quantities and units (de Jong and Geerlings, 2003). Instead it became very important to learn from the views of others and to develop concepts jointly. Joint-problem formulation (Enserink, 2000), Joint-fact finding (Ehrman and Stinson, 1999), Negotiated knowledge (de Bruijn and ten Heuvelhof, 1999) and Participatory policy analysis (Innes and Booher, 2000) are only a selection of the buzz-words of the interactive planning perspective that appeal to the necessity of integrating stakeholders in policy making.

The advantage of involving stakeholders is that the content of information is enriched and also accepted by the people that need to use the information in the planning and decisionmaking process (Enserink, 2000). Also, participation may lead to shared visions and a sense of ownership of the results (Kørnøv and Thissen, 2000). Another feature of the interactive planning perspective is that the planning and decision-making process is not seen as an orderly sequence of phases (de Bruijn and ten Heuvelhof, 1999). A feedback mechanism is assumed between the formulation of the problem, the selection of alternatives and the definition of criteria. While designing the alternatives one can see the problem in another light and redefine it, amongst other things. A third feature of the interactive planning perspective is that the ultimate goal of this participatory way of planning is to come to a shared view of reality and a single alternative with a wide support base (de Jong and Geerlings, 2003).

At first sight the interactive planning perspective is very attractive because - at the end of the day - all stakeholders and shareholders have a shared view of reality and are satisfied with the selected solution. However, De Jong and Geerlings (2003) conclude - based on the evidence of various Dutch dissertations - that: 'interaction and wider participation cannot in themselves solve fundamental oppositions in concepts and values. Crucial information can remain unused if the decision-making process is allowed to take place in an unstructured manner, responsible parties can simply put aside the results of the interactive process.' Van Eeten (1999) concludes that there is nothing wrong with stakeholders freely exchanging their arguments and other ideas influenced by the work of Jürgen Habermas, yet nobody has taken up the challenge that arises when the open exchange of valid arguments produces nothing but a "dialogue of the deaf". De Bruijn et al. (2002) conclude that a dialogue conducted between communicatively-minded but poorly-informed actors can lead to 'negotiated nonsense'.

Also, a main issue with the interactive planning perspective is its aim to arrive at a solution that is satisfying for all stakeholders. 'The results of such practice include hugely expensive, but supposedly environment saving, underground tunnels that make few people really happy' (De Jong and Geerlings, 2003). A negative example of interactive planning in the Netherlands 
is discussed in de Jong (1999). In the planning process for the Southern High Speed Railway Line there was a large role for private individuals in formulating alternatives. There was the inexpensive 'TU variant' and there was the 'Bos variant' that did not cut as much through the Dutch 'Green Heart' as the other variants but did mean a certain time loss. De Jong (1999) concludes that - after long deliberation in the Dutch House of Representatives - a choice was made for a very expensive and typically Dutch compromise: 'through the Green Heart after all, but with a tunnel'. Although process was placed above content in the case of the Southern High Speed Railway, the consultancy agency, Moret, Ernst \& Young, concluded that 145 research reports had been developed for the House of Representatives with respect to this project. A conclusion of this evaluation was that the documentation was organized, but not verified for consistency, completeness, clarity or quality (de Jong, 1999). Analyzing the interactive planning perspective, de Jong and Geerlings (2003) conclude that if interactive communication and compromise formation led to such irrational decisions, the time was ripe for an objective measurement instrument.

\subsubsection{The comeback of Cost-Benefit Analysis}

In response to the perception that the interactive planning model led to irrational decisions, research regarding economic effects of infrastructure projects got special attention in the Netherlands in the late 1990s. The Ministry of Economic Affairs and the Ministry of Transport, Public Works and Water Management initialized the Economic Effects Infrastructure Research Program ("Onderzoeksprogramma Economische Effecten Infrastructuur, OEEI). The ministries were not only moved by the poor quality of the information provided to the House of Representatives to start this project but also because the fact that economic effects of another major project decided upon during the 1990s, the Betuwelijn - a freight-transport railway line linking the Port of Rotterdam with the European hinterland - were estimated using diverse methods (Eijgenraam et al., 2000). The objective of the program was twofold. On the one hand there was an aspiration to increase methodological consensus, on the other hand the program aimed at the provision of instruments for project appraisal that are able to assess the project's welfare effects. The most important report in the OEEI-program concluded that CBA should be the preferred approach for project evaluation. The OEEI-program resulted in a broad consensus amongst the actors involved in the appraisal of large infrastructure projects concerning the significance of CBA for the 'ex-ante' evaluation of infrastructure projects and the guidelines regarding the way CBA practitioners should undertake a CBA. In the year 2000 the result of the program was a guide for carrying out transport appraisals using a CBA (the OEEI Guideline). Since then, a CBA that is in line with the OEEI Guideline has become compulsory in the decision-making process for all large infrastructure projects. Moreover, the House of Representatives ordered that CBAs for all large national projects should be reviewed in a second opinion (Letter 26248 nr. 21, 19992000 to the House of Representatives of the Netherlands). This was because a review could contribute to the quality of the research and, as a consequence, to the political decisionmaking process. In the year 2003, the OEEI Guidelines were evaluated and expanded and are now called the OEI Guideline (Overview Effects Infrastructure Manual). 
Besides the 'Economic Effects Infrastructure Research Program', the need to improve the 'exante' appraisal of infrastructure projects was emphasized by the Temporary Committee on Infrastructure Projects ( $\mathrm{TCI}^{7}$, also known as the Duivesteijn Committee). This ad hoc Committee confirmed the poor quality of Dutch decision making on infrastructure projects before 1998, concluding that decision making for the Southern High Speed Railway Line and the Betuweline was based on a combination of fear, hope and belief instead of research findings, debate and creativity (Annema et al., 2007). In its final report, 'Grote projecten uitvergroot' ("Large projects enlarged"), the Committee identified many shortcomings in the decision-making process for large infrastructure projects (Priemus, 2007) and concluded that the House of Representatives had been regularly misinformed about the costs and benefits of projects (House of Representatives 2004-2005, 29 283, nrs. 5-6). The TCI emphasized the value of CBA based on the OEI Guideline concerning the quality of decisions under the assumption that a positive $\mathrm{CBA}$ is not a sufficient condition for a decision to develop an infrastructure project. Thus, a positive Benefit-Cost Ratio (BCR) was not considered to be a formal requirement for approved funding. The official function of CBA was to provide transparent policy information for the preparation of infrastructure projects and public administrators were not formally bound to the results of the studies. However, ministers who did not act in line with the results had some explaining to do (de Jong and Geerlings, 2003). After the OEI Guideline was put in place, the national government predominantly used the CBA as information for decision making with regard to the extent to which funding was approved for specific spatial-infrastructure projects. This 'individual approach' is in contrast to countries such as Sweden where CBA is applied to rank large numbers of investments against each other (see Eliasson and Lundberg, 2012). Since 2007, it is also obligatory to assess spatial-infrastructure projects, (co-) funded by the Dutch national government, with a CBA (Ministry of Transport, Public Works and Water Management and Ministry of Housing, Spatial Planning and the Environment, 2009).

In 2010, the formal role of CBA in the planning and decision-making process for spatialinfrastructure projects was modified. The Manual for exploring spatial-infrastructure projects (Ministry of Infrastructure and the Environment, 2010) determines that Cost-Benefit Analysis should be used by the National Government as supporting information for the decision to select a favorable alternative out of a shortlist of three different alignments. Although, formally, the Cost-Benefit Analysis no longer plays any role as supporting information for the 'go/no go' decision about spatial-infrastructure projects, the information from the CBA study is predominantly used for this purpose by politicians in debates about specific projects (see for instance, House of Representatives November $25^{\text {th }}, 2013$ ).

Since 2000, around 120 CBAs for candidate transport policies became publicly available on a very broad range of topics (such as new roads, new railroads, tunnels, sea port extensions, airport extensions, pricing policies, speed policies, and so forth). Also, a multitude of Cost-

\footnotetext{
${ }^{7}$ Parliamentary Commission on Infrastructure Projects.
} 
Benefit Analyses were carried out for internal use in this period and are not publically available.

\subsubsection{Thesis, Antithesis, Synthesis}

The return of the Cost-Benefit Analysis in spatial-infrastructure planning did not mean a total relap se into the rational planning model. Presently, both the 'rational planning perspective' and the 'interactive planning perspective' are blended into the Dutch planning and decisionmaking model for spatial-infrastructure projects. A philosopher would probably characterize the planning and decision-making model in the Netherlands in the period 1980-2010 as an example of applied Hegelian dialectics. The rational planning model - used in the period 1980-1990 - can be labeled as the 'thesis', which was in need of an 'antithesis' in the shape of the interactive planning model. The period after the year 2000 can be viewed as the 'synthesis', reconciling the common truths of both the 'thesis' and the 'antithesis'.

In the first years of the planning process for spatial-infrastructure projects - in which the National Government was involved - the 'interactive planning perspective' dominates 'the rational planning perspective'. In the so-called 'initiative phase', ministers (assisted by civil servants) discuss which challenges should be tackled in their jurisdiction with politicians from decentralized governments. If both agree that a challenge is of major importance they mutually decide to proceed to the 'exploration phase'. The 'initiative phase' is free from any systematic process or content-related requirements (Ministry of Infrastructure and the Environment, 2010) and has a 'garbage can' or 'policy soup' kind of character (both concepts are discussed in Kørnøv and Thissen, 2000). The first year of the 'exploration phase' consists of two phases. Firstly, in a problem analysis the politicians' perception of the problem is refined by the project team (civil servants) and discussed with stakeholders and the public. Secondly, stakeholders and the public are involved in generating alternatives for solving the problem. At the end of the first year of the 'exploration phase', three potentially favorable alternatives are selected. After the selection of these three alternatives, the 'interactive planning perspective' is put on hold for a while and 'the rational planning perspective' enters the scene. The effects of the three alignments are evaluated in a Cost-Benefit Analysis, amongst other things. When the information is available, the 'interactive planning perspective' informed by information of the Cost-Benefit Analysis, starts up again and remains the dominant perspective until the final decision is made. In this context the research carried out for this thesis was conducted.

\subsection{Theoretical background}

The most important aim of the Cost-Benefit Analysis is to estimate 'the social welfare effect' of a project. For the experienced CBA practitioner the concept 'social welfare' and the debates in the literature with regard to this concept are 'common sense'. For readers who fit this category, they can skip the rest of this section and continue with chapters 2-6 of this thesis in which the results are discussed. For the reader who is unfamiliar with the theoretical underpinnings of the Cost-Benefit Analysis, I will provide a brief discussion of the most important concepts in this section. For a more in-depth discussion of theoretical 
underpinnings of CBA, excellent guidebooks are available (e.g. Boardman et al., 2008; Mishan and Quah, 2007).

Besides being a practical instrument with practical pros and cons, CBA is an instrument with deep roots in moral theory. CBA is the only well-developed form of applied consequentialism (Hansson, 2007). Consequentialism is 'the view that normative properties depend only on consequences.' Consequentialism refers to the family of moral theories which hold that the consequences of a particular action form the basis for any valid moral judgment about that action. Thus, from a consequentialist standpoint, a morally right action is one that produces a good outcome, or consequence. CBA stems from the moral theory of 'utilitarianism', a specific form of consequentialism. Utilitarianism (developed by Jeremy Bentham and John Stuart Mill) is the idea that the moral worth of an action is solely determined by its contribution to overall utility (social welfare). Only if the social welfare effect of a project is positive, should the project be implemented.

Of course the next question is: 'how to define changes in social welfare'? Although economic theory does not provide an indefinite answer to this question, different criteria were developed in the past to give an explicit answer. A first criterion worth mentioning is the Pareto criterion which entails that the social welfare effect of a project is positive if it makes someone better off without making anyone worse off (Nyborg, 2012). The problem with this criterion is, however, that it can be rather unreasonable: for example, if one single person suffers an almost imperceptibly small cost, the Pareto criterion will classify the project as 'social welfare diminishing', even if it improves everyone else's situation dramatically. The Pareto criterion never takes a stand when different people's interests conflict, no matter how small or unimportant the conflict is (Nyborg, 2012). A second criterion is the Kaldor - Hicks compensation test which is also coined as 'potential Pareto improvement test' (Brent, 1996). The essence of this criterion is that the social welfare effect of a project is positive when the size of the benefits is such that the gainers could compensate the losers, even though the compensation does not actually have to be carried out. This test is also called the overcompensation test because the gainers can compensate the losers and have something positive left over. A third position in literature is that there is no such thing as an unambiguous definition for 'social welfare' and that analysts should not try to draw unambiguous conclusions with regard to the social welfare effect of a specific project (e.g. Nyborg, 2012; Heertje, 2006; Hennipman, 1977; Stolwijk, 2010).

In the Netherlands, a variant of the Kaldor - Hicks test is applied in practice. In the Dutch General CBA Guidelines (Romijn and Renes, 2013) it is stated that the social welfare effect of a project is positive when the benefits for the gainers exceed the losses for the losers. It is not necessary to verify whether the gainers are potentially able to compensate the losers. This is common practice in the lion's share of the countries which use CBA to inform decision makers (Kanemoto, 2011).

The next question is: 'how are the benefits and costs for, respectively, gainers and losers measured'. The answer is that benefits and costs are measured via alterations in 'consumer 
surplus'. Dupuit (1844, cited in Mishan and Quah, 2007) defines this concept as follows: 'the consumer surplus of a person is measured by the most he would pay for a thing less the amount he actually pays for it'. Hence, if a person is willing to pay 25 euros for a certain product and - as a result of a project - the price of the product diminishes from 15 euros to 12 euros the consumer surplus is enhanced by 3 euros, which is counted as a benefit of the project in the Cost-Benefit Analysis. Besides people benefiting from a project there will also be people losing from the project. For instance, a new highway might lead to noise pollution. How are these losses measured? Kanemoto (2011) explains that the losses can be interpreted as the subsidy needed to persuade the consumer to accept the change. For a more in-depth discussion of concepts used to measure costs and benefits in a Cost-Benefit Analysis, see Mishan and Quah (2007 p. 22-48) and Kanemoto (2011).

\subsection{Outline of this thesis and representation of the respondents}

The core of this thesis (chapters 2-5) consists of four papers that have been submitted, are forthcoming or have already been published in scientific peer-reviewed journals. In chapter 6 the conclusions, topics that may be considered for further research, policy recommendations and reflections on this thesis are addressed.

\section{Textbox: 'key individuals', 'key actors' or 'key participants'?}

The results of this thesis stem, for a large part, from interviews with 86 respondents. The respondents are not always labeled in the same way all the way through the thesis. In chapters 1 and 6 the respondents are labeled as 'key individuals in the Dutch CBA practice' In chapter 2 the respondents are represented as '86 key participants in the Dutch CBA practice', whereas in chapters 4 and 5 the respondents are represented as ' 86 key actors in the Dutch appraisal practice for spatial-infrastructure projects'. The reason for using 'key individuals' instead of 'key participants' for representing the respondents in chapters 1 and 6 is that the reader could interpret the term 'participants' as a group of individuals that actively participate in debates with regard to the merits of CBA. However, actors that conduct many CBAs but do not actively participate in debates were also recruited. The reason for using 'key individuals' instead of 'key actors' for representing the respondents is that the reader could interpret the term 'key actors' as an assembly of institutions (and not individuals) that use, carry out or study CBA, whereas the research focused on perceptions of individuals. Hence, I decided that 'key individuals' was a more precise representation of the respondents. Because chapters 2-5 were already published or submitted before I made this decision, the respondents are still represented as 'key participants' or 'key actors' in these chapters.

In chapters 4 and 5 respondents are represented as 'key actors in the appraisal practice for spatial-infrastructure projects' instead of 'key actors in the Dutch CBA practice' (chapters 1, 2, 3 and 6). This was the result of a remark of a reviewer of chapter 5 that the reader could interpret 'actors in the Dutch CBA practice' as a group of people for whom it is a priori certain that they are in favor of using CBA in the appraisal of spatial-infrastructure projects and that I should change 'actors in the Dutch CBA practice' into 'actors in the Dutch appraisal practice' when known CBA antagonists are included in the sample. Because 
individuals who explicitly argued against the way CBA is used in the status quo in the current Dutch appraisal practice for spatial-infrastructure projects (in the media, papers and conferences, for instance) participated in the study, I decided to concede with the request of the reviewer. However, the problem with the label 'appraisal practice' is that the reader could think that only individuals that actively participate in the appraisal of projects with a CBA participated in the study, which is not the case at all. Hence, I believe that 'key individuals in the Dutch CBA practice' is still the most precise representation of the respondents, enriched with the notion that known CBA antagonists are also included in the sample. Because chapters 4 and 5 were already published before I made this decision, the respondents are still represented as 'key actors in the Dutch appraisal practice for spatial-infrastructure projects' in these chapters.

\section{References}

Ackerman, F., Heinzerling. L., 2002. Pricing the Priceless. Cost-Benefit Analysis of Environmental Protection (Washington, DC: Georgetown Environmental Law and Policy Institute, Georgetown University Law Center).

Annema, J.A., Koopmans, C.C, Van Wee, G.P., 2007. Evaluating transport infrastructure: the Dutch experience with standardised approach, Transport Reviews, Vol. 27, no. 2, pp. 125-150.

Beukers, E., Bertolini, L., Te Brömmelstroet, M.C.G., 2012. Why cost-benefit analysis is perceived as a problematic tool for assessment of transport plans: a process perspective. Transportation Research Part A 46 (1), 68-78.

Boardman, A., Weimer, D., Vining, A., Greenberg, D., 2010. Cost-Benefit Analysis. Concepts and practice. 4th Edition. Pearson.

Brent, R.J., 1996. Applied cost-benefit analysis, Cheltenham, Edward Elgar.

Bristow, A.L., Nellthorp, J., 2000. Appraisal of transport projects in the European Union. Transport Policy 7 (1), 51-60.

Bryman, A., 2006. Integrating quantitative and qualitative research: how is it done? Qualitative Research 6 (1), 97 - 113.

Checkland, P.B., 1980. Formulating Problems for System Analysis, WP-80-59, IIASA, Laxenburg, Austria.

Christiaans, H. H. C. M., Fraaij, A. L. A., de Graaf, E., Hendriks, C. F., 2004. Methodologie van technisch-wetenschappelijk onderzoek. Lemma B.V. Utrecht.

Creswell, J.H., 2009. Research Design. Qualitative, Quantitative and Mixed Methods Approaches. 3rd edition. SAGE Publications inc.

De Bruijn, J. A., ten Heuvelhof, E.F., in 't Veld, J., 2002. Procesmanagement; over procesontwerp en besluitvorming (Academic Service, Schoonhoven).

De Bruijn, J. A., ten Heuvelhof, E.F., 1999. Scientific expertise in complex decision-making processes. Science and Public Policy, Volume 26, number 3, pages 179-184.

De Jong, W.M. 1999. Institutional Transplantation; how to adopt Good Transport Infrastructure Decision Making Ideas from other Countries? (Eburon Publishers, Delft). 
De Jong., W.M., Geerlings, H., 2003. Exposing weaknesses in interactive planning: the remarkable return of comprehensive policy analysis in The Netherlands. Impact Assessment and Project Appraisal 21 (4), 281-291.

Dupuit, J., 1844. De la mesure de l'Utilité des Travaux Publics, Annales de Ponts et Chaussées, Second series, volume 8. Translated as: Dupuit, J., 1952, On the measurement of utility of public works. International Economic Papers (2), 83-110.

Eijgenraam, C.J.J., Koopmans, C.C., Tang, P.J.G., Verster, A.C.P., 2000. Evaluation of Infrastructural Projects; Guide for cost-benefit analysis, Sections I and II, CPB, The Hague, NEI (Changed Name to ECORYS), Rotterdam.

Ehrmann, J., Stinson, B., 1999. Joint fact-finding and the use of technical experts. In: Susskind, L., McKearnan, S., Thomas-Larmer, J. (Eds.), The Consensus Building Handbook. Sage Publications, Thousand Oaks, CA.

Eliasson, J., Lundberg, M., 2012. Do Cost-Benefit Analyses Influence Transport Investment

Decisions? Experiences from the Swedish Transport Investment Plan 2010-21. Transport reviews 32 (1), 29-48.

Enserink, B., 2000. A quick scan for infrastructure planning: screening alternatives through interactive stakeholder analysis. Impact Assessment and Project Appraisal, 18(1), March, pages 15-22.

Frank, R.H., 2000. Why is Cost-Benefit analysis so controversial? Journal of Legal Studies vol. XXIX, $913-930$.

Hamers, D., Bijlsma, L., Hoorn, V.A., 2012. The plan review: a new approach to urban project assessment. AESOP $26^{\text {th }}$ Annual Congres. 11.15 July 2012. Ankara

Hayashi, Y., and Morisugi, H., 2000. International comparison of background concept and methodology of transportation project appraisal. Transport Policy 7 (1), 73-88.

Hansson, S.-O., 2007. Philosophical problems in cost-benefit analysis. Economics and Philosophy 23 (2), 163-183.

Healey, P., 1992. Planning through debate. The communicative turn in planning theory. Town Planning Review. (63)2, 143-162.

Heertje, A., 2006. Echte Economie. Een verhandeling over schaarste en welvaart en over het geloof in leermeester en lernen. Annalen van het thijmgenootschap. Jaargang 94, aflevering 4. Valkhof Pres.

Hennipman, P., Welvaartstheorie en economische politiek, Samson, Alphen aan den Rijn, 1977.

Huijs, M., 2011. Building Castles in the (Dutch) Air: Understanding the Policy Deadlock of Amsterdam Airport Schiphol 1989 - 2009. Ph.D. Dissertation, TU Delft.

House of Representatives, 2000. Letter of Minister of Transport, Public Works and Watermanagement 26428 nr. 21. (Perspectievennota Verkeer en Vervoer). The Hague, April 20th, 2000.

House of Representatives. 2004. Grote Projecten Uitvergroot: Een Infrastructuur voor Besluitvorming (The Hague: Tweede Kamer der Staten-Generaal, 2004, TK 2004-2005, 29 283, nr.5-6).

House of Representatives, 2013. Debates on the Dutch spatial-infrastructure investment program November 25th 2013 (In Dutch: Notaoverleg MIRT, 25 November, 2013). The Hague. 
Innes, J.E., Booher, D.E., 2000. Indicators for sustainable communities: a strategy building on complexity theory and distributed intelligence. Planning Theory and Practice (1) 173186.

Kanemoto, Y., 2011. Surplus theory. A Handbook of Transport Economics. Edited by André de Palma, Robin Lindsey, Emile Quinet and Roger Vickerman. Edward Elgar.

Kørnøv, L., Thissen, W.A.H., 2000. Rationality in decision- and policy-making: implications for strategic environmental assessment, Impact Assessment and Project Appraisal, 18:3, 191-200.

Koopmans, C.C., Oosterhaven, J., 2011. SCGE modeling in cost-benefit analysis: the Dutch experience. Research in Transportation Economics. 31 (1), 29-36.

Lee Jr., D. B., 2000. Methods for evaluation of transportation projects in the USA. Transport Policy 7 (1), 41-50.

Lohmann, L., 1997. Cost-benefit analysis: whose interest, whose rationality? London: The corner house.

Mackie, P., 2010. Cost-Benefit Analysis in Transport: A UK Perspective. International Transport Forum, Mexico.

Mackie, P., Nellthorp, J., 2001. Cost-benefit analysis in transport, in K. Button and D. Hensher (Eds) Handbook of Transport Systems and Traffic Control, 143-174 (Oxford: Elsevier).

Mackie, P., Preston, J., 1998. Twenty-one sources of error and bias in transport project appraisal. Transport Policy 5 (1), 1-7.

Mackie, P., Worsley, T., 2013. International Comparisons of Transport Appraisal Practice. Overview Report. Institute for Transport Studies. University of Leeds.

Ministry of Transport, Public Works and Water management and Ministry of housing spatial planning and the environment, 2009. Spelregels van het Meerjarenprogramma Infrastructuur, Ruimte en Transport. The Hague: Ministry of transport and water management \& Ministry of housing, spatial planning and the environment.

Ministry of Infrastructure and the Environment (2010) Manual for exploration phase spatialinfrastructure projects (In Dutch: Handreiking MIRT-Verkenning). The Hague.

Mishan, E.J., Quah, E., 2007. Cost-BenefitAnalysis. 5th Edition. Routledge.

Morgan, D., 1998. Practical strategies for combining qualitative and quantitative methods: Applications to health research. Qualitative health research 8 (3), 362-276.

Mouter, N., Annema, J.A., Van Wee, B., 2012. Maatschappelijke Kosten- en Batenanalyse inhoudelijk geëvalueerd. NICIS: Den Haag.

Mu, R., 2013. Transit-Oriented Development in China How can it be planned in complex urban systems? Ph.D. Dissertation, TU Delft.

Naess, P., 2006. Cost-benefit analysis of transportation investments. Neither critical nor realistic. Journal of critical realism 5 (1), 32-60.

Nyborg, K., 1998. Some Norwegian politicians' use of cost-benefit analysis. Public Choice 95, 381-401.

Nyborg, K., 2012. The Ethics and Politics of Environmental Cost-Benefit Analysis. Routledge.

Odeck, J., 1996. Ranking of regional road investment in Norway. Transportation 23 (2), 123140 . 
Odeck, J., 2010. What determines decision-makers' preferences for road investments? Evidence from the Norwegian road sector. Transport reviews 30 (4), 473-494.

Odgaard, T., Kelly, C., Laird, J., 2005. Current practice in project appraisal in Europe, in: Proceedings of the European Transport Conference. 3-5 October, Strasbourg, Association for European Transport.

Priemus, H., 2007. Decision-making on large infrastructure projects: the role of the Dutch Parliament. Transportation Planning and Technology, 30 pp 71-93.

Quinet, E., 2000. Evaluation methodologies of transportation projects in France. Transport Policy 7, 27-34.

Rittel, H.W.J., M.M. Webber (1973), Dilemmas in a General Theory of Planning, Policy Sciences, 4, pp. 155 - 169.

Rothengatter, W., 2000. Evaluation of infrastructure investments in Germany. Transport Policy 7 (1), 17-25.

Romijn, G., Renes, G., 2013. General Dutch CBA Guideline. (In Dutch: Algemene Leidraad voor maatschappelijke kosten-batenanalyse. Centraal Planbureau en Planbureau voor de Leefomgeving. The Hague.

Sager, T., Ravlum I.A., 2005. The political relevance of planners' analysis: the case of a parliamentary standing committee. Planning Theory 4 (1), 33-65. Sayers, T.M., Jessop, A.T., Hills, P.J., 2003. Multi-criteria evaluation of transport options-flexible, transparent and user-friendly?. Transport Policy 10 (2), 93-105.

Salling, K.B., Leleur, S., 2012. Modelling of transport project uncertainties: feasibility risk assessment and scenario analysis. European journal of transport and infrastructure research. 12 (1), 21-38.

Sayers, T.M., Jessop, A.T., Hills, P.J., 2003. Multi-criteria evaluation of transport optionsflexible, transparent and user-friendly? Transport Policy 10 (2), 93-105.

Sen, A.K., 2000. The discipline of cost-benefit analysis. The journal of Legal Studies 29 (2), 931-952.

Simon, H.A., 1979. Rational Decision Making in Business Organizations, The American Economic Review, 69, 4, pp. 493 - 513.

Stolwijk, H., 2010. Economische beleidsevaluaties en welvaart, CPB Memorandum 245.

Sunstein, C.R., 2000. Cognition and Cost-Benefit Analysis, Journal of Legal Studies vol. XXIX, $1059-1103$.

Thomopoulos, N., Grant-Muller, S., Tight, M.R., 2009. Incorporating equity considerations in transport infrastructure evaluation: current practice and a proposed methodology. Evaluation and Program Planning 32 (4), 351-359.

Tsamboulas, D.A., 2007. A tool for prioritizing multinational transport infrastructure investments. Transport Policy 14 (1), 11-26.

Tudela, A., Akiki, N., Cisternas, R., 2006. Comparing the output of cost benefit and multicriteria analysis: an application to urban transport investments. Transportation Research Part A 40 (5), 414-423.

Weber, R.P., 1990. Basic Content Analysis, 2nd ed. Newbury Park, CA.

Van Eeten, M., 1999. Dialogues of the Deaf; defining New Agendas for Environmental Deadlocks (Eburon Publishers, Delft).

Van de Riet, O (2003), Policy Analysis in a Multi-Actor Setting (Eburon Publishers, Delft). 
Van Wee, B., 2007. Rail Infrastructure: Challenges for Cost-Benefit Analysis and Other ex ante Evaluations. Transportation Planning and Technology, Vol 30 (1) 31-48

van Wee, B., 2011. Transport And Ethics. Ethics and the Evaluation of Transport Policies and Projects. Edward Elgar Publishing.

Van Wee, B., 2012. How suitable is CBA for the ex-ante evaluation of transport projects and policies? A discussion from the perspective of ethics. Transport Policy 19 (1), 1-7.

Veisten, K., Elvik, R., Bax, C., 2010. Assessing conceptions of cost-benefit analysis among road safety decision-makers: misunderstandings or disputes? Impact Assessment and Project Appraisal 28 (1), 57-67.

Voogd, H., 1983. Multicriteria Evaluation for Urban and Regional Planning (Pion Limited, London). Hoofdstuk 6.

World Bank., 2010. Cost-Benefit Analysis in World Bank Projects. Washington D.C.: The International Bank for reconstruction and development/The World Bank. 


\section{Ranking the substantive problems in the Dutch Cost-Benefit Analysis practice}

This chapter has originally been published as: Mouter, N., Annema, J.A., van Wee, G.P., 2013. Ranking the substantive problems in the Dutch Cost-Benefit Analysis practice. Transportation Research Part A. 49. pp 241-255;

\subsection{Introduction}

In most western countries (Social) Cost-Benefit Analysis (CBA) is a widely used ex-ante evaluation tool used to support the decision making process in transport (e.g. Grant Muller et al., 2001; Hayashi and Morisugi, 2000; Odgaard et al., 2005; Vickerman, 2007). Nevertheless, many process and content related problems with the use of CBA in the decision making process can still be found in scientific literature (see section 2.2). To the best of the authors' knowledge, a systematic empirical analysis concerning the perceptions of different participants in a CBA practice on content related problems has not been carried out. A study of participants' perceptions can clarify whether substantive problems discussed in the scientific literature are actually experienced in practice.

In this paper we investigate the perceptions of 86 key participants in the Dutch CBA practice concerning substantive problems that arise when appraising spatial-infrastructure projects using CBA. We define the way welfare effects are estimated and the way the estimations are presented in the CBA reports as substantive problems. We attempt to identify which substantive problems key participants experience and what the relative order of importance of substantive problems is according to 86 key participants. Moreover, we aim to identify the extent to which perceived substantive problems are specific CBA problems or just problems related to any ex-ante policy evaluation tool. Finally, we aim to analyze to which extent different groups in the Dutch CBA practice (e.g. consultants, scientists, policy makers) 
perceive substantive problems differently. Our empirical results can be used as inspiration for CBA research agendas. When researchers take into account the perceptions of key practitioners by the determination of a CBA research agenda, this might enhance the acceptance of the use of the instrument in the decision making process.

The remainder of this contribution is organized as follows. Section 2.2 positions this paper in CBA-related transport literature. Section 2.3 discusses the research methodology. Section 2.4 presents the quantitative results regarding the ranking of substantive problems in the Dutch CBA practice. Section 2.5 discusses the perceived substantive problems in more detail. Section 2.6 analyzes the extent to which different groups in the Dutch CBA practice perceive the substantive problems differently. Finally, section 2.7 concludes and discusses the results.

\subsection{Transport CBAs: an overview of literature}

This section describes seven categories of transport-related CBA literature that we identified in some of the main transport-related journals (section 2.2.1). In section 2.2.2 we use this literature for clustering the empirical results with regard to the perceptions of key participants in the Dutch CBA practice on substantive problems (see section 2.3.3) and discuss the literature on (solutions for) substantive problems in more detail.

\subsubsection{Seven categories of transport-related CBA literature}

CBA is a popular research topic in transport literature. In general seven types of CBA literature can be identified. First, some contributions present a CBA of an (innovative) transport project (e.g. Cardell 1980; Nguyen-Hoang and Yeung, 2010; Rotaris et al., 2010; Saelensminde, 2004). A second category of transport-related CBA literature studies the impact of CBA results on decision making (e.g. Eliasson and Lundberg et al., 2011; Odeck et al., 1996; Sager and Ravlum et al., 2005). Third, some contributions reflect on the merits of CBA compared to other ex-ante evaluation methods (e.g. Sayers et al., 2003; Tsamboulas, 2007; Tudela et al., 2006). A fourth category of transport-related CBA literature compares different CBA practices (e.g. Bristow and Nellthorp, 2000; Hayashi and Morisugi, 2000; Odgaard et al., 2005) or describes a CBA practice (e.g. Lee, 2000; Quinet, 2000; Rothengatter, 2000). A fifth group of transport-related CBA literature reflects on the CBA process itself (Beukers et al., 2012; Damart and Roy, 2009; Gao et al., 2011). Sixth, some contributions discuss general theoretical problems of the CBA method (e.g. Ackerman and Heinzerling, 2002; Hansson, 2007; Hyard, 2012; Naess, 2006; Sen, 2000; Wee, 2012). Seventh, and finally, there is a wealth of literature on (solutions for) substantive problems.

\subsubsection{Literature on (solutions for) substantive problems}

Below, we discuss this seventh category of transport-related CBA literature in more detail. We selected transport-related CBA literature from the period 1995-2012 appearing in some of the main transport-related journals. In addition, contributions published before 1995 that were cited frequently are taken into account in our selection. It is beyond the scope of this paper to provide an exhaustive study of the transport-related CBA literature on (solutions for) substantive problems. Table 2-1 shows a brief overview of CBA related literature on (solutions for) substantive problems. Table 2-1 does not present the frequency of the studies 
that cover a category of substantive problems because the only aim of this overview is to identify which categories of substantive problems are studied in the literature and not which category of substantive problems is studied most frequently.

Table 2-1: Overview of categories of literature on (solutions for) substantive problems in some main transport-related journals.

\begin{tabular}{|c|c|}
\hline Substantive problem categories & Example papers that study (solutions for) substantive problems \\
\hline Reference case & Damart and Roy (2009); Mackie and Preston (1998); Quinet (2000) \\
\hline Project alternatives & Quinet (2000) \\
\hline Estimating non-monetized effects in & Damart and Roy (2009); Grant-Muller et al. (2001) \\
\hline $\begin{array}{l}\text { Estimating non-monetized transport } \\
\text { effects }\end{array}$ & $\begin{array}{l}\text { Damart and Roy (2009); Flyvbjerg (2005); Flyvbjerg et al. (2005); } \\
\text { Grant-Muller et al. (2001); Hayashi and Morisugi (2000); Holz-Rau } \\
\text { and Scheiner (2011); Lee (2000); Mackie and Preston (1998); Morisugi } \\
\text { (2000); Salling and Banister (2009); Ševcíková et al. (2011); } \\
\text { Vickerman (2000); Van Wee (2007) }\end{array}$ \\
\hline Estimating costs & Salling and Banister (2009); Van Wee (2007) \\
\hline Indirect effects & $\begin{array}{l}\text { Annema et al. (2007); Bristow and Nellthorp (2000); Grant-Muller et } \\
\text { al. (2001); Morisugi (2000); Quinet (2000); Rothengatter (2000); } \\
\text { Vickerman (2007) }\end{array}$ \\
\hline External benefits & $\begin{array}{l}\text { Brahten and Hervik (1997); Grant-Muller et al. (2001); Hayashi and } \\
\text { Morisugi (2000); Quinet (2000); Rietveld (1994); Vickerman (2000); } \\
\text { Vickerman (2007) }\end{array}$ \\
\hline External costs & $\begin{array}{l}\text { Forkenbrock (2001); Grant-Muller et al. (2001); Mandell (2011); } \\
\text { Morisugi (2000); Quinet (2000); Rothengather (2000); Verhoef (1994); } \\
\text { Vickerman (2007); Willis et al. (1998) }\end{array}$ \\
\hline Monetizing in general & $\begin{array}{l}\text { Annema et al. (2007); Damart and Roy (2009); Grant-Muller et al. } \\
\text { (2001); Hyard (2012) }\end{array}$ \\
\hline Value of time & $\begin{array}{l}\text { Borjesson (2012); Brahten and Hervik (1997); Fosgerau (2007); Grant- } \\
\text { Muller et al. (2001); Hayashi and Morisugi (2000); Hensher (2006); } \\
\text { Holz-Rau and Scheiner (2011); Mackie and Preston (1998); Morisugi } \\
\text { (2000); Lee (2000) }\end{array}$ \\
\hline Value of statistical life & $\begin{array}{l}\text { Grant-Muller et al. (2001); Hauer (1994); Holz-Rau \& Scheiner (2011); } \\
\text { Verhoef (1994) }\end{array}$ \\
\hline Value of reliability & Hollander (2006); Peer et al. (2012) \\
\hline Presentation & $\begin{array}{l}\text { Annema et al. (2007); Damart and Roy (2009); Grant-Muller et al. } \\
\text { (2001); Quinet (2000); Van Wee (2007) }\end{array}$ \\
\hline Discounting & Annema et al. (2007); Grant-Muller et al. (2001); Weitzman (1998) \\
\hline Distribution & $\begin{array}{l}\text { Annema et al. (2007); Bristow and Nellthorp (2000); Hyard (2012); } \\
\text { Lee (2000); Quinet (2000); Rothengather (2000) }\end{array}$ \\
\hline Uncertainty in CBA & $\begin{array}{l}\text { Annema et al. (2007); Damert and Roy (2009); Flyvbjerg et al. (2005); } \\
\text { Grant-Muller et al. (2001); Holz-Rau and Scheiner (2011); Salling and } \\
\text { Banister (2009); Ševcíková et al. (2011); Van Wee (2007); Weitzman } \\
\text { (1998) }\end{array}$ \\
\hline
\end{tabular}

Table 2-1 shows that most contributions study (solutions for) a specific substantive problem. A few studies (e.g. Annema et al., 2007; Damart and Roy, 2009; Grant-Muller et al., 2001; van Wee, 2007) describe (solutions for) multiple substantive problems. Most studies base the analysis of (solutions for) substantive problems on analytical thinking or the authors' own 
experience in a CBA practice. We did not find a study with the same aim as this paper: empirically investigating perceptions of key participants in a CBA practice concerning substantive CBA problems.

\subsection{Research methodology}

This paper presents the perceptions of key participants in the Dutch CBA practice with regard to substantive problems. We have chosen the Netherlands for two reasons. First, the Dutch CBA practice is state-of-the-art and can be regarded as representative for many countries that use CBA as an ex-ante evaluation tool in the decision making process for infrastructure projects. Second, it is argued by Odgaard et al. (2005) that, within the European Union, the Dutch CBA practice is - together with the Danish CBA practice - the CBA practice that takes the highest variety of effects into account when constructing a CBA for infrastructure projects.

Two research methods are combined to study the perceptions. Firstly, 86 key participants in the Dutch CBA practice were interviewed in-depth in order to obtain an overview and a ranking of perceived substantive CBA problems in the Netherlands. Secondly, we sent a questionnaire to these 86 key participants, in which they were asked to rank the substantive problems once again in order to improve the validity of the ranking of the substantive problems based on the interviews, which 74 participants completed. Below we present the methods in more detail.

\subsubsection{Selection of respondents}

In order to investigate perceptions from Dutch key participants of the substantive problems with the appraisal of spatial-infrastructure projects using CBA, the aim of the research was to interview the entire population of key participants in the Dutch CBA practice in the last decade. All individuals that had an explicit and recognizable role in the Dutch CBA practice in the last decade are included in this population ${ }^{8}$. First, we interviewed 10 consultants that carried out a number of important CBAs, 10 scientists/employees of assessment bureaus that reflected on important CBAs and 10 policymakers that actually use the CBA results. All 30 people were willing to participate.

The rest of the population of key participants in the Dutch CBA practice was detected and approached for an interview in two steps. First, the 30 respondents were asked which people, in their view - besides the people that were already interviewed - were paramount in order to be certain that the Dutch population of key CBA participants was interviewed for this research. The 30 respondents mentioned 51 people. 42 of these 51 people were interviewed. Next, the list of the 72 interviewed respondents was presented to four respondents that were often mentioned as key participants in the Dutch CBA process during the interviews. These respondents were asked to add to the list the names of the people that needed to be interviewed in order to make sure that all of the key participants in the Dutch CBA practice

\footnotetext{
${ }^{8}$ The second and the third authors of this contribution are part of this population; however they were not interviewed in order to avoid bias.
} 
were interviewed. According to the four respondents, 20 people had to be interviewed to attain this objective. Finally, 14 out of these 20 respondents were interviewed.

In order to determine to what extent different groups in the Dutch CBA practice perceive the substantive problems differently, in the written questionnaire the respondents were asked to express their main specialization regarding CBA (economics, spatial-planning or ecology ${ }^{9}$, transportation), main profession regarding CBA (consultant, scientist or researcher, policy maker or lobbyist ${ }^{10}$ ) and their most important role in the Dutch CBA practice over the last decade (initiator of a plan or lobbyist ${ }^{11}$, someone who reviews and advises on funding applications, CBA practitioner, CBA reviewer, academic who studies CBA, developer of CBA guidelines). Because two of the three authors of this paper have extensive experience in the Dutch CBA practice it was possible to classify the 12 respondents who did not fill in the questionnaire. Table 2-2 classifies the respondents in relation to their main specialization, main profession and most important role.

Table 2-2: Respondents classified in relation to their specialization, profession and most important role.

\begin{tabular}{|c|c|c|c|c|c|c|c|}
\hline Specialization & Profession & 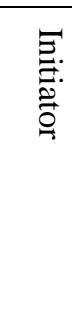 & 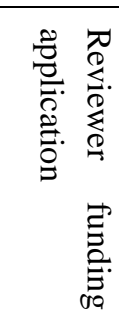 & 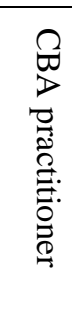 & 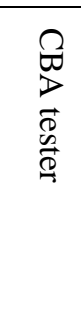 & 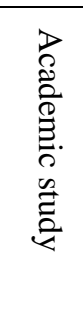 & 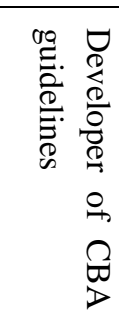 \\
\hline \multirow[t]{3}{*}{ Economics (44) } & Consultant & 1 & 0 & 8 & 1 & 0 & 3 \\
\hline & Scientist / Researcher & 2 & 0 & 6 & 5 & 6 & 5 \\
\hline & Policy maker & 0 & 5 & 0 & 1 & 0 & 1 \\
\hline \multirow[t]{3}{*}{ Spatial Planning (17) } & Consultant & 0 & 0 & 0 & 0 & 1 & 0 \\
\hline & Scientist / Researcher & 1 & 1 & 0 & 0 & 3 & 0 \\
\hline & Policy maker & 6 & 3 & 1 & 0 & 1 & 0 \\
\hline \multirow[t]{3}{*}{ Transportation (25) } & Consultant & 1 & 0 & 3 & 1 & 0 & 0 \\
\hline & Scientist / Researcher & 0 & 0 & 1 & 0 & 3 & 4 \\
\hline & Policy maker & 6 & 2 & 1 & 1 & 0 & 2 \\
\hline Total & & 17 & 11 & 20 & 9 & 14 & 15 \\
\hline
\end{tabular}

Table 2-2 shows, for instance, that three respondents consider 'economics' as their main specialization, 'consultant' as their main profession and 'developer of CBA guidelines' as their most important role in the Dutch CBA practice over the last decade (second row down, last column).

\footnotetext{
${ }^{9}$ From now on this group of respondents is labeled as 'spatial planning'.

10 ('policy maker').

11 ('initiator of a plan').
} 


\subsubsection{Structure of the interviews}

The interviews were qualitative, semi-structured, in-depth interviews (approximately one hour long). The interviews consisted of two parts. Firstly, the respondents were asked to mention the five most important substantive problems they experience with CBA. Secondly, we asked clarifying questions (e.g. What is, in your view, the exact problem? Why do you think this is a problem? Could you give an example of a CBA where the problem occurred?). In the second part of the interview the interviewer (first author of this paper) tried to challenge the statements the respondent made, in order to sharpen the arguments that the respondent used for the substantive problems he experiences; for instance, by confronting the respondent with contradicting statements made by other respondents.

\subsubsection{Analysis of the interviews}

Soon after the interview (within 24 hours where possible), the interviewer processed a report which then constituted textual data for analysis. The method used to analyze the data was content analysis. Content analysis has been defined as a systematic, replicable technique for compressing many words of text into fewer content categories based on explicit rules of coding and categorizing (Weber, 1990). To make the coding process transparent and replicable, we developed a 'coding and categorizing protocol' (42 pages long) in which the rules for coding are described. The content analysis in this paper was carried out in two steps. The first step of the content analysis for this study was coding the substantive problems that were mentioned by the respondents in the interviews.

Because the aim of this paper is to inspire scientific research regarding solutions for substantive CBA problems, we are only interested in perceptions on (theoretically) solvable negative aspects of CBA. Hence, an important aim of the coding protocol was to clarify whether a respondent's perception on a negative aspect of the CBA could be defined as a (theoretically) solvable negative aspect or a (theoretically) insolvable negative aspect. In this paper, we label the (theoretically) solvable negative aspects as 'substantive problems' and the (theoretically) insolvable negative aspects as 'disadvantages'. For instance, when a respondent states that it is inherently impossible to take all welfare effects of a project into account in a CBA, this is characterized as a disadvantage of CBA and not as a substantive problem.

The second step of the content analysis in this study was the clustering of perceptions on substantive problems into problem clusters. First, the perceptions of substantive problems were classified into problem categories. The different problem categories were based on the literature (see section 2.2) and Dutch CBA guidelines (e.g. Eijgenraam et al., 2000). The demarcation of the different problem categories was described in the 'coding and categorizing protocol'. Next, the problem categories were grouped into problem clusters in accordance with the 'coding and categorizing protocol'. Having completed the two steps of the content analysis, it was then possible to determine which substantive problems are perceived by the Dutch CBA practice. Moreover, it was possible to rank the problem clusters by analyzing the number of times the respondents mentioned a substantive problem that could be categorized into a problem cluster. 
The two steps of the content analysis were carried out by the first author (first coder). In some cases the first author was not sure whether a respondent mentioned a substantive problem, in other cases he was not sure in which cluster a substantive problem should be placed. In either of these cases the first author discussed the issue with the second author (second coder) until an agreement was reached.

\subsubsection{Intercoder reliability}

The intercoder reliability of the content analysis of the interviews was tested by an independent coder (third coder). The independent coder has some knowledge of CBA but is not a participant in the Dutch CBA practice nor has any involvement in this research. In accordance with the literature (e.g. Lombard et al., 2004) more than $10 \%$ of the body of content was tested by the independent coder (10 randomly selected out of the 86 interviews). More specifically, the third coder coded the perceptions of substantive problems in the 10 interviews and grouped them into problem clusters in accordance with the coding and categorizing protocol'. As a consequence, the reliability of both steps of the content analysis was tested. We think that it is important to test the reliability of the first step of the content analysis because this paper aims to provide an overview of perceptions of substantive problems. Moreover, we think that it is important to test the reliability of the second step of the content analysis because problem clusters are ranked in this paper by the number of times the respondents mentioned a substantive problem that could be categorized into a problem cluster.

We used Holsti's coefficient to assess the intercoder reliability of the first step of the content analysis (Holsti, 1969). The intercoder reliability of the second step of the content analysis is assessed using Krippendorff's Alpha. We used Krippendorff's Alpha for two reasons. First, this agreement measure considers the possibility that coders cluster a substantive problem into the same problem cluster by chance. Second, Krippendorff's Alpha adjusts - in contrast to Scott's Pi, for instance - for small sample bias (Krippendorff, 2004; Riffe et al., 2005).

\subsubsection{Written questionnaire used as validation}

From the content analysis of the interviews, one can see which substantive problem clusters Dutch practice considers to be the most important with regard to the appraisal of spatialinfrastructure projects using CBA. As a form of triangulation (Erlandson et al., 1993), in order to improve the validity of this ranking, the respondents were asked to rank the problem clusters in the written questionnaire. 74 of the 86 respondents filled in the written questionnaire. The respondents were asked to choose the most important substantive problem cluster, the second most important problem cluster and the third most important problem cluster out of the problem clusters (Top 3 Analysis).

In addition, the respondents were asked - in the written questionnaire - to evaluate the quality of each problem cluster on a 5 point Likert scale. The respondents could state that they thought that the quality of the problem cluster was 'problematically low', that they were 'very satisfied' with the quality of the problem cluster, or something between these extremes. 


\subsection{Results: ranking substantive problems in Dutch CBA practice}

\subsubsection{Nine problem clusters}

The coding of the 86 interviews resulted in 636 unique perceptions of substantive problems. As described in section 3.3 the different codes were grouped into problem categories. The 636 codes were categorized into 92 problem categories. Subsequently, it was possible to cluster the 92 problem categories into 9 problem clusters. These problem clusters are related to the so called seven 'CBA-steps' (figure 2-1).

The seven CBA steps start with the problem analysis (step 1). After that, one has to construct the reference case (step 2) and the project alternatives (step 3). By comparing the project alternatives with the reference case, one can estimate the non-monetized project effects of the project alternatives (step 4). In order to make the analysis a Cost-Benefit Analysis, the nonmonetized project effects have to be transferred as far as possible into monetary terms (step 5) and the cash flows have to be discounted to one base year (step 6). Finally, the results are presented in the CBA report (step 7).

The eighth problem cluster is 'problems with distributional effects'. In a pure CBA, distributional effects are not (necessarily) taken into account. Nevertheless, some respondents think that it is important to have insight into these distributional effects for political reasons. When a respondent thinks that it is a problem that the CBA report does not pay enough attention to the distributional effects, the problem is assigned to this problem cluster. The ninth problem cluster is 'problems with uncertainty in CBAs'. The participants who make a CBA have to deal with uncertainty in different 'CBA steps'. The reference case, estimations of non-monetized effects and the discount rate are uncertain. Some respondents experience problems with the way present Dutch CBAs deal with uncertainty. These perceptions are assigned to this ninth problem cluster.

\subsubsection{Ranking substantive problems in the interviews}

Figure 2-1 presents - for each problem cluster - the frequencies of substantive problems mentioned by the respondents that could be categorized into a problem cluster. Moreover, figure 2-1 presents (in italics) - for each problem cluster - how many respondents mentioned a substantive problem that could be categorized into a problem cluster. 


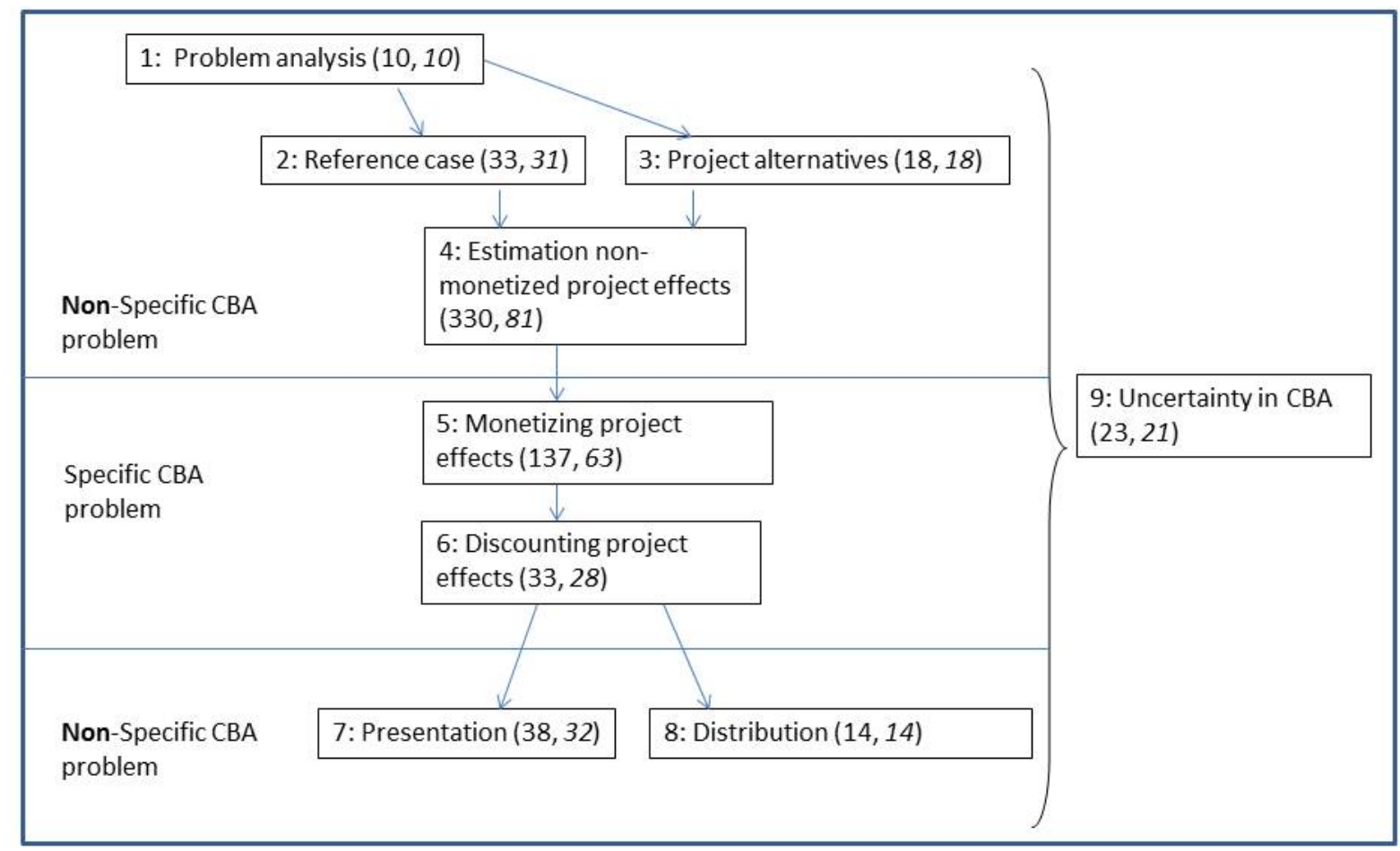

Figure 2-1: number of codes / respondents per problem cluster

Figure 2-1 shows that most substantive problems mentioned by the respondents are clustered into the problem cluster 'problems with the estimation of the non-monetized project effects' $(52 \%)$. Moreover, $22 \%$ of the substantive problems mentioned are clustered into the problem cluster 'monetizing of project effects'. $27 \%$ of the substantive problems mentioned by the respondents are specific CBA problems: monetizing of projects effects, discounting of project effects. A characteristic of a CBA in comparison to other ex-ante impact evaluation studies (e.g. multi-criteria analysis, cost-effectiveness analysis, environmental impact analysis) is that a CBA aspires to monetize and discount effects. The other ex-ante impact methods have to face the other seven problem clusters as well.

\subsubsection{Results of the intercoder reliability test}

The intercoder reliability of the results given in section 2.4 .2 is tested in this study. The results of the intercoder reliability test are presented in figure 2-2. 


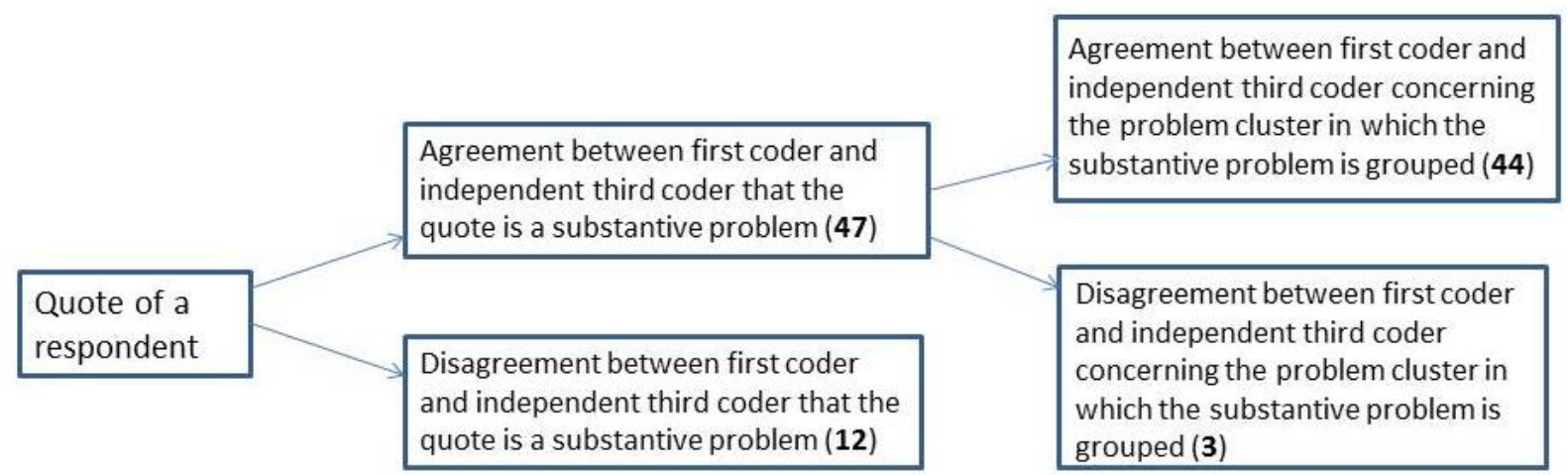

Holsti's coefficient: 0.886

Krippendorff's Alpha: 0.919

\section{Figure 2-2: results of the intercoder reliability test}

Figure 2-2 shows that the first coder and the independent third coder agreed 47 times that a respondent's quote must be qualified as a substantive problem and 12 times they disagreed. This results in a Holsti's coefficient of 0.886 . For four of the twelve times that the coders disagreed, one of the two coders coded a quote of a respondent as a substantive problem, whilst the other coder coded the quote as a disadvantage. The first coder coded a quote of a respondent as a substantive problem 7 (presentation) five times, whereas the independent third coder did not code the quote. Moreover, figure 2-2 shows that Krippendorff's Alpha is 0.919 for the agreement of the two coders concerning which problem cluster a substantive problem should be grouped under.

The next question is whether or not it can be determined that the coefficients of 0.886 (Holsti's coefficient) and 0.919 (Krippendorff's Alpha) should lead us to the conclusion that the content analysis in this study is reliable. Lombard et al. (2002) state that there is no established standard for determining an acceptable level of reliability. Neuendorf (2002, p.145) reviews 'rules of thumb' set out by several methodologists and concludes that 'coefficients of 0.90 or greater would be acceptable to all, 0.80 or greater would be acceptable in most situations and below that, there exists great disagreement.' We conclude that the results of section 2.4.2 are highly reliable and not the result of a purely subjective process. However, there are reliability problems with the number of times problem cluster number 7 (presentation, see figure 2-1) is coded by the first coder. As a consequence the frequencies of substantive problems that are grouped into problem cluster 7 should be interpreted with caution.

\subsubsection{Ranking substantive problems in the questionnaires}

To check the validity of the results in section 2.4.2, the respondents were asked - in the written questionnaire - to select the most important substantive problem cluster out of the nine problem clusters, the second most important problem cluster and the third most important problem cluster (Top 3 Analysis). 73 respondents completed this question in the questionnaire. Figure 2-3 presents the results of this 'Top 3 Analysis'. 


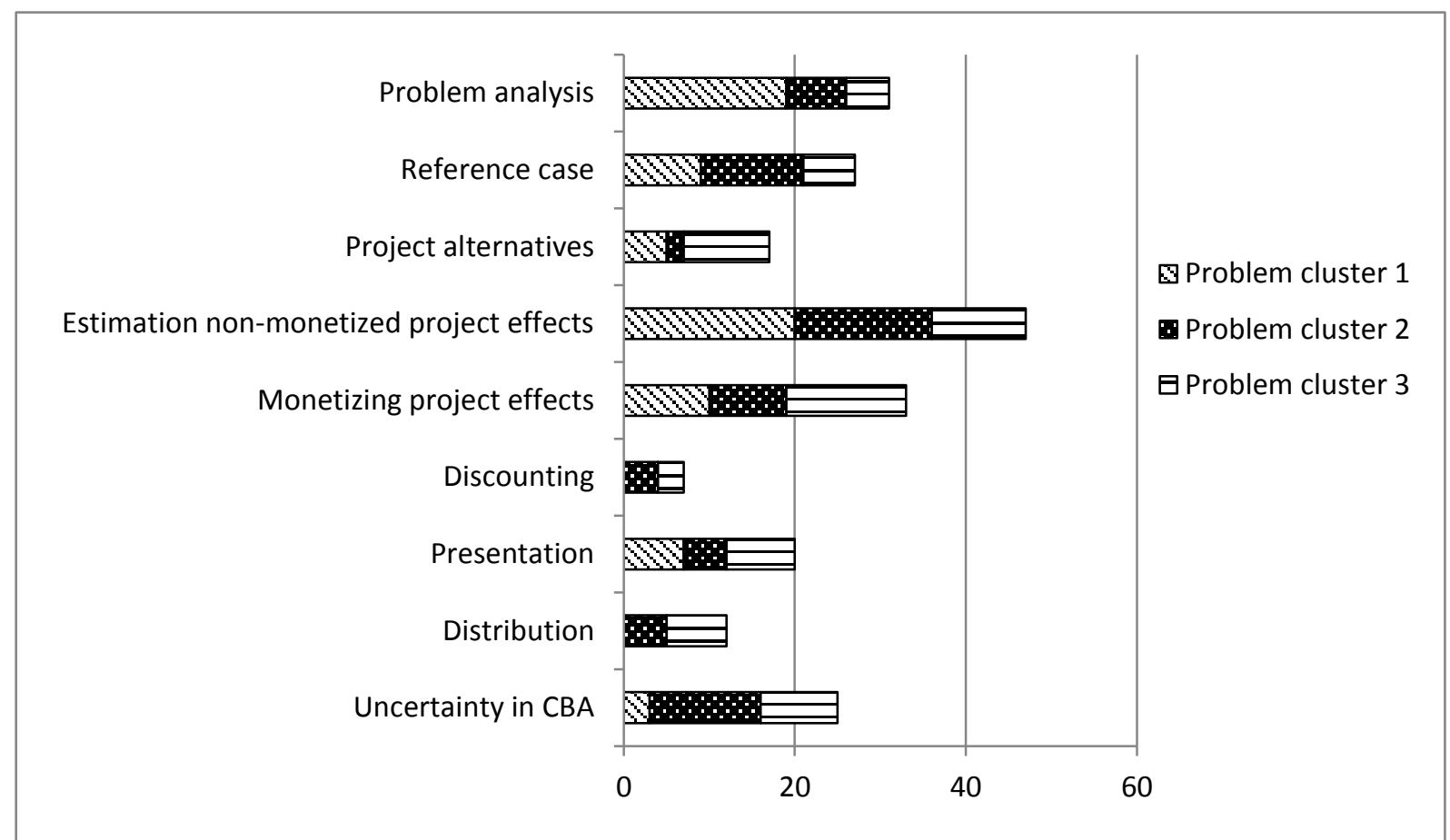

Figure 2-3: number of respondents that select the problem clusters as a 'top 3 problem cluster'

Figure 2-3 shows that 47 out of 73 respondents (64\%) state that 'problems with the estimation of the non-monetized project effects' is a 'top 3 problem cluster'. 33 out of 73 respondents (45\%) think that 'monetizing of project effects' is a 'top 3 problem cluster'. A comparison of the interview and questionnaire results reveals that the respondents select the same problem clusters as 'important problem clusters'. Likewise, the respondents rank the other problem clusters in approximately the same way in the interviews as in the written questionnaires (Kendall's tau 0.389). The 'problem analysis' problem cluster is the only cluster that is ranked significantly differently in the interviews and in the questionnaires. 'Problem analysis' is the least mentioned problem cluster in the interviews and is ranked as 'problem cluster number 3' in the 'Top 3 Analysis'. 19 respondents even select this problem cluster as the 'most important problem cluster'.

\subsection{Interesting concrete sub-categories of problems clusters}

To start up research that aspires to solve the substantive problems identified in this study it is necessary to have a deeper insight into the exact perceptions of substantive problems. Hence, this section decomposes the nine problem clusters (figure 2-3) into concrete sub-categories of substantive problems and discusses these sub-categories in brief. It is impossible to discuss all the 636 individual substantive problems in detail in this paper hence, we only discuss the most interesting sub-categories of the problems mentioned. These are the categories which were often mentioned or, in contrast, categories which were mentioned by an unexpectedly few amount of key participants in relation to the attention these sub-categories of problems receive in the scientific literature. 


\subsubsection{Problem analysis, reference case and project alternatives}

In relation to the 'problem analysis' problem cluster, the problem sub-category that is mentioned by far the most is that practitioners simply miss a high quality independent problem analysis being carried out in both the CBA and the decision making process concerning spatial-infrastructure projects. Key participants mentioned two causes for this absence. Firstly, they state that most clients of CBAs do not see the absence of a problem analysis in project proposals as worrisome, because clients often perceive that they already carried out an appropriate problem analysis themselves. Secondly, it is - according to the interviewed respondents - not clear what makes a problem analysis a 'high quality' problem analysis. The importance of carrying out an independent problem analysis was already explained 40 years ago by Williams (1972, p. 204): 'over and over again one hears of cases where the problem the clients thought they had, turned out not to be the problem they actually had, and any operations research or cost-benefit analysis practitioner who accepts the client's initial formulation of the problem uncritically is heading for disaster'.

Most of the key participants interviewed that mentioned 'reference case' as a substantive problem (21 out of 31) stated that the construction of reference cases is especially problematic when a project includes a large spatial development such as the development of a new residential area. According to these key participants it is - for example, because of the absence of a housing market model - extremely difficult to decide what 'the world without the spatial elements (in this example, the new residential area) of the spatial-infrastructure project' (the reference case) would look like in these cases. According to the people in practice, the lack of suitable spatial models results frequently in controversies among the participants in a decision making process concerning the reference case that should be used in the CBA.

Looking at the 'project alternatives' problem cluster, five key participants in the Dutch CBA practice mention that they see as a problem the fact that, in their view, far too often the project alternatives evaluated in a CBA are very suboptimal. Moreover, three respondents state that spatial project alternatives especially are often not articulated to an extent that it is feasible to estimate their effects in a CBA.

\subsubsection{Problems with the estimation of non-monetized project effects}

Based on the content analysis of the interviews, this large problem cluster (which, therefore, deserves a separate sub-paragraph) can be subdivided into two problem sub-categories: 'general problems with the estimation of non-monetized effects' and 'problems with the estimation of non-monetized specific effects'. Figure 2-4 illustrates that the sub-category 'problems with the estimation of specific effects' relates to four specific effects: 'direct effects', 'indirect effects ${ }^{12}$, ' 'external effects' and 'synergy effects'. Figure 2-4 presents the frequencies of the problems mentioned by the respondents. For the most disaggregated sub-

\footnotetext{
${ }^{12}$ The CBA literature does not demarcate direct, indirect and external effects in an unambiguous way. This paper bases the demarcation between these effects on the Dutch CBA guideline (Eijgenraam et al., 2000): direct effects are effects on the transport market, indirect effects are effects on markets other than the transport market (for instance, the labor market or the real estate market) and external effects are non-market effects.
} 
categories not only these frequencies are given (a single number) but also the frequency of the nature of the problems is given. Three main categories exist: a) 'the effect is not (sufficiently) taken into account'; b) 'the effect is taken into account in a contestable way'; c) other. These three categories are depicted between brackets in figure 2-4. For instance, zero respondents perceive that the nature of 'problems with estimation of costs' is that this effect is not taken into account sufficiently in the CBA, ten respondents state that cost estimations are contestable and four respondents mention other problems with cost estimations.

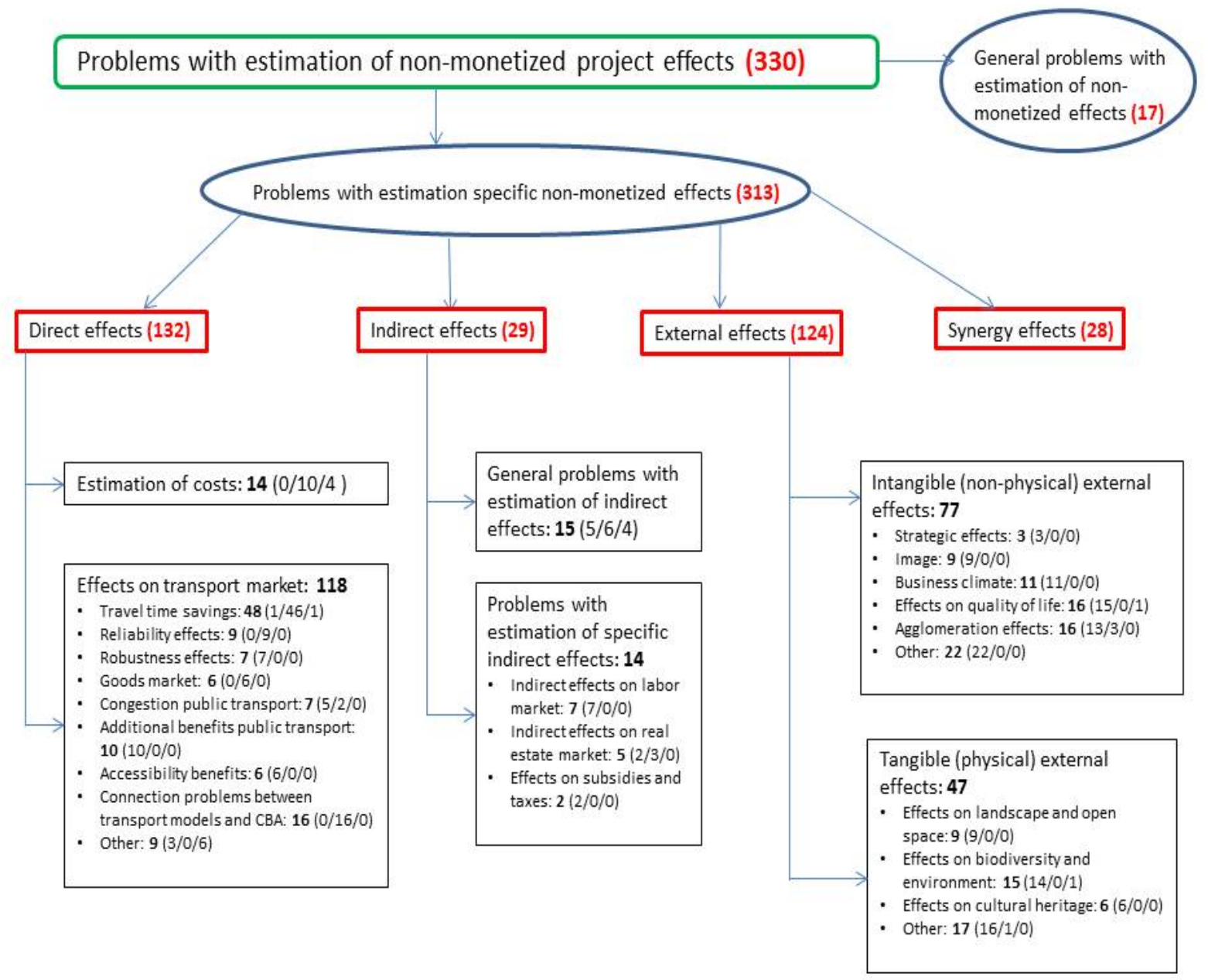

\section{Figure 2-4: problem cluster 'problems with the estimation of non-monetized project effects', sub-divided}

Figure 2-4 shows that key participants in the Dutch CBA practice experience many problems with the estimation of direct effects. In particular, respondents perceive problems with the estimation of travel time savings (48 respondents). Respondents mentioned for instance, the following three problems:

- Too often you see that the estimations of travel time savings by transport models are unexplainable and CBA guidelines do not prescribe how to deal with these unexplainable mistakes that the transport models make (10 respondents); 
- The estimations of project effects on the transport market are frequently based on one future year and subsequently, the transport effects for the other years in the future are extrapolated from this one future year, which they think is highly contestable (6 respondents);

- Transport models are developed to estimate the intensity / capacity ratio on highways and not travel time savings as a result of a new highway. Hence, transport models perform poorly when it comes to the estimation of travel time savings (5 respondents).

Respondents state that, as a result of these three problems, the estimations of travel time savings for project alternatives are contestable to an extent that it can severely influence the outcome of a CBA and the ranking of project alternatives.

Figure 2-4 also shows that key participants in the Dutch CBA practice experience many problems with the estimation of external effects and in particular intangible (non-physical) effects $^{13}$. In most cases (73 out of 77 times) the nature of the problem with intangible effects is that the effect is - in the view of the respondents - not or not sufficiently taken into account. Some respondents state that in most cases the underlying problem with the estimation of intangible effects is that the effects are more often based on the wishful thinking of project initiators rather than on sound research. On the other hand, some project initiators interviewed for this study state that it is very difficult, if not impossible, to 'prove' these effects.

\subsubsection{Problems with monetizing project effects}

Table 2-3 presents - for each sub-category of the other large problem cluster, 'problems with monetizing project effects' - the frequencies of substantive problems mentioned by the respondents. Moreover, table 2-3 subdivides the perceptions of these substantive problems according to their nature (top row).

\footnotetext{
${ }^{13}$ We define intangible effects as non-physical effects, which are therefore difficult to concretely estimate both 'ex ante' and 'ex post'. To the contrary, tangible effects are physical and hence, relatively easy to determine.
} 
Table 2-3: problem cluster 'problems with monetizing project effects', subdivided

\begin{tabular}{|c|c|c|c|c|c|c|c|c|}
\hline Nature & 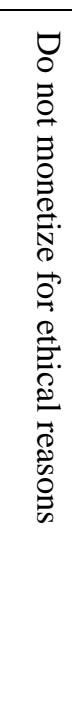 & 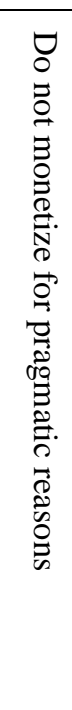 & 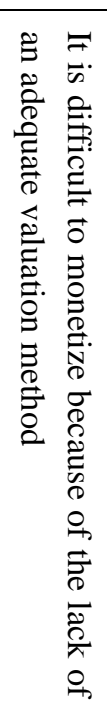 & 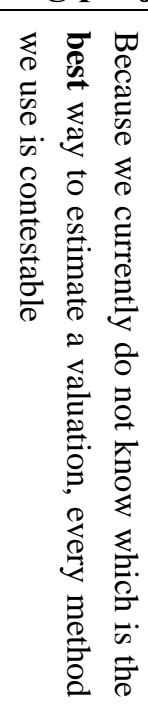 & 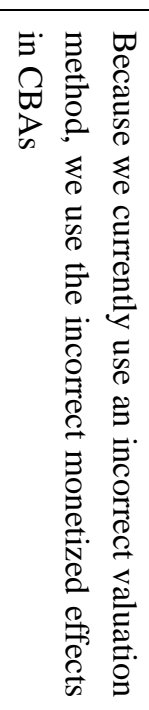 & 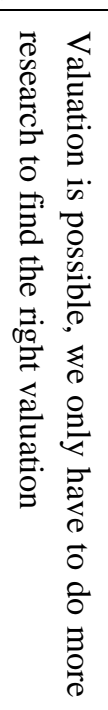 & 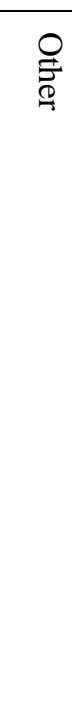 & $\overrightarrow{0}$ \\
\hline $\begin{array}{l}\text { General problems with monetizing } \\
\text { project effects }\end{array}$ & 4 & 2 & 3 & 3 & 0 & 1 & 1 & 14 \\
\hline $\begin{array}{l}\text { Valuation with standard numbers / } \\
\text { benefit transfers }\end{array}$ & 0 & 0 & 0 & 0 & 9 & 0 & 5 & 14 \\
\hline Valuation method Stated Preference & 0 & 0 & 0 & 0 & 9 & 0 & 0 & 9 \\
\hline Valuation method Hedonic Pricing & 0 & 0 & 0 & 0 & 4 & 0 & 0 & 4 \\
\hline Choice of a valuation method & 0 & 0 & 0 & 2 & 0 & 0 & 0 & 2 \\
\hline Valuation method Revealed Preference & 0 & 0 & 0 & 0 & 1 & 0 & 0 & 1 \\
\hline $\begin{array}{l}\text { Netherlands Bureau of Economic } \\
\text { Policy Analysis }(\mathrm{CPB}) \text { is too strict with } \\
\text { allowing valuation methods }\end{array}$ & 0 & 0 & 0 & 0 & 0 & 0 & 8 & 8 \\
\hline Monetizing value of time & 2 & 0 & 0 & 0 & 14 & 0 & 5 & 21 \\
\hline $\begin{array}{l}\text { Monetizing effects on landscape and } \\
\text { open space }\end{array}$ & 0 & 2 & 9 & 0 & 0 & 2 & 2 & 15 \\
\hline Monetizing effects on biodiversity & 1 & 1 & 4 & 0 & 3 & 1 & 0 & 10 \\
\hline Monetizing effects on the housing & 0 & 0 & 8 & 0 & 0 & 0 & 0 & 8 \\
\hline Monetizing value of reliability & 0 & 0 & 1 & 0 & 2 & 2 & 0 & 5 \\
\hline Monetizing effects on urban quality & 0 & 0 & 3 & 0 & 1 & 1 & 0 & 5 \\
\hline Monetizing value of a statistical life & 3 & 0 & 0 & 2 & 0 & 0 & 0 & 5 \\
\hline Monetizing effects on air pollution & 0 & 0 & 1 & 0 & 2 & 0 & 1 & 4 \\
\hline Monetizing effects on cultural heritage & 0 & 1 & 1 & 0 & 0 & 1 & 0 & 3 \\
\hline Monetizing effects on aesthetic quality & 0 & 0 & 2 & 0 & 0 & 1 & 0 & 3 \\
\hline Monetizing effects on comfort in traffic & 0 & 0 & 2 & 0 & 0 & 0 & 0 & 2 \\
\hline Monetizing effects on recreation & 0 & 0 & 0 & 0 & 1 & 1 & 0 & 2 \\
\hline $\begin{array}{l}\text { Monetizing effects on archaeological } \\
\text { excavations }\end{array}$ & 0 & 0 & 0 & 0 & 0 & 1 & 0 & 1 \\
\hline Monetizing effects on noise pollution & 0 & 0 & 0 & 0 & 1 & 0 & 0 & 1 \\
\hline Total & 10 & 6 & 34 & $7(7)$ & $47(36)$ & $11(8)$ & 22 & 137 \\
\hline
\end{tabular}

* In italics: the number of respondents that mentioned the nature of a monetizing problem. For instance, 14 respondents mention 16 substantive problems with the nature 'do not monetize for ethical / pragmatic reasons.' 
We make the following observations:

- The problem sub-category most mentioned is 'monetizing value of time' (21 times). Respondents experience different problems in regard to monetizing travel time savings with the value of time. Two problems were mentioned by more than three respondents. Firstly, five respondents state that small travel time savings, which are hardly observed by travelers (less than five minutes) and larger time savings (more than five minutes) are taken into account in an equal (linear) way in the Dutch CBA practice. These key participants state that, as a result, the effects on the transport market of projects that chiefly lead to small travel time savings are overestimated. Secondly, three respondents see a problem in the fact that the value of time used in transport models to estimate travel time savings, and the value of time that is used to monetize travel time savings, are inconsistent;

- It is remarkable that although there is an abundance of literature on substantive problems with the value of a statistical life (e.g. Grant-Muller et al., 2001; Hauer., 1994; Verhoef., 1994) only five respondents feel that this valuation is an important substantive problem;

- Key participants interviewed mentioned because we currently use an incorrect valuation method, we use incorrect monetized effects' most frequently as the nature of substantive problems with monetizing project effects (47 times). Nine respondents criticize the standard numbers / benefit transfer method. Respondents claim that applying this method leads to incorrect valuations in specific contexts. Furthermore, respondents state that standard numbers do not take diminishing marginal returns sufficiently into account. Nine respondents criticize the application of the Stated Preference method. The main issue respondents mentioned was that this method does not take the free-ridership and strategic behavior of respondents into account sufficiently;

- It is remarkable that although there is an abundance of literature on ethical problems with applying CBA (e.g., Hansson, 2007; Sen, 2000; van Wee, 2012) only nine key participants experience this as an important substantive problem.

\subsubsection{Problems with presentation, distributional effects and uncertainty}

Thirty two key participants stated in their interviews that the quality of the presentation of CBA reports is problematic and should be enhanced. The four most mentioned sub-categories of problems in the 'presentation' cluster are:

- Too much jargon is used in the texts of CBA reports (15 respondents);

- Conclusions in CBA reports are stated as 'false certainties'. As a result readers of CBA reports are insufficiently aware of the contestability of conclusions (12 respondents);

- CBA reports do not sufficiently make clear which effects are and are not taken into account (4 respondents);

- It is not possible to check the way effects are computed in the CBA reports because the reports do not elaborate in detail on computations (4 respondents). 
Eleven respondents state it is a problem that CBA reports do not pay enough attention to distributional effects. Moreover, three key participants interviewed claim that (academic) research should focus on improving methods to estimate distributional effects because they think it is currently very difficult to predict distributional effects. As an example, one of the key participants mentioned that it is very difficult to estimate how an investment project in one Dutch port affects other Dutch ports (distributional effects).

Twenty one key participants experience problems with the way current Dutch CBA reports deal with uncertainty. Dutch CBA guidelines (Eijgenraam et al., 2000) prescribe to handle future uncertainty in CBAs with scenarios and sensitivity analyses. Eighteen respondents mentioned three different problems with the way Dutch CBAs deal with the uncertainty of the future:

- Scenarios used in the Dutch practice are often incorrect scenarios for the future and they do not relate to the context of the specific project alternatives under scrutiny in the CBA (10 respondents);

- Too often we see that effects are estimated using different scenarios yet only the outcomes of the middle scenario are presented in the summary of the CBA report, whereas the outcomes of other scenarios are only discussed in the appendix (5 respondents);

- It is a problem that some CBAs only use one scenario to estimate the project effects (3 respondents).

As well as the respondents that criticized the way CBAs deal with uncertainty of the future, three other respondents stated that they experience problems with the way CBAs deal with uncertainty within the scenarios as a result of a lack of knowledge.

\subsection{How do different groups in the Dutch CBA practice evaluate the problem clusters}

This section explores the extent to which results differ for each of the categories of key participants as presented in table 2-2. Because the respondents can be considered to be the entire population of key participants in the Dutch CBA practice, it is not necessary to test whether or not a difference between groups is significant using methods of statistical analyses. However, 15 people were not able to or were not interested in participating in the research. On the one hand we could consider these 15 people as non-responsive and conclude that the 86 people that were interviewed represent the population of key participants. On the other hand it is possible to conclude that we did not manage to interview the entire population and the 86 respondents must be considered as a sample of the entire population of key participants. As a precautionary measure we tested the significance of the results that followed out of the 'Top 3 analysis' and the 'Likert scale analysis' with logistic regressions under the assumption that the 86 respondents are a random sample of the entire population of key participants in the Dutch CBA practice. All the results are significant ( $<<0.05)$. Hence, we conclude that the results of section 2.6 are applicable for the entire Dutch population of 
key participants, when the 86 respondents are considered to be a random sample of key participants in the Dutch CBA practice.

The main finding of this exercise is that there is, in a broad sense, consensus among the different groups in the Dutch CBA practice in their perception of the quality of problem clusters and the way they rank the problem clusters. Below we will elaborate on four findings regarding differences in perception on substantive problems between groups in the Dutch CBA practice. First, economists (55\%) select the 'problems with the estimation of the nonmonetized project effects' problem cluster as a 'top 3 problem cluster' less often than spatial planners $(77 \%)$ and transport researchers $(75 \%)$. Moreover, economists evaluate the quality of this problem cluster more positively than spatial planners and transport researchers in the 'Likert scale analysis'. Second, economists evaluate the quality of the 'monetizing project effects' problem cluster more positively than spatial planners and transport researchers in the 'Likert scale analysis'. Third, policy makers (30\%) select the 'problem analysis' problem cluster as a 'top 3 problem cluster' less often than consultants (56\%) and scientists/researchers (44\%). Moreover, policy makers evaluate the quality of this problem cluster more positively than consultants and scientists/researchers in the 'Likert scale analysis'. As opposed to scientists/researchers and consultants, none of the 19 policy makers perceive the quality of the 'problem analysis' problem cluster as problematic. Fourth, the respondents in the CBA practice who focus on finding solutions for (fundamental) problems with CBA (academics that study CBA and developers of CBA guidelines/manuals') rank the problem clusters differently in the 'Top 3 Analysis' when compared to the respondents who apply the CBA (initiators of a plan, reviewers of funding applications, CBA practitioners and CBA testers). Table 2-4 compares the way 'academics' and 'developers of guidelines/manuals' rank the nine problem clusters compared to 'CBA appliers'.

Table 2-4: ranking problem clusters: respondents with the role of 'academic study' and 'developers of guidelines' compared to 'appliers'

\begin{tabular}{|l|l|l|}
\hline CBA Appliers (47) & Academic study (14) & Developer of CBA guidelines (12) \\
\hline $\begin{array}{l}\text { 1. Estimation non-monetized } \\
\text { project effects }\end{array}$ & $\begin{array}{l}\text { Estimation non-monetized } \\
\text { project effects }\end{array}$ & Problems with uncertainty in CBA \\
\hline 2. Reference case & Monetizing project effects & Monetizing project effects \\
\hline 3. Problem analysis & Problem analysis & Problem analysis \\
\hline 4. Monetizing project effects & Distribution & Reference case \\
\hline 5. Presentation & $\begin{array}{l}\text { Problems with uncertainty in } \\
\text { CBA }\end{array}$ & $\begin{array}{l}\text { Estimation non-monetized project } \\
\text { effects / Project alternatives }\end{array}$ \\
\hline $\begin{array}{l}\text { 6. Problems with uncertainty in } \\
\text { CBA }\end{array}$ & Presentation & \\
\hline 7. Project alternatives & Discounting & Presentation \\
\hline 8. Distribution & Project alternatives & Discounting \\
\hline 9. Discounting & Reference case & Distribution \\
\hline
\end{tabular}


Table 2-4 shows that 'academics that study CBAs' rank the problem clusters of 'distribution' and 'discounting' higher and the 'reference case' problem cluster lower than the appliers of CBA. Moreover, Table 2-4 demonstrates that 'developers of CBA guidelines/manuals' rank the 'problems with uncertainty in CBAs' problem cluster higher and the 'problems with the estimation of the non-monetized project effects' problem cluster lower than the CBA appliers.

\subsection{Conclusions and discussion}

\section{Large variety}

Firstly, we can conclude that key participants in the Dutch CBA practice experience a large variety of substantive problems regarding the appraisal of spatial-infrastructure projects using CBA. The 86 key participants interviewed mentioned 636 substantive problems that were categorized in 92 problem categories. Subsequently, it was possible to cluster the 92 problem categories into 9 problem clusters.

Estimation of the non-monetized project effects as the most important problem cluster

A second main conclusion is that key participants in the Dutch CBA practice consider 'problems with the estimation of the non-monetized project effects' as the most important substantive problem cluster. One might argue that this result is not very surprising because CBA is about estimating project effects. However, one might also argue that research related to ex-ante estimating transport project effects has been on-going for a long time, which makes it remarkable that the estimation of non-monetized project effects is still perceived as the most important substantive problem.

More specifically, we think it is surprising that, despite the long tradition with transport modeling, 'problems with estimation of travel time savings' is the most mentioned problem category in the interviews. Key participants in the CBA practice perceive that errors in the estimation of travel time savings might severely influence the outcome of a CBA and the ranking of project alternatives. However, the issue is absent in the Ministry of Infrastructure and the Environment's CBA research agenda (Ministry of Infrastructure and the Environment, 2011). Our empirical analysis suggests that the low position of 'problems with travel time savings' on this research agenda is not correct. We assume that the long tradition of transport modeling and the perception that Dutch transport models are state-of-the-art may give developers of CBA guidelines, and / or academics that study CBA, the idea that the further development of the capability for transport models to estimate travel time savings is not very important for increasing the quality of CBAs.

Because Dutch transport models are perceived as state-of-the-art by key participants and studies of Flyvbjerg (2005) and Flyvbjerg et al., (2005) show that inaccuracy in travel demand forecasts is a worldwide problem, we have no reason to assume that the conclusion 'estimation of travel time savings is an important problem category' is unique for the Netherlands. Hence, we recommend analyzing whether this issue has an unjustifiable low position on research agendas in all countries using CBA. 


\section{Specific versus non-specific CBA problems}

An interesting third main conclusion of this study is that a large part of the substantive problems mentioned by the key participants in the Dutch CBA practice are not specifically CBA related. If people experience problems with the estimation of the non-monetized project effects (the problem cluster most mentioned) or other non-specific CBA problems (see figure 2-1) they would face the same problem when using other ex-ante impact studies (e.g. multicriteria analysis, cost-effectiveness analysis, environmental impact analysis). Because of this, a policy recommendation is that it would be wise to identify whether or not a specific or a non-specific CBA problem is emphasized when the use of CBA in a particular decision making process regarding spatial-infrastructure projects is criticized. When a non-specific CBA problem is stressed as an argument to criticize the use of CBA in the decision making process, one should emphasize that other ex-ante impact evaluation studies have to face the non-specific CBA problems as well. This might improve the acceptability of CBA as an exante evaluation method and the usage of $\mathrm{CBA}$ in the decision making process regarding spatial-infrastructure projects. Moreover, we think that this observation should be taken into account in debates concerning research agendas for improving CBA usage. In these debates, much attention often goes to specific CBA issues such as 'problems with monetizing project effects' and 'problems with discounting' but it seems that there is also much to gain from 'simply' improving methods (and models) to assess the effects of new spatial-infrastructure projects in their own non-monetized units (see previous point on the incorrect low position of problems with the estimation of travel time savings on CBA research agendas).

Consultants and scientists/researchers, especially, perceive 'problem analysis' as an important problem

A fourth conclusion that comes out of this empirical research is that, in a broad sense, there is consensus among the different groups in the Dutch CBA practice concerning their perception of the seriousness of problem clusters and the way they rank the problem clusters. The 'problem analysis' problem cluster is an interesting exception. Although key participants in the Dutch CBA practice on average perceive that the absence of high quality independent problem analyses in CBAs is a very important substantive problem, none of the 19 policy makers that filled out the questionnaire perceives that the quality of the 'problem analysis' problem cluster is problematic. Based on the literature (Miser and Quade, 1988; Priemus, 2010; Williams, 1972) we assume that it is conceivable that this difference in perception among policy makers and consultants/scientists/researchers holds true for other countries using CBA. Hence, we recommend that consultants and scientists/researchers study how the presence of high quality problem analyses could be enhanced in CBAs and / or decision making processes with regard to spatial-infrastructure projects, with or without the support of policy makers.

\section{To what extent are results of this study imperative for setting a research agenda?}

Contrary to our expectations, key participants in the Dutch CBA practice perceive substantive problems with the estimation of costs, the estimation of the value of a statistical life and discounting as less important substantive problems. We are surprised here because there is a wealth of literature on (solutions for) substantive problems with cost estimations (e.g. 
Flyvbjerg et al., 2003; Cantarelli et al., 2010), discounting (e.g. Stern Review, 2006; Nordhaus, 2007) and the value of a statistical life (e.g. Grant-Muller et al., 2001; Hauer, 1994; Verhoef, 1994). However, one should be careful to conclude that these problems are 'insignificant substantive problems' in the Dutch CBA practice. Using the perception of key participants in the Dutch CBA practice is an important way of analyzing the significance of substantive problems but it is not the only way. For instance, it is plausible to defend the case that the impact the problem has on the CBA outcome is decisive for the determination of the significance of the problem. For instance, van Wee (2007) concludes that substantive problems with cost estimations and demand forecasts might be considered as major CBA problems because of the impact of faulty cost estimations and demand forecasts on the CBA outcome in recent CBA practices.

\section{Building a superior CBA model}

This paper details the perceptions of different participants in the Dutch CBA practice concerning substantive problems with CBA. Turner (1979) and Mackie (2010) emphasize that CBA practices differ in place, time and culture. As a consequence one should be cautious when applying the results of this study to other CBA practices. However, we are convinced that the results of this study are very relevant for other uses of CBA because this study could be a building block of 'the superior international CBA model', suggested by Hayashi and Morisugi (2000). Hayashi and Morisugi (2000, p 87) state that 'by conducting a careful study on the components of the different models, it would be possible to come up with a superior model by integrating all the good components of the existing models. This is a simple case of learning from each country's experience'. A suggestion for generating more building blocks is to replicate this research in other CBA practices and compare the results with this study.

\section{Politicians underrepresented in this contribution}

An interesting observation regarding the methodology of this study is that although politicians are participants in the decision making process regarding spatial-infrastructure projects, and they have to make a decision - informed by a CBA - about the development of a spatialinfrastructure project, only four (ex) politicians were mentioned by respondents as people that needed to be interviewed in order to make sure that the entire population of key participants in the Dutch CBA practice was interviewed. On the one hand one could interpret this observation as a limitation of this study. On the other hand there is some evidence in the literature that politicians are in fact relatively unimportant participants in the CBA practice. For instance, Eliasson and Lundberg (2011) concluded that planners' rankings of investments are influenced by CBA outcomes while politicians rankings are not. Moreover, Sager and Ravlum (2005) found that 'political decision makers gather information and do not use it; ask for more information and ignore it; make decisions first and look for relevant information afterwards; and collect and process a great deal of information that has little or no direct relevance to decisions'.

\section{Acknowledgment}

The authors wish to thank Diana Vonk Noordegraaf (Delft University of Technology) for carrying out the intercoder reliability test, as well as the 86 respondents for their open- 
heartedness. Moreover, we wish to thank two anonymous reviewers for their useful comments.

\section{References}

Ackerman, F. and Heinzerling., 2002. Pricing the Priceless. Cost-Benefit Analysis of Environmental Protection (Washington, DC: Georgetown Environmental Law and Policy Institute, Georgetown University Law Center).

Annema, J.A., Koopmans, C., Van Wee, B., 2007. Evaluating transport infrastructure investments: the Dutch experience with a standardized approach. Transport Reviews 27 (2), 125-150.

Beukers, E., Bertolini., Te Brömmelstroet, M., 2012. Why cost-benefit analysis is perceived as a problematic tool for assessment of transport plans: a process perspective. Transportation Research Part A 46 (1), 68-78.

Börjesson, M., Fosgerau, M., Algers., 2012. On the income elasticity of the value of travel time. Transportation Research Part A 46 (2), 368-377.

Brathen, S. and Hervik, A., 1997. Strait crossings and economic development: Developing economic impact assessment by means of ex post analyses. Transport Policy 4 (4), 193 200.

Bristow, A.L. and Nellthorp, J., 2000. Appraisal of transport projects in the European Union. Transport Policy 7 (1), 51-60.

Cantarelli, C.C., Flyvbjerg, B., Molin, E.J.E., Van Wee, B., 2010. Cost overruns in large-scale transport infrastructure projects: explanations and their theoretical embeddedness. European Journal of Transport and Infrastructure Research, 10 (1), 5-18.

Cardell, N., Dunbar, F.C., 1980. Measuring the societal impacts of automobile downsizing. Transportation Research Part A: General 14 (5-6), 423-434.

Damart, R. and Roy, B. 2009. The uses of cost-benefit analysis in public transportation decision making in France. Transport Policy 16 (4), 200-212.

Eijgenraam, C. J. J., Koopmans, C.C., Tang, P.J.G., Verster, A.C.P., 2000. Evaluation of Infrastructural Projects; Guide for cost-benefit analysis, Sections I and II, CPB, The Hague, NEI (Changed Name to ECORYS), Rotterdam.

Eliasson, J. and Lundberg, M., 2012. Do Cost-Benefit Analyses Influence Transport Investment Decisions? Experiences from the Swedish Transport Investment Plan 201021. Transport reviews 32 (1), 29-48.

Erlandson, D.A., Harris, E.L., Skipper, B.L., Allen, S.D., 1993. Doing Naturalistic Inquiry: A Guide to Methods. Newbury Park, CA: Sage Publications.

Flyvbjerg, B., Skamris Holm, M.K., Buhl, S.L., 2003. How common and how large are cost overruns in transport infrastructure projects?. Transport Reviews 23 (?), 71-88.

Flyvbjerg, B., 2005. Measuring inaccuracy in travel demand forecasting: methodological considerations regarding ramp up and sampling. Transportation Research Part A 39 (6), 522-530.

Flyvbjerg, B., Skamris Holm, M.K., Buhl, S.L., 2005. How (in)accurate are demand forecasts in public works projects? The case of transportation. Journal of the American Planning Association 71, 131-146. 
Forkenbrock, D.J., 2001. Comparison of external costs of rail and truck freight Transportation. Transportation Research Part A 35 (4), 321-337.

Fosgerau, M., 2007. Using non-parametrics to specify a model to measure the value of travel time. Transportation Research Part A 41 (9). 842-856.

Gao, S., Frejinger, E., Ben-Akiva, M., 2011. Cognitive cost in route choice with real-time information: an exploratory analysis. Transportation Research Part A 45 (4), 916-926.

Grant-Muller, S., Mackie, P., Nellthorp, J., Pearman, A., 2001. Economic appraisal of European transport projects - The state of the art revisited. Transport Reviews 21 (2), 237-261.

Hansson, S.-O., 2007. Philosophical problems in cost-benefit analysis. Economics and Philosophy 23 (2), 163-183.

Hauer, E., 1994, Can one estimate the value of life or is it better to be dead than stuck in traffic?. Transportation Research Part A 28 (2), 109-118.

Hayashi, Y., and Morisugi, H., 2000. International comparison of background concept and methodology of transportation project appraisal. Transport Policy 7 (1), 73-88.

Hollander, Y., 2006. Direct versus indirect models for the effects of unreliability. Transportation Research Part A 40 (9), 699-711.

Hensher, D., 2006. Towards a practical method to establish comparable value of travel time savings from stated choice experiments with differing design dimensions. Transportation Research Part A 40 (10), 829-840.

Holsti, O.R., 1969. Content Analysis for the Social Sciences and Humanities. Reading, MA: Addison-Wesley.

Holz-Rau, C. and Scheiner, J., 2011. Safety and travel time in cost-benefit analysis: A sensitivity analysis for North Rhine-Westphalia. Transport Policy 18 (2), 336-346.

Hyard., 2012. Cost-benefit analysis according to Sen: An application in the evaluation of transport infrastructure in France. Transportation Research A 46 (4), 707-719.

Krippendorff, K., 2004. Content analysis: an introduction to its methodology. Sage Publications Ltd. London.

Lee Jr., D. B., 2000. Methods for evaluation of transportation projects in the USA. Transport Policy 7 (1), 41-50.

Lombard, M., Snyder-Duch, J., Bracken, C.C., 2002. Content analysis in mass communication: Assessment and reporting of intercoder reliability. Human Communication Research 28, 587-604.

Lombard, M., Snyder-Duch, J., Bracken, C.C., 2004. Practical Resources for Assessing and Reporting Intercoder Reliability in Content Analysis Research. Retrieved April 2008, 2004.

Mackie, P., Preston, J., 1998. Twenty-one sources of error and bias in transport project appraisal. Transport Policy 5 (1), 1-7.

Mackie, P., 2010. Cost-Benefit Analysis in Transport: A UK Perspective. International Transport Forum, Mexico.

Mandell, S., 2011. Carbon Emission values in cost benefit analyses. Transport Policy 18 (6), 888-892.

Ministry of Infrastructure and the Environment., 2011. Research Agenda Cost-Benefit Analysis (In Dutch: Ontwikkelagenda OEI). The Hague, December 2011. 
Miser, H.J., Quade, E.S., 1988. Handbook of systems analysis: craft issues and procedural choices. Elsevier science Publishing Co., Inc.

Morisugi, H., 2000. Evaluation methodologies of transportation projects in Japan. Transport Policy 7 (1), 35-40.

Naess, P., 2006. Cost-benefit analysis of transportation investments. Neither critical nor realistic. Journal of critical realism 5 (1), 32-60.

Neuendorf, K.A., 2002. The content analysis guidebook. Thousand Oaks, CA: Sage.

Nguyen-Hoang, P. and Yeung, R., 2010. What is paratransport worth?. Transportation Research Part A 44 (10), 841-853.

Nordhaus, W.D., 2007. A review of the Stern review on the economics of climate change. Journal of economic literature. Vol XLV, 686-702.

Odeck, J., 1996. Ranking of regional road investment in Norway. Transportation 23 (2), 123 140 .

Odgaard, T., Kelly, C., Laird, J., 2005. Current practice in project appraisal in Europe, in: Proceedings of the European Transport Conference. 3-5 October, Strasbourg, Association for European Transport.

Peer, S., Koopmans, C.C., Verhoef, E.T., 2012. Prediction of travel time variability for costbenefit analysis. Transportation Research Part A 46 (1), 79-90.

Priemus, H., 2010. Decision-making on Mega-projects: Drifting on Political Discontinuity and Market Dynamics. European journal of transport and infrastructure research. 10 (1), 19-29.

Quinet, E., 2000. Evaluation methodologies of transportation projects in France. Transport Policy 7, 27-34.

Riffe, D., Lacy, S., Fico, F.G., 2005. Analyzing media messages: Using quantitative content analysis in research. Mahwah, NJ: Lawrence Erlbaum Associates.

Rotaris, L. Danielis, R., Marcucci, E., Massiani, J., 2010. The urban road pricing scheme to curb pollution in Milan, Italy: Description, impacts and preliminary cost-benefit analysis assessment. Transportation Research Part A 44 (5), 359-375.

Rothengatter, W., 2000. Evaluation of infrastructure investments in Germany. Transport Policy 7 (1), 17-25.

Saelensminde, K., 2004. Cost-benefit analysis of walking and cycling track networks taking into account insecurity, health effects and external costs of motorized traffic. Transportation Research Part A 38 (8), 593-606.

Sager , T. and Ravlum I.-A., 2005. The political relevance of planners' analysis: the case of a parliamentary standing committee. Planning Theory 4 (1), 33-65. Sayers, T.M., Jessop, A.T., Hills, P.J., 2003. Multi-criteria evaluation of transport options-flexible, transparent and user-friendly?. Transport Policy 10 (2), 93-105.

Salling, K.B., Banister, D., 2009. Assessment of large transport infrastructure project: the CBA-DK model. Transportation Research Part A 43 (9), 800-813.

Sen, A.K., 2000. The discipline of cost-benefit analysis. The journal of Legal Studies 29 (2), 931-952.

Ševcíková, H., Raftery, A.E., Waddell, P.A., 2011. Uncertain benefits: application of Bayesian melding to the Alaskan way viaduct in Seattle. Transportation Research Part A 45 (6), 540-553. 
Stern, N., S. Peters, V. Bakhshi, A. Bowen, C. Cameron, S. Catovsky, D. Crane, S. Cruickshank, S. Dietz, N. Edmonson, S.-L. Garbett, L. Hamid, G. Hoffman, D. Ingram, B. Jones, N. Patmore, H. Radcliffe, R. Sathiyarajah, M. Stock, C. Taylor, T. Vernon, H. Wanjie, and D. Zenghelis (2006), Stern Review: The Economics of Climate Change, HM Treasury, London.

Tsamboulas, D.A., 2007. A tool for prioritizing multinational transport infrastructure investments. Transport Policy 14 (1), 11-26.

Tudela, A., Akiki, N., Cisternas, R., 2006. Comparing the output of cost benefit and multicriteria analysis: an application to urban transport investments. Transportation Research Part A 40 (5), 414-423.

Turner, R.K., 1979. Cost-Benefit analysis - a critique. Omega 7 (5), 411-419.

Vickerman, R., 2000. Evaluation methodologies for transport projects in the United Kingdom. Transport Policy 7 (1), 7-16.

Vickerman, R., 2007. Cost-benefit analysis and large-scale infrastructure projects: state of the art and challenges. Environment and Planning B 34, 598-610.

Verhoef, E., 1994. External effects and social costs of road transport. Transportation Research Part A 28 (4), 273-287.

Wardman, M., 2004. Public transport values of time. Transport Policy 11 (4), 363-377.

Weber, R. P. (1990). Basic Content Analysis, 2nd ed. Newbury Park, CA.

Van Wee, B., 2006. Large Infrastructure Project: The Quality of Demand Forecasts and Cost Estimations. A Review of Literature. Environment and Planning B 34, 611-625.

Van Wee, B., 2012. How suitable is CBA for the ex-ante evaluation of transport projects and policies? A discussion from the perspective of ethics. Transport Policy 19 (1), 1-7.

Weitzman, M., 1998. Why the far-distant future should be discounted at its lowest possible rate. Journal of Environmental Economics and Management 36, 201-108.

Williams, A., 1972. CBA: Bastard Science and/or Insidious Poison in the Body Politick? In J.N. Wolfe (ed.) Cost-Benefit and Cost Effectiveness, pp. 30-63.

Willis, K.G., Garrod, G.D., Harvey, D. R., 1998. A review of cost-benefit analysis as applied to the evaluation of new road proposals in the UK. Transportation Research Part D 3 (3), 141-156. 


\section{Attitudes towards the role of Cost-Benefit Analysis in the decision-making process for spatial-infrastructure projects: A Dutch case study}

This chapter has originally been published as: Mouter, N., Annema, J.A., van Wee, G.P., 2013. Attitudes towards the role of Cost-Benefit Analysis in the decision-making process for spatial-infrastructure projects: A Dutch case study. Transportation Research Part A. 58. pp $1-14$;

\subsection{Introduction}

The (Social) Cost-Benefit Analysis (CBA) is a widely used ex-ante evaluation tool used to support the decision-making process in transport in most western countries (e.g. Grant Muller et al., 2001; Hayashi and Morisugi, 2000; Odgaard et al., 2005; Vickerman, 2007). Despite its popularity, the role of CBA in decision-making processes for transport projects is a continuous topic of debate in countries and institutions where it is used (e.g. Hamers et al., 2012; Mackie, 2010; Sager and Ravlum, 2005; World Bank, 2010). The topic of the role of CBA is often discussed in academic literature as well. For the purpose of this paper, we distinguish two categories of literature. One category aims to determine the actual influence of CBA on investment decisions with both quantitative and qualitative analysis (e.g. Eliasson and Lundberg, 2012; Grant Muller et al., 2001; Nellthorp and Mackie, 2000; Nyborg, 1998; Odeck, 1996; Odeck, 2010). The broad picture is that these studies show that planners'/politicians' rankings of investments are to some extent influenced by benefit-cost ratios and CBAs are in some cases used for enhancing project alternatives and for evaluating alternative options (for the same project) but not for making a final decision. 
A second category of literature analyzes the disagreement about the usefulness of CBA as a decision-making support tool, reflects on the actual role of CBA or presents a view on the ideal role in the decision-making process (e.g. Frank, 2000; Lohmann, 1977; Mackie, 2010; Quinet, 2000; Sen, 2000; Shapiro, 2010; Sunstein, 2000; World Bank, 2010). Although this literature produces many useful recommendations for improved use of and the role of CBA in the decision-making process, it should be acknowledged that the analyses and recommendations are solely based on deep knowledge and the perceptions of the author(s).

Based on the literature, we conclude that CBA is used to some extent (in other words, plays some role) in actual decision-making processes in the world. The main aim of this paper is to add to the literature by systematically analyzing the attitudes of 86 key actors (e.g. consultants, scientists, policy makers) in the Dutch CBA practice towards the role of CBA in the decision-making process for spatial-infrastructure projects ${ }^{14}$. This paper also aims to give possible explanations for converging and diverging attitudes towards the role of CBA in a decision-making process based on the 86 actors' perceptions of advantages and disadvantages of CBA.

In our view, analyzing key actors' attitudes towards CBA's role is scientifically relevant in itself because, to the best of our knowledge, this focus on attitudes of actual CBA actors has never been carried out before. The societal contribution of this paper is that the results can lead to more productive and efficient discussions regarding the role of CBA in decision making, because actors with different backgrounds (e.g. economists and spatial planners) may understand each other better if their attitudes towards CBA's role (which may be very different) are made explicit. Additionally, we think that more insight into the converging and diverging attitudes of key actors in regard to the role of CBA can pave the way for more specific scientific research towards (understanding and enhancing) the role of the CBA in practice.

Section 3.2 presents the research methodology. Section 3.3 presents the results. Section 3.4 provides some possible explanations for the results. Finally, section 3.5 provides conclusions and discusses the results.

\subsection{Research methodology}

We have chosen to select the Netherlands as a case study because we are Dutch researchers and we know the Dutch community and procedures better than those of other countries. In the Netherlands, a guideline for carrying out a CBA for infrastructure projects (the so-called OEIGuideline, Eijgenraam et al., 2000) was constructed in the year 2000. Since then, a CBA that is in line with the OEI-Guideline has become compulsory in the decision-making process for all large infrastructure projects. Since 2007, it is also obligatory to assess spatial-infrastructure projects, (co-) funded by the Dutch national government, with a CBA (Ministry of transport

\footnotetext{
${ }^{14}$ Because in the Netherlands ex-ante evaluation using CBA is obligatory for all spatial-infrastructure projects (and not only transport projects) applying for co-funding by the Dutch Government, we decided to adjust our aim to this obligation.
} 
and water management and Ministry of housing spatial planning and the environment, 2009). Besides a CBA, it is obligatory to carry out an Environmental Impact Assessment (EIA) which, amongst other things, scrutinizes the project alternative that is most favorable for the environment. Both the CBA and the EIA are presented to decision makers.

In the Netherlands, spatial-infrastructure plans are predominantly developed on a regional level. However, regions do have limited financial resources and frequently need to apply for funding by the national government. A positive Benefit-Cost Ratio (BCR) is not a formal requirement for approved funding. The official function of $\mathrm{CBA}$ is to provide transparent policy information for the preparation of infrastructure projects, and public administrators are not formally bound to the results of the studies. However, ministers who do not act in line with the results have some explaining to do (De Jong and Geerlings, 2003). In the Netherlands the national government applies the CBA in their decision about the extent to which funding is approved for the specific project. This 'individual approach' is in contrast to countries such as Sweden where CBA is applied to rank large numbers of investments against each other (see Eliasson and Lundberg, 2012). Because of the extensive use of CBA in the Netherlands over the last 13 years, we think that the Dutch CBA practice can be regarded as an interesting case study.

In this study, two research methods are combined - in-depth interviews and a written questionnaire - to study the key actors' attitudes towards the role of the CBA in the decisionmaking process. Because we did not have an a priori idea about which questions were paramount to ask in the written questionnaire in order to reveal key actors' attitudes towards the role of CBA in the decision-making process, we first interviewed them in-depth. In the interviews, we asked them about their attitude towards the role of CBA. Moreover, we asked them to mention the most important advantage and the most important disadvantage they experience when using CBA in the decision-making process and why they think this is an (dis)advantage. We asked specifically for their perceptions of advantages and disadvantages because we think it is likely that the actors' attitudes towards the role of the CBA in the decision-making process are mainly founded in their assessment of CBA advantages and CBA disadvantages.

\subsubsection{Selection of respondents}

In order to obtain a more or less complete overview of Dutch key actors' attitudes towards the role of CBA in the decision-making process for spatial-infrastructure projects, the aim of the research was to interview all the individuals that had an explicit and recognizable role in the Dutch CBA practice in the last decade. ${ }^{15}$ For this research 86 key actors were interviewed. To identify the key actors in the Dutch CBA practice, we used a three-stage method (see, Mouter et al., 2013). Fifteen people that were also approached were not able to or were not interested in participating in the research. Thus, we did not manage to interview the entire population as intended and the 86 respondents must be considered as a sample of the entire population of key actors. Therefore, we test the significance of the results that followed out of this study

\footnotetext{
15 The second and the third authors of this contribution are part of this population; however they were not interviewed in order to avoid bias.
} 
with logistic regressions under the assumption that the 86 respondents are a random sample of the entire population of key actors in the Dutch CBA practice. Our main argument for considering the sample to be random is that 'lack of time' was the reason for the nonparticipation of fourteen of the fifteen people that did not participate in the research.

\subsubsection{Questions asked in the written questionnaire}

From the interviews we concluded that three questions were paramount to ask in the written questionnaire - see below. Question (3) is split into four sub-questions. We asked these three questions because we found in the interviews many different and subtle viewpoints on the role of CBA, the value which should be attributed to CBA (e.g. negative CBA results should mean a negative decision), and the comparison of CBA with other tools. In this paper we use these different viewpoints from the in-depth interviews to explain agreements and controversies (see section 4). In addition, via a written questionnaire, we checked key actor's attitudes towards three core topics such as: "do you see any role for CBA or none at all”, for example? The questionnaire was completed by 74 of the 86 respondents.

(1) Do you think CBA must have any role in the appraisal of spatial-infrastructure projects?

- Yes, I think that CBA should have a role;

- No, I think that CBA should not have any role;

- No opinion.

(2) How do you evaluate the value that is attributed to CBA in the decision-making process for spatial-infrastructure projects nowadays?

- I am satisfied with the value that is currently attributed to the CBA in the decisionmaking process;

- I think that too much value is attributed to the CBA in the decision-making process;

- I think that too little value is attributed to the CBA in the decision-making process;

- No opinion.

(3) Do you think that the advantages of CBA outweigh the disadvantages compared to:

- Multi-criteria analysis (MCA) ${ }^{16}$, for the ex-ante evaluation to support 'go' or 'no go' decisions for investments in classic infrastructure projects ${ }^{17}$ ?

- MCA, for the ex-ante evaluation to support 'go' or 'no go' decisions for investments in spatial projects ${ }^{18}$ ?

\footnotetext{
${ }^{16}$ Like Cost-Benefit Analysis, Multi-Criteria Analysis (MCA) is an ex-ante evaluation instrument. A CostBenefit Analysis is based on welfare theory. A CBA evaluates the effects of project alternatives on the welfare of - in most cases - a country. A MCA evaluates how different project alternatives 'score' on different criteria (the welfare effect of the project might be one of the criteria). Although we are aware of literature suggesting hybrid models combining CBA and MCA (see section 3.5) interview results reveal that a MCA is often seen by Dutch key actors as competing with CBA.

${ }^{17}$ In the written questionnaire, 'highways' and 'railroads' were stated as examples of classic infrastructure projects.

${ }^{18}$ In the written questionnaire 'integrated land use and transportation projects' and 'flood protection projects' were stated as examples of spatial projects.
} 
- A situation without CBA or MCA, for the ex-ante evaluation to support 'go' or 'no go' decisions for investments in classic infrastructure projects?

- A situation without CBA or MCA, for the ex-ante evaluation to support 'go' or 'no go' decisions for investments in spatial projects?

- CBA has got more advantages than disadvantages compared to the alternative ${ }^{19}$;

- CBA has got more disadvantages than advantages compared to the alternative;

- I am neutral concerning advantages or disadvantages of CBA compared to the alternative;

○ No opinion.

In order to determine the extent to which different groups in the Dutch CBA practice have a different attitude towards the role and (dis)advantages of CBA, the respondents were asked in the written questionnaire - to express their main specialization regarding CBA (economics, spatial planning or ecology ${ }^{20}$, transportation) and their main profession regarding CBA (consultant, scientist or researcher, policy maker or lobbyist ${ }^{21}$ ). Table 3-1 classifies the respondents in relation to their main specialization and main profession.

Table 3-1: Respondents classified in relation to their specialization and profession

\begin{tabular}{|l|l|l|l|l|}
\hline & Profession & & & \\
\hline Specialization & Consultants & Scientist/Researcher & Policy maker & Total \\
\hline Economics & 13 & 24 & 7 & 44 \\
\hline Spatial Planning & 1 & 5 & 11 & 17 \\
\hline Transportation & 5 & 8 & 12 & 25 \\
\hline Total & 19 & 37 & 30 & 86 \\
\hline
\end{tabular}

\subsubsection{Analysis of the interviews with content analysis}

Soon after the interview (within 24 hours when possible), the interviewer processed a report which then constituted textual data for analysis. This report contained the word-for-word texts of the interviewee (based on audio recordings). The method used to analyze the data is content analysis. Its main aim was to compress many words of text into fewer content categories based on explicit rules of coding and categorizing (e.g. Krippendorff, 2004; Lombard et al., 2004). The content analysis was carried out in two steps. First, perceptions of advantages and disadvantages that were mentioned by the respondents in the interviews were coded and grouped into (dis)advantage categories by the first author. To make the coding process transparent and replicable, the first author developed a 'coding and categorizing protocol' in which the rules for coding are described. For the development of the protocol, different (dis)advantage categories had to be distinguished. The categories were based on the literature (e.g. Annema et al., 2007; Mackie, 2010; Naess, 2006; De Jong and Geerlings, 2003; Eliasson and Lundberg, 2012; Nguyen-Hoang and Yeung, 2010; Quinet, 2010; Saelensminde, 2004; Salling and Banister, 2009; Ševcíková et al., 2011; Tudela et al., 2006), the Dutch CBA-guidelines (Eijgenraam et al., 2000) and evaluations of the Dutch CBA

\footnotetext{
${ }^{19}$ For questions $3 \mathrm{a}$ and $3 \mathrm{~b}$ 'MCA' was the alternative; for questions $3 \mathrm{c}$ and $3 \mathrm{~d}$ 'a situation without CBA or MCA was the alternative'.

${ }^{20}$ From now on this group of respondents is labeled as 'spatial planning'.

21 'policy maker'.
} 
practice (BUCK, 2002; B\&A, 2010). Besides the demarcation of the different (dis)advantage categories an important aim of the coding and categorizing protocol was to clarify whether a respondent's perception of a negative aspect of the CBA could be defined as a (theoretically) solvable negative aspect or a (theoretically) insolvable negative aspect. In accordance with Mouter et al. (2013), in this paper we label the (theoretically) solvable negative aspects as 'substantive problems' and the (theoretically) insolvable negative aspects as 'disadvantages'. Moreover, the respondents' negative perceptions concerning the use, the interpretation and the extent to which people understand the CBA are considered as disadvantages in this study and not as substantive problems because the quotes do not refer to the content of the CBA. For further elaboration on the results of actors' perceptions of substantive problems when appraising spatial-infrastructure projects with CBA, we refer to Mouter et al. (2013).

After the first round of coding the 'coding and categorizing protocol' was revised. For instance, (dis)advantage categories needed to be added because respondents mentioned (dis)advantages that were not found in the literature. This revised 'coding and categorizing protocol' was verified by the second and third author. For the second step of the content analysis all perceptions of advantages and disadvantages in the interviews were coded and categorized all over again based on the revised 'coding and categorizing protocol'. This second step was carried out by the first author (first coder). In a case where the first author was not sure whether a respondent mentioned a (dis)advantage, or when he was not sure in which category a (dis)advantage should be placed, he discussed the issue with the second author (second coder) until an agreement was reached.

\subsubsection{Intercoder reliability}

The intercoder reliability of the content analysis was tested in two phases by two independent coders. In accordance with the literature (e.g. Lombard et al., 2004), more than $10 \%$ of the body of content was tested. In the first phase, the first independent coder (not one of the authors of this paper but a $\mathrm{PhD}$ student in the research group involved in another topic) repeated the full coding task (coding substantive problems, advantages and disadvantages, and grouping them into categories) for 10 randomly selected interviews. With this test we analyzed the extent to which two coders coded the same textual data as 'advantages' and 'disadvantages' and grouped these codes in the same (dis)advantage categories. In the second phase, the second independent coder (a Master student) repeated a part of the coding task. His task was to group the advantages and disadvantages that were coded by the first author into (dis)advantage categories. The second independent coder completed this task for nine interviews (one interview was used as practice). Through this test we analyzed the extent to which two coders group textual data that is coded as (dis)advantage into the same (dis)advantage categories. The results of the intercoder reliability test are presented in section 3.4.1.

\subsection{Results}

This section presents the results regarding the attitudes towards the role of CBA in the decision-making process for spatial-infrastructure projects on which actors agree (section 3.1) and on which there is controversy (section 3.2). 


\subsubsection{Agreement on the role of CBA}

Key actors agree on two aspects regarding the role of CBA in the decision-making process for spatial-infrastructure projects. Firstly, 73 out of 74 respondents in the written questionnaire believe that CBA must have ' $a$ ' role in the appraisal of spatial-infrastructure projects. Secondly, 71 out of $72^{22}$ respondents prefer the use of CBA in the ex-ante evaluation to support 'go' or 'no go' decisions for investments in classic infrastructure projects and spatial projects over a situation in which no ex-ante decision-support system (like CBA or MCA) is used.

\subsubsection{Controversy about the role of CBA}

In the written questionnaire key actors were asked to evaluate the value that is attributed to CBA (question 2). Table 3-2 presents - in total (row 2) and per group in the Dutch CBA practice (rows 4-10) - the number of respondents that mentioned each of the three possible answers.

Table 3-2: Attitudes towards the value that is attributed to CBA in the current decisionmaking process for spatial-infrastructure projects

\begin{tabular}{|l|l|l|l|l|l|}
\hline & Too little value & Satisfied & Too much value & No opinion & Total \\
\hline Total & $22(30 \%)$ & $29(39 \%)$ & $19(26 \%)$ & $4(5 \%)$ & 74 \\
\hline Consultant & & & & & \\
\hline Scientist/Researcher & $4(22 \%)$ & $11(61 \%)$ & $3(17 \%)$ & $0(0 \%)$ & 18 \\
\hline Policy maker & $13(38 \%)$ & $12(35 \%)$ & $6(18 \%)$ & $3(9 \%)$ & 34 \\
\hline & $5(23 \%)$ & $6(27 \%)$ & $10(45 \%)$ & $1(5 \%)$ & 22 \\
\hline Economics & & & & & \\
\hline Spatial planning & $16(40 \%)$ & $21(53 \%)$ & $0(0 \%)$ & $3(7 \%)$ & 40 \\
\hline Transport & $2(14 \%)$ & $1(7 \%)$ & $10(71 \%)$ & $1(7 \%)$ & 14 \\
\hline
\end{tabular}

Table 3-2 shows that none of the 40 respondents that consider themselves economists think that, in the current practice, too much value is attributed to CBA, whereas $71 \%$ of the spatial planners think that too much value is attributed to CBA in the decision-making process. Ordinal logistic regressions reveal that the attitude of economists towards the value that is attributed to CBA in the decision-making process significantly differs from the attitude of spatial planners and transport specialists $(\mathrm{p}<0.05)$. At first sight, table 3-2 seems to show that scientists/researchers assess the value that is attributed to CBA in current practice differently from consultants and policy makers. However, ordinal logistic regression reveals that there is no significant relation. Probably, the reason for this apparent difference is that the majority of the scientists/researchers participating in this study were economists as well (23). Based on the answers to questions ( $3 a$ ) and ( $3 b$ ) in the written questionnaire, we distinguish a second aspect of the role of CBA on which key actors disagree (table 3-3).

\footnotetext{
${ }^{22}$ One respondent did not fill in this question, another filled in 'no opinion'. Both consider themselves to be 'policy maker' and 'spatial planner'.
} 
Table 3-3: Assessment advantages and disadvantages of CBA compared to MCA for exante evaluation to support 'go' or 'no go' decisions for investments in spatialinfrastructure projects

\begin{tabular}{|c|c|c|c|c|c|c|c|}
\hline \multicolumn{8}{|c|}{$\begin{array}{l}\text { Do you think that the advantages of CBA outweigh the disadvantages compared to MCA for the ex-ante evaluation to } \\
\text { support 'go' or 'no go' decisions for investments in classic infrastructure projects? }\end{array}$} \\
\hline & $\stackrel{\overrightarrow{0}}{\stackrel{D}{D}}$ & 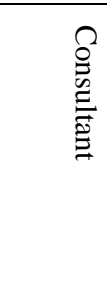 & 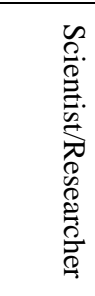 & 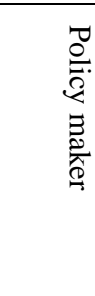 & 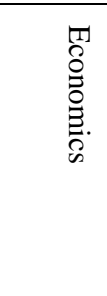 & 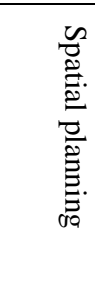 & 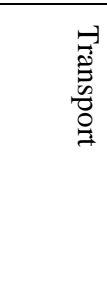 \\
\hline $\begin{array}{l}\text { CBA has advantages compared to MCA } \\
\text { (classic infra project) } \\
\text { CBA }\end{array}$ & $\begin{array}{l}54 \\
(74 \%)\end{array}$ & $\begin{array}{l}17 \\
(94 \%)\end{array}$ & $\begin{array}{l}26 \\
(76 \%)\end{array}$ & $\begin{array}{l}11 \\
(52 \%)\end{array}$ & $\begin{array}{l}37 \\
(93 \%)\end{array}$ & $\begin{array}{l}3 \\
(23 \%)\end{array}$ & $\begin{array}{l}14 \\
(70 \%)\end{array}$ \\
\hline $\begin{array}{l}\text { I am neutral concerning advantages or } \\
\text { disadvantages of CBA compared to } \\
\text { MCA (classic infra project) }\end{array}$ & $\begin{array}{l}8 \\
(11 \%)\end{array}$ & $\begin{array}{l}1 \\
(6 \%)\end{array}$ & $\begin{array}{l}3 \\
(9 \%)\end{array}$ & $\begin{array}{l}4 \\
(19 \%)\end{array}$ & $1(3 \%)$ & $\begin{array}{l}3 \\
(23 \%)\end{array}$ & $\begin{array}{l}4 \\
(20 \%)\end{array}$ \\
\hline $\begin{array}{l}\text { MCA has advantages compared to CBA } \\
\text { (classic infra project) }\end{array}$ & $\begin{array}{l}8 \\
(11 \%)\end{array}$ & $\begin{array}{l}0 \\
(0 \%)\end{array}$ & $\begin{array}{l}4 \\
(12 \%)\end{array}$ & $\begin{array}{l}4 \\
(19 \%)\end{array}$ & $0(0 \%)$ & $\begin{array}{l}6 \\
(46 \%)\end{array}$ & $\begin{array}{l}2 \\
(10 \%)\end{array}$ \\
\hline No opinion & $\begin{array}{l}3 \\
(4 \%)\end{array}$ & $\begin{array}{l}0 \\
(0 \%)\end{array}$ & $\begin{array}{l}1 \\
(3 \%)\end{array}$ & $\begin{array}{l}2 \\
(10 \%)\end{array}$ & $2(5 \%)$ & $\begin{array}{l}1 \\
(8 \%)\end{array}$ & $\begin{array}{l}0 \\
(0 \%)\end{array}$ \\
\hline \multicolumn{8}{|c|}{$\begin{array}{l}\text { Do you think that the advantages of CBA outweigh the disadvantages compared to MCA for the ex-ante evaluation to } \\
\text { support 'go' or 'no go' decisions for investments in spatial projects? }\end{array}$} \\
\hline & $\stackrel{\vec{O}}{\stackrel{0}{D}}$ & 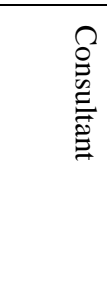 & 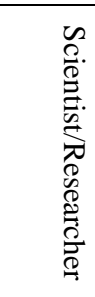 & 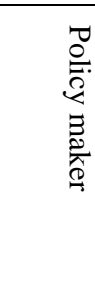 & 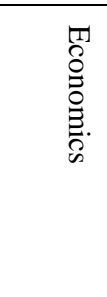 & 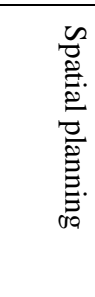 & 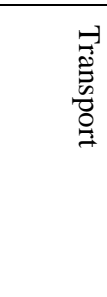 \\
\hline $\begin{array}{l}\text { CBA has advantages compared to MCA } \\
\text { (spatial project) }\end{array}$ & $\begin{array}{l}41 \\
(56 \%)\end{array}$ & $\begin{array}{l}11 \\
(65 \%)\end{array}$ & $\begin{array}{l}24 \\
(69 \%)\end{array}$ & $\begin{array}{l}6 \\
(29 \%)\end{array}$ & $\begin{array}{l}31 \\
(78 \%)\end{array}$ & $\begin{array}{l}1 \\
(8 \%)\end{array}$ & $\begin{array}{l}9 \\
(45 \%)\end{array}$ \\
\hline $\begin{array}{l}\text { I am neutral concerning advantages or } \\
\text { disadvantages of CBA compared to } \\
\text { MCA (spatial project) }\end{array}$ & $\begin{array}{l}14 \\
(19 \%)\end{array}$ & $\begin{array}{l}5 \\
(29 \%)\end{array}$ & $\begin{array}{l}4 \\
(11 \%)\end{array}$ & $\begin{array}{l}5 \\
(24 \%)\end{array}$ & $\begin{array}{l}8 \\
(20 \%)\end{array}$ & $\begin{array}{l}2 \\
(15 \%)\end{array}$ & $\begin{array}{l}4 \\
(20 \%)\end{array}$ \\
\hline $\begin{array}{l}\text { MCA has advantages compared to CBA } \\
\text { (spatial project) }\end{array}$ & $\begin{array}{l}15 \\
(21 \%)\end{array}$ & $\begin{array}{l}1 \\
(6 \%)\end{array}$ & $\begin{array}{l}6 \\
(17 \%)\end{array}$ & $\begin{array}{l}8 \\
(38 \%)\end{array}$ & $1(3 \%)$ & $\begin{array}{l}9 \\
(69 \%)\end{array}$ & $\begin{array}{l}5 \\
(25 \%)\end{array}$ \\
\hline No opinion & $\begin{array}{l}3 \\
(4 \%)\end{array}$ & $\begin{array}{l}0 \\
(0 \%)\end{array}$ & $\begin{array}{l}1 \\
(3 \%)\end{array}$ & $\begin{array}{l}2 \\
(10 \%)\end{array}$ & $0(0 \%)$ & $\begin{array}{l}1 \\
(8 \%)\end{array}$ & $\begin{array}{l}2 \\
(10 \%)\end{array}$ \\
\hline
\end{tabular}

Table 3-3 shows that, looking at the Dutch CBA practice in total, respondents prefer CBA over MCA for the ex-ante evaluation to support 'go' or 'no go' decisions for investments in both classic infrastructure projects and spatial projects. However, economists and transport 
specialists on the one hand and spatial planners on the other hand have a significantly different attitude towards the advantages and disadvantages of CBA compared to MCA for this purpose $(\mathrm{p}<0.05)$. To illustrate, only 1 out of 40 of the economists $(2.5 \%)$ perceives that MCA is a better alternative than CBA when it comes to the ex-ante evaluation to support 'go' or 'no go' decisions for investments in spatial projects, whereas 9 out of 13 of the spatial planners (69\%) perceive that MCA is a better alternative than CBA for this type of ex-ante evaluation. Moreover, ordinal logistic regression reveals that policy makers are more likely to prefer MCA over CBA for the ex-ante evaluation to support 'go' or 'no go' decisions for investments in spatial projects than consultants and scientists/researchers.

We conclude that the most important controversy concerning the role of the CBA in the decision-making process for spatial-infrastructure projects is among economists and spatial planners. Transport experts have a 'middle position'. The key actor's 'specialism' is more decisive for explaining his/her attitude towards 'the' role of CBA than his/her 'profession'.

\subsection{Possible explanations for agreement and controversy}

In order to give possible explanations for the agreements and controversy, we used the respondents' perceptions of advantages and disadvantages in which were uncovered during the in-depth interviews because we think that it is likely that the agreement and controversy of key actors towards the role of the CBA in the decision-making process is founded in their assessments of CBA advantages and CBA disadvantages. Section 3.4.1 presents the actors' perceptions of the CBA advantages and CBA disadvantages that they discussed in the interviews. The intercoder reliability of these results is tested in this study. The results of the intercoder reliability test are presented in section 3.4.1 as well. Section 3.4.2 discusses the way in which the perceptions of CBA (dis)advantages might be helpful to explain and understand the agreements and controversy among Dutch key actors towards the role of CBA in the decision-making process for spatial-infrastructure projects.

\subsubsection{Actors' perceptions of CBA advantages and CBA disadvantages}

Before we discuss the perceptions of CBA (dis)advantages we will present the results of the intercoder reliability tests. The result from the first phase of the intercoder reliability test was that the first author and the first independent coder found more or less the same (dis)advantage categories in the 10 interviews that were tested by the independent coder. However, we also conclude that the number of times advantage and disadvantage categories coded by the first coder and the first independent coder varied greatly, so this is, thus, unreliable. After the intercoder reliability test the first author and the first independent coder jointly discussed their differences in coding in order to explain the low intercoder reliability scores. They concluded that the most important reason for the low intercoder reliability score was that the coding task was complex. Firstly, the 'coding and categorizing protocol' entails many decision rules regarding the demarcation of the substantive problems, advantages and disadvantages (categories). As a result, it was very difficult for the first independent coder to take all decision rules into account simultaneously, leading to coding errors. For instance, the first independent coder forgot to consider the rule that quotes from respondents concerning the use, the interpretation and the extent to which people understand the CBA are considered 
as disadvantages during the coding of four interviews, which resulted in very low intercoder reliability scores. Secondly, it is more difficult to code the word-for-word texts of an interview compared to very structured news articles. ${ }^{23}$ For more details regarding the explanations for the low intercoder reliability scores, we refer to Mouter and VonkNoordegraaf (2012).

We will now discuss the results of the second phase of the intercoder reliability test. The results from this phase were assessed using Krippendorff's Alpha, for two reasons. First, this agreement measure takes into account the possibility that coders could cluster a (dis)advantage into the same (dis)advantage category by chance. Second, Krippendorff's Alpha adjusts - in contrast to Scott's Pi, for instance - for small sample bias (Krippendorff, 2004; Riffe et al., 2005). Krippendorf's alpha is $0.71^{24}$ for the agreement of the first author and the second independent coder concerning which advantage category an advantage coded by the first author should be grouped under, and 0.82 for the agreement concerning which disadvantage category a disadvantage coded by the first author should be grouped under. After the intercoder reliability test, the first author and the second independent coder jointly discussed their differences in coding in order to explain the differences. The second independent coder concluded that the demarcation of (dis)advantage categories in the 'coding and categorizing protocol' was clear; however, sometimes quotes by respondents were vague, leading to coding errors.

Next, we analyzed whether or not it can be determined that these coefficients $(0.71$ and 0.82$)$ should lead us to the conclusion that the categorization of (dis)advantages into (dis)advantage categories is reliable. Lombard et al. (2002) state that there is no established standard for determining an acceptable level of reliability. Neuendorf (2002, p.145) reviews 'rules of thumb' set out by several methodologists and concludes that 'coefficients of 0.90 or greater would be acceptable to all, 0.80 or greater would be acceptable in most situations and below that, there exists great disagreement.' For instance, Riffe et al. (2005) state that a coefficient of 0.667 would be appropriate for research that is breaking new ground with concepts that are rich in analytical value. We conclude that the intercoder reliability scores of the categorization of (dis)advantages into (dis)advantage categories are acceptable and is not the result of a purely subjective process based on one person's (the first author) choices.

Considering both the results of the first and the second phase of the intercoder reliability test, we conclude that the demarcation of categories as presented in tables 3-4 and 3-5 are reliable. However, we emphasize that the frequencies of CBA (dis)advantages mentioned should be interpreted with caution.

\footnotetext{
${ }^{23}$ The content analysis method is often applied to these types of content.

${ }^{24} \mathrm{We}$ learned from the first phase of the intercoder reliability test that it was very difficult for coders to decide whether a quote like 'CBA enhances transparency' should be categorized into advantage category 7 or 9 (see table 3-4). We calculated Krippendorf's alpha after clustering these two categories into the advantage category 'CBA enhances transparency'. As a result the Krippendorf's alpha improved to 0.76 .
} 
Table 3-4 presents - for each advantage category - the total number of respondents that mentioned that category, as well as the subdivisions by 'specialization' and 'profession'. Finally, the last column shows whether differences between groups regarding the number of times the advantage category was mentioned are significant $(\mathrm{p}<0.05)$. For instance, economists mentioned advantage category 2 'CBA results in a better decision-making process and better decision making regarding usefulness, necessity and design of a project' relatively more often compared to spatial planners ${ }^{25}$.

Table 3-4: Key actors' perceptions of CBA advantages

\begin{tabular}{|c|c|c|c|c|c|c|c|c|}
\hline Advantages & 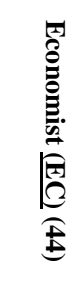 & 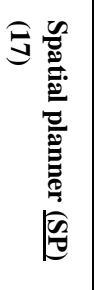 & 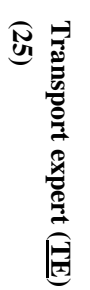 & 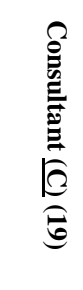 & 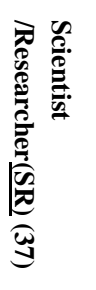 & 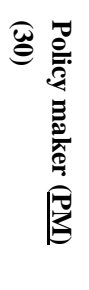 & $\frac{\overrightarrow{0}}{\stackrel{0}{0}}$ & \\
\hline $\begin{array}{l}\text { 1: CBA enhances contemplation concerning the } \\
\text { usefulness, necessity and design of a project. }\end{array}$ & $\begin{array}{c}22 \\
(50 \%)\end{array}$ & $\begin{array}{c}\mathbf{1 0} \\
(59 \%)\end{array}$ & $\begin{array}{c}11 \\
(44 \%)\end{array}$ & $\begin{array}{c}\mathbf{1 2} \\
(63 \%)\end{array}$ & $\begin{array}{c}18 \\
(49 \%)\end{array}$ & $\begin{array}{c}\mathbf{1 3} \\
(43 \%)\end{array}$ & 43 & \\
\hline $\begin{array}{l}\text { 2: CBA results in a better decision-making process and } \\
\text { better decision making regarding the usefulness, } \\
\text { necessity and design of a project. This prevents the } \\
\text { development of projects that have a negative impact on } \\
\text { the welfare of a country. }\end{array}$ & $\begin{array}{c}\mathbf{2 2} \\
(50 \%)\end{array}$ & $\begin{array}{c}\mathbf{3} \\
(17 \%)\end{array}$ & $\begin{array}{c}10 \\
(40 \%)\end{array}$ & $\begin{array}{c}\mathbf{8} \\
(42 \%)\end{array}$ & $\begin{array}{c}\mathbf{1 5} \\
(41 \%)\end{array}$ & $\begin{array}{c}\mathbf{1 2} \\
(40 \%)\end{array}$ & 35 & $\begin{array}{l}\mathrm{EC}> \\
\mathrm{SP}\end{array}$ \\
\hline $\begin{array}{l}\text { 3: CBA gives insight into the order of magnitude of } \\
\text { different welfare effects and into the ratio of costs } \\
\text { versus benefits of a project. }\end{array}$ & $\begin{array}{c}\mathbf{1 4} \\
(32 \%)\end{array}$ & $\begin{array}{c}\mathbf{6} \\
(35 \%)\end{array}$ & $\begin{array}{c}9 \\
(36 \%)\end{array}$ & $\begin{array}{c}\mathbf{4} \\
(21 \%)\end{array}$ & $\begin{array}{c}16 \\
(43 \%)\end{array}$ & $\begin{array}{c}\mathbf{9} \\
(30 \%)\end{array}$ & 29 & \\
\hline $\begin{array}{l}\text { 4: CBA provides objective and independent } \\
\text { information. }\end{array}$ & $\begin{array}{c}\mathbf{2 4} \\
(54 \%)\end{array}$ & \begin{tabular}{c|c|}
$\mathbf{5}$ \\
$(29 \%)$
\end{tabular} & $\begin{array}{c}\mathbf{3} \\
(12 \%)\end{array}$ & $\begin{array}{c}\mathbf{7} \\
(36 \%)\end{array}$ & $\begin{array}{c}17 \\
(46 \%)\end{array}$ & $\begin{array}{c}\mathbf{8} \\
(27 \%)\end{array}$ & 28 & $\begin{array}{l}\mathrm{EC}> \\
\mathrm{TE}\end{array}$ \\
\hline $\begin{array}{l}\text { 5: CBA enhances discussion concerning the } \\
\text { usefulness, necessity and design of a project. }\end{array}$ & $\begin{array}{c}\mathbf{1 2} \\
(27 \%)\end{array}$ & $\begin{array}{c}\mathbf{5} \\
(29 \%)\end{array}$ & $\begin{array}{c}7 \\
(28 \%)\end{array}$ & $\begin{array}{c}\mathbf{5} \\
(26 \%)\end{array}$ & $\begin{array}{c}\mathbf{1 1} \\
(30 \%)\end{array}$ & $\begin{array}{c}\mathbf{8} \\
(27 \%)\end{array}$ & 24 & \\
\hline $\begin{array}{l}\text { 6: A high quality CBA gives insight into the welfare } \\
\text { effects for different relevant stakeholders (distribution } \\
\text { effects). }\end{array}$ & $\begin{array}{c}9 \\
(20 \%)\end{array}$ & $\begin{array}{c}\mathbf{2} \\
(12 \%)\end{array}$ & $\begin{array}{c}\mathbf{5} \\
(20 \%)\end{array}$ & $\begin{array}{c}\mathbf{4} \\
(21 \%)\end{array}$ & $\begin{array}{c}\mathbf{7} \\
(19 \%)\end{array}$ & $\begin{array}{c}\mathbf{5} \\
(17 \%)\end{array}$ & 16 & \\
\hline $\begin{array}{l}\text { 7: CBA makes the decision makers' decision more } \\
\text { transparent for other stakeholders / CBA contributes to } \\
\text { the justification of decisions. }\end{array}$ & $\begin{array}{c}\mathbf{6} \\
(17 \%)\end{array}$ & $\begin{array}{c}\mathbf{3} \\
(18 \%)\end{array}$ & $\begin{array}{c}\mathbf{6} \\
(23 \%)\end{array}$ & $\begin{array}{c}\mathbf{4} \\
(21 \%)\end{array}$ & $\begin{array}{c}\mathbf{6} \\
(16 \%)\end{array}$ & $\begin{array}{c}\mathbf{5} \\
(17 \%)\end{array}$ & 15 & \\
\hline 8: CBA provides standardized information. & $\begin{array}{c}\mathbf{1 2} \\
(27 \%)\end{array}$ & $\begin{array}{c}1 \\
(6 \%)\end{array}$ & $\begin{array}{c}\mathbf{7} \\
(28 \%)\end{array}$ & $\begin{array}{c}\mathbf{3} \\
(16 \%)\end{array}$ & $\begin{array}{c}\mathbf{1 0} \\
(27 \%)\end{array}$ & $\begin{array}{c}\mathbf{7} \\
(23 \%)\end{array}$ & 13 & \\
\hline $\begin{array}{l}\text { 9: CBA makes the policy options more transparent for } \\
\text { decision makers. }\end{array}$ & $\begin{array}{c}9 \\
(20 \%)\end{array}$ & $\begin{array}{c}\mathbf{2} \\
(12 \%)\end{array}$ & $\begin{array}{c}\mathbf{1} \\
(4 \%)\end{array}$ & $\begin{array}{c}\mathbf{4} \\
(21 \%)\end{array}$ & $\begin{array}{c}\mathbf{5} \\
(14 \%)\end{array}$ & $\begin{array}{c}\mathbf{3} \\
(10 \%)\end{array}$ & 12 & \\
\hline $\begin{array}{l}\text { 10: Due to standardization, it is possible to compare } \\
\text { the welfare effects of different projects. }\end{array}$ & $\begin{array}{c}\mathbf{5} \\
(11 \%)\end{array}$ & $\begin{array}{c}\mathbf{1} \\
(6 \%)\end{array}$ & $\begin{array}{c}\mathbf{3} \\
(12 \%)\end{array}$ & $\begin{array}{c}\mathbf{2} \\
(11 \%)\end{array}$ & $\begin{array}{c}\mathbf{3} \\
(8 \%)\end{array}$ & $\begin{array}{c}\mathbf{4} \\
(13 \%)\end{array}$ & 9 & \\
\hline $\begin{array}{l}\text { 11: The Benefit-Cost Ratio communicates very } \\
\text { powerfully. }\end{array}$ & $\begin{array}{c}\mathbf{5} \\
(11 \%)\end{array}$ & $\begin{array}{c}1 \\
(6 \%)\end{array}$ & $\begin{array}{c}\mathbf{2} \\
(8 \%)\end{array}$ & $\begin{array}{c}\mathbf{2} \\
(11 \%)\end{array}$ & $\begin{array}{c}\mathbf{2} \\
(5 \%)\end{array}$ & $\begin{array}{c}\mathbf{4} \\
(13 \%)\end{array}$ & 8 & \\
\hline $\begin{array}{l}\text { 12: The Benefit-Cost Ratio is easy to use in the } \\
\text { decision-making process. }\end{array}$ & $\begin{array}{c}\mathbf{4} \\
(9 \%)\end{array}$ & $\begin{array}{c}\mathbf{0} \\
(0 \%)\end{array}$ & $\begin{array}{c}\mathbf{0} \\
(0 \%)\end{array}$ & $\begin{array}{c}\mathbf{1} \\
(5 \%)\end{array}$ & $\begin{array}{c}\mathbf{1} \\
(3 \%)\end{array}$ & $\begin{array}{c}\mathbf{2} \\
(7 \%)\end{array}$ & 4 & \\
\hline $\begin{array}{l}\text { 13: CBA provides the decision maker with high quality } \\
\text { information. }\end{array}$ & $\begin{array}{c}3 \\
(7 \%)\end{array}$ & $\begin{array}{c}\mathbf{0} \\
(0 \%)\end{array}$ & $\begin{array}{c}\mathbf{0} \\
(0 \%)\end{array}$ & $\begin{array}{c}\mathbf{1} \\
(5 \%)\end{array}$ & $\begin{array}{c}\mathbf{2} \\
(5 \%)\end{array}$ & $\begin{array}{c}\mathbf{0} \\
(0 \%)\end{array}$ & 3 & \\
\hline $\begin{array}{l}\text { 14: CBA encourages different stakeholders to } \\
\text { cooperate. }\end{array}$ & $\begin{array}{c}\mathbf{0} \\
(0 \%)\end{array}$ & $\begin{array}{c}\mathbf{2} \\
(12 \%)\end{array}$ & $\begin{array}{c}\mathbf{0} \\
(0 \%)\end{array}$ & $\begin{array}{c}\mathbf{0} \\
(0 \%)\end{array}$ & $\begin{array}{c}1 \\
(3 \%)\end{array}$ & $\begin{array}{c}1 \\
(3 \%)\end{array}$ & 2 & \\
\hline
\end{tabular}

${ }^{25}$ Although we acknowledge that the frequencies are indicative, we believe that these differences are interesting to report because we have no reason to assume that the intercoder reliability scores are biased between economists and spatial planners. 
Table 3-4 shows that, based on the advantages mentioned by the respondents, we can distinguish fourteen different advantages of using CBA. Analyzing the different advantage categories we conclude that some advantage categories focus on positive characteristics of the CBA. For instance, advantage category 11: 'the Benefit-Cost Ratio communicates very powerfully'. Other advantage categories focus on a positive 'role' CBA can play in the decision-making process. For instance, key actors perceive the CBA as a proper tool to support decision making (category 2), a platform for discussion (category 5) and a platform for systematic information (category 8). Because key actors mentioned multiple 'positive role' advantage categories, we conclude that (according to Dutch key actors) CBA can have different (positive) 'roles' in the decision-making process.

Indicatively, we can see that the relatively important advantage categories (five advantage categories are coded in more than 20 interviews by the first author, but note the low reliability) seem to be:

- CBA enhances contemplation concerning the usefulness, necessity and design of a project;

- CBA results in a better decision-making process and better decision making regarding the usefulness, necessity and design of a project. This prevents the development of projects that have a negative impact on the welfare of a country;

- CBA gives insight into the order of magnitude of different welfare effects and into the ratio of costs versus benefits of a project;

- $\mathrm{CBA}$ provides objective and independent information;

- CBA enhances discussions concerning the usefulness, necessity and design of a project.

The advantage category most frequently coded by the first author was 'contemplation concerning the use, necessity and design of a project is enhanced due to CBA'. Respondents explained that the CBA stimulates actors in the Dutch decision-making process for spatialinfrastructure projects to very thoroughly contemplate the extent to which it is useful and necessary to develop the project. According to respondents, this contemplation frequently resulted in an improvement of the design of the project. In some cases the contemplation led to the insight that the initial project was not a very useful solution for the problems faced in the area, which resulted in the development of another type of project.

Table 3-5 presents - for each disadvantage category - the total number of respondents that mentioned that category, as well as the subdivisions by 'specialization' and 'profession'. Finally, the last column expresses whether differences between groups regarding the number of times the disadvantage category was mentioned are significant $(\mathrm{p}<0.05)$. 
Table 3-5: Key actors' perceptions of CBA disadvantages

\begin{tabular}{|c|c|c|c|c|c|c|c|c|}
\hline Disadvantages & 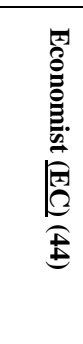 & 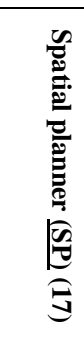 & 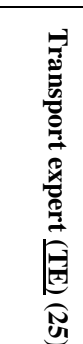 & 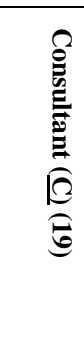 & 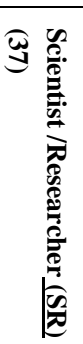 & 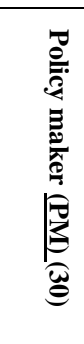 & $\stackrel{\overrightarrow{0}}{\overrightarrow{0}}$ & \\
\hline $\begin{array}{l}\text { 1: An inherent limitation of CBA is that welfare } \\
\text { effect estimates are always uncertain and } \\
\text { contestable. }\end{array}$ & $\begin{array}{c}\mathbf{1 2} \\
(24 \%)\end{array}$ & $\begin{array}{c}\mathbf{1 2} \\
(71 \%)\end{array}$ & $\begin{array}{c}\mathbf{1 2} \\
(48 \%)\end{array}$ & $\begin{array}{c}\mathbf{6} \\
(32 \%)\end{array}$ & $\begin{array}{c}\mathbf{1 4} \\
(38 \%)\end{array}$ & $\begin{array}{c}\mathbf{1 6} \\
(53 \%)\end{array}$ & 36 & $\mathrm{SP}>\mathrm{EC}$ \\
\hline $\begin{array}{l}\text { 2: Some actors in the Dutch CBA practice } \\
\text { position the CBA outcome - unintentionally or } \\
\text { deliberately - as an instrument with too few } \\
\text { limitations. As a result people attribute too } \\
\text { much value to the CBA outcome. The position } \\
\text { of the CBA is too strong. }\end{array}$ & $\begin{array}{c}9 \\
(20 \%)\end{array}$ & $\begin{array}{c}\mathbf{1 2} \\
(71 \%)\end{array}$ & $\begin{array}{c}14 \\
(56 \%)\end{array}$ & $\begin{array}{c}\mathbf{5} \\
(26 \%)\end{array}$ & $\begin{array}{c}9 \\
(24 \%)\end{array}$ & $\begin{array}{c}\mathbf{2 1} \\
(70 \%)\end{array}$ & 35 & $\begin{array}{l}\mathrm{SP}>\mathrm{EC}+ \\
\mathrm{TE}, \\
\mathrm{PM}>\mathrm{C}+\mathrm{SR}\end{array}$ \\
\hline $\begin{array}{l}\text { 3: An inherent limitation of CBA is that not all } \\
\text { welfare effects (and effects other than welfare } \\
\text { effects) can be taken into account in a CBA. }\end{array}$ & $\begin{array}{c}\mathbf{8} \\
(18 \%)\end{array}$ & $\begin{array}{c}\mathbf{1 3} \\
(76 \%)\end{array}$ & $\begin{array}{c}\mathbf{1 2} \\
(48 \%)\end{array}$ & $\begin{array}{c}7 \\
(36 \%)\end{array}$ & $\begin{array}{c}\mathbf{1 2} \\
(32 \%)\end{array}$ & $\begin{array}{c}\mathbf{1 4} \\
(47 \%)\end{array}$ & 33 & $\begin{array}{l}\mathrm{SP}+\mathrm{TE}> \\
\mathrm{EC}\end{array}$ \\
\hline $\begin{array}{l}\text { 4: Actors in the Dutch CBA practice are aware } \\
\text { of CBA limitations. However, they use the } \\
\text { limitations strategically in the decision-making } \\
\text { process by exaggerating or marginalizing them. }\end{array}$ & $\begin{array}{c}\mathbf{1 3} \\
(30 \%)\end{array}$ & $\begin{array}{c}\mathbf{8} \\
(37 \%)\end{array}$ & $\begin{array}{c}9 \\
(36 \%)\end{array}$ & $\begin{array}{c}\mathbf{4} \\
(21 \%)\end{array}$ & $\begin{array}{c}\mathbf{1 4} \\
(38 \%)\end{array}$ & $\begin{array}{c}\mathbf{1 2} \\
(40 \%)\end{array}$ & 30 & \\
\hline $\begin{array}{l}\text { 5: The incorrect use of CBA in the decision- } \\
\text { making process diminishes the quality of the } \\
\text { decision-making process in regard to the } \\
\text { usefulness, necessity and design of a project. }\end{array}$ & $\begin{array}{c}\mathbf{1 2} \\
(27 \%)\end{array}$ & $\begin{array}{c}\mathbf{4} \\
(24 \%)\end{array}$ & $\begin{array}{c}\mathbf{1 2} \\
(48 \%)\end{array}$ & $\begin{array}{c}\mathbf{1 0} \\
(52 \%)\end{array}$ & $\begin{array}{c}9 \\
(24 \%)\end{array}$ & $\begin{array}{c}\mathbf{9} \\
(30 \%)\end{array}$ & 28 & $\mathrm{C}>\mathrm{SR}$ \\
\hline $\begin{array}{l}\text { 6: Actors in the Dutch CBA practice are } \\
\text { insufficiently aware of the limitations of CBA. }\end{array}$ & $\begin{array}{c}\mathbf{1 2} \\
(24 \%)\end{array}$ & $\begin{array}{c}\mathbf{7} \\
(41 \%)\end{array}$ & $\begin{array}{c}\mathbf{5} \\
(20 \%)\end{array}$ & $\begin{array}{c}\mathbf{3} \\
(16 \%)\end{array}$ & $\begin{array}{c}\mathbf{1 2} \\
(32 \%)\end{array}$ & $\begin{array}{c}\mathbf{9} \\
(30 \%)\end{array}$ & 24 & \\
\hline $\begin{array}{l}\text { 7: Because the Benefit-Cost Ratio } \\
\text { communicates very powerfully, many of the } \\
\text { people reading CBA reports only read the } \\
\text { summary and, therefore, are not aware of } \\
\text { nuances that are communicated in the rest of } \\
\text { the report. }\end{array}$ & $\begin{array}{c}9 \\
(20 \%)\end{array}$ & $\begin{array}{c}\mathbf{7} \\
(41 \%)\end{array}$ & $\begin{array}{c}\mathbf{4} \\
(16 \%)\end{array}$ & $\begin{array}{c}\mathbf{4} \\
(21 \%)\end{array}$ & $\begin{array}{c}\mathbf{6} \\
(16 \%)\end{array}$ & $\begin{array}{c}\mathbf{1 0} \\
(33 \%)\end{array}$ & 20 & \\
\hline $\begin{array}{l}\text { 8: For users of the CBA it is difficult to } \\
\text { understand the CBA limitations because they } \\
\text { are presented in an insufficient way in the CBA } \\
\text { report. }\end{array}$ & $\begin{array}{c}\mathbf{5} \\
(11 \%)\end{array}$ & $\begin{array}{c}\mathbf{6} \\
(35 \%)\end{array}$ & $\begin{array}{c}\mathbf{8} \\
(32 \%)\end{array}$ & $\begin{array}{c}\mathbf{2} \\
(11 \%)\end{array}$ & $\begin{array}{c}\mathbf{1 0} \\
(27 \%)\end{array}$ & $\begin{array}{c}7 \\
(23 \%)\end{array}$ & 19 & $\begin{array}{l}\mathrm{SP}+\mathrm{TE}> \\
\mathrm{EC}\end{array}$ \\
\hline $\begin{array}{l}\text { 9: Because the CBA systematics are very } \\
\text { complicated, it is difficult to understand CBA } \\
\text { limitations in the limited time users have to } \\
\text { read the report. }\end{array}$ & $\begin{array}{c}\mathbf{1 0} \\
(23 \%)\end{array}$ & $\begin{array}{c}\mathbf{4} \\
(24 \%)\end{array}$ & $\begin{array}{c}\mathbf{3} \\
(12 \%)\end{array}$ & $\begin{array}{c}\mathbf{4} \\
(21 \%)\end{array}$ & $\begin{array}{c}9 \\
(24 \%)\end{array}$ & $\begin{array}{c}\mathbf{4} \\
(13 \%)\end{array}$ & 17 & \\
\hline $\begin{array}{l}\text { 10: In the decision-making process, effects that } \\
\text { are easy to quantify/monetize dominate over } \\
\text { effects that are difficult to quantify/monetize. }\end{array}$ & $\begin{array}{c}\mathbf{4} \\
(21 \%)\end{array}$ & $\begin{array}{c}\mathbf{5} \\
(14 \%)\end{array}$ & $\begin{array}{c}\mathbf{6} \\
(20 \%)\end{array}$ & $\begin{array}{c}9 \\
(20 \%)\end{array}$ & $\begin{array}{c}\mathbf{4} \\
(24 \%)\end{array}$ & $\begin{array}{c}\mathbf{2} \\
(8 \%)\end{array}$ & 15 & \\
\hline
\end{tabular}


Table 3-5 continued: Key actors' perceptions of CBA disadvantages

\begin{tabular}{|l|c|c|c|c|c|c|c|c|}
\hline Disadvantages & & & & & & & \\
\end{tabular}

Table 3-5 shows that, based on the disadvantages mentioned by the respondents, we can distinguish fifteen different disadvantages. A striking result of table 3-5 is that for some respondents the most important CBA disadvantage was that some actors in the decisionmaking process for spatial-infrastructure projects attribute too much value to the CBA outcome (category 2) whereas other respondents find a CBA disadvantage as being that some actors attribute too little value to the CBA outcome (category 11). Moreover, table 3-5 shows that ordinal logistic regression shows that the disadvantage categories $1,2,3$ and 8 are mentioned relatively more often by spatial planners compared to economists. ${ }^{26}$ In addition, we observe from table 3-4 and table 3-5 that the characteristic 'the CBA ratio communicates very powerfully' is perceived both as an advantage (category 11, table 3-4) and as a disadvantage (category 7, table 3-5).

One result of the content analysis is that interviewed actors often linked different disadvantage categories when they were asked to express their most important CBA disadvantage. In particular respondents mentioned two three-step arguments.

In the first three-step argument (coded 22 times by the first author), actors start by mentioning that the CBA method has (an) inherent limitation(s). Disadvantage categories 1, 3 and 13 in table 3-5 represent the three different inherent limitations that are perceived by these

\footnotetext{
${ }^{26}$ We only discuss the categories that are mentioned relatively more often by spatial planners than economists because these categories can help by explaining controversies between these groups.
} 
respondents. In the second step of this argument the respondents state that (some) actors in the Dutch CBA practice are insufficiently aware of these limitations (disadvantage category 6), the two explanations for this insufficient awareness being disadvantage categories 8 and 9. In the third step respondents mention that, as a result of the insufficient awareness of CBA limitations, (some) decision makers assign either too much value or too little value to the CBA in the decision-making process (disadvantage categories 2 and 13). To illustrate this first three-step argument, one respondent states that Because the limitations of CBA (step 1) are poorly presented in the reports (step 2), some people are insufficiently aware of the limitations and think that the CBA ratio is equal to the definite answer to the question as to whether or not the project should be developed. They erroneously use CBA as a holy grail (step 3). On the other hand, skeptical people - as a result of an insufficient presentation of limitations in the CBA report (step 2) - easily lose their trust in its conclusions (step 3).' The second three-step argument (coded 8 times by the first author) starts, like the first three-step argument, with the statement that the CBA method has (an) inherent limitation(s) (disadvantage categories 1, 3 and 13). Secondly, the respondents claim that (some) actors utilize these limitations strategically (disadvantage category 4). To illustrate this, a respondent states that 'if the CBA outcome does not support the political interest of a participant, the participant emphasizes the limitations of the method, and when the CBA outcome supports the political interest of a participant, the participant ignores its limitations'. Thirdly, actors state that the result of this strategic behavior is that participants attribute either too much value or too little value to the CBA in the decision-making process (disadvantage categories 2 and 13). The two three-step arguments are illustrated in figure 3-1.

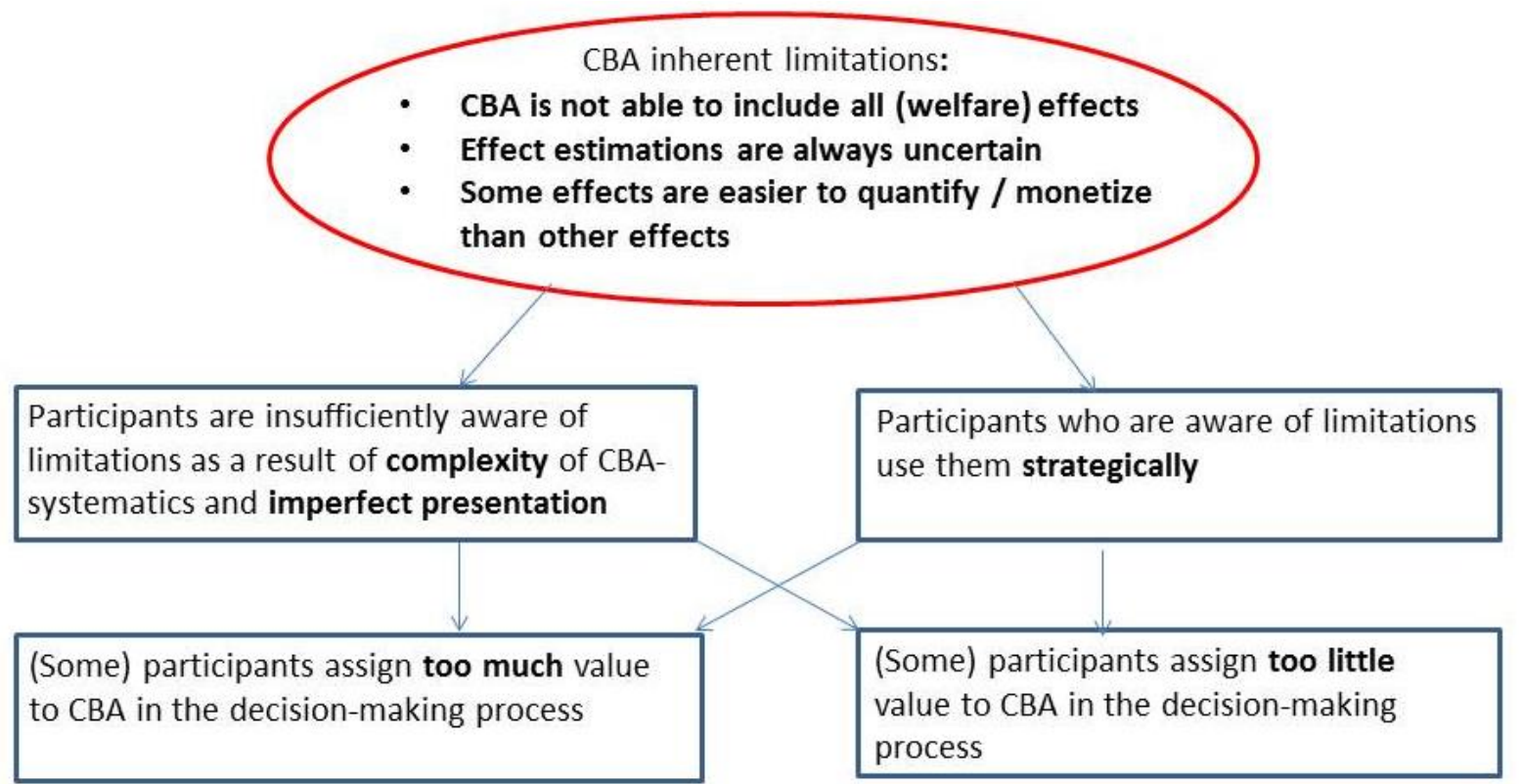

Figure 3-1: Illustration of the two three-step arguments mentioned by respondents

Some respondents discussed why they perceive it as problematic that some actors assign too much value to the CBA, whilst other actors assign too little value to the CBA. They perceive that debates on assigning too much or too little value to the CBA diminish the quality of discussions and decision making (disadvantage categories 5 and 15, table 3-5). In the 
interviews, respondents stated that the quality of discussions among actors on the usefulness of a new spatial-infrastructure project could diminish when the actors, in the process of discussing this project, chiefly focus their discussions on the perceived incorrect value that is assigned to the CBA. This leads to frustrations. Respondents stated that the contemplation, discussion and decision making on the usefulness, necessity and design of a spatialinfrastructure project is not enhanced when frustrations about a support tool for this contemplation, discussion and decision-making process dominate the debate.

\subsubsection{Possible explanations for agreement and controversy}

\section{$\underline{\text { Agreement }}$}

We think that the agreement among key actors that CBA should have a role in the decisionmaking process can be clearly understood through the fourteen perceived advantage categories distinguished in this study. Analyzing the advantage categories we conclude that according to the key actors - CBA can have multiple positive 'roles' in the decision-making process. Actors could have different views on 'the' role CBA should play in the decisionmaking process. However, it is plausible that every actor recognizes at least one 'positive role of the CBA', explaining why, in the written survey, 73 out of 74 respondents state that CBA must have 'a' role.

\section{Controversy}

Possible explanations for disagreement among Dutch key actors in regard to the role of the CBA in the decision-making process deserve a bit more attention.

Section 3.3.2 concludes that two groups of actors have opposing attitudes towards the role of CBA: economists (CBA's role is too weak) versus spatial planners (too strong). Our hypothesis is that this controversy is founded in the different assessments of CBA advantages and CBA disadvantages ${ }^{27}$. From the analysis of perceptions of advantages and disadvantages it can be seen that advantage category 2 (CBA results in a better decision-making process and better decision making) is mentioned relatively more often by economists compared to spatial planners. Moreover, our analysis shows that spatial planners mention four disadvantage categories more often than economists: category 1 (an inherent limitation of CBA is that effect estimations are always uncertain), category 2 (the role of CBA is too strong), category 3 (an inherent limitation of CBA studies is that they are always incomplete) and category 8 (the imperfect presentation of CBA limitations in the CBA report). Our hypothesis is that economists tend to think that a higher value should be assigned to CBA in the decisionmaking process compared to spatial planners because they perceive that the CBA can be used as a proper decision-support instrument, whereas spatial planners are more prone to view the CBA as an instrument with (poorly communicated) inherent limitations which should not play a too important role in the final decision about the development of the project. Spatial

\footnotetext{
${ }^{27}$ The difference in attitude between economists and spatial planners towards the role of CBA might be founded in the difference in their perception of (unsolved) substantive problems as well. However, Mouter et al. (2013) find that there is, in a broad sense, consensus among the different groups in the Dutch CBA practice concerning their perception of the seriousness of substantive problems and the way they rank substantive problems. Hence, our hypothesis is that the controversy between economists and spatial planners is not founded in a different perception of substantive problems.
} 
planners perceive CBA more as an instrument to contemplate the design of the project and a proper discussion platform which encourages different stakeholders to cooperate.

Perhaps three main reasons can explain these opposing attitudes. First, economists, through their education, are probably far more familiar with the theoretical pros and cons of CBA and, based on this knowledge, are more prone to give CBA results the benefit of the doubt in the final decision. In contrast, spatial planners are probably less educated in the use of CBA and welfare economics in general, resulting in more feelings of 'unknown, unloved' about CBA, compared to economists. This might explain why spatial planners, when compared to economists, view CBA as an instrument with ' $a$ ' role and not as 'the' instrument to support decision making. De Jong and Geerlings (2003) provide another, second, possible explanation for this difference in attitude. According to them, the specialty of spatial planners is to put into perspective the claims to the truth of each policy-relevant discipline and the type of information they supply (e.g. the economic discipline). As a consequence, spatial planners reject every absolute claim to the truth. After all, there are so many parties, so many interests, so many perspectives and so many views and concepts, constantly diverging and all claiming to have a monopoly on the truth. According to de Jong and Geerlings (2003), economists in Dutch practice - in contrast to spatial planners - tend to regard their approach and their instruments (e.g. CBA) as being able to encompass all relevant aspects of policy. Thirdly, some of the spatial planners interviewed perceive the presentation of an oversight of positive and negative effects to the decision maker as a useful role of CBA. However, they have a problem with the fact that CBA reduces effects to monetary terms followed by an aggregation of effects into an overall indicator (such as the Benefit-Cost Ratio). These respondents perceive that some effects (e.g. effects on traffic casualties and effects on biodiversity) should not be transferred into monetary terms because they are incomparable with other effects, such as travel time savings. ${ }^{28}$ According to the respondents, transferring incomparable effects into a common unit in the CBA report incorrectly communicates to decision makers that it is possible to outweigh negative effects on biodiversity, for instance, and positive effects on travel time savings, for instance. Our hypothesis is that economists have less problems than spatial planners with the CBA characteristic that effects are transferred as much as possible into monetary units, and therefore have a more positive attitude towards the value that should be assigned to the CBA (ratio) in the decision-making process than spatial planners.

\subsection{Conclusions and discussion}

The most important conclusion of this paper is that in the Dutch CBA practice there is agreement that CBA must have ' $a$ ' role in the appraisal process of spatial-infrastructure projects. However, despite this wide support for CBA, there is a lot of controversy among economists and spatial planners concerning the value that is and should be assigned to CBA in the decision-making process. Economists predominantly believe that too little value is assigned to the CBA in the decision-making process, whereas spatial planners predominantly think that too much value is assigned to the CBA. Both economists and spatial planners

\footnotetext{
28 'Incomparability issues' are discussed in the literature as well. See for instance: Adler (1998), Aldred (2002), Hansson (2007) and Naess (2006).
} 
believe that this controversy is problematic as it results in debates about the pros and cons of CBA instead of the pros and cons of the spatial-infrastructure projects. We think that this result is noteworthy and surprising for two reasons. First, we did not expect that even the respondents who were known as CBA-antagonists are not opposed to the use of CBA completely, but are 'only' against attributing too strong a value to CBA in the decisionmaking process. Second, we think it clearly clarifies that an actor's 'specialism' is more decisive for explaining his/her attitude towards the value that is assigned to CBA in the decision-making process than his/ her 'profession'.

Next, we discuss three topics based on our results. The first one concerns solutions to overcome the controversy among economists and spatial planners. In the second topic we discuss some suggestions for further research. The third topic is about the limitations of this study.

\subsubsection{The use of CBA in a 'subtle' way as a solution}

From this paper it can be deduced that economists and spatial planners perceive that actors other than themselves in the Dutch CBA practice assign a value that is too absolute or too marginal to $\mathrm{CBA}$ results in the decision-making process regarding spatial-infrastructure projects and that this is problematic. Although we did not ask respondents to mention solutions for this problem in a systematic way, in some interviews there was time to discuss solutions. Respondents mentioned two ways for arriving at a solution. First, some stress the importance of politicians communicating - more than they do at present - that they will assign an important but, at the same time, not too absolute value to the CBA in the decisionmaking process for a specific spatial-infrastructure project. According to these actors, this political view might result in a more 'subtle' behavior by actors in the Dutch CBA practice towards each other, through which they will not (endlessly) fight each other over the proper value that should be assigned to CBA in the decision-making process but will try more to help to facilitate the decisions about proper projects. Second, in the interviews some respondents state that improving the communication of inherent limitations (especially uncertainty - table 3-5, disadvantage category 1) in CBA reports could enhance the 'subtle' use of CBA in decision-making processes regarding spatial-infrastructure projects. Some respondents even claim that this solution is 'the salvation' of the CBA in the Netherlands because it will effectively reduce absolute use of the method.

Thus, some respondents state that CBA reports should communicate CBA limitations more prominently (see before). However, other respondents - who had the time to discuss solutions in their interview - perceive that communication of inherent limitations that is too prominent eventually leads to 'the collapse' of the instrument in the decision-making process. One respondent states that 'the instrument is dead when the report emphasizes the inherent limitations of the method.' Interviewees perceive two risks from too much emphasis on CBA limitations. First, they perceive that politicians will not use a CBA report that communicates an uncertain message because politicians will not consider this as useful information and certainly not as a solid basis for decision making. 
The second risk mentioned is that some interviewees fear that a CBA deteriorates into a 'toothless' instrument when politicians and the CBA report put too much emphasis on CBA limitations. They state that the threat of the national government to assign a significant value to the CBA is an incentive for local authorities to optimize project proposals, which compete for limited resources provided by the national government for spatial-infrastructure projects. Beukers et al. (2012) confirm that spatial planners in the Dutch CBA practice perceive that the national government (in particular the Ministry of Finance) assigns a significant value to the CBA outcome and that a negative CBA balance (ratio below 1) could lead to disapproval of subsidies for the project. This practice also seems to apply in Sweden (Eliasson and Lundberg, 2012, p. 46): 'the mere fact that CBA would be used as a prioritization instrument made planners 'trim' proposed investments by trying to reduce investment costs without significantly reducing benefits. In other words, the mere awareness that CBA would be used as a prioritization instrument made investment suggestions more cost-efficient'. So, although the threat of the national government to assign a significant value to the CBA outcome may result in some frustrations for local authorities, it simultaneously motivates them to optimize the design of the project. Hence, a conceivable disadvantage of a CBA with too much emphasis on CBA limitations is that this could take the sting out of the instrument. A 'toothless' CBA does not motivate local or other authorities to contemplate the optimal design of spatial-infrastructure projects (table 3-4, advantage category 1).

In our view, this discussion point means that further research on solutions for enhancing 'subtle' use of CBA in the decision-making process is required. We think that solutions must on the one hand enhance the communication of CBA limitations (especially uncertainty) regarding $\mathrm{CBA}$ results in, for instance, the $\mathrm{CBA}$ report. On the other hand one must be cautious when communicating CBA limitations in a wrong ('unsubtle') way, in order to prevent the risk that the CBA will no longer be used in the decision-making process or that it becomes a 'toothless' instrument. Next, we think that more solutions to enhance 'subtle' use of CBA than the solutions mentioned by respondents could be scrutinized in further research. Firstly, we believe, that more explicit communication on 'the role' that CBA should play according to different actors in a specific decision-making process is an interesting solution to be researched. In the status quo, situations in which different actors agree to carry out a CBA for different purposes (for instance, the spatial planner to use the CBA as a discussion platform and the economists to support the final decision) could lead to confusion and frustrations when actors only implicitly disagree about 'the' role. It would be interesting to study whether explicit communication of this difference of opinion might lead to mutual understanding (agree to disagree) and a more 'subtle' use of CBA. Secondly, we think it would be interesting to study whether a more prominent communication of CBA advantages and limitations to actors in, for instance, guidelines, publications and fact sheets might enhance 'subtle' use. Our hypothesis is that the probability that people assign a value that is too absolute or too marginal to CBA in a discussion diminishes when actors participating in a discussion are aware of both CBA advantages and CBA limitations. 


\subsubsection{Further research on understanding and enhancing specific roles of the CBA}

Based on our analysis of perceived CBA advantages, we conclude that key actors distinguish multiple (positive) roles that the CBA can play in the decision-making process for spatialinfrastructure projects. For instance: for contemplating the design of the project, for being a discussion platform and for supporting 'go' or 'no go' decisions. Another finding of this study is that there is controversy among economists and spatial planners concerning the assessment of advantages and disadvantages of CBA compared to MCA to support 'go' or 'no go' decisions. We emphasize that one should be careful when concluding that economists and spatial planners weight the advantages and disadvantages of CBA compared to MCA differently for all roles of CBA or MCA. It is possible that both spatial planners and economists perceive that CBA is a more appropriate method than MCA for facilitating other roles in the decision-making process. We think this is an interesting topic for further research. Moreover, we think it is interesting to analyze more thoroughly which roles spatial planners and economists both perceive as 'appropriate roles' of the CBA, why they think some roles are inappropriate and whether they perceive that the appropriateness of the 'role of the CBA' is related to the phase of the decision-making process. Do spatial planners, for instance, consider 'weeding out projects with very negative CBA scores in the early planning phase' as appropriate and sustaining the final 'go' or 'no go' decision predominantly on the CBA results as inappropriate?

Moreover, we think it is worthwhile scrutinizing the advantages and disadvantage of a hybrid model (which combines CBA and MCA) compared to the single use of only a CBA or MCA in further research. Recent literature (e.g. Ambrasaite et al., 2011; Barfod et al., 2011; Grant Muller et al., 2001; Gühnemann et al., 2012; Quinet, 2010; Thomopoulos and Grant Muller, 2012; van Wee, 2012) states that although MCA is often seen as competing with CBA, both approaches may be used in an entirely complementary manner within an overall framework or a hybrid model. We think that a hybrid model could have clear advantages, especially when it is not possible to take important project effects into account in a CBA because it is not possible to estimate or monetize effects in a reliable way. However, we think that the (actors' perceptions of) advantages and disadvantages of a hybrid model have not yet been researched extensively and that this is an interesting subject for further research.

\subsubsection{Politicians underrepresented, results are limited to Dutch key actors and low intercoder reliability}

Although politicians are key actors in the decision-making process regarding spatialinfrastructure projects and they have to make a decision - informed by a CBA - about the development of a spatial-infrastructure project, only two politicians were interviewed in this study. The reason for this was that key actors in the Dutch CBA practice only mentioned four (ex) politicians as people that needed to be interviewed in order to make sure that the entire population of key actors in the Dutch CBA practice was interviewed and two of the suggested (ex) politicians had no time for an interview (see Mouter et al., 2013 for more information regarding the selection of respondents). On the one hand one could interpret this observation as a limitation of this study. On the other hand there is some evidence in the literature that politicians are in fact relatively unimportant actors in CBA practice (e.g. Eliasson and 
Lundberg, 2011; Sager and Ravlum, 2005). Nevertheless, we think it is interesting to scrutinize the attitudes of (Dutch) politicians towards the role of CBA in further research.

A second limitation of this study is that results are limited to key actors in the Dutch CBA practice and are not necessarily applicable to CBA practices in other countries. Several studies (e.g. Grant Muller et al., 2001; Hayashi and Morisugi, 2000; Odgaard et al., 2005; Quinet, 2000; Rothengatter, 2000; Vickerman, 2007) revealed differences between CBA practices. In the literature we find contributions which reflect differently on the role of CBA in the decision-making process in France and the value that must be assigned to CBA (e.g. Damart and Roy, 2009; Hyard, 2012; Quinet, 2000). Moreover, Veisten et al. (2010) found, amongst other things, that European road-safety decision makers that consider themselves economists have a more positive attitude towards the use and usefulness of CBA than the decision makers that did not consider themselves economists. For further research we suggest replicating this research in other countries that use CBA and compare the results with this study.

We regard the low scores of the first phase of the intercoder reliability test as a third limitation of this study. We regard the 'ranking of CBA advantages and CBA disadvantages' by key actors in a CBA practice as an interesting topic for further research.

\section{Acknowledgment}

The authors wish to thank Diana Vonk Noordegraaf and Marc Holleman (Delft University of Technology) for carrying out the intercoder reliability test, as well as the 86 respondents for their open-heartedness. Moreover, we wish to thank three anonymous reviewers for their useful comments.

\section{References}

Adler, M., 1998. Incommensurability and Cost-Benefit Analysis. University of Pennsylvania Law Review 146 (5), 1371-1418.

Aldred, J., 2002. Cost-benefit analysis, incommensurability and rough equality. Environmental Values 11, 27-47.

Ambrasaite, I., Barfod, M. B., Salling, K.B., 2011. MCDA and Risk Analysis in Transport Infrastructure Appraisal: the Rail Baltica Case. Procedia Social and Behavioral Sciences 20, 944-953.

Annema, J.A., Koopmans, C., Van Wee, B., 2007. Evaluating transport infrastructure investments: the Dutch experience with a standardized approach. Transport Reviews 27 (2), 125-150.

B\&A Consultants (2010). Evaluatie maatschappelijke kosten- en batenanalyses nota ruimte budgetprojecten, The Hague: B\&A groep.

Barfod, M. B., Salling, K.B., Leleur, S., 2011. Composite Decision Support by Combining Cost-Benefit and Multi-Criteria Decision Analysis. Decision Support Systems 51, $167-$ 175 . 
Beukers, E., Bertolini., Te Brömmelstroet, M., 2012. Why cost-benefit analysis is perceived as a problematic tool for assessment of transport plans: a process perspective. Transportation Research Part A 46 (1), 68-78.

Buck Consultants International, 2002. Evaluatie OEEI-leidraad. The Hague. Buck Consultants.

Damart, R. and Roy, B. 2009. The uses of cost-benefit analysis in public transportation decision-making in France. Transport Policy 16 (4), 200-212.

Eijgenraam, C. J. J., Koopmans, C.C., Tang, P.J.G., Verster, A.C.P., 2000. Evaluation of Infrastructural Projects; Guide for cost-benefit analysis, Sections I and II, CPB, The Hague, NEI (Changed Name to ECORYS), Rotterdam.

Eliasson, J. and Lundberg, M., 2012. Do Cost-Benefit Analyses Influence Transport Investment Decisions? Experiences from the Swedish Transport Investment Plan 201021. Transport reviews 32 (1), 29-48.

Frank, R.H., 2000. Why is Cost-Benefit analysis so controversial? Journal of Legal Studies vol. XXIX, $913-930$.

Grant-Muller, S., Mackie, P., Nellthorp, J., Pearman, A., 2001. Economic appraisal of European transport projects - The state of the art revisited. Transport Reviews 21 (2), 237-261.

Gühnemann, A., Laird, J.J., Pearman, A.D., 2012. Combining cost-benefit and multi-criteria analysis to prioritise a national road infrastructure programme. Transport Policy 23, 1524.

Hamers, D., Bijlsma, L., Hoorn, V.A., 2012. The plan review: a new approach to urban project assessment. AESOP $26^{\text {th }}$ Annual Congres. 11.15 July 2012. Ankara

Hansson, S.-O., 2007. Philosophical problems in cost-benefit analysis. Economics and Philosophy 23 (2), 163-183.

Hayashi, Y., and Morisugi, H., 2000. International comparison of background concept and methodology of transportation project appraisal. Transport Policy 7 (1), 73-88.

Hyard, A., 2012. Cost-benefit analysis according to Sen: An application in the evaluation of transport infrastructure in France. Transportation Research A 46 (4), 707-719.

Jong., D.M., Geerlings, H., 2003. Exposing weaknesses in interactive planning: the remarkable return of comprehensive policy analysis in The Netherlands. Impact Assessment and Project Appraisal 21 (4), 281-291.

Krippendorff, K., 2004. Content analysis: an introduction to its methodology. Sage Publications Ltd. London.

Lohmann, L., 1997. Cost-benefit analysis: whose interest, whose rationality? London: The corner house.

Lombard, M., Snyder-Duch, J., Bracken, C.C., 2002. Content analysis in mass communication: Assessment and reporting of intercoder reliability. Human Communication Research 28, 587-604.

Lombard, M., Snyder-Duch, J., Bracken, C.C., 2004. Practical Resources for Assessing and Reporting Intercoder Reliability in Content Analysis Research. Retrieved April 2008, 2004.

Mackie, P., 2010. Cost-Benefit Analysis in Transport: A UK Perspective. International Transport Forum, Mexico. 
Ministry of transport and water management and Ministry of housing spatial planning and the environment, 2009. Spelregels van het Meerjarenprogramma Infrastructuur, Ruimte en Transport. The Hague: Ministry of transport and water management \& Ministry of housing, spatial planning and the environment.

Mouter, N., Annema, J.A., Van Wee, B., 2013. Ranking the substantive problems in the Dutch Cost-Benefit Analysis practice. Transportation Research Part A. 49. pp 241-255

Mouter, N., Vonk Noordegraaf, D., 2012 Intercoder reliability for qualitative research. You win some, but do you lose some as well? TRAIL Conference 2012. TRAIL Research School.

Naess, P., 2006. Cost-benefit analysis of transportation investments. Neither critical nor realistic. Journal of critical realism 5 (1), 32-60.

Nellthorp, J., Mackie., P., 2000. The UK Roads Review - a hedonic model of decision making. Transport Policy 7 (2), 127-138.

Neuendorf, K.A., 2002. The content analysis guidebook. Thousand Oaks, CA: Sage.

Nguyen-Hoang, P. and Yeung, R., 2010. What is paratransport worth?. Transportation Research Part A 44 (10), 841-853.

Nyborg, K., 1998. Some Norwegian politicians' use of cost-benefit analysis. Public Choice 95, 381-401.

Odeck, J., 1996. Ranking of regional road investment in Norway. Transportation 23 (2), 123 140.

Odeck, J., 2010. What determines decision-makers' preferences for road investments? Evidence from the Norwegian road sector. Transport reviews 30 (4), 473-494.

Odgaard, T., Kelly, C., Laird, J., 2005. Current practice in project appraisal in Europe, in: Proceedings of the European Transport Conference. 3-5 October, Strasbourg, Association for European Transport.

Quinet, E., 2000. Evaluation methodologies of transportation projects in France. Transport Policy 7, 27-34.

Quinet, E., 2010. The practice of cost-benefit analysis in transport: The case of France. International Transport Forum, Mexico.

Riffe, D., Lacy, S., Fico, F.G., 2005. Analyzing media messages: Using quantitative content analysis in research. Mahwah, NJ: Lawrence Erlbaum Associates.

Rothengatter, W., 2000. Evaluation of infrastructure investments in Germany. Transport Policy 7 (1), 17-25.

Saelensminde, K., 2004. Cost-benefit analysis of walking and cycling track networks taking into account insecurity, health effects and external costs of motorized traffic. Transportation Research Part A 38 (8), 593-606.

Sager, T., Ravlum, I.A., 2005. The political relevance of planners' analysis: the case of a parliamentary standing committee. Planning Theory 4 (1), 33-65.

Salling, K.B., Banister, D., 2009. Assessment of large transport infrastructure project: the CBA-DK model. Transportation Research Part A 43 (9), 800-813.

Sen, A.K., 2000. The discipline of cost-benefit analysis. The journal of Legal Studies 29 (2), 931-952. 
Ševcíková, H., Raftery, A.E., Waddell, P.A., 2011. Uncertain benefits: application of Bayesian melding to the Alaskan way viaduct in Seattle. Transportation Research Part A 45 (6), 540-553.

Shapiro, S., 2010. The evolution of Cost-Benefit Analysis in U.S. Regulatory Decision making. Jerusalem Papers in Regulation \& Governance, Working Paper No. 5, Jerusalem: The Hebrew University Mount Scopus.

Sunstein, C.R., 2000. Cognition and Cost-Benefit Analysis, Journal of Legal Studies vol. XXIX, $1059-1103$.

Tudela, A., Akiki, N., Cisternas, R., 2006. Comparing the output of cost benefit and multicriteria analysis: an application to urban transport investments. Transportation Research Part A 40 (5), 414-423.

Veisten, K., Elvik, R., Bax, C., 2010. Assessing conceptions of cost-benefit analysis among road safety decision-makers: misunderstandings or disputes? Impact Assessment and Project Appraisal 28 (1), 57-67.

Vickerman, R., 2007. Cost-benefit analysis and large-scale infrastructure projects: state of the art and challenges. Environment and Planning B 34, 598-610.

Wee, V. B., 2012. How suitable is CBA for the ex-ante evaluation of transport projects and policies? A discussion from the perspective of ethics. Transport Policy 19 (1), 1-7.

World Bank., 2010. Cost-Benefit Analysis in World Bank Projects. Washington D.C.: The International Bank for reconstruction and development/The World Bank. 


\section{Solutions for substantive Cost-Benefit Analysis problems: a key actors' perspective}

This paper is currently under review as: Mouter, N., Annema, J.A., van Wee, G.P., Solutions for substantive Cost-Benefit Analysis problems: a key actors' perspective

\subsection{Introduction}

The (Social) Cost Benefit Analysis (CBA) has a long tradition as a widely used ex-ante evaluation instrument to support the decision-making process in transport in most western countries (e.g. Hayashi and Morisugi, 2000; Vickerman, 2007). Nevertheless, the tool is still disputed as shown in the abundant literature regarding substantive problems with the appraisal of spatial-infrastructure projects using CBA (e.g. Mackie and Preston, 1998; Mouter et al., 2013a for overviews).

Although there is a rich offering of academic literature concerning solutions for these problems (e.g. Van Wee, 2007a; Mackie and Nellthorpe, 2001; Koopmans and Oosterhaven, 2011; Salling and Leleur, 2012), these contributions reflect chiefly on solutions that are perceived as important by academics. We argue that it is also interesting to study solutions proposed by key actors that use or carry out CBAs - who are predominantly non-academics which is the aim of this paper. More specifically, we provide an overview of perceptions from 55 Dutch key actors (e.g. consultants, academics, policy makers) in the appraisal practice for spatial-infrastructure projects $^{29}$ of internationally relevant solutions that aspire to solve (perceived) substantive CBA problems. In our view, analyzing solutions proposed by key actors is scientifically relevant in itself because, to the best of our knowledge, this focus on solutions proposed by actual CBA actors has never been carried out before. Another aim of

\footnotetext{
${ }^{29}$ Because in the Netherlands ex-ante evaluation using CBA is obligatory for all spatial-infrastructure projects (and not only transport projects) applying for co-funding by the Dutch Government, we decided to adjust our aim to fit in with this obligation.
} 
this study is to determine the extent to which scrutinizing key actors' perceptions of solutions is indeed valuable additional input for research agendas. Here, we discuss, amongst other things, the extent to which key actors' solutions make a positive addition to existing literature. The societal contribution of this paper is that taking key actors' perceptions of solutions for substantive CBA problems into account by the determination of the research agenda might enhance the acceptance of the research agenda and the use of the CBA in the decision-making process.

The remainder of this paper is organized as follows: in section 4.2 we describe the research methodology that was used to collect empirical data, section 4.3 discusses Dutch key actors' perceptions of CBA solutions. Section 4.4 analyzes the perceptions and section 4.5 provides concluding remarks.

\subsection{Research methodology}

We have chosen the Netherlands as a case study because we are Dutch researchers and we know the Dutch community and procedures better than those of other countries. We think that the Netherlands' practice can give some useful international insights because of the extensive use of CBA in the Netherlands over the last 13 years. Since 2000 around 110 CBAs for candidate transport policies became publicly available on a very broad range of topics (such as new roads, new railroads, tunnels, sea port extensions, airport extensions, pricing policies, speed policies and so forth). Mackie and Worsley (2013) discuss four reasons why the Netherlands has been a leading country in the international CBA practice along with the UK and Scandinavia: 1) it has a strong tradition of doing transport project appraisal; 2) it has guidance manuals which constitute a clearly defined framework for appraisal; 3) it has a framework populated with measures and values of the impacts, which are based on evidence generated from research studies; 4) it has a policy intention that the results of appraisal work should have a significant influence on the case for investment and on prioritization within programs.

The research on which this paper is based has been carried out as part of a larger research program. One aim of this program was to interview the entire population of key actors in the Dutch appraisal practice for spatial-infrastructure projects in the last decade with regard to substantive CBA problems and solutions that aspire to solve the substantive problems. In this larger research program negative aspects of CBA that can (theoretically) be solved are defined as 'substantive problems'. Insolvable negative aspects of CBA - such as uncertainty surrounding effect estimations - are defined as 'insolvable CBA limitations'. In this paper, we only focus on perceptions of solutions for 'substantive problems'. Perceptions of 'insolvable CBA limitations' and solutions to manage these 'insolvable CBA limitations' are discussed in Mouter et al. (2012 and 2013b). Key actors' perceptions of substantive CBA problems are discussed in-depth in Mouter et al. (2013a).

The aim of the research was to interview all the individuals that had an explicit and recognizable role in the Dutch appraisal practice for spatial-infrastructure projects in the last 
decade. For this research 86 key actors were interviewed in the period August 2010 - April 2011. To identify the key actors in the Dutch CBA practice, we used a three-stage method (see Mouter et al., 2013a for an in-depth discussion of this method). Fifteen people that were also approached were not able to or were not interested in participating in the research. Moreover, we think that it is possible that although we consider the three-stage method as a comprehensive way to identify the Dutch key actors, it is possible that we missed a few key actors. Thus, we did not manage to interview the entire population as intended and the 86 respondents must be considered as a selection of the entire population of key actors.

In 55 of the 86 interviews respondents discussed solutions which we considered potentially relevant for an international audience. ${ }^{30} \mathrm{We}$ considered a solution internationally relevant if it met two criteria. Firstly, the proposed solution should be specific enough to be of any value (e.g. a solution such as 'we need better methods for such and such' is too vague). Secondly, the solutions should not only relate to very specific Dutch circumstances (e.g. a particular Dutch project). We do not have the pretension that the internationally relevant solutions that we present in this paper are interesting for all CBA practices. Some of the solutions proposed by Dutch key actors are already successfully implemented in the UK CBA practice, for instance, (see, the WebTag: http://www.dft.gov.uk/webtag/) but might be considered as enlightening for practitioners and researchers in other practices. We did not consider the number of respondents that mentioned a particular solution as a kind of selection criterion for including a solution in this paper because one of our main aims is to generate interesting solutions. In our view 'interesting' is not dependent on the number of times a solution is given. Just one person can have the 'brilliant' solution.

\subsection{Results}

In this section we discuss the perceived solutions by key actors. The order of presentation is based on the sequential steps one needs to pass through when carrying out a CBA (see Mouter et al., 2013a). In each sub-section, we briefly discuss the problems which the solutions should help to solve, as well as what the literature describes (if applicable) before we present respondents' perceptions of the solutions. Finally - and only if applicable - we discuss which actions are already taken in the Dutch practice related to the solutions proposed.

\subsubsection{Absence of an appropriate problem analysis}

Problem: respondents state that often an independent problem analysis is missing in both the CBA and the decision-making process concerning spatial-infrastructure projects. They do not consider the present problem analyses to be objective and independent because these are mostly copies of the problem analyses carried out by the project initiators. Respondents explained that the main reason for this is that currently in the Netherlands you are no longer obliged to include an independent, high quality problem analysis in a CBA study (Ministry of Infrastructure and the Environment, 2012). Private consultants who were interviewed stated that without this obligation they have no other incentive to carry out a high-quality problem analysis in a CBA study. Most clients do not ask CBA consultants to carry out a high-quality

\footnotetext{
${ }^{30}$ Mouter et al. (2012) elaborate on all the solutions mentioned in the interviews by key actors.
} 
independent problem analysis voluntarily because clients often perceive that they have already carried out an appropriate problem analysis themselves. Also, if a private consultant still offers to carry out a CBA study that includes a problem analysis, their study might be more expensive than the study of a competing private consultant. Therefore, they are inclined not to offer these kinds of additional analyses. In existing literature some contributions emphasize the importance of a high-quality problem analysis in policy analysis. For instance, Miser and Quade (1988) state that problems should be analyzed thoroughly because problems tend to be more complex than they seem to be at first sight and, as a result, clients make incorrect problem analyses. According to them, deep knowledge of problems automatically leads to good solutions. Williams (1972, p. 204) emphasizes the hazards of a low-quality problem analysis: 'over and over again one hears of cases where the problem the clients thought they had, turned out not to be the problem they actually had, and any operations research or Cost-Benefit analysis practitioner who accepts the client's initial formulation of the problem uncritically is heading for disaster'.

Solution: respondents agree about the 'best solution' for the absence of appropriate problem analyses. According to them it is important that CBA guidelines oblige CBA consultants in a more compelling way to carry out an objective problem analysis as part of the CBA study. This, in contrast to vague prescriptions like it is advisable to include a critical reflection of the problem in the research assignment of the CBA practitioner (Official Dutch CBA manual for infrastructure projects: OEI-Leidraad, Eijgenraam et al., 2000)'. Moreover, respondents think that reviewers of CBA studies should specifically address the quality of the problem analysis in their review report. ${ }^{31}$

\subsubsection{Unrealistic reference cases}

Problem: respondents state that too often the reference cases of projects are unrealistic. They state that the reference cases are frequently not in line with the 'do-minimum' principle. Ossokina and Eijgenraam (2010) discuss how this principle should be interpreted. ${ }^{32}$ According to the respondents, the reference cases are either too optimistic (as a result of which it is almost impossible for the project alternatives to score positively in the CBA) or 'doom scenarios' (as a result of which project alternatives score unrealistically positively in the CBA). Some contributions in existing literature emphasize the importance of correct reference cases. According to Mackie and Preston (1998), a plausible reference case is essential to the realism of the appraisal. Damart and Roy (2009) conclude that the choice of the reference case involves making subjective choices, thus introducing bias, although the impact of the choice of the reference case may have a significant impact on the results of the CBA.

\footnotetext{
${ }^{31}$ In the Netherlands - contrary to Denmark, for example - a lively review culture exists concerning CBAs that are carried out. CBA studies of large spatial-infrastructure projects, in particular, are reviewed by the Netherlands Bureau for Economic Policy Analysis, the Netherlands Environmental Assessment Agency, the Netherlands Institute for Transport Policy Analysis, academics or other private consultant, to mention but a few. ${ }^{32}$ The interpretation of the do-minimum principle in Ossokina and Eijgenraam (2010) is the same as the interpretation discussed in the WebTag (Tag Unit 2.1).
} 
Solution: as a solution for making realistic reference cases, a respondent suggests that CBA guidelines should provide a rule of thumb that dictates that the amount of investments assumed in the reference case should be a ratio of the investments in the project alternatives such as: 'assumed investments in the reference case should be between 10\%-30\% of the investments in the project alternatives'.

\subsubsection{Lack of clarity in how to deal with spatial developments in the reference cases}

Problem: most of the respondents that mention 'reference case' as a substantive problem stated that the construction of reference cases is especially difficult when a spatialinfrastructure project includes a large spatial development, such as the development of 30,000 dwellings in the Amsterdam area, for instance. There is consensus between respondents that one cannot assume in the reference case that no dwellings are developed. Because of a high demand for dwellings in the Amsterdam area, the non-development of the dwellings in the project area results in the development of another spatial project in the same region (but then: What kind of project? The same number of dwellings? And where?). According to the respondents - because of the absence of a housing market model, for example - it is extremely difficult to decide what 'the world without the spatial elements of the spatialinfrastructure project' (in this example: the new residential area) would look like in these cases.

Solution: respondents suggest three lines of solutions to handle these issues. When we take the development of the 30,000 dwellings as an example, the first group of respondents states that in the reference case, the 30,000 dwellings should be located somewhere in another region other than the region of the project alternatives. The second group claims that projects that include a large spatial development should not be evaluated ex-ante with a CBA, but with a variant of cost-effectiveness analysis (CEA). In the CEA the goal of 'developing 30,000 dwellings in the region' is considered as a given fact. The CEA takes one project alternative as the reference project alternative and compares the costs and benefits of other project alternatives with this reference project alternative. The third group of respondents states one should determine the number of dwellings that are assumed in the reference case in a more objective way: by using land-use models, for instance. The three groups of respondents all emphasized that, preferably, CBA guidelines should explicitly prescribe which line of solution should be used, because the absence of an explicit rule leads to inconsistencies and 'cherry picking'.

In a Dutch language paper, Romijn and Zondag (2012) provide two recommendations for the construction of a reference case in the above mentioned case. Firstly, they recommend assuming, in the reference case, that dwellings are built at a location in a region other than the region of the project alternatives. Secondly, they recommend estimating the welfare effects of the project alternative for more than one reference case (for instance: a reference case in which the 30,000 dwellings are developed in a region close to the project area; spreading the 30,000 dwellings over the Netherlands; the 30,000 dwellings are allocated with a land-use model). Subsequently, decision makers can decide which reference case they consider to be most plausible. Finally, the paper provides quantitative evidence that the welfare effects of the 
project alternative (such as travel time savings and agglomeration effects) largely depend on the selected reference case.

\subsubsection{Sub-optimal project alternatives are analyzed}

Problem: respondents perceive that too often the project alternatives evaluated in a CBA are very sub-optimal project alternatives, and they consider this to be a problem. Mackie and Preston (1998) endorse this statement. They mention the omission of low-cost alternatives and the gold plating of project alternatives as sources of error in transport project appraisal.

Solution: one respondent states that it is possible to deal with the problems regarding suboptimal project alternatives by optimizing project alternatives before the effects of the project alternatives are estimated in a CBA. This respondent states that there is a need for an instrument with which a multitude of project alternatives can be optimized before carrying out a CBA. In this step, positive elements of the project alternatives that have already been proposed in the decision-making process should be combined, in order to construct better project alternatives. Then, these high-quality project alternatives are appraised in the CBA.

\subsubsection{Several problems with the estimation of non-monetized project effects}

Respondents perceive 'problems with the estimation of non-monetized project effects' as the most important substantive problems with the appraisal of spatial-infrastructure projects using CBA (Mouter et al., 2013a). In the interviews, respondents give solutions to overcome substantive problems with the estimation of non-monetized effects in general (discussed in section 4.3.5.1) and with the estimation of specific non-monetized effects (discussed in sections 4.3.5.2-4.3.5.8).

\subsubsection{Problems with the contestability of the non-monetized effect estimations in general}

Problem: respondents perceive the contestability of the ex-ante effect estimations as a serious problem. The contestability of effect estimations is a topic that is also widely discussed in existing literature (e.g. Beattie, 1995; Self, 1970).

Solution: 'carrying out ex-post analyses' is mentioned as an important solution to enhance the quality of ex-ante effect estimations. Hence, respondents state that current appraisal guidelines should be extended by including the obligation that effect estimations in ex-ante CBA studies are always checked with ex-post analyses.

\subsubsection{Extrapolation problems in estimating effects on the transport market}

Problem: according to respondents, a problem with the quality of the estimation of nonmonetized project effects on the transport market is that the effects in the Dutch practice are frequently estimated for one future year and, subsequently, the transport effects for other years in the future are extrapolated from this future year. Respondents state that, as a result, estimations of transport effects are highly contestable.

Solution: respondents who mentioned this problem stated that the inclusion in the Dutch CBA guidelines of the obligation that project effect estimations should be based on two or more future years is an important first step to enhance the quality of effect estimations. 


\subsubsection{Problems with estimating reliability effects}

Problem: respondents state that both the estimation of non-monetized reliability effects and the monetization of reliability effects of spatial-infrastructure projects are highly contestable in the Dutch CBA practice. Because developments regarding the estimation of non-monetized reliability effects and the value of reliability were still in their infancy when the first Dutch CBA guidelines (Eijgenraam et al., 2000) were constructed, a rule of thumb for the estimation of reliability effects in total for highway projects was added to the CBA guidelines in 2004, which stated that reliability effects of road infrastructure projects are equal to $25 \%$ of the travel time savings (Besseling et al., 2004). For rail infrastructure projects, there is no rule of thumb. However, some respondents claim that it is irresponsible to use such a rough rule of thumb because, in their view, for some projects it holds true that reliability effects are negatively correlated with travel time savings or are equal to $300 \%$ of the travel time savings.

Solution: in a broad sense, respondents perceive that it will be possible in the near future to estimate non-monetized reliability effects of spatial-infrastructure projects - likewise travel time effects - in transport models. Until then, respondents think it is better to use different rules of thumb to estimate reliability effects as a ratio of travel time savings for different categories of spatial-infrastructure projects, instead of using one rule of thumb. One respondent perceives that the reliability effects of traffic management projects should be estimated with a different rule of thumb to that of a new highway project.

Recently, the Netherlands Ministry of Infrastructure and Environment started a research project that aims to include the estimation of reliability effects for car travelers in the Dutch national transport model. When this project is completed, it will be possible to include the reliability effects of a specific project for car travelers in a CBA in a far more sophisticated way, compared to the rule of thumb. For rail infrastructure projects there are no current research projects aiming at reliability effects in the national transport model, nor is there a rule of thumb.

\subsubsection{Problems with unexplainable transport effects}

Problem: respondents consider handling unexplainable effect estimations made by transport models as problematic. They perceive that transport models frequently predict travel time effects on highways in a part of the country that cannot reasonably be affected by the spatialinfrastructure project under scrutiny in the CBA, and Dutch CBA guidelines do not clearly prescribe how to deal with these unexplainable mistakes.

Solution: in a broad sense, respondents argue that this is not an easy problem to solve because there are several solution lines to deal with this issue (e.g. 'do not take into account unexplainable outcomes in a CBA', 'only filter out negative unexplainable outcomes' or 'take into account the unexplainable outcomes in a CBA by asking experts to make a best guess'). The respondents think that each solution line has its advantages and disadvantages - but they stress that it is very important to choose one solution line and apply this consistently. 


\subsubsection{Problems with estimation of (construction) costs}

Problem: respondents find that (construction) costs of a project are often underestimated in the CBA and they state two different causes for this. Firstly, project alternatives, as they are evaluated in CBAs, are upgraded in the final decision-making phase - with additional tunnels, for instance, or measures that aspire to diminish noise pollution - which leads to higher costs than estimated in the CBA. Secondly, the people responsible for the cost estimations do not report their calculations for the (construction) costs in a transparent way. Respondents state that, as a result of this lack of transparency, it is very difficult - if not impossible - for consultants that carry out CBAs to control the cost estimations thoroughly, whilst this thorough check could, in their view, contribute to the quality of estimations. As an illustration, one respondent states that often streetlights are forgotten in cost estimations. Also, the occurrence of and causes for inaccurate cost estimations in infrastructure planning are extensively discussed in scientific literature (e.g. Cantarelli et al., 2010; Flyvbjerg et al., 2004; Nicolaisen, 2012).

Solution: as a solution to tackle the first cause of the underestimation of costs, respondents state that an obligation could be added to the CBA guidelines to update CBAs when (construction) costs of a project become higher than assumed in the CBA - in later phases of the decision-making process. As a solution to tackle the second cause, respondents state that cost estimation studies that are used as input for the CBA should be made more transparent so that it is easier for the consultant that makes the CBA to check the quality of the cost estimations.

\subsubsection{The estimation of indirect effects is too rough}

Problem: respondents state that the way indirect effects of spatial-infrastructure projects (effects related to other markets than the transport market) are estimated in Dutch CBAs is highly contestable. A supplement to the official Dutch CBA guidelines defines - as a rule of thumb - that indirect effects of a spatial-infrastructure project are between 0\%-30\% of the travel time savings (Elhorst et al., 2004). Another supplement states that indirect effects are only taken into consideration if it is reasonable to expect that some sort of market failure exists or if the project causes welfare redistribution (Ministry of Infrastructure and the Environment, 2012). Some respondents perceive that the rule of thumb (0-30\%) is too rough. They claim that indirect effects could be negatively correlated with travel time savings or could be $60 \%$ of the travel time savings for specific types of projects.

Solution: to overcome this issue, respondents suggest using different rules of thumb to calculate indirect effects based on travel time savings for different types of spatialinfrastructure projects. For instance, one respondent states that indirect effects for spatialinfrastructure projects that might have a structuring effect on the economy of a country should be assumed to be higher than $30 \%$ of the estimated travel time savings.

\subsubsection{Neglecting labor market effects in CBAs}

Problem: respondents state that positive effects on the labor market as a result of spatialinfrastructure projects (a specific indirect effect) are underestimated in CBAs. These 
respondents state that CBAs often do not take into account project effects on the labor market and wrongfully claim that these effects are negligible because the spatial-infrastructure project only results in a redistribution of employment between regions and, therefore, no additional effects on the labor market accrue for the country as a whole. They state that effects on the labor market as a result of the development of a spatial-infrastructure project are per definition not equal to zero.

Solution: respondents suggest that state-of-the-art so-called 'Spatial Computable General Equilibrium' (SCGE) models (e.g. Knaap and Oosterhaven, 2011 discuss SCGE models) should be developed in order to make it possible to estimate effects on the labor market for specific spatial-infrastructure projects in a comprehensible way. As a downside of the development of state-of-the-art SCGE models, respondents mention that costs in time and money might be high.

\subsubsection{Problems estimating non-monetized external effects}

Problem: another problem mentioned by respondents is that it is very difficult to operationalize the sometimes very vague (positive) external effects of a spatial-infrastructure project - like enhanced quality of life and enhanced spatial quality - which are frequently perceived by project initiators as positive project effects.

Solution: respondents state that CBA practitioners should try to start a discussion with spatial planners, amongst others, to come to a better operationalization of these perceived external effects.

\subsubsection{Problems with monetizing project effects}

In the interviews, respondents give solutions to overcome substantive problems with monetizing project effects in general (discussed in section 4.3.6.1) and the monetization of specific effects (discussed in sections 4.3.6.2 and 4.3.6.5).

\subsubsection{The research costs problem of estimating the willingness to pay for specific projects}

Problem: as a general problem concerning monetizing project effects, respondents mention the costs in time and money for estimating the willingness to pay for an effect in specific projects.

Solution: as a solution to overcome this substantive problem, one respondent states that CBA practitioners should make more use of social media in order to generate information in regard to the valuation of effects in a quick and cost-efficient way. Another respondent states that more standard numbers and rules of thumb should be developed to make it possible for a consultant to carry out a CBA within the unforgiving deadlines. This consultant states the following: 'just give me a standard number to estimate the effect; we do not have the time to undertake a full PhD-study to estimate an effect in a specific case.' 


\subsubsection{The problem of how to deal with small travel time savings}

Problem: respondents see the following as a problem: small travel time savings, which travelers barely notice (less than five minutes) and larger time savings (more than five minutes) are taken into account in an equal (linear) way in the Dutch CBA valuation practice. Respondents state that, as a result, the effects on the transport market of projects that chiefly lead to small travel time savings are overestimated (for references in literature see Daly, 2011; Mackie et al., 2001; Welch and Williams, 1997, for instance).

Solution: respondents perceive that finding the best solution for this substantive problem should have high priority on the Dutch research agenda because of the possible high impact on the CBA outcome. They perceive that the outcome of the research might be that travel time savings of less than five minutes and/or travel time savings of less than $5 \%$ of the total trip should not be taken into account in a CBA or should be taken into account to a proportionally lesser extent than larger time savings (i.e. not just simply in a linear way).

\subsubsection{Problems with the rule-of-half method}

Problem: respondents state that the estimation of effects on the transport market using the rule-of-half method (e.g. Neuburger, 1971) is highly contestable, especially when the main aim of a spatial-infrastructure project is to increase 'accessibility' instead of 'reducing travel time'.

Solution: respondents suggest the Logsum method (e.g. Geurs et al., 2010; Koopmans and Kroes, 2003 discuss this method) as an alternative to estimate accessibility effects of a spatialinfrastructure project. According to one respondent an additional benefit of the Logsum method is that it is possible to take into account improvements of other 'qualities' of the transport system (such as comfort benefits). On the other hand, one respondent states that a downside of the Logsum method is that the method is very difficult to understand for decision makers.

\subsubsection{Valuation of external effects is highly contestable}

Problem: respondents find that the valuation of external effects is often highly contestable and thus is a substantive problem. There is also a huge body of literature on this issue (e.g. Atkinson and Mourato, 2008; Hanley and Shogren, 2005; Niemeyer and Spash, 2001; Spash and Vatn, 2006).

Solution: as a solution to overcome this problem, respondents mention that the willingness to pay for external effects should be determined by using two different valuation techniques (for instance, both Hedonic pricing and Contingent valuation) to make the derived willingness to pay more robust. Other respondents state that a more frequent use of experimental economics and behavioral economics could result in a great leap forward concerning monetizing external effects. 


\subsubsection{Standard national numbers are too rigid}

Problem: respondents see the following as a problem: in CBAs, standardized national numbers are frequently used as the basis for monetizing external effects and these standard national numbers lead to an incorrect valuation of external effects in specific cases.

Solution: respondents think it is not possible to estimate the exact willingness to pay for each specific case from scratch, taking time and budget constraints into account, and believe that standard numbers are therefore necessary. However, they prefer more context-specific standard numbers to the national standard numbers used at present. They feel using regional standard numbers would be a first step in the right direction.

\subsubsection{Discounting: two problems related to discounting}

\subsubsection{Discount rate is too high for irreversible negative external effects}

Problem: in Dutch CBAs practitioners are obliged to use a discount rate of $5.5 \%$. The discount rate consists of a risk-free discount rate of $2.5 \%$ and a risk surcharge of $3 \%$ (Ministry of Finance, 2009). Based on an analysis done by Aalbers (2009), the Ministry of Finance (2009) determined that the discount rate for irreversible negative external effects (such as climate change impacts) should be discounted with a lower discount rate (4\%). Still, respondents perceive that negative external effects - especially irreversible ones - are discounted with too high a discount rate in the Dutch CBA practice, which leads to an underestimation of these effects in CBAs. The 'correct' discount rate for irreversible negative external effects is also hotly debated in international literature (e.g. Pearce et al., 2006; Portney and Weyant, 1999; Stern Review, 2006; Nordhaus, 2007).

Solution: to overcome this problem some respondents suggest that a good line to take for a solution is to discount irreversible effects using a downward-sloping discount rate. Other respondents state that irreversible effects of a spatial-infrastructure project should not be discounted at all. One respondent states that infinite value should be assigned to irreversible negative external effects in a CBA, which leads to a situation in which a project with negative irreversible effects will always score infinitely negatively in a CBA.

\subsubsection{Risk surcharge in the discount rate is too rigid}

Problem: although CBA Guidelines (Ministry of Transport, Public Works and Water Management et al., 2004) prescribe to determine a specific risk surcharge for each CBA, the CBAs in the Dutch practice always use the standard risk surcharge of 3\% (Fakton et al., 2011). Respondents in the Dutch CBA practice perceive that the risk surcharge is applied too rigidly in the Dutch CBA practice. According to these respondents this rigid risk surcharge is incorrect for specific cases and, as a result, leads to an incorrect CBA score. The Review of the Norwegian CBA practice (Hagen et al., 2012) also observes that practitioners only use the standard risk surcharge - although there is an ambition to estimate a specific risk surcharge for each CBA.

Solution: respondents state that effects of spatial-infrastructure projects should be discounted with a more context-specific discount rate to rectify this issue. 


\subsubsection{Presentation}

Problem: respondents state that poor intelligibility and verifiability of effect estimations might lead to distrust and rejection of the results of the CBA study. Respondents, mainly noneconomists, perceive that it is difficult to understand how effects are estimated in the CBA. This can be illustrated by the following quote from a respondent: "when I try to read a CBA report, I feel like a Muggle at Hogwarts. It is like magic and I think it is really hard to follow what these CBA magicians do." Besides intelligibility, respondents state that a precondition for safeguarding the readers' trust in CBA is that it is possible for the readers to verify the (counterintuitive) effect estimations themselves. According to the respondents, very few examples of CBA studies exist that provide sufficient data to make it possible for readers to verify the effect estimations.

The statements of respondents in regard to the negative effects of poor intelligibility of CBA reports and poor verifiability of effect estimations are endorsed in the existing literature (e.g. de Jong and Geerlings 2003; Naess, 2006; Page, 2006). Page (2006) states that readers of a report - who are moderately skeptical - lose trust in the method when they cannot find the conclusions that are important for them, and the basis for these conclusions, in less than five minutes. This especially holds true for conclusions that are not in line with the reader's intuition and view of reality. Both Hajer (1997) and Nicolaisen (2012) found that poor intelligibility and verifiability of decision-support documents enhances the probability that users distrust the results. Naess (2006, page 43) states: 'for politicians, the public at large, as well as experts within other fields, lack of transparency makes it difficult or impossible to evaluate the results and find a basis for critique and development of alternative solutions'. Weiss (1989) depicts the dangers of poorly intelligible reports as a result of poor readability of Environmental Impact Statements as follows: "an unreadable EIS is an environmental hazard, potentially as deadly as dioxin". Finally, the International Transport Forum (2011, p. 13) expresses the need for an understandable presentation as follows: 'one suggestion is to spend a bit less energy on pushing the technical boundary of CBA and more on presentation and discussion of results'.

Solution: respondents mention different solutions to enhance the intelligibility and verifiability of CBA reports. Some respondents suggest that reviews of CBA studies should not only focus on the plausibility of effect estimations, but also on the readability of the CBA report. Moreover, respondents state that a solution to rectify insufficient verifiability is that CBA reports should be written in a way that the reader must be able to check the effect estimations and find an explanation for the way effects are estimated. One respondent proposes to make a scheme in which the reader could check the way effects are estimated. This respondent states that, in his opinion, it does not matter if the scheme is very extensive, as long as it is possible for him to check the way every effect is estimated. Respondents discussed several solutions to iron out the poor intelligibility of CBA reports. One respondent claims it is very important that CBA reports present the results in both a numerical, verbal, graphical and maybe even audio-visual way, to respond to the fact that people process information in a different way. Another respondent believes that the readability of the summary of the CBA report improves when the summary only includes text and no figures. 
The summary of a CBA report should resemble the story one tells about the outcome of the project to a non-economists co-worker who is not involved in the project. Some respondents state that a co-worker who is not involved in the project is able to write a better summary than the co-worker who estimated all the effects. One respondent states that involving a communication specialist will substantially enhance the readability of CBA reports. A communication specialist will, for instance, be able to explain economic jargon such as 'discounting', 'sensitivity analysis' and 'net present value' in a way that is intelligible for laypeople. Some respondents propose to amplify the intelligibility of the CBA study by enhancing the simplicity of the instrument. They think that a CBA study should only include the effects that can be monetized straightforwardly and that the report should communicate that this 'simplified CBA' should have a modest position in the decision-making process. However, we found contradicting remarks for this solution in the interviews. Some respondents propose to include more welfare effects in the CBA study.

\subsubsection{Uncertainty related problems}

Problem: respondents mentioned problems with the methods that are currently used in Dutch CBA studies to handle uncertainty. ${ }^{33}$ At present, Dutch CBA Guidelines prescribe that effect estimates should be analyzed using two or more different scenarios that vary in economic growth and demographic development, amongst other things (Ministry of Infrastructure and the Environment, 2012). However, Annema et al. (2013) have analyzed 106 Dutch transport CBAs published in the period $2000-2012$ and found, amongst other things, that in only $25 \%$ of the projects evaluated the CBA results were presented with a clear bandwidth to the decision makers; in the other $75 \%$ just point estimates were given in the main results. Respondents perceive it as a problem that sometimes incorrect scenarios for the future are used that do not relate to the context of the specific project alternatives under scrutiny in the CBA. Moreover, respondents perceive it as problematic that effects are estimated using different scenarios, yet only the outcomes of the middle scenario are presented in the summary of the CBA report, whereas the outcomes of other scenarios are only discussed in the appendix.

Solution: respondents suggest as a solution, the idea that project effects should be estimated with context-specific scenarios instead of standard scenarios. One respondent illustrates this with the following example: "if the project effects of an extension of the Rotterdam harbor largely depend on the question whether or not competing harbors will respond with an extension of their harbor, then project effects should be estimated for a scenario that assumes an extension of the competing harbors and a scenario that does not assume the extension of competing harbors instead of one scenario that assumes high economic growth and one scenario that assumes low economic growth." Moreover, respondents think that CBA reports should always use an uneven number of scenarios and present them as equally likely to the reader, so that the reader is not likely to use only one (the middle) scenario.

\footnotetext{
${ }^{33}$ Uncertainty can also be considered an insolvable limitation of applying CBA because estimations of future project effects are inherently very uncertain (e.g. Flyvbjerg et al., 2003; Naess, 2006; Naess and Strand, 2012; Salling and Banister, 2009). Perceptions of solutions to manage these insolvable CBA limitations are discussed in Mouter et al. (2012).
} 


\subsection{Analysis of the results}

This section analyzes the solutions perceived by the respondents (section 3). In section 4.4.1 we compare the perceived solutions with those addressed in existing literature. Section 4.4.2 discusses the extent to which we think the perceived solutions are promising.

\subsubsection{Comparison of perceived solutions with the literature}

In table 4-1 we present, for each group of perceived solutions, the extent to which they are discussed in existing literature, to the best of our knowledge. 
Table 4.1: extent to which solutions are discussed in the literature

\begin{tabular}{|c|c|c|c|c|c|c|c|c|c|c|c|c|}
\hline 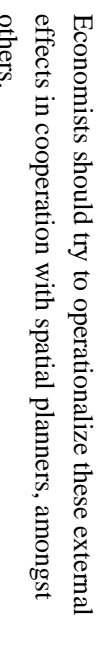 & 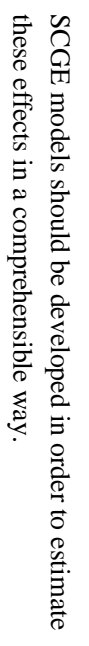 & 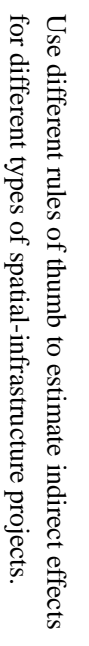 & 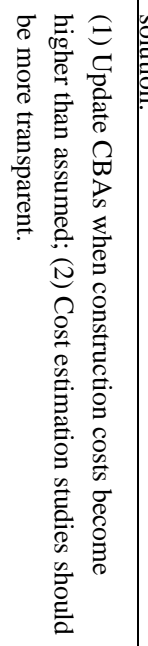 & 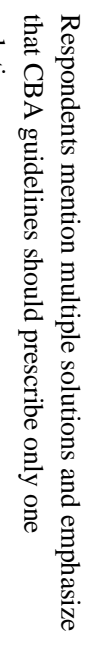 & 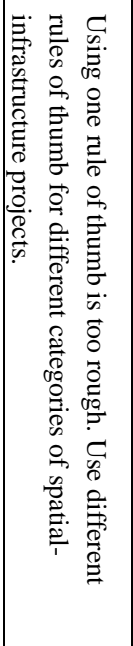 & 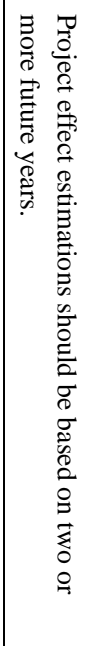 & 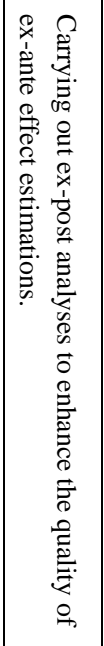 & 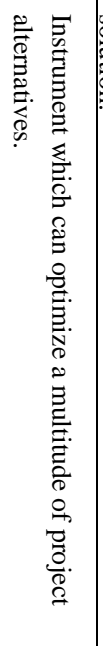 & 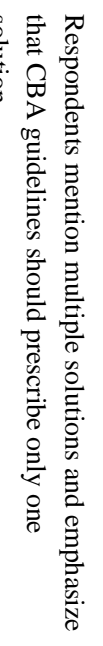 & 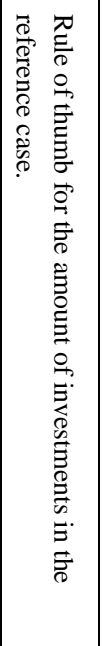 & 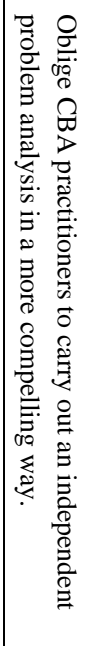 & 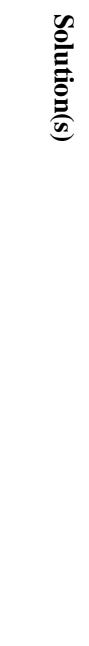 \\
\hline 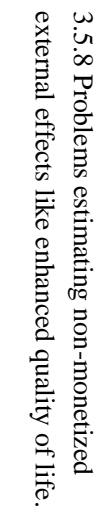 & 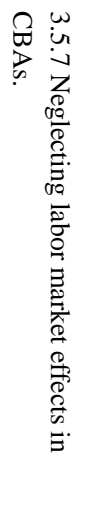 & 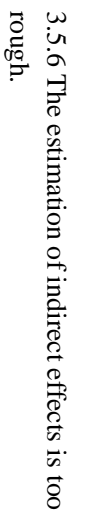 & 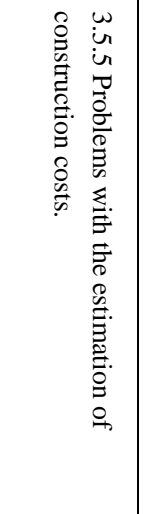 & 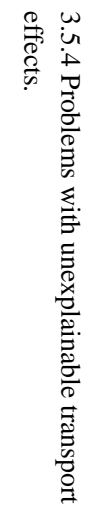 & 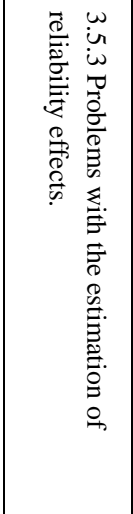 & 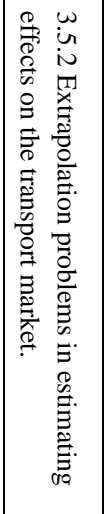 & 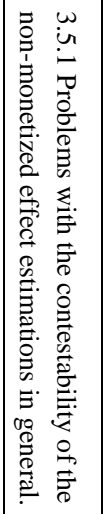 & 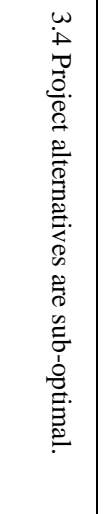 & 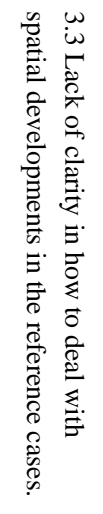 & 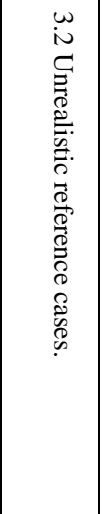 & 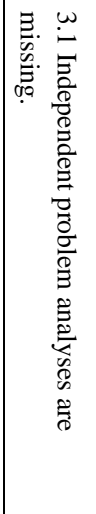 & $\frac{\overline{0}}{\frac{0}{0}}$ \\
\hline 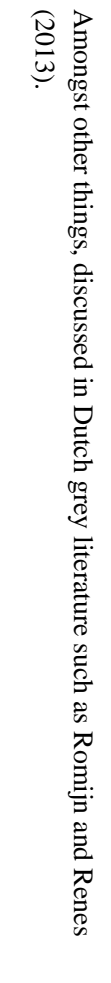 & 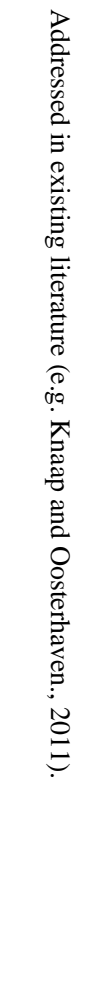 & 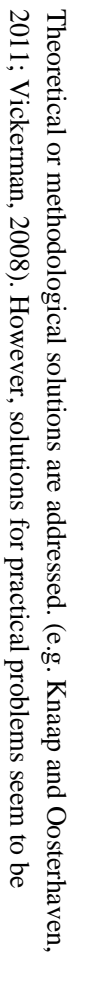 & 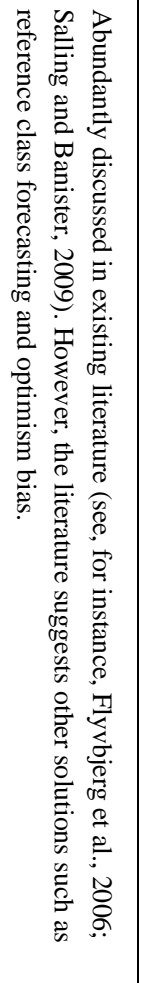 & 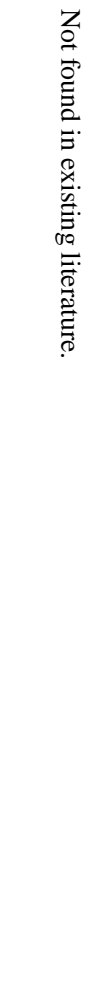 & 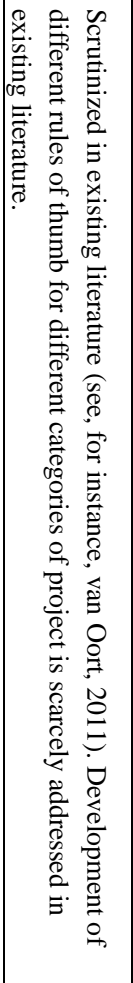 & 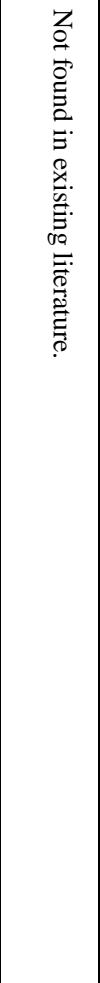 & 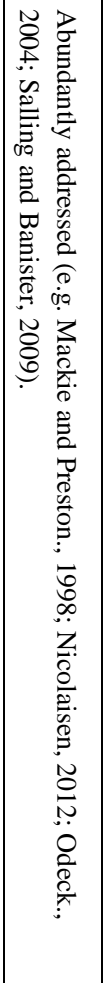 & 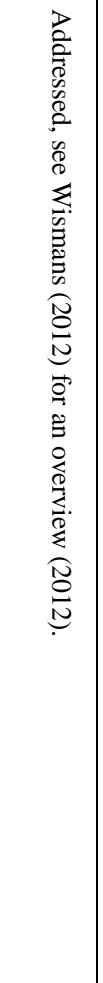 & 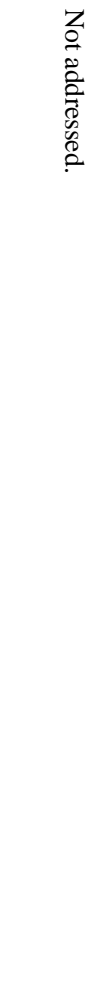 & 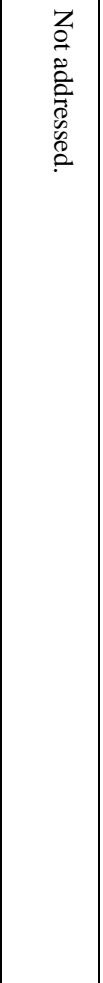 & 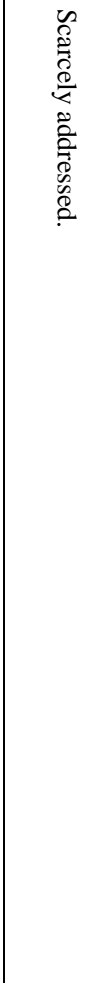 & 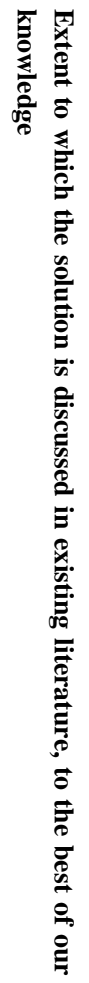 \\
\hline
\end{tabular}


Table 4.1 continued: extent to which solutions are discussed in the literature

\begin{tabular}{|c|c|c|c|c|c|c|c|c|c|}
\hline 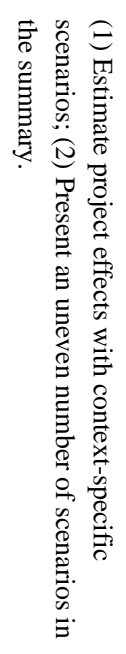 & 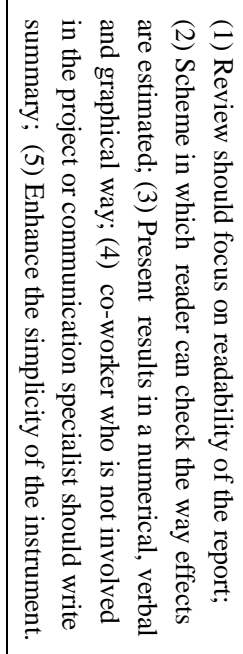 & 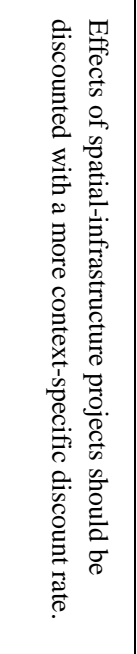 & 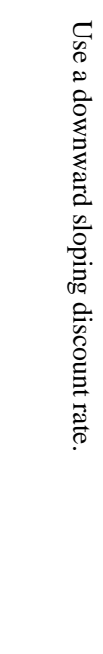 & 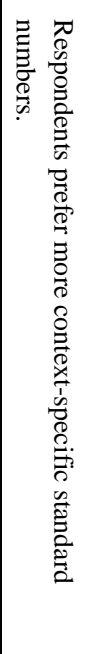 & 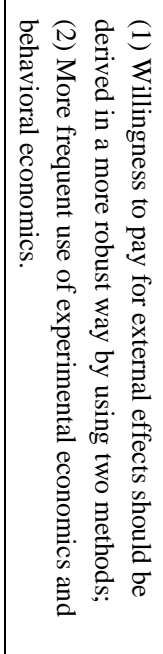 & 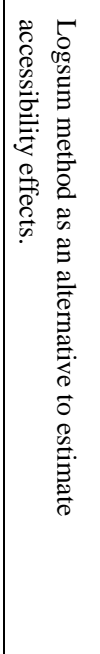 & 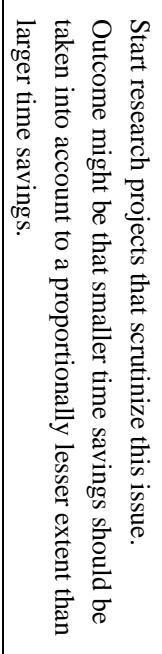 & 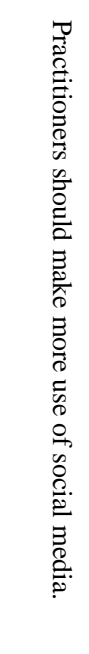 & \\
\hline 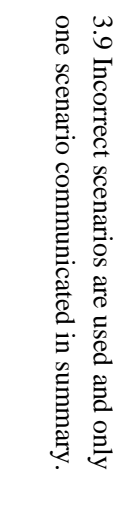 & 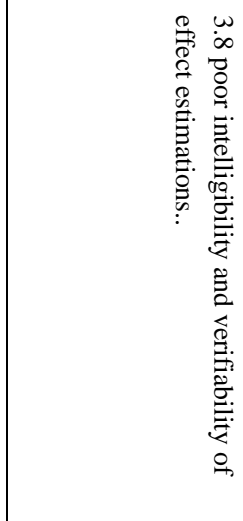 & 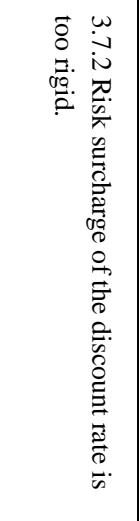 & 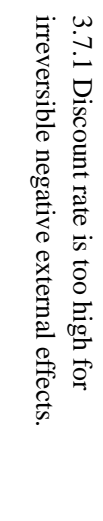 & 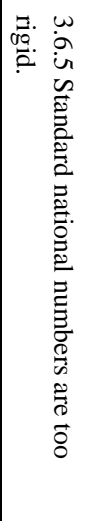 & 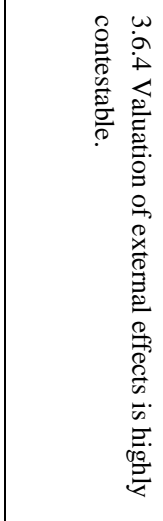 & 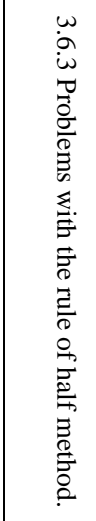 & 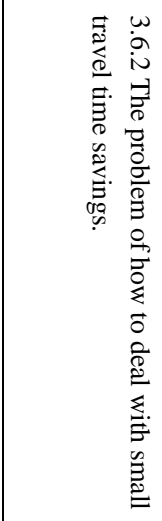 & 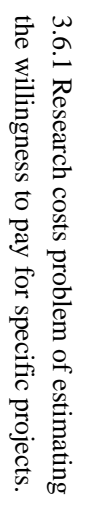 & \\
\hline 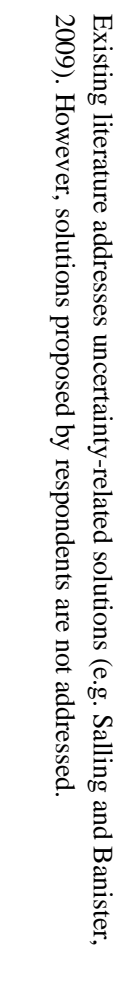 & 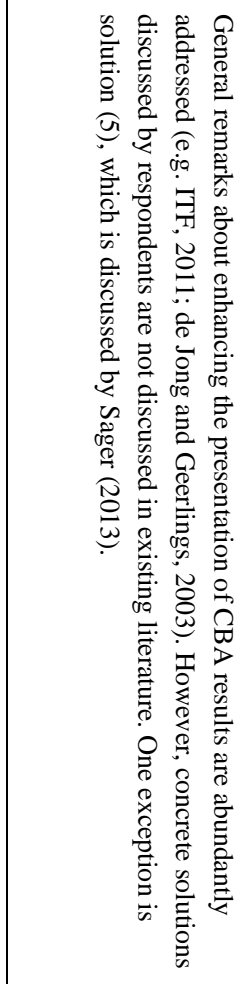 & 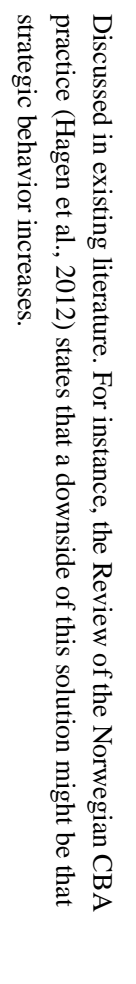 & 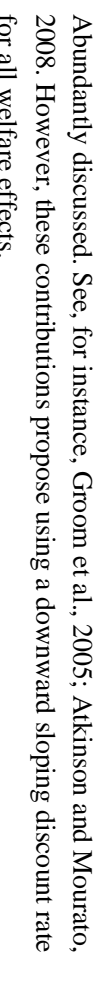 & 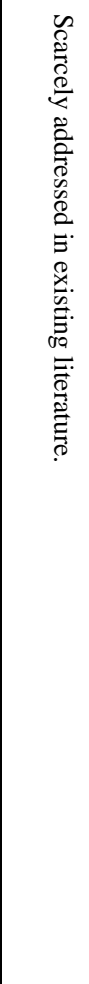 & 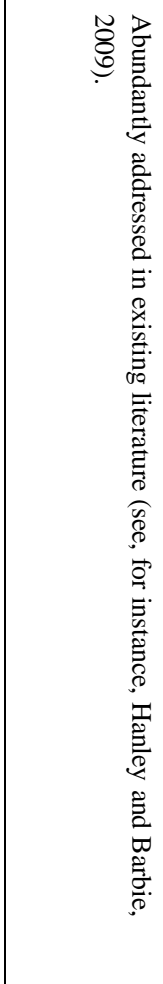 & 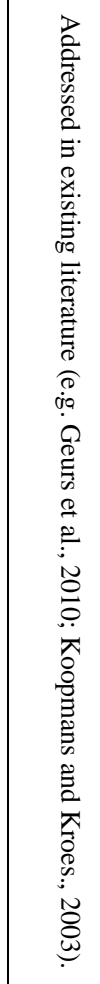 & 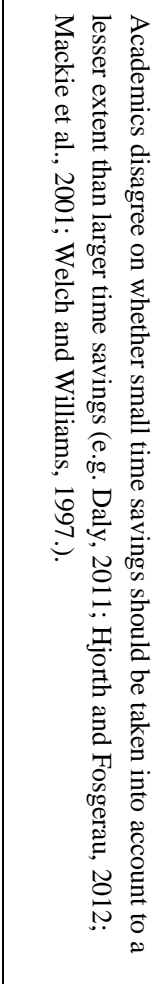 & 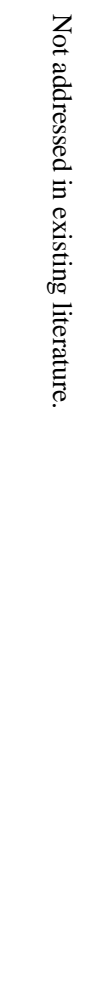 & 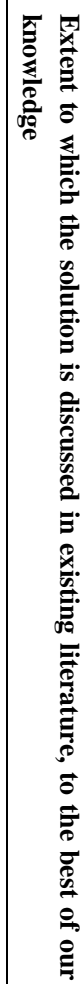 \\
\hline
\end{tabular}


Table 4-1 shows that some solutions proposed by the practitioners have already been addressed in existing literature, whereas other solutions clearly add to the literature. From now on, we will only discuss the topics on which the respondents suggested solutions that add something to existing literature or on which respondents, to some extent, surprisingly did not mention the prevailing solutions in existing literature. Based on table 4-1, we can distinguish four categories of solutions that make a positive addition to existing literature.

Respondents provide solutions on topics for which solutions are scarcely addressed in existing literature: although existing literature discusses problems with the reference case, the problem analysis and the presentation of CBA reports, it mainly provides general solutions to these problems (such as, 'we should focus more on presentation and discussion of the results'). Respondents - on a contrary - provide specific solutions.

Respondents provide original solutions: an example of an original idea is the use of social media to diminish the research costs for willingness to pay studies.

Respondents ask for provision of explicit instructions in guidelines and the enforcement of these in an independent review: a solution category rarely discussed in existing literature is that the low quality of a certain aspect of CBAs can be rectified by providing very clear and explicit instructions in guidelines, combined with a strict enforcement of these instructions in an independent review (see, for instance, the solutions discussed in sections 4.4.3.1 and 4.4.3.8). Mainly private consultants state that they can use the clear guidelines and the knowledge that the quality of the CBA will be assessed in a review as a 'weapon' to convince the client to carry out a high-quality independent CBA in accordance with the guidelines. The review culture in the Netherlands in the first years after the introduction of the Dutch CBA Guideline (Leidraad-OEI, Eijgenraam et al., 2000) could be considered as an interesting example for other CBA practices. The quality of CBA studies for spatial-infrastructural projects was reviewed by the Netherlands Bureau for Economic Policy Analysis. However, in the status quo the quality of the lion share of CBA studies for Dutch spatial-infrastructure projects is reviewed by institutes that are aligned to the Ministry of Infrastructure and the Environment. The question is whether these second opinions can still be labeled as independent reviews, because it is in the interest of the Ministry of Infrastructure and the Environment that the CBA outcome of politically desirable projects is positive.

Respondents discuss pragmatic solutions for practical problems: whereas literature predominantly discusses theoretical or methodologically complicated solutions, the solutions proposed by Dutch key actors mainly entail pragmatic solutions for practical problems. To illustrate this, solutions discussed in academic literature that aim to iron out problems with the estimation of indirect effects mainly propose to develop and apply Spatial Computable General Equilibrium (SCGE) models (e.g. Knaap and Oosterhaven, 2011; Vickerman, 2008). However, in practice, it is often too ambitious to estimate indirect effects using SCGE models. Practitioners need rules of thumb to estimate indirect effects. Here, we can identify a gap between the academic and practical world, which aims for pragmatic solutions. In practice, it is impossible to estimate all the effects in a CBA with scientific precision within the 
unforgiving deadlines. One needs to use shortcuts, standard numbers and rules of thumb, also to support consistency in the assumptions. However, a conclusion that can be made from our study is that respondents sometimes have problems with the practical standard numbers and rules of thumb when these are perceived as too rough, which leads to a situation in which they are no longer valid for specific cases. Respondents then provide practical solutions to overcome these problems, which are scarcely addressed in the academic literature (for instance, developing different rules of thumb for different categories of projects).

We think it is also very interesting to note that some of the prevailing solutions for problems that are discussed in existing literature are not mentioned as solutions by the key actors. One of these solutions is 'reference class forecasting' as a solution to diminish problems with cost estimations in a CBA (e.g. suggested by Flyvbjerg, 2007; Salling and Banister, 2009). To say that Dutch key actors are totally unaware of this solution is maybe too strong a conclusion. However, we think it is an interesting result that - contrary to our expectation - not many key actors in the Dutch appraisal practice for spatial-infrastructure projects perceive substantive problems with the estimation of costs as an important substantive problem (Mouter et al., 2013a) and that key actors did not mention the prevailing solutions in the literature.

\subsubsection{To which extent are solutions promising?}

In this section, we aim to evaluate the extent to which the proposed solutions are promising. Which solutions are 'no regret' and could be implemented relatively quickly? Which solutions need to be studied in-depth before they are put into practice? Here, we wish to emphasize that we realize that the reader can have different views on the extent to which solutions are promising. We carried out our analysis using five criteria ${ }^{34}$ (not presented in order of importance):

1. Costs in time and money related to the implementation of the solution;

2. Impact of the implementation of the solution on the CBA outcome;

3. Extent to which the implementation of the solution results in a more reliable and valid way of estimating welfare effects;

4. The applicability of the solution. More specifically, we consider a solution that can be applied in all CBA studies to be more promising than a solution that can only be applied in one single CBA study;

5. Extent to which other promising solutions for the perceived problem are available in the existing literature, to the best of our knowledge.

We do not have the pretension that the scores we give to the solutions are exact truths. The scores should be interpreted as indications.

\footnotetext{
34 The first criterion is based on respondents' perceptions. 19 respondents spontaneously discussed in their interview that costs in time and money should be contemplated before developers of CBA guidelines decide to add a solution to the guideline. The other four criteria were determined in a discussion between the authors.
} 
Table 4.2: extent to which we consider solutions as promising

\begin{tabular}{|c|c|c|c|c|c|c|c|c|c|c|c|c|}
\hline 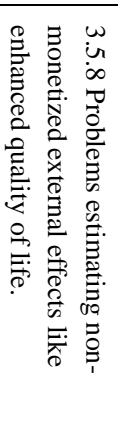 & 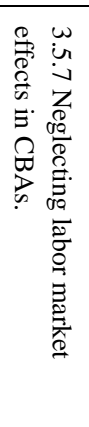 & 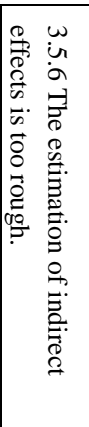 & 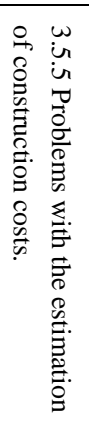 & 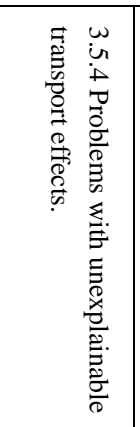 & 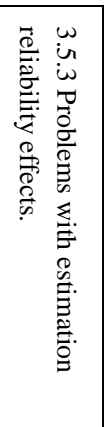 & 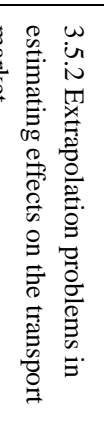 & 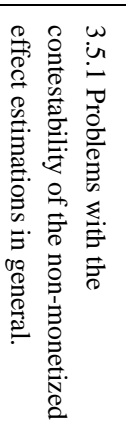 & 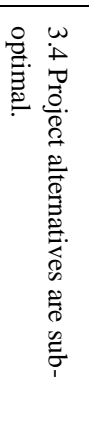 & 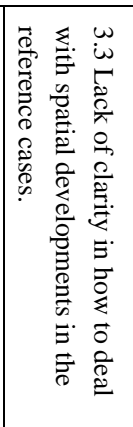 & 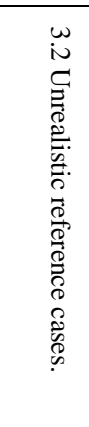 & 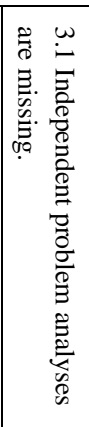 & $\frac{\bar{g}}{\frac{\vec{\theta}}{g}}$ \\
\hline 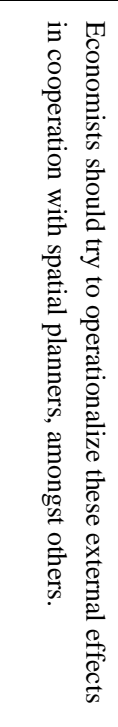 & 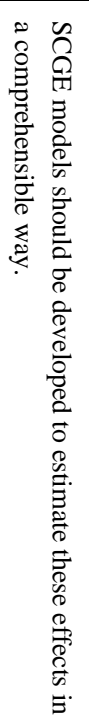 & 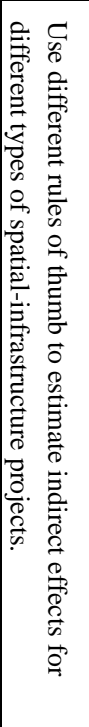 & 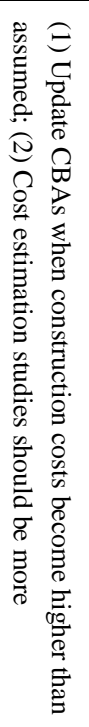 & 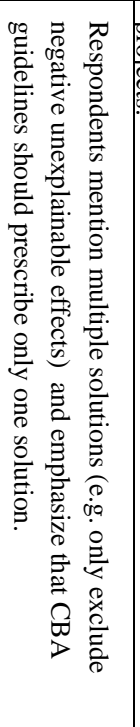 & 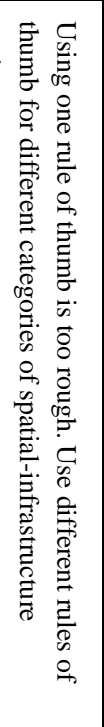 & 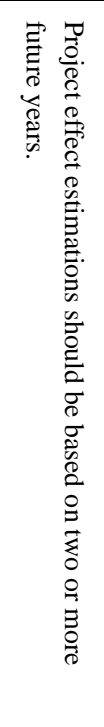 & 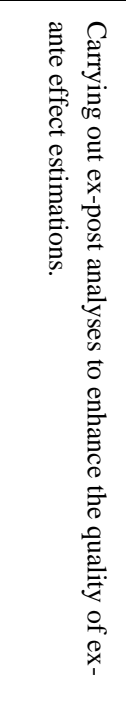 & 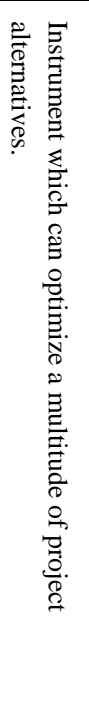 & 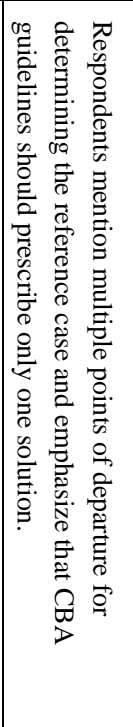 & 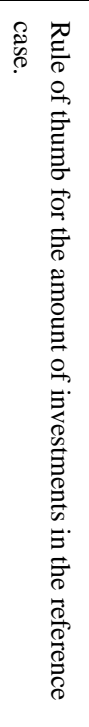 & 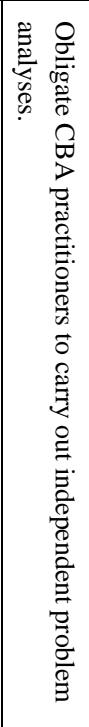 & $\begin{array}{l}\frac{n}{0} \\
\frac{0}{0} \\
\frac{0}{0.0}\end{array}$ \\
\hline 5 & 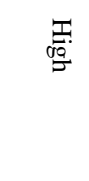 & 5 & $\begin{array}{l}3 \\
\frac{3}{0} \\
\text { : }\end{array}$ & 5 & $\underset{8}{\$}$ & 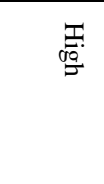 & 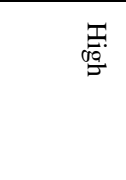 & $\begin{array}{l}\frac{3}{0} \\
\stackrel{0}{0} \\
\text { : }\end{array}$ & $\stackrel{0}{8}$ & 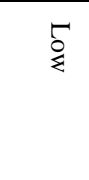 & 5 & 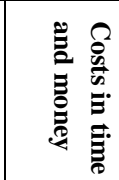 \\
\hline$\underset{8}{5}$ & $\begin{array}{l}5 \\
\&\end{array}$ & 5 & 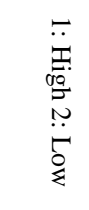 & 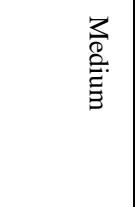 & 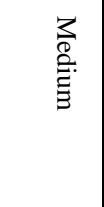 & $\begin{array}{l}\frac{3}{0} \\
\stackrel{0}{0} \\
\text { : }\end{array}$ & ¿ & $\underset{\substack{g \\
g}}{\underline{g}}$ & 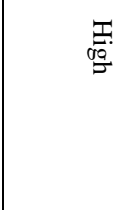 & 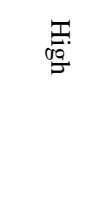 & 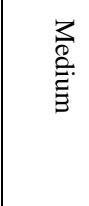 & 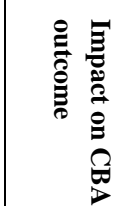 \\
\hline 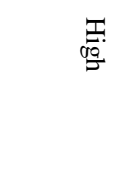 & $\underset{\substack{g \\
g}}{\stackrel{g}{g}}$ & $\begin{array}{l}\text { 3. } \\
\text { : } \\
\text { 音 }\end{array}$ & 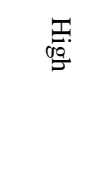 & $\stackrel{\nexists}{8}$ & $\begin{array}{l}\underset{3}{0} \\
\stackrel{0}{0} \\
\stackrel{1}{\mid}\end{array}$ & 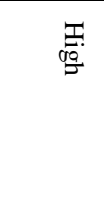 & 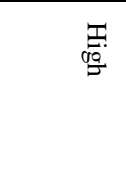 & 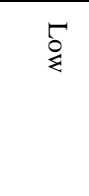 & ל & $\stackrel{5}{8}$ & 5 & 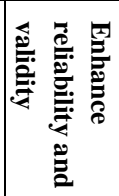 \\
\hline 5 & $\underset{8}{5}$ & $\begin{array}{l}\text { za } \\
\stackrel{0}{0} \\
\text { : }\end{array}$ & 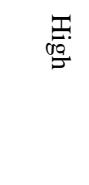 & 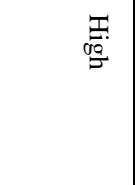 & 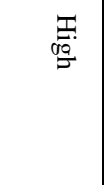 & 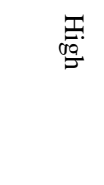 & $\underset{\substack{g \\
g}}{\stackrel{\Xi}{\sigma}}$ & 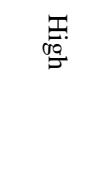 & 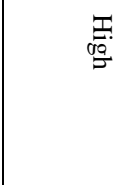 & 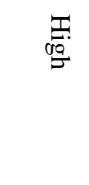 & 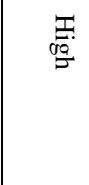 & 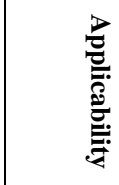 \\
\hline z & $\underset{\&}{\overparen{\infty}}$ & $\underset{\wp}{\sigma}$ & 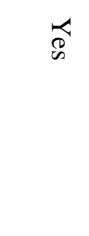 & $z$ & z & z & $z$ & $z$ & z & ż & z & 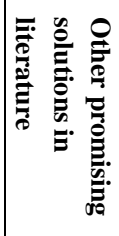 \\
\hline
\end{tabular}


Table 4.2 Continued: extent to which we consider solutions as promising

\begin{tabular}{|c|c|c|c|c|c|c|c|c|c|}
\hline 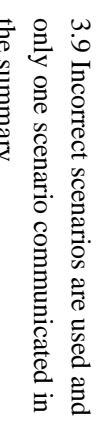 & 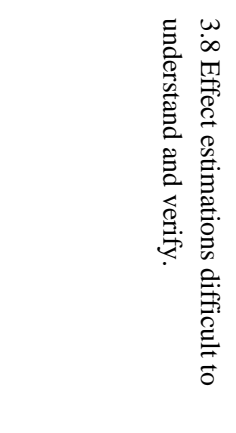 & 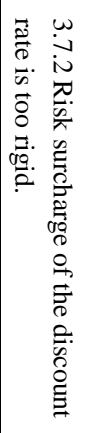 & 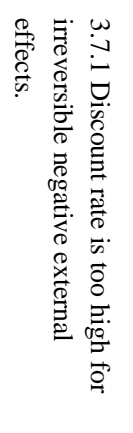 & 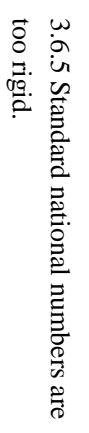 & 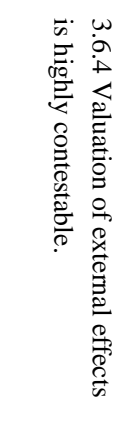 & 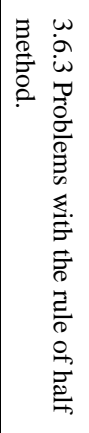 & 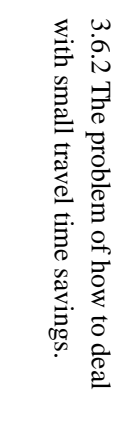 & 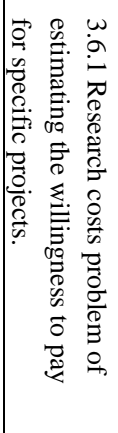 & $\frac{70}{\frac{0}{0}}$ \\
\hline 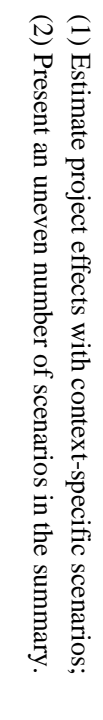 & 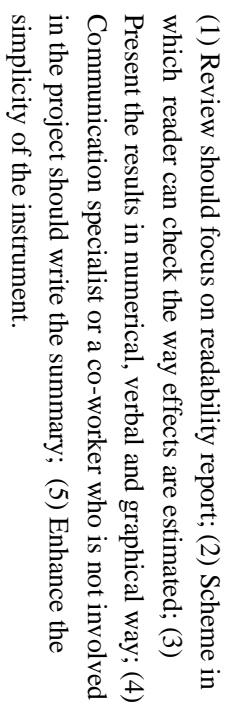 & 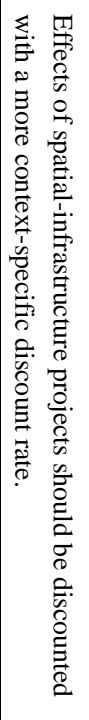 & 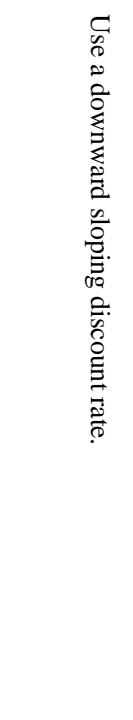 & 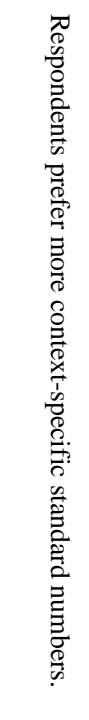 & 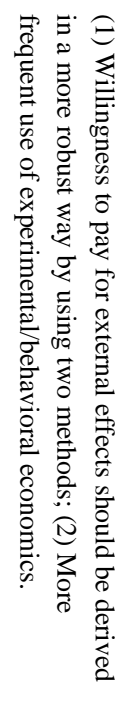 & 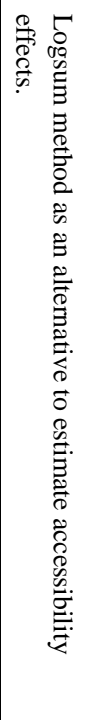 & 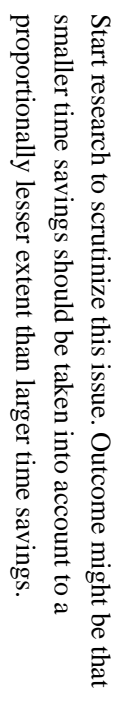 & 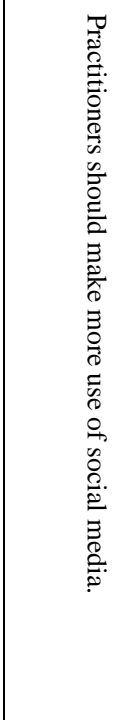 & $\frac{\mathscr{\sigma}}{\frac{0}{0}}$ \\
\hline 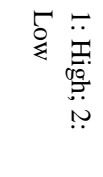 & 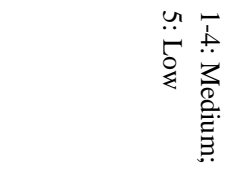 & $\begin{array}{l}\text { 3. } \\
\stackrel{0}{0} \\
\stackrel{0}{0}\end{array}$ & $\stackrel{5}{8}$ & $\begin{array}{l}\text { 3. } \\
\stackrel{0}{0} \\
\stackrel{0}{0}\end{array}$ & 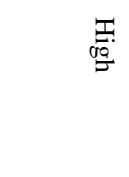 & 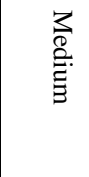 & 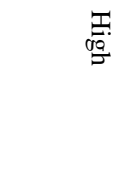 & $\stackrel{5}{8}$ & 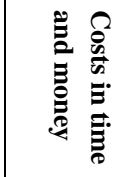 \\
\hline 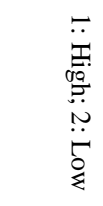 & ¿ & $\begin{array}{l}\text { 3. } \\
\text { : } \\
\text { : }\end{array}$ & 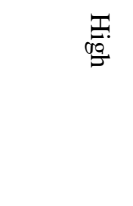 & $\begin{array}{l}\text { 3. } \\
\stackrel{0}{0} \\
\text { : }\end{array}$ & 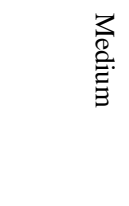 & 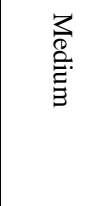 & $\begin{array}{l}\frac{3}{0} \\
\stackrel{0}{0} \\
\text { : }\end{array}$ & $\sim$ & 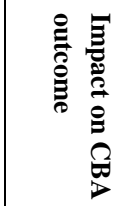 \\
\hline 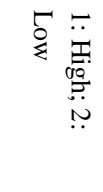 & $\stackrel{5}{8}$ & 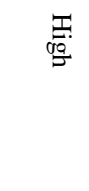 & v & $\begin{array}{l}\text { 3. } \\
\text { : } \\
\text { : }\end{array}$ & 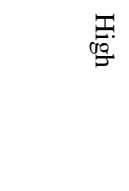 & 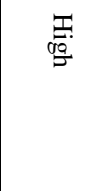 & 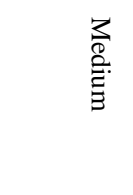 & $\stackrel{5}{8}$ & 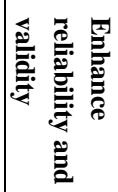 \\
\hline 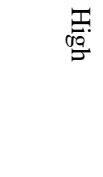 & 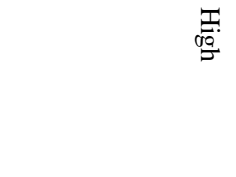 & 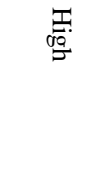 & 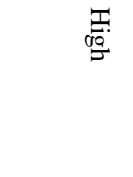 & 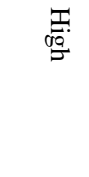 & $\underset{\substack{\text { 楚 } \\
g}}{ }$ & 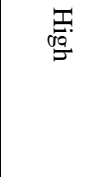 & 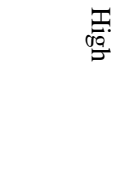 & 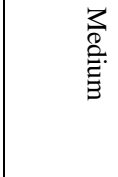 & 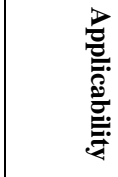 \\
\hline$\overparen{\phi}$ & z & ఠ్ర & 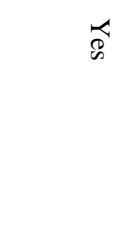 & $z$ & z & z & z & z & 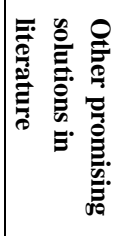 \\
\hline
\end{tabular}


The main goal of our study was to provide an overview of Dutch key actors' perceptions of solutions that aspire to solve (perceived) substantive CBA problems. Hence, it is out of the scope of this paper to discuss the extent to which we think a solution is promising for all the proposed solutions. To give an impression of the extent to which we consider solutions promising, we discuss some solutions that we consider as 'very promising', 'potentially promising' and 'probably not very promising.'

Table 4-2 shows that we think some solutions are very promising and can be implemented relatively quickly. For instance, the solution 'to obligate CBA practitioners to carry out an independent problem analysis in a more compelling way', 'the extension of current appraisal guidelines with the obligation that effect estimations in ex-ante CBA studies are always checked with ex-post analyses' and solution 4.3.5.8: 'economists should try to operationalize external effects in cooperation with spatial planners, amongst others'. Respondents indicated that CBA research agendas should predominantly focus on grasping the quick wins (low cost solutions). We agree with the respondents that it is sensible to implement 'quick wins'. However, we think that solutions with high benefits (for instance, the solution substantially enhances the quality of the effect estimation for a multi-billion project) can also be very promising as well, despite high implementation costs.

In addition, table 4-2 shows that we think some solutions are potentially promising. For instance, the solution to use a rule of thumb for the amount of investments in the reference case such as 'assumed investments in the reference case should be between 10\%-30\% of the investments in the project alternatives' (section 4.3.2). We think that this solution can be promising. The costs in time and money to implement the solution are low, the impact on the CBA outcome and the applicability of the solution are high. However, we doubt whether this solution would result in a more reliable and valid way of estimating welfare effects. On the one hand the solution may diminish the number of unrealistic reference cases (too optimistic or 'doom scenarios'). On the other hand - if the rule of thumb is applied rigidly - the rule of thumb may lead to unreliable effect estimations (for instance, a realistic reference case entails $50 \%$ of the investments in the project alternative). For these potentially promising solutions we suggest a more in-depth scrutiny of the advantages and disadvantages before putting them into practice.

Finally, table 4-2 shows that we think some solutions have major disadvantages, which should be considered carefully before they are developed further. This, for instance, holds true for the solution 'social media' (4.3.6.1). We think that this solution is original and can inspire researchers into developing new solutions to derive the willingness to pay against low costs. However, we think that it is doubtful whether or not this solution is promising in the short run. In the status quo, social media is mainly used by young people (selectiveness), and many people tend to make extreme statements when using social media (strategic answers or exaggerated answers). Hence, we think that the willingness to pay derived from social media is not valid and, therefore, not useful for current CBAs. 


\subsubsection{Conclusions and discussion}

\subsubsection{Conclusions}

We can conclude that key actors in the Dutch appraisal practice for spatial-infrastructure projects were able to provide a large variety of solutions for substantive CBA problems. More than $60 \%$ of the respondents interviewed proposed solutions which we considered internationally relevant. Some of the proposed solutions have already been addressed in existing literature: an example being the proposed solution 'carrying out 'ex-post' analyses to enhance the quality of ex-ante effect estimation' (section 4.3.5.1). However, we conclude that Dutch key actors also mentioned solutions which are not addressed in existing literature. We conclude that scrutinizing key actors' perceptions of solutions for substantive CBA problems is very useful input for CBA research agendas. This, firstly, because respondents provide solutions on topics for which solutions are scarcely addressed in existing literature. Secondly, Dutch key actors propose some pragmatic solutions for practical substantive problems that add to the scientific literature, which predominantly discusses theoretical solutions. When only scientific literature is the input for CBA research agendas, the risk is that the research agenda will only include solutions like the development of highbrow models, whereas especially key actors that carry out CBAs need rules of thumb and temporary solutions to safeguard consistency. Finally, an interesting result for an international audience is that Dutch key actors suggest the solution that they are clearly in need of very clear and explicit instructions in CBA guidelines, which are enforced in an independent review. Predominantly private consultants stated in the interviews that they can use these clear guidelines and the fact that the quality of the CBA will be assessed in an independent review as a 'weapon' to convince the client to carry out a CBA that can be considered to be as independent as possible. Based on this study we recommend institutionalizing systematic independent reviews of CBA studies as part of the appraisal process for spatial-infrastructure projects.

\subsubsection{Discussion}

In the discussion, we focus on the implications of our research for country-specific research agendas because CBA guidelines and the way CBA is embedded in the decision-making process differs in place, time and culture (e.g. Turner, 1979; Mackie, 2010; Hayashi and Morisugi, 2000). We discuss two topics. In the first topic we discuss a guiding principle to design a CBA research agenda inspired by our study of key actors' perceptions of solutions. The second topic concerns the positive implications of surveying key actors for the support of CBA research agendas.

Based on our study, we recommend using three inputs as a guiding principle for the design of a CBA research agenda: 1) key actors' perceptions of solutions; 2) solutions discussed in scientific literature; 3) solutions implemented in other countries. In the conclusion above we already discussed why we think key actors' perceptions of solutions for substantive CBA problems is useful input for CBA research agendas. At the same time, we think that key actors' perceptions alone are insufficient input for CBA research agendas. We think that solutions discussed in academic literature and solutions implemented in other countries are very valuable inputs as well, for three reasons. Firstly, both inputs are useful when key actors 
in the practice under scrutiny are relatively unaware of solutions for CBA problems discussed in other countries or in existing literature. In the Netherlands, for instance, it seems that there is an unawareness of state-of-the-art developments in literature regarding discounting. From Mouter et al. (2013a) it can be derived that Dutch key actors perceive "problems with discounting' as the least important problem category and none of the respondents mentioned solutions to this topic that are prevailing in current literature (see for instance, Arrow et al., 2012; Groom et al., 2005; Gollier, 2012). Moreover, in contrast to the UK Guidelines (WebTag), the French Guidelines and the review of the Norwegian Guidelines (Hagen et al., 2012), Dutch CBA Guidelines and policy documents do not discuss state-of-the-art literature on this topic. Secondly, both the literature and guidelines from other countries may provide (creative) methods to enhance the possibility to estimate welfare effects or the reliability/validity of welfare effect estimations. An example is a method for measuring the welfare effect of a safer walking route to a train station as discussed in Börjesson (2012). Thirdly, solutions used in other guidelines and literature can provide other - and maybe better - solutions besides the solutions proposed by key actors in the practice under scrutiny. For instance, the solution 'more context-specific standard numbers' (section 3.6.5) proposed by Dutch key actors can be interesting. However, we also think that the solution used in the Swedish CBA guidelines might be interesting. The Swedish solution is that CBA practitioners are obliged to estimate welfare effects with standard numbers, but are also allowed to estimate the effects with context-specific information alongside the effect estimations based on standard numbers.

Perhaps synthesizing the three inputs (key actors perceptions of solutions, solutions discussed in literature and solutions implemented in other countries) might lead to even better solutions. To illustrate this, our study shows that Dutch key actors are in need of CBA reports that are both intelligible and verifiable. We can conclude that proposed solutions that aspire to enhance the verifiability and intelligibility of CBA reports point in opposite directions (solutions to enhance intelligibility advocate a simplification of the CBA report, whereas the solution to enhance the verifiability of effect estimations leads to more complexity). In existing literature we find a study which points at a possible way out of this dilemma. Grant Muller et al. (2001, p. 253): 'the use of a written document to store and present outputs carries certain limitations and there is increasing interest in and support for the idea of computerized presentational tools'. The UK appraisal Guideline (Webtag) is a good example of a document that follows the recommendation of Grant Muller et al. (2001). Webtag is presented in a digital and multi-layered way. Thus, based on current literature (Grant Muller et al., 2001), a solution in another country (the Webtag) and the remarks of Dutch key actors, experimenting with a 'digital multi-layered CBA' that aims to reconcile both objectives (intelligibility and verifiability) seems to be a very interesting solution for the Dutch CBA research agenda. This 'digital multi-layered CBA' aims to fulfill the need of the group of readers that want to find relevant information as soon as possible and the needs of readers that want to know in detail how every effect is estimated in the CBA study.

Our second discussion point is that surveying key actors' perceptions may enhance the support for the research agenda, especially when key actors receive feedback as to why the 
solutions they proposed are still not included. For example, relatively many key actors in the Dutch practice felt that a solution to improve the CBA practice would be that 'one should take into account smaller time savings to a proportionally lesser extent than larger time savings'. However, this solution might never be considered by people who develop the CBA guidelines because their position (which they never clearly communicate) could be that this problem does not exist and they are not aware that practitioners think otherwise. In existing literature, namely, both positions ('lower value for small time savings' and 'equal value for small time savings') are defended and maybe the developers of guidelines hold the second position (see, for instance, Daly, 2011; Fowkes, 1999; Hjorth and Fosgerau, 2012; Mackie et al., 2001; Welch and Williams, 1997, for a discussion of arguments for the two positions). By surveying key actors' perceptions, however, it becomes clear that in the practice the first position is also defended. Subsequently, a workshop or seminar with all key actors (practitioners, scientists and developers of guidelines) on this issue could be organized, in which the arguments can clearly be exchanged and debated. A result of such a workshop or seminar could be that all agree that indeed the second position is the best and actors who came up with other solutions would then understand why 'their' solution is not implemented in the Dutch CBA practice and included in the research agenda.

\section{Acknowledgment}

The authors wish to thank the 86 respondents for their open-heartedness.

\section{References}

Atkinson, G., Mourato, S., 2008. Environmental Cost-Benefit Analysis. Annual Review of Environmental Resources. 33, 317-344.

Annema, J.A., Frenken, K., Koopmans, C., 2013. Twaalf jaar MKBA van transportprojecten. 106 rapporten geanalyseerd. Bijdrage aan het Colloquium Vervoersplanologisch Speurwerk 2013, Rotterdam.

Arrow, K.J., Cropper, M.L., Gollier, C., Groom, B., Heal, G.M., Newell, R.G., Nordhaus, W.D., Pindyck, R.S., Pizer, W.A., Portney, P.R., Sterner, T., Tol, R.J.S., Weitzman, M.L., 2012. How should benefits and costs be discounted in an intergenerational context?

Beattie, R.B., 1995. Everything you already know about EIA (but don't often admit). Environmental Impact Assessment Review. 15, 109-114.

Besseling, P., Groot, W., Verrips, A., 2004. Economische toets op de nota mobiliteit. CPB Document 65, CPB Netherlands Bureau for Economic Policy Analysis, The Hague, Netherlands.

Börjesson, M., 2012. Valuing perceived insecurity associated with use of and access to public transport. Transport Policy 22, 1-10.

Cantarelli, C.C., Flyvbjerg, B., Molin, E.J.E., Van Wee, B., 2010. Cost overruns in large-scale transport infrastructure projects: explanations and their theoretical embeddedness. European Journal of Transport and Infrastructure Research, 10 (1), 5-18.

Daly, A., Tsang, F., Rohr. C., 2011. The value of small time savings for non-business travel. Bijdrage aan het ETC 2011. 
Damart, R. and Roy, B. 2009. The uses of cost-benefit analysis in public transportation decision-making in France. Transport Policy 16 (4), 200-212.

Eijgenraam, C. J. J., Koopmans, C.C., Tang, P.J.G., Verster, A.C.P., 2000. Evaluation of Infrastructural Projects; Guide for cost-benefit analysis, Sections I and II, CPB, The Hague, NEI (Name Changed to ECORYS), Rotterdam.

Elhorst, J. P., Heyma, A., Koopmans, C. C., Oosterhaven, J., 2004. Indirecte Effecten Infrastructuurprojecten; Aanvulling op de Leidraad OEI. [Indirect effects of infrastructure; Addition to the CBA Guide]. Amsterdam, Netherlands: SEO Economic Research.

Fakton, BUCK Consultancy International, SEO. 2011. Werkinstructie 'van GREX naar MKBA'. In elf stappen van de grondexploitatie naar de input voor de maatschappelijke kosten baten analyse.

Flyvbjerg, B., Bruzelius, N., Rothengatter, W., 2003. Megaprojects and Risk - An Anatomy of Ambition. Cambridge University Press, Cambridge.

Flyvbjerg, B., Skamris Holm, M.K., Buhl, S.L., 2004. What causes cost overrun in transport infrastructure projects? Transport reviews, 24 (1), 3-18.

Flyvbjerg, B., 2007: Policy and Planning for Large-Infrastructure Projects: Problems, Causes, Cures in environment and planning B

Fowkes, A.S., 1999. Issues in evaluation. A justification for awarding all time savings and losses, both small and large, Equal Unit Value in scheme evaluation. In: Accent/Hague, 341-359.

Geurs, K., de Bok, M., Zondag, B., 2010. Spatial planning and public transport investments: searching for synergies. A case study of new town Almere in the Netherlands. ERSA papers, 19-23 August 2010, Jönköping, Sweden.

Gollier, C., 2012. Pricing the Planet's Future: The Economics of Discounting in an Uncertain World. Princeton, NJ: Princeton University Press.

Grant-Muller, S., Mackie, P., Nellthorp, J., Pearman, A., 2001. Economic appraisal of European transport projects - The state of the art revisited. Transport Reviews 21 (2), 237-261

Groom, B., Hepburn, C., Koundouri, P., Pearce, D,W., 2005. Declining discount rates: the long and the shortof it. Environ. Resour. Econ. 33:445-93.

Hagen, K. P., Berntsen, S., Bye, B., Hultkranz, L., Nyborg, K., Pedersen, K, R., Sandsmark, M., Volden, G, H., Avitsland, G., 2012. Official Norwegian Reports NOU 2012: 16. Review from a committee appointed by Royal Decree of 18 February 2011. Oslo.

Hanley, N., Shogren, J.F., 2005. Is Cost-Benefit Analysis Anomaly-Proof?, Environmental and Resource Economics. 32, 13-34.

Hanley, N., Barbier, E., 2009. Pricing Nature. Cost-Benefit Analysis and Environmental Policy. Edward Elgar.

Hayashi, Y., Morisugi, H., 2000. International comparison of background concept and methodology of transportation project appraisal. Transport Policy 7 (1), 73-88.

Hjorth, K., Fosgerau, M., 2012. Using prospect theory to investigate the low marginal value of travel time for small time changes. Transportation Research Part B 46 (2012) 917-932 
International Transportforum, 2011. Summary and Conclusions of the Roundtable on Improving the Practice of Cost Benefit Analysis in Transport (21-22 October 2010, Queretaro, Mexico). 'Improving the Practice of Cost Benefit Analysis in Transport'.

Jong, D.M., Geerlings, H., 2003. Exposing weaknesses in interactive planning: the remarkable return of comprehensive policy analysis in The Netherlands. Impact Assessment and Project Appraisal 21 (4), 281-291.

Knaap, T., Oosterhaven, J., 2011. Measuring the welfare effects of infrastructure: a simple spatial equilibrium evaluation of Dutch railway proposals. Research in Transportation Economics. 31, 19-28.

Koopmans, C.C., Kroes, E., 2003. Estimation of congestion costs in the Netherlands. Paper presented at the European Transport Conference, Strasbourg, 8-10 October.

Koopmans, C.C., Oosterhaven, J., 2011. SCGE modeling in cost-benefit analysis: the Dutch experience. Research in Transportation Economics. 31 (1), 29-36.

Mackie, P., Preston, J., 1998. Twenty-one sources of error and bias in transport project appraisal. Transport Policy 5 (1), 1-7.

Mackie, P., Jara-Diaz, S., Fowkes, A.S., 2001. The value of travel time savings in evaluation. Transportation Research Part E. 37 (2-3), 91-106.

Mackie, P., Nellthorp, J., 2001. Cost-benefit analysis in transport, in K. Button and D. Hensher (Eds) Handbook of Transport Systems and Traffic Control, 143-174 (Oxford: Elsevier).

Mackie, P., Worsley, T., 2013. International Comparisons of Transport Appraisal Practice. Overview Report. Institute for Transport Studies. University of Leeds.

Ministerie van Financiën, 2009. 'Waardering van risico's bij publieke investeringsprojecten' brief naar Tweede Kamer 29352, nr. 4. Vergaderjaar 2008 - 2009. Den Haag.

Ministerie van Verkeer en Waterstaat, Ministerie van Financiën, CPB, Rebel groep, 2004. Aanvulling op de Leidraad OEI 'Risicowaardering'.

Ministry of Infrastructure and the Environment., 2012. Kader 'KBA bij MIRTVerkenningen'. Den Haag.

Miser, H.J., Quade, E.S., 1988. Handbook of systems analysis: craft issues and procedural choices. Elsevier Science Publishing Co., Inc.

Mouter, N., Annema, J.A., Van Wee, B., 2012. Maatschappelijke Kosten- en Batenanalyse inhoudelijk geëvalueerd. NICIS: Den Haag.

Mouter, N., Annema, J.A., Van Wee, B., 2013a. Ranking the substantive problems in the Dutch Cost-Benefit Analysis practice. Transportation Research Part A 49, 241-255.

Mouter, N., Annema, J.A., van Wee, B., 2013b. Attitudes towards the role of Cost-Benefit Analysis in the decision-making process for spatial-infrastructure projects: a Dutch case study. Transportation Research Part A 58, 1-14.

Naess, P., 2006. Cost-benefit analysis of transportation investments. Neither critical nor realistic. Journal of critical realism 5 (1), 32-60.

Naess, P., Strand., 2012. What kinds of traffic forecasts are possible? Journal of critical realism 11 (3), 277-295.

Neuburger, H., 1971. User benefits in the evaluation of transport and land-use plans. Journal of Transport Economics and Policy. 5(1), 52-75. 
Nicolaisen, M. S., 2012. Forecasts: Fact or Fiction? Uncertainty and Inaccuracy in Transport Project Evaluation. Department of Develpment and Planning, Aalborg University.

Niemeyer, S., Spash, C.L., 2001. Environmental valuation analysis, public deliberation and their pragmatic syntheses: a critical appraisal, Environment and Planning C: Government and Policy. 19, 567-585.

Nordhaus, W.D., 2007. A review of the Stern review on the economics of climate change. Journal of economic literature. Vol XLV, 686-702.

Odeck, J., 2004. Cost overruns in road construction - what are their sizes and determinants? Transport Policy 11 (1), 43-53.

Oort, N. van, 2011. Service Reliabiity and Urban Public Transport Design. April 2011. TRAIL thesis series, the Netherlands.

Ossokina, I., Eijgenraam, C.C., 2010. Probleemanalyse en daaruit volgende project- en nulalternatieven in MKBA's, CPB-memorandum 234, Den Haag: Centraal Planbureau.

Page, J., 2006. Make it easy to your readers: ideas on environmental impact document focus, organization, and style. Impact Assessment and Project Appraisal, 24(3), 233-245.

Pearce, D., Atkinson, G., Mourato, S., 2006, Cost-Benefit Analysis and the Environment, Paris: Organisation for Economic Co-operation and Development (OECD).

Portney, P.R., Weyant, J.P., (eds) 1999. Discounting and Intergenerational Equity, Washington: Resources for the Future.

Romijn, G., Zondag, B., 2012. Het nulalternatief voor KBA's van grote gebiedsgerichte projecten: een verkenning op basis van de casus Schaalsprong Almere. CPB en PBL report, november 2012.

Romijn, G., Renes, G., 2013a Algemene Leidraad voor maatschappelijke kostenbatenanalyse. Centraal Planbureau en Planbureau voor de Leefomgeving.

Salling, K.B., Banister, D., 2009. Assessment of large transport infrastructure project: the CBA-DK model. Transportation Research Part A 43 (9), 800-813.

Salling, K.B., Leleur, S., 2012. Modelling of transport project uncertainties: feasibility risk assessment and scenario analysis. European journal of transport and infrastructure research. 12 (1), 21-38.

Self, P., 1970. Nonsense on stilts: the futility of Roskill, Political Quarterly, (reprinted in New Society, 2 July 1970).

Spash, C.L., Vatn, A., 2006. Transferring environmental value estimates: Issues and alternatives, Ecological Economics. 60, 379-388.

Stern, N., S. Peters, V. Bakhshi, A. Bowen, C. Cameron, S. Catovsky, D. Crane, S. Cruickshank, S. Dietz, N. Edmonson, S.-L. Garbett, L. Hamid, G. Hoffman, D. Ingram, B. Jones, N. Patmore, H. Radcliffe, R. Sathiyarajah, M. Stock, C. Taylor, T. Vernon, H. Wanjie, and D. Zenghelis (2006), Stern Review: The Economics of Climate Change, HM Treasury, London.

Turner, R.K., 1979. Cost-Benefit analysis - a critique. Omega 7 (5), 411-419.

Vickerman, R.W. (2008), Cost Benefit Analysis and the Wider Economic Benefits from Megaproject, in Flybjerg, B., H. Priemus e B. van Wee (2008), Decision-Making On Mega-Projects: Cost-benefit Analysis, Planning and Innovation, Cheltenham, UK Northampton, MA, Edward Elgar. 
Van Wee, B., 2007. Rail infrastructure: challenges for Cost-Benefit Analysis and other exante evaluation. Transportation, Planning and Technology. 30 (1), 31-47.

Weiss, E, H., 1989. An unreadable EIS is an environmental hazard. The Environmental Professional 11, 236-240.

Welsh, M., Williams, H., 1997. The sensitivity of Transport investments benefits to the evaluation of small travel-time savings. Journal of Transport Economics and Policy.

Williams, A., 1972. CBA: Bastard Science and/or Insidious Poison in the Body Politick? In J.N. Wolfe (ed.) Cost-Benefit and Cost Effectiveness, pp. 30-63. 


\section{Managing the insolvable limitations of Cost- Benefit Analysis: results of an interview based study}

This paper is currently under review as: Mouter, N., Annema, J.A., van Wee, G.P., Managing the insolvable limitations of Cost-Benefit Analysis: results of an interview based study

\subsection{Introduction}

Cost-benefit analysis (CBA) has been an important tool for transport planners for several decades, in particular for evaluating and ranking transport infrastructure investments (e.g. Eliasson and Lundberg, 2012; Grant Muller et al., 2001; Hayashi and Morisugi, 2000; Odgaard et al., 2005). Despite its popularity CBA has often been criticized for several reasons, most of them related to the insolvable limitations when it is applied in practice. For instance, estimations of future project effects are inherently very uncertain (e.g. Flyvbjerg et al., 2003; Flyvbjerg et al., 2005; Naess, 2006; Naess and Strand, 2012; Salling and Banister, 2009). Moreover, there is an extensive body of literature (e.g. Ackerman and Heinzerling, 2004; Atkinson and Mourato, 2008; Boadway, 2006; Kelman, 2002; Martens, 2011; Sen, 2000; van Wee, 2012) that states that the focus of CBA (and the moral view on which the method is based: utilitarianism) on the benefits and the costs that accrue from the project is insufficient as a moral view. Some projects whose costs exceed their benefits may be morally right and, contrarily, some decisions where the benefits are greater than the costs may be morally wrong. For instance, Atkinson and Mourato (2008, p. 328) state that: 'given that equity and justice concerns often dominate discourse about social decisions, it has often struck critics as bordering on the perverse that CBA has chosen to focus its attention so squarely on efficiency'. 
In a previous phase of our research program, we found that a very large majority of key actors in the Dutch appraisal practice for spatial-infrastructure projects participating in our study thinks that - in spite of the insolvable limitations of the method - CBA should be used in the decision-making process for spatial-infrastructure projects (Mouter et al., forthcoming) ${ }^{35} \mathrm{In}$ our research, as well as holding in-depth, face-to-face interviews with 86 key actors, we also asked them to fill out a written questionnaire. 74 key actors responded and 73 made clear that in their view CBA should play a role in the appraisal process for spatial-infrastructure projects.

In this paper we examine and scrutinize the perceptions of key actors in the Dutch appraisal practice for spatial-infrastructure projects (hereafter referred to as "the Dutch practice") with regard to insolvable CBA limitations, the problems these limitations lead to, and solutions to manage these problems in the decision-making process. In the in-depth interviews with the 86 key actors in the Dutch practice we pursued these three topics specifically. In our view, analyzing key actors' perceptions of solutions that aim to manage (the problems that are a consequence of) insolvable CBA limitations is scientifically relevant in itself because, to the best of our knowledge, this focus on the perceptions of actual CBA actors regarding solutions has never been carried out before. The societal contribution of this paper is that the proposed solutions can be used to enhance the management of insolvable CBA limitations in the decision-making process. Finally, the proposed solutions can be used as inspiration for further research.

The remainder of this paper is organized as follows: section 5.2 presents the research methodology. Sections 5.3-5.5 present the results. Finally, section 5.6 provides concluding remarks and reflections.

\subsection{Research methodology}

The research on which this paper is based was carried out as part of a larger research program, which aspires to improve the appraisal of spatial-infrastructure projects using CBA in the Netherlands and simultaneously aims to contribute to the scientific CBA literature. In this research project the intention was to interview the entire population of key actors that had an explicit and recognizable role in the Dutch practice in the last decade. To identify the key actors in the Dutch practice, we used a three-stage method (see, Mouter et al., 2013a for a more detailed elaboration of the three-stage method).

In the first stage, $30 \mathrm{key}$ actors were interviewed (consultants, policy makers, scientists and politicians with an important role in the Dutch practice in the last decade). We asked these 30 respondents which people, in their view, were paramount - besides the people that were already interviewed - to be certain that we interviewed the full Dutch population in this area. Based on these suggestions, in the second stage, 42 additional respondents were interviewed.

\footnotetext{
${ }^{35}$ This paper defines spatial-infrastructure projects as both the classic infrastructure projects such as 'highways' and 'railroads' and spatial projects such as 'integrated land use and transportation projects' and 'flood protection projects'.
} 
In the third stage, the list of the 72 interviewed respondents was presented to four respondents that were often mentioned as key actors in the Dutch practice during the interviews. These respondents were asked to add the names of the people that needed to be interviewed to the list in order to make sure that all of the key actors in the Dutch practice were interviewed. In this third stage, 14 additional respondents were interviewed.

Thus, in total, we managed to interview 86 key actors in the Dutch practice (see Appendix 5.1 for a list of the respondents). Fifteen other people were also approached for an interview but they were not able to, or were not interested in participating in the research. Thus, we did not manage to interview the entire population as intended and the 86 respondents must be considered as a selection of the entire population of key actors. Moreover, we think that it is possible that although we consider the three-stage method as a comprehensive way to identify the key actors in the Dutch appraisal practice for spatial-infrastructure projects it is possible that we missed a few key actors. In the interviews, amongst other things, we asked the respondents to mention the most important advantages, disadvantages, problems and limitations they experience with the CBA methodology and when using CBA in the decisionmaking process. Moreover, we asked them to mention the solutions they perceive for minimizing or managing the limitations and problems they identified.

We used content analysis to analyze the interviews. Content analysis is defined as a systematic, replicable technique for compressing many words of text into fewer content categories based on explicit rules of coding and categorizing (Weber, 1990). We coded the respondents' quotes as a perception of an insolvable CBA limitation when the respondent stated that he/she perceives the limitation as insolvable. ${ }^{36}$ We also coded the respondents' perceptions of problems that are the result of the insolvable CBA limitations and their perceptions of solutions to manage these problems. The content analysis resulted in 79 perceptions of insolvable CBA limitations, 95 perceptions of related problems and 159 perceptions of solutions to manage the problems that are a result of CBA limitations.

We use the Netherlands as a case study because we are Dutch researchers and we know the Dutch community and procedures better than those of other countries. We think that the Dutch practice can give useful international insights for other CBA practices because of the extensive use of CBA in the Netherlands over the last 13 years. Mackie and Worsley (2013) state that, along with the UK and Scandinavia, the Netherlands has been a leading country in the international CBA practice for four reasons: 1) it has a strong tradition of doing transport project appraisal; 2) it has guidance manuals which constitute a clearly defined framework for appraisal which is to be followed throughout the project cycle; 3) it has a framework populated with measures and values of the impacts, which are based on evidence generated from research studies 4) the Netherlands has a policy whereby the intention is that the results of appraisal work should have a significant influence on the case for investment and on

\footnotetext{
${ }^{36}$ Besides insolvable CBA limitations, respondents addressed the fact that a limitation of the CBA is that it does not take other elements in the decision-making process into account, other than project effects and efficiency, such as public support and political support issues. We did not consider these issues in this study because we think they are not related to ex-ante evaluation of project effects but to the decision-making process in general.
} 
prioritization within programs. Since 2000, around 110 CBAs for candidate transport policies became publicly available on a very broad range of topics (such as new roads, new railroads, tunnels, sea port extensions, airport extensions, pricing policies, speed policies, and so forth). Moreover, the projects are both on a national as well as a regional level (so, CBAs are made for projects ranging from large, national, multi-billion euro projects to relatively small, multimillion, local projects). Important effects considered in the Netherlands practice are: direct transport benefits (such as travel time savings and reliability effects), wider economic impacts, and all kinds of external impacts such as environmental and safety impacts (see Mackie and Worsley, 2013 for a more in-depth discussion of effects that are considered in Dutch CBAs). The official Dutch CBA Guideline (OEI-Manual, Eijgenraam et al., 2000) states that CBA practitioners should aim to monetize effects as much as possible. In addition, the guideline states that specific effects (such as effects on unique landscapes) cannot be monetized in an objective way and should be expressed in the CBA report in a quantitative or qualitative way.

In this paper we discuss the 132 perceptions of solutions for managing insolvable CBA limitations which we consider to be internationally relevant. In a Dutch language report (Mouter et al., 2012) we elaborate on all of the solutions mentioned in the interviews by key actors. In the next sections we do not present the number of respondents that mentioned a particular solution because one of our main aims is to generate interesting solutions for managing insolvable CBA limitations. In our view 'interesting' does not depend on the number of times a solution is given. Just one person can have the 'brilliant' solution. Nevertheless, to get an impression of the number of respondents that mentioned a solution we provide an overview of these frequencies in Appendix 5.2.

\subsection{Results: insolvable CBA limitations}

Our results show that key actors perceive three main insolvable CBA limitations (figure 5-1): incompleteness, uncertainty and the relatively weak position of effects that are difficult to estimate. This section discusses how these three categories can be decomposed (based on the content analysis of the interviews) and describes how the respondents specifically define these limitations. We also give briefly the views on these specifically defined limitations found in international literature (if available). 


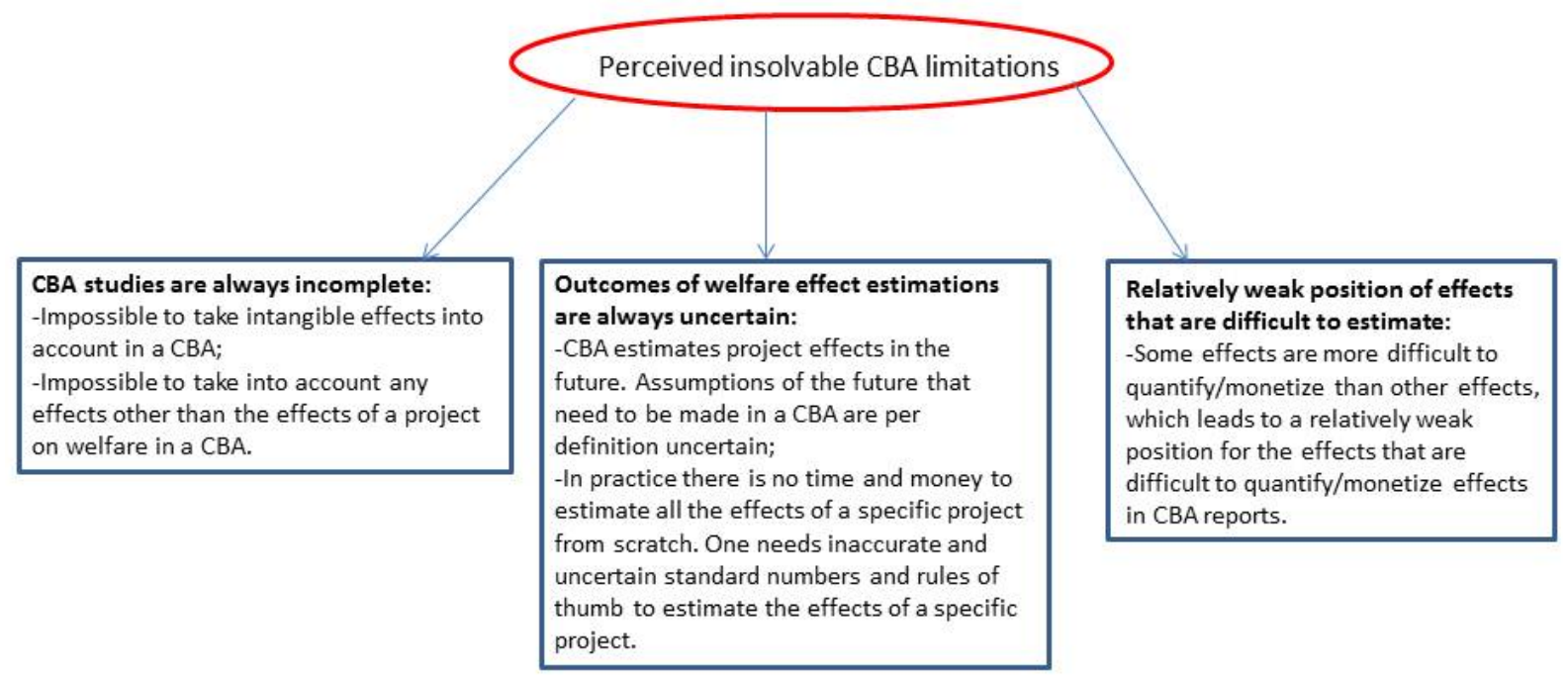

Figure 5-1: insolvable CBA limitations perceived by respondents

\subsubsection{CBA studies are always incomplete}

One insolvable CBA limitation that respondents mention is that CBAs are always incomplete, because in their view it is inevitable that relevant welfare effects are overlooked in CBA studies or that it is not possible to include some welfare effects in a CBA (sometimes even not in a qualitative way) because it is not possible to estimate these welfare effects with sufficient reliability. The respondents label these types of effects as intangible effects (figure 5-1). Respondents define intangible effects as (a) effects for which it is unknown whether the effect will accrue at all; (b) effects for which it is difficult to determine the causality between the project and a claimed effect, and/or; (c) effects for which it is difficult to determine the extent to which the effect is additional or non-additional to the national welfare. Most respondents labeled an effect as 'intangible' when it complies with only one of the three conditions. An example of an effect that complies with the three conditions is the often claimed effect of an 'enhanced business climate' as a result of a spatial-infrastructure project. Other intangible effects mentioned by respondents are: effects on the image of the country, positive knowledge spillovers, effects on 'regional identity', agglomeration effects, positive effects of innovative projects and effects on the quality of life.

Respondents' perceptions are confirmed in scientific literature. For instance, Ambrasaite et al., (2011), Odgaard et al., (2005) and Mackie (2010) conclude that the ideal of CBA studies to take into account all the welfare effects in the study is unrealistic because it is not possible to estimate some welfare effects in a sufficiently reliable way. Börjesson et al., (2013, p.3) state that: 'it is uncontroversial that investment CBAs do not capture all possible relevant effects or considerations. For example, some costs and benefits cannot be accurately valued or measured.' 
Another incompleteness issue mentioned by respondents is that CBA studies exclude project effects that have no effect on the welfare of a country ${ }^{37}$ but should still be evaluated in the exante evaluation process, in their opinion (figure 5-1). Respondents discuss three examples of such effects. Firstly, in CBA, poor people count less than rich people because poor people's willingness to pay is, generally, relatively low. Secondly, they perceive that the CBA is incomplete as a result of the anthropocentric perspective of the method. The CBA determines negative effects of biodiversity by the value humans assign to the loss of biodiversity as a result of a project. Biodiversity in itself has no value in the CBA. One respondent states that the CBA is not sustained on the principle that one needs to give something back to the planet when one takes something from it and perceives it as a limitation of the CBA that the method does not consider this approach at all. Thirdly, respondents perceive that the perspective of CBAs applied in practice is incomplete because CBAs predominantly tend to scrutinize the costs and the benefits of a project for a specific country. These respondents perceive that it is incorrect when CBAs in the Dutch practice only include welfare effects for the Netherlands and therefore communicate a positive message when the project results in a net positive welfare effect for the Netherlands although the project has very negative effects for other countries.

In conclusion, Dutch CBAs evaluate the effects of a project on the welfare of the country; however the evaluation of specific types of distribution of welfare (between rich versus poor people, humans versus nature and Dutch residents versus non-Dutch residents) is often neglected both in Dutch CBA studies and the wider ex-ante evaluation process of spatialinfrastructure projects.

Martens (2011), Rietveld et al. (2007), Thomopoulos et al. (2009) and van Wee (2012), amongst others, also discuss that the distributional effects of a project tend to be underexposed in CBA studies.

\subsubsection{Outcomes of welfare effect estimations are always uncertain}

Respondents also mention - as an insolvable limitation of the CBA - that estimations of welfare effects of a project in a CBA are very uncertain (figure 5-1, middle box). The first main reason mentioned is that consultants who carry out ex-ante CBAs need to make assumptions for the unknown future when they want to estimate effects. Secondly, in practice, consultants do not have the time and money to estimate all the effects of a specific project from scratch, and as a result they have to use shortcuts, national standard numbers and rules of thumb to estimate the effects of a specific project, which leads to uncertainty.

The inherent uncertainty of ex-ante effect estimations in CBA studies is also abundantly addressed in scientific literature (e.g. Beattie, 1995; Flyvbjerg et al., 2003; Nicolaisen, 2012; Self, 1970).

\footnotetext{
${ }^{37}$ The OEI-Leidraad (official Dutch CBA Guideline) defines welfare effects of a project as: 'all financial and non-financial effects of a project for Dutch residents'. Project effects on safety and the environment are used in the guideline as illustrations of non-financial welfare effects.
} 


\subsubsection{Effects that are difficult to quantify/monetize have a relatively weak position}

Some respondents state that an insolvable limitation of CBA is that effects that are difficult to quantify/monetize - such as effects on biodiversity - per definition, have a relatively weak position in CBA reports ${ }^{38}$ (figure 5-1, right) compared to impacts that are easy to quantify/monetize, such as construction costs and transport benefits. Because project effects on biodiversity are difficult to quantify/monetize, consultants that carry out CBAs frequently decide to include them in a non-monetized way, which gives these welfare effects - according to some respondents - a relatively weak position in the CBA report compared to monetized effects. Respondents state that this relatively weak position cannot be rectified by monetizing the effects, for two reasons. Firstly, they state that monetization leads to the risk that - as a result of quantification and monetization problems - only a part of the effects on biodiversity are monetized and taken into account in the CBA report, whilst the reader thinks that the total effect is included. Secondly, some respondents oppose the monetization of effects, like effects on biodiversity and traffic casualties, because they think it is incorrect to transfer these types of effects into the same unit as effects like travel time savings and construction costs. ${ }^{39}$

Existing literature (e.g. Mackie and Preston, 1998; Mishan, 1988) also mentions this limitation. Mishan (1988) addresses this insolvable limitation as follows: 'if you take one horse and one rabbit, no matter how you combine them the taste of horse dominates the stew. Similarly, if you take one set of quantifiable impacts and one set of non-quantifiable impacts in an appraisal, one set will dominate'.

\subsection{Results: when and why do respondents perceive that insolvable CBA limitations are problematic?}

In the interviews, respondents frequently mentioned that the fact that $\mathrm{CBA}$ is a tool with insolvable limitations is not problematic in itself. According to the respondents, problems only arise when insolvable limitations are not managed properly. Respondents perceive that, as a result of bad management, actors might use or position the CBA as an instrument with too many or too few limitations and attribute an incorrect value to the CBA (either too much or too little value). Below, we will discuss this respondents' position in more depth and, again, we also give views taken from existing literature on the positions discussed.

\subsubsection{Why are insolvable limitations problematic?}

Figure 5-2 displays the lines of reasoning used by the respondents to explain why they think that the insolvable CBA limitations can be problematic in this respect. The respondents' arguments frequently had different steps to them. The different steps are depicted by the arrows and characters in figure 5-2.

\footnotetext{
${ }^{38}$ There is no clear consensus in the Dutch practice that this is an insolvable CBA limitation. Some respondents perceive that this is an insolvable limitation; others perceive that it is currently - or will in the near future be possible to quantify and monetize all effects that are included in a CBA study equally well. For example, with a more frequent use of insights obtained from experimental economics and behavioral economics.

${ }^{39}$ This position of respondents is more extensively discussed in section 5.5.
} 


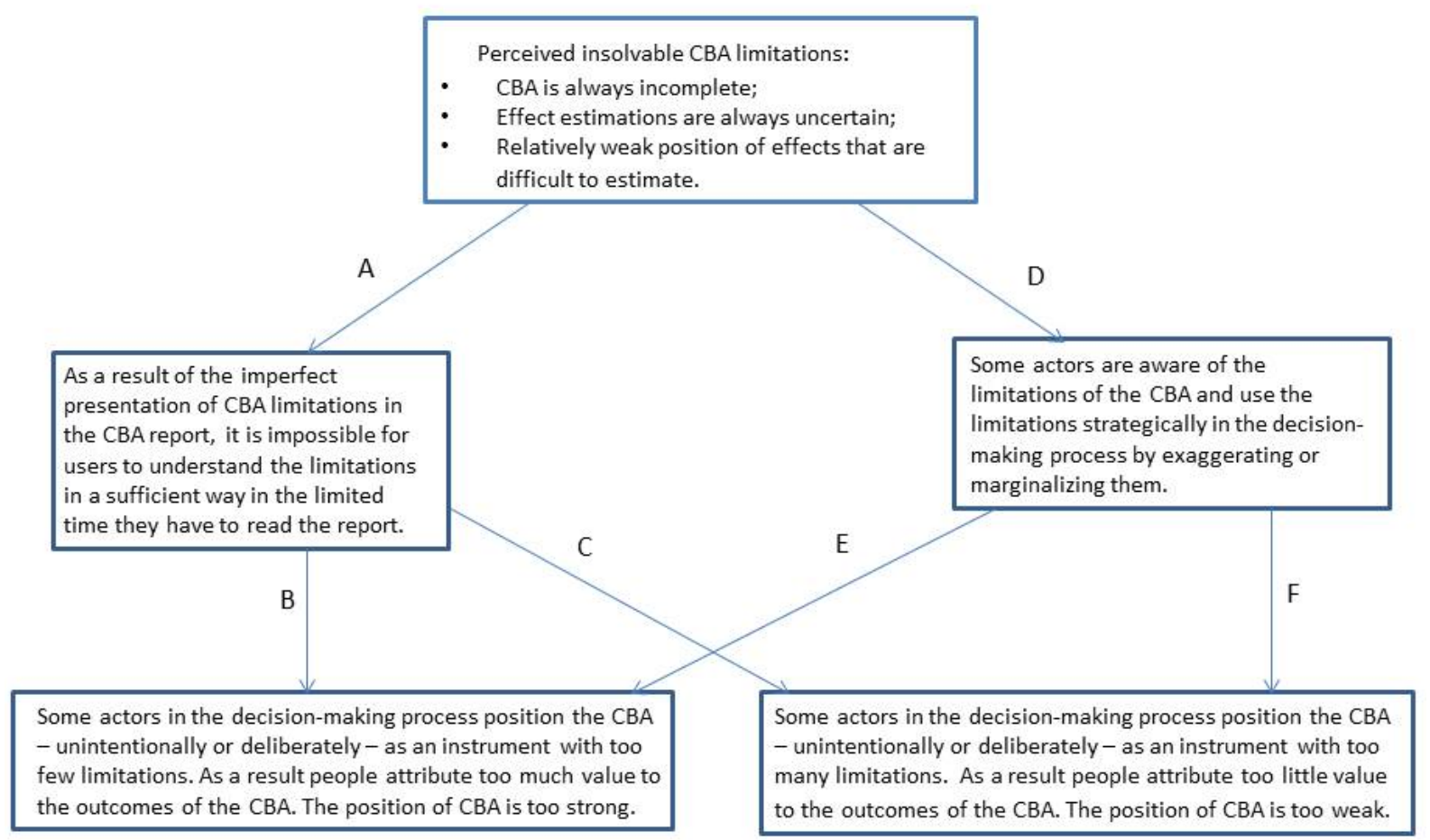

Figure 5-2: problems resulting from the perceived insolvable limitations according to respondents

More detail will now be given about the two most important observations that can be derived from figure 5-2.

\section{Imperfect presentation of CBA limitations leads to assigning incorrect value to CBA}

The first observation is that respondents perceive that - as a result of imperfect presentation of CBA limitations in the CBA report - readers find it very difficult to understand the limitations of the CBA sufficiently. One respondent states: 'how is it possible for a politician to know that assumptions are very contestable when the CBA report does not communicate this explicitly in the executive summary of the report?' Respondents observe that the chance that users understand the CBA limitations in an insufficient way as a result of an imperfect communication of CBA limitations in the CBA report is especially high when users have limited time to read the report. Here, respondents emphasize that especially politicians - who are important users of CBA studies - have limited time to read a CBA report and frequently only read the summary of a CBA report, whilst summaries especially tend to neglect the communication of limitations.

Figure 5-2 shows that respondents perceive that, as a result of the imperfect presentation of CBA limitations, some actors might assign too much value to the CBA (A-B in figure 5-2), but others might assign too little value (A-C in figure 5-2). They state that some actors in the Dutch practice (unintentionally) assign too much value to the CBA because they are not aware of CBA limitations and, as a result, use it as a holy grail ("we decide positively only if the benefit-cost ratio is above 1"). On the other hand respondents state that a lack of communication of CBA limitations enhances suspicion by skeptical actors, which leads to a 
situation where these actors assign too little value to the CBA ("I don't trust instruments that produce false certainties and are not honest about the limitations of the results").

The fact that CBA reports tend to communicate limitations of the study insufficiently is endorsed in the literature. According to Welsh and Williams (1997), CBA outcomes are usually presented as if they are endowed with considerable accuracy, even though estimations of traffic models, for instance, are very uncertain. Naess and Strand (2012) state that the high degrees of uncertainty are often not displayed in Cost-Benefit Analyses. From an analysis of decision support documents for 78 Norwegian and Danish road projects, Nicolaisen (2012, p. 7) finds that: "uncertainties are often toned down or ignored in the decision support prepared for policy makers. This neglect makes impact appraisals appear more accurate than warranted, which causes distrust towards the results among policy makers". Out of an evaluation of the Dutch practice in 2002 (BCI, 2002) it could be seen that, although effect estimations in CBA studies are very uncertain, CBA reports present the outcomes of CBA studies as exact truths.

\section{Strategic use of CBA limitations leads to assigning incorrect value to CBA}

The second main observation related to figure 5-2 is that respondents perceive that CBA limitations are also used in a strategic way by actors in the Dutch practice. To illustrate this, a respondent states that: "if the outcome of the CBA does not support the political interest of an actor, the actor emphasizes the limitations of the method, and when the outcome of the CBA supports the political interest of an actor, the actor ignores its limitations." Hence, respondents perceive that as a result of strategic use of CBA limitations, some actors might assign too much value to the CBA by neglecting the limitations (D-E in figure 5-2), but others assign too little value to the CBA by overemphasizing the limitations (D-F in figure 5-2).

In addition to the respondents' perceptions, de Jong and Geerlings (2003) discuss that strategic behavior is interrelated. They conclude that when people assign absolute value to the CBA in a discussion, other people in that discussion - who are more skeptical about CBA will be prone to marginalize the value of CBA as a reaction.

\subsubsection{Why is assigning an incorrect value problematic?}

In section 5.4.1 we discussed the different causes respondents perceive for assigning an incorrect value to the CBA in the decision-making process. Now, we discuss why respondents perceive attributing an incorrect value (too much or too little, figure 5-2) to CBA as being problematic? They mention several reasons. Firstly, they state that the quality of discussions among key actors in decision-making processes on the usefulness, necessity and design of a new spatial-infrastructure project could deteriorate. Respondents state that the contemplation, discussion and decision-making on the usefulness, necessity and design of a spatialinfrastructure project are not enhanced when frustrations about the perceived incorrect use of CBA dominate the debate. Secondly, they perceive it as undesirable when (other) key actors attribute marginal value to the $\mathrm{CBA}$ in the decision-making process for spatial-infrastructure 
projects because attributing a marginal value to CBA will lead to a marginal utilization of the advantages of the use of CBA in the decision-making process. ${ }^{40}$

A third and final reason mentioned is that using the CBA as a 'holy grail' (too much value, i.e. when the CBA outcome is positive, a project should be developed; when the CBA outcome is negative, a project should not be developed) leads to four different problems. A first problem related to using CBA as a 'holy grail' perceived by respondents is that effects which are not - or are not taken well - into account in a CBA, are erroneously neglected or have a relatively weak position in the decision-making process ("if you assign absolute value to the CBA in the decision-making process, you neglect other effects that are important in the decision-making process and then your ally becomes your enemy"). Secondly, respondents state that experts know that there is hardly any difference between a benefit-cost ratio of 1.1 and a benefit-cost ratio of 0.9. However, in practice, respondents find that the former project is marked as a fantastic project and the latter project is considered as a bad project, which they perceive as problematic. Thirdly, they state that using CBA as a 'holy grail' catalyzes manipulation in regard to effect estimations in CBA studies ("carrying out a CBA is useless when the initiator of a project only receives financial resources when the CBA score is positive, so the initiator of the project adjusts the effect estimations until the CBA score is positive"). Fourthly, attributing absolute value to the CBA is seen as problematic because respondents perceive that assigning absolute value to a tool with major limitations will eventually lead to the collapse of the instrument in the long run (one respondent denotes this as 'overshoot and collapse').

This final statement from the respondents is endorsed in the literature. According to De Jong and Geerlings (2003), the use of the CBA in an absolute way will lead to the resistance of other actors, which can become so strong that at a certain point CBA will lose the necessary political support.

\subsection{Results: respondents' perceptions of how to manage insolvable CBA limitations}

Respondents perceive that the fact that $\mathrm{CBA}$ is a tool with insolvable limitations is not problematic in itself. According to the respondents, problems only arise when actors use or position the CBA as an instrument with too many or too few limitations as a result of bad management of these insolvable issues. This section describes the solutions proposed by the respondents for managing the perceived problems that result from the insolvable CBA limitations.

Table 5-1 gives an overview of these solutions and shows that some proposed solutions aspire to minimize insolvable CBA limitations, whereas other solutions aspire to manage the insolvable CBA limitations and stimulate a 'correct' use or 'subtle' use of the CBA in the

\footnotetext{
${ }^{40}$ Perceived advantages of key actors in the Dutch practice are discussed in Mouter et al. (2013, forthcoming).
} 
decision-making process. ${ }^{41}$ Table 5-1 also shows that for some proposed solutions there is controversy among respondents with regard to the 'best solution' and for others no contradicting remarks were found in the interviews. ${ }^{42}$

Table 5-1: Proposed solutions for managing problems that result from the insolvable CBA limitations

\begin{tabular}{|c|c|c|c|}
\hline $\begin{array}{l}\text { Proposed solution to manage incorrect use } \\
\text { of CBA }\end{array}$ & $\begin{array}{l}\text { Which limitation does the } \\
\text { solution aspire to } \\
\text { minimize or manage? }\end{array}$ & $\begin{array}{l}\text { Does the solution } \\
\text { aspire to minimize } \\
\text { or manage the } \\
\text { CBA limitation? }\end{array}$ & $\begin{array}{l}\text { Is there } \\
\text { controversy on the } \\
\text { 'best solution' } \\
\text { among } \\
\text { respondents? }\end{array}$ \\
\hline 1. Organize effect survey meetings & Incompleteness & Minimize & $\begin{array}{l}\text { No contradictory } \\
\text { remarks }\end{array}$ \\
\hline $\begin{array}{l}\text { 2. Provide high quality qualitative information } \\
\text { with regard to intangible effects }\end{array}$ & Incompleteness & Minimize & $\begin{array}{l}\text { No contradictory } \\
\text { remarks }\end{array}$ \\
\hline $\begin{array}{l}\text { 3. CBA reports should be supplemented with } \\
\text { an analysis of distributional effects }\end{array}$ & Incompleteness & Minimize & $\begin{array}{l}\text { No contradictory } \\
\text { remarks }\end{array}$ \\
\hline 4. Carry out ex-post analyses & Uncertainty & Minimize & $\begin{array}{l}\text { No contradictory } \\
\text { remarks }\end{array}$ \\
\hline 5. Monetize as much as possible & $\begin{array}{l}\text { Relatively weak position of } \\
\text { effects that are difficult to } \\
\text { monetize }\end{array}$ & Minimize & Controversy \\
\hline $\begin{array}{l}\text { 6. Use indicators other than money to express } \\
\text { effects that are difficult to monetize }\end{array}$ & $\begin{array}{l}\text { Relatively weak position of } \\
\text { effects that are difficult to } \\
\text { monetize }\end{array}$ & Minimize & Controversy \\
\hline $\begin{array}{l}\text { 7. Monetize effects in CBA studies whenever } \\
\text { possible. However, when monetizing leads to } \\
\text { severe criticism and frustrations one should not } \\
\text { monetize }\end{array}$ & $\begin{array}{l}\text { Relatively weak position of } \\
\text { effects that are difficult to } \\
\text { monetize }\end{array}$ & Minimize & Controversy \\
\hline $\begin{array}{l}\text { 8. Referent assesses the position of effects that } \\
\text { are difficult to monetize in the CBA report }\end{array}$ & $\begin{array}{l}\text { Relatively weak position of } \\
\text { effects that are difficult to } \\
\text { monetize }\end{array}$ & Minimize & $\begin{array}{l}\text { No contradictory } \\
\text { remarks }\end{array}$ \\
\hline $\begin{array}{l}\text { 9. Explicitly discuss the way monetized and } \\
\text { non-monetized effects relate to each other in } \\
\text { the summary of the CBA report }\end{array}$ & $\begin{array}{l}\text { Relatively weak position of } \\
\text { effects that are difficult to } \\
\text { monetize }\end{array}$ & Minimize & $\begin{array}{l}\text { No contradictory } \\
\text { remarks }\end{array}$ \\
\hline $\begin{array}{l}\text { 10. Implement a 'showstopper' procedure in } \\
\text { the CBA analysis for effects that difficult to } \\
\text { monetize and that are irreversible }\end{array}$ & $\begin{array}{l}\text { Relatively weak position of } \\
\text { effects that are difficult to } \\
\text { monetize }\end{array}$ & Minimize & $\begin{array}{l}\text { No contradictory } \\
\text { remarks }\end{array}$ \\
\hline $\begin{array}{l}\text { 11. Enhance communication about the } \\
\text { incompleteness in CBA reports }\end{array}$ & Incompleteness & Manage & $\begin{array}{l}\text { No contradictory } \\
\text { remarks }\end{array}$ \\
\hline $\begin{array}{l}\text { 12. Enhance communication about the } \\
\text { uncertainty in CBA reports }\end{array}$ & Uncertainty & Manage & Controversy \\
\hline $\begin{array}{l}\text { 13. Estimate the project effects for at least one } \\
\text { flexible investment strategy in a CBA study }\end{array}$ & Uncertainty & Manage & $\begin{array}{l}\text { Contradictory } \\
\text { remarks }\end{array}$ \\
\hline $\begin{array}{l}\text { 14. Communicate the fact that readers should } \\
\text { also take into account the effects that are } \\
\text { difficult to monetize }\end{array}$ & $\begin{array}{l}\text { Relatively weak position of } \\
\text { effects that are difficult to } \\
\text { monetize }\end{array}$ & Manage & $\begin{array}{l}\text { No contradictory } \\
\text { remarks }\end{array}$ \\
\hline
\end{tabular}

${ }^{41}$ Mouter et al. (2012) denote the 'subtle' use of the CBA, based on Aristotle's Ethica Nicomachea: 'virtuous use of the $\mathrm{CBA}$ in the decision-making process for spatial-infrastructure projects'. Aristotle defines acting 'virtuously' as acting at the balance point between two non-virtuous extremes. Like acting 'bravely' is the balance point between acting 'cowardly' and acting 'recklessly', attributing a 'virtuous' value to CBA in a decision-making process is the balance point between assigning absolute value to the CBA and marginalizing the value of CBA.

${ }^{42} \mathrm{We}$ cannot say that there is consensus because we have not confronted all actors with all solutions. 
Below, we first discuss the proposed solutions that aspire to minimize perceived insolvable limitations. According to the respondents, minimizing the insolvable CBA limitations could possibly downsize the problems that result from CBA limitations. Next, we discuss the proposed solutions that aspire to manage the problems that result from the insolvable CBA limitations.

$\underline{\text { 'Actor participation' as a solution - to take more welfare effects into account (solution } 1 \text { in }}$ table 5-1)

One solution that respondents propose is to organize 'effect survey meetings' (Effect Arenas) preceding a CBA study to take into account as many welfare effects as possible in the CBA study and, as a result, minimize the limitation that CBA studies are always incomplete. They state that all relevant actors affected by the project should be invited to this meeting. The purpose of this meeting is that all actors should get the opportunity to articulate which effects they think will accrue as a result of the project. To be clear, only effects that increase national welfare are included in the CBA (the idea of the Effect Arena is that the CBA analysts can clarify to other actors why the non-welfare effects will not be included in the CBA report). Respondents perceive that, as a consequence of such a meeting, effects that would be overlooked without an Effect Arena will now be included in the CBA study. One respondent states that he experienced in practice that the efficiency of these 'effect survey meetings' could be optimized when the people responsible for the organization of the meeting communicate to the invited actors, in advance of the meeting, that this meeting will be the only opportunity to articulate the project effects that will be scrutinized in the CBA study. Moreover, respondents state that an additional benefit of 'effect survey meetings' with actors might be that public support for the use of CBA to appraise spatial-infrastructure projects will increase.

Try to provide high quality qualitative information with regard to intangible effects (solution 2 in table 5-1)

Respondents state that CBA analysts should not decide too quickly that it is not possible to take intangible welfare effects into account in a CBA study because it is not possible to estimate the welfare effect with sufficient reliability. They propose that analysts should strive to provide high quality objective information with regard to these effects. For example, one respondent states that if decision makers believe that a new bridge will contribute to a positive image of their region (such as the Erasmus bridge in Rotterdam), then the CBA should provide qualitative information regarding 'the effect of architectonically innovative bridges on the image of the region'. This could be carried out by addressing what the success and failure factors of architectonical innovative bridges on the image of the region are and what the potential benefits of a successfully 'image enhancing bridge' are. According to the respondent, the specific CBA should discuss the extent to which the identified success and failure factors are entailed in the specific bridge under scrutiny in the CBA study.

Supplement CBA reports with an analysis of distributional effects (solution 3 in table 5-1)

Dutch CBAs evaluate the effects of a project on the welfare of the country. However, information regarding the distribution of welfare is often underexposed or even neglected. Respondents propose minimizing the underexposure of distributional effects by including a 
discussion on the relevant distributional effects in the CBA report. According to these respondents, CBA studies do not have to exclude a discussion of distributional effects. The respondents state that $\mathrm{CBA}$ analysts should display separate 'balance sheets' for relevant stakeholder groups besides the national CBA results (for instance, a separate CBA for relevant regions, interest groups, income classes). The respondents emphasize that including a 'distributional analysis' in the CBA report ensures that the CBA study can be used by politicians because politicians are interested in the distributional effects as well as the effects of a project on national welfare. One respondent states that Dutch CBA guidelines should prescribe supplementary distributional analyses in a more compelling way.

Carry out 'ex-post' analyses to diminish uncertainty with regard to effect estimations (solution 4 in table 5-1)

As a strategy to diminish uncertainty with regard to effect estimations, respondents propose establishing an obligation within Dutch planning guidelines to carry out ex-post analyses to verify the ex-ante estimations of project effects in the CBA. Respondents think that 'ex-post analyses' could help by improving models, rules of thumb and standard national numbers that are used to estimate project effects for specific CBA studies, which could help to reduce uncertainty by improving models.

This is confirmed in the literature (e.g. Salling and Banister, 2009; Nicolaisen, 2012). Moreover, one respondent states that an additional benefit of institutionalizing ex-post analysis might be that the trust in government decision making would be enhanced because the government shows that it really does check the quality of the information it uses in decision-making processes.

Controversy about the 'best strategy' for taking into account effects that are difficult to monetize in a CBA study (solutions 5, 6, 7, 8, 9 and 10 in table 5-1)

Respondents concede that effects that are difficult to monetize should be discussed in the CBA analysis. However, they disagree to a great extent when answering the question about how to minimize the relatively weak position of effects that are difficult to monetize in a CBA study. Respondents mentioned six different solutions. The first three solutions (5, 6 and 7) focus on the question about whether or not monetization of effects that are difficult to monetize helps to minimize the relatively weak position of these effects in CBA studies. The last three solutions discuss other solutions (7, 8 and 9). Below, we firstly discuss solutions 5, 6 and 7. In a broad sense, two of these three solutions can be labeled as extreme positions: 'monetize as much as possible' (solution 5) and 'use other indicators than money to express effects that are difficult to monetize' (solution 6), and the other one is a middle position (solution 7). Next we discuss the three positions in more depth.

The first group of respondents emphasizes that it is important to monetize effects as much as possible, for two reasons. Firstly, they perceive that monetizing an effect in a CBA study is the only way to guarantee a serious position for the effect in the decision-making process because they perceive that there is a very high risk that decision makers will, in the end, only look at the monetary figures that are presented in the CBA report. Secondly, they state that an 
important benefit of the CBA is that studies provide insight into the order of magnitude of different welfare effects and the ratio of costs versus benefits of a project and that this benefit can only be utilized in an optimal way when one tries to monetize as many effects as possible. These respondents argue that new research could improve valuation methods and standard numbers that can be used to monetize effects in CBA studies. This group of respondents believes that it will eventually be possible to monetize all welfare effects equally well - for instance with a more frequent use of experimental economics and behavioral economics which implies a rectification of the limitation that some effects are more difficult to monetize than others.

The second group of respondents states that some effects (e.g. the effects on traffic casualties and the effects on biodiversity) should not be transferred into monetary terms because they are incommensurable, which implies that the nature of the effects resists transferring them into a common unit with other effects, such as travel time savings. According to the respondents, transferring incommensurable effects into a common unit in the CBA report erroneously communicates to decision makers that it is feasible to outweigh negative effects on biodiversity, for instance, and positive effects on travel time savings, for instance. The respondents accept that, as a result of taking into account the effects on biodiversity in nonmonetary terms in CBA studies, these effects can have a relatively weak position in the decision-making process. As an alternative for monetization, this group of respondents proposes using a "nature value indicator" ${ }^{43}$, which measures the effects of a project on biodiversity in weighted hectares. The weight is determined by the ecological quality of the area and the degree of threat of the ecosystem(s). The indicator proposed is called T-EQA, an acronym of Threat-weighted Ecological Quality Area. This T-EQA (Sijtsma et al., 2011; Sijtsma et al. 2013a) aims to measure the effect of a project on biodiversity from an ecological perspective (what is the effect of a project on the biodiversity in the Netherlands?) using a standardized ratio scale measurement. The 'nature value indicator' aims to measure project effects on biodiversity as objectively and rigorously as possible and aggregates this evaluative information in one indicator (T-EQA). Its relation to welfare economics is subtle. Instead of being from the perspective of welfare economics (what is the effect of a project on the welfare of Dutch citizens?) it uses a 'mere' ecological perspective. On the other hand it can be argued that biodiversity preferences concern citizens' (non-consumer) preferences (Sijtsma, 2006). Or, in Maslow terms, they concern the higher order needs (Sijtsma et al., 2013a). T-EQA then measures the size of something relevant to well-being or welfare, without giving an a priori weight or fixed monetary value per unit (Sijtsma et al., 2013a).

A third group of respondents can be positioned in the middle of the two groups of respondents described above. This group perceives that initiators of CBAs and CBA analysts should base their decision about monetizing or not monetizing effects in CBA studies on pragmatic reasons. More specifically, the respondents state that one should monetize effects in CBA studies when possible. However, when initiators and consultants feel that monetizing effects will give rise to severe criticism by important actors in the decision-making process, and

\footnotetext{
${ }^{43}$ Natuurpunten (in Dutch).
} 
when this will lead to a situation in which frustrations regarding monetization of the effect will dominate the debate, one should not monetize the effect.

Next, we discuss the three other solutions (8, 9 and 10 in table 5-1) The first solution proposed by respondents suggests that a more equal position for effects that are difficult to monetize can be safeguarded when an independent referent assesses in a draft version of the CBA report whether the position of effects that are difficult to monetize in the report is strong enough. ${ }^{44}$ The second solution entails that the position of effects that are difficult to monetize in the decision-making process can be improved when CBA practitioners explicitly discuss the way monetized and non-monetized effects relate to each other in the summary of the CBA report. The respondent illustrates his suggestion as follows: 'CBA practitioners should, for instance, divide the net present value (NPV) of all monetized effects by the number of hectares of nature that are sacrificed as a result of the project. Hence, one can provide the decision maker with the 'value of a sacrificed hectare', for instance, 50,000 euros NPV per hectare. This enhances the attention for non-monetized effects.' This solution suggests implementing a 'showstopper' procedure in the decision-making process for spatial-infrastructure projects for effects that are difficult to monetize and that are irreversible (for instance, the effects of the project on endangered species). According to the respondents, the CBA report should explicitly address whether the non-monetized effect exceeds an 'environmental constraint'. When this environmental constraint ${ }^{45}$ is exceeded, the project cannot be developed in spite of a positive welfare effect. This solution is implemented in the German appraisal practice for infrastructure projects (Mackie and Worsley, 2013).

\section{Enhance communication of incompleteness in the CBA report (solution 11 in table 5-1)}

Respondents propose enhanced communication about the incompleteness of CBA studies in the CBA report as a solution to manage the inherent incompleteness of CBA reports. They emphasize the benefits of prominent communication about incompleteness in the summary of the CBA report. Respondents perceive that, as a result of articulating incompleteness in a prominent way in the CBA report, actors in the Dutch practice are less prone to attribute absolute value to the $\mathrm{CBA}$ in the decision-making process. Moreover, respondents perceive that the explicit communication of the elements and effects that are not considered in the CBA study will diminish the tendency of some actors to marginalize the value of CBA in the decision-making process because they feel that the CBA is honest about its limitations.

Enhance communication about the uncertainty of effect estimations in the CBA report (solution 12 in table 5-1)

Respondents propose a variety of methods to communicate uncertainty in CBA reports (e.g. presenting bandwidths instead of point estimates, carrying out more sensitivity analyses, using more future scenarios, articulate uncertainties in an explicit and prominent way in the summary of the CBA report, for instance by discussing the assumptions that need to be made

\footnotetext{
${ }^{44}$ The respondent did not discuss this solution in more depth during the interview.

${ }^{45}$ The respondent did not discuss precisely which constraints he had in mind.
} 
to change the sign of the outcome of the $\mathrm{CBA}^{46}$ ). One respondent takes it a step further and states that the most effective way of communicating uncertainty is by carrying out a large amount of sensitivity analyses on the most important assumptions in the CBA study and, subsequently, presenting the outcomes of these sensitivity analyses in a scatter plot. Moreover, respondents state that CBA analysts should - as a result of the severe uncertainties - restrict themselves to present the effect estimations and never make suggestions in regard to the possible consequences of the results for the decision-making process. One respondent states that the passage: 'the outcome of the CBA score is negative, thus the development of the project will have a negative effect on the welfare of the Netherlands' is already a bridge too far, given the uncertainties.

Mouter et al. (2013, forthcoming) conclude that another group of Dutch key actors suggests that one must be cautious about communicating CBA limitations in a way that is too prominent. Some even perceive that a too prominent communication of uncertainties will lead to 'the collapse' of the instrument in the decision-making process. Below, we discuss two risks that they perceive that are related to a too prominent communication of uncertainties. Firstly, respondents state that politicians prefer certain, plain and easy to comprehend information over uncertain and nuanced information. One respondent states that: 'politicians desire a study that reports only one figure in the conclusion, which communicates whether or not the study supports the project'. Another respondent perceives that politicians' preference for certain information over uncertain information could be explained by a specific inclination that politicians have of making some decisions during their term of office. The respondent states that research reports which communicate uncertainty, in most cases lead to a delay in the decision-making process and that this delay can be very undesirable for politicians. Moreover, respondents perceive that politicians will not consider a CBA report that communicates an uncertain message as a solid base for decision making. According to the respondents, this might eventually lead to a situation in which the use of CBA in the decisionmaking process will be abandoned. Secondly, some respondents perceive that prominent communication of uncertainty in CBA reports will lead to more strategic use of the CBA in the decision-making process, which they feel would be undesirable.

Estimate the effects of at least one flexible investment strategy in a CBA (solution 13 in table 5-1)

A group of respondents thinks that one should manage uncertainty regarding estimations of project effects by estimating project effects for at least one flexible project alternative alongside the non-flexible project alternatives. ${ }^{47}$ For instance, in a CBA effects are estimated for a new railroad which connects cities A, B, C and D (non-flexible project alternative). Here, the idea is to include a project alternative in this CBA in which a new railroad connects cities $\mathrm{A}$ and $\mathrm{B}$ and additional busses connect cities B, C and D. When the railroad between A

\footnotetext{
${ }^{46}$ One respondent suggests communicating in a specific CBA in which the effects of a new rail connection and a spatial planning project were assessed, that the BCR ratio will only be positive when one assumes that housing prices in the project area will increase by 20,000 euros as a result of the new rail connection.

${ }^{47}$ For some types of projects it might be very difficult to design a flexible investment strategy (for instance, bridges). For other types of projects it might be easier to develop flexible investment strategies (for instance, airport and harbor extensions).
} 
and $\mathrm{B}$ is a success, the line can be extended to cities B, C and D (this is the flexible project alternative). Hence, for the flexible project alternative it is assumed that the project is planned in an incremental way. The group of respondents is in favor of this idea because only the elements of the project are developed for which it is to some extent certain that the benefits will very likely be higher than the cost. Respondents label these elements as 'no regret' elements. If the future develops in a favorable way for the project, the other elements can be built as well. When there is an unfavorable development, the other elements are not developed or alternative elements are developed.

With real option analysis it is possible to assess the costs and benefits of a flexible investment strategy against the strategy to develop the whole project in one go (see, for instance, Reuer and Tong, 2007 for a discussion regarding the merits of this method). Respondents perceive as a potential benefit of a flexible strategy the fact that one can adapt the design of the project to the way the future unfolds, especially when the future unfolds in a different way than expected. They perceive as a potential downside of such a strategy the fact that residents will live for years in uncertainty as to whether the second part of the project will or will not be built. According to respondents, a flexible strategy might also be disadvantageous when the specific transport market is characterized by a so-called 'first mover advantage'. For example, when newly developed large container vessels can only call at one Northern European harbor, it is very likely that this harbor will capture all the benefits of large container vessels. In that case, an incremental planning process where the expansion of a harbor starts after the large container vessels are on the market might have its downsides. Respondents perceive that real option analysis can assist with outweighing the benefits and the costs of a flexible investment strategy compared to a non-flexible investment strategy.

Some respondents also discuss the downsides of using real option analysis for evaluating flexible investment strategies. These respondents doubt whether it is possible for decision makers and other users of CBA reports to understand the results of the analysis. Moreover, for the application of real option analysis it is necessary to determine the probability that the different futures included in the analysis will unfold. Respondents think that it is problematic to convince users of CBA reports that it is possible to determine these probabilities.

\section{Communicate non-monetized effects in a prominent way (solution 14 in table 5-1)}

Respondents propose that the summary of the CBA report should communicate to the readers of the CBA report in a very prominent way that they should take into account both monetized and non-monetized effects. Respondents emphasize that it is important to manage the way non-monetized effects are taken into account in the CBA report in order to make sure that their position in the decision-making process is as equal as possible compared to monetized effects because they perceive that actors in the Dutch practice use this lack of balance as the main argument to oppose the use of CBA.

\subsection{Conclusion and reflections}

Although we did not manage to interview the entire population of key actors in the Dutch appraisal practice for spatial-infrastructure projects - fifteen people approached were not able 
to or were not interested in participating in this research - we are confident that it is possible to make a general conclusion by stating that most key actors in the Dutch practice acknowledge insolvable CBA limitations, but perceive the CBA - in spite of these limitations - as a useful instrument. ${ }^{48}$ A large proportion of the respondents think that insolvable CBA limitations can be managed and were able to come up with several pragmatic solutions. We think this is an interesting conclusion because it contrasts with the conclusions of some publications (e.g. Naess, 2006; Kelman, 2002) that take the insolvable CBA limitations as an argument to oppose the use of CBA in the decision-making process at all.

We can also conclude that the key actors perceive that if the insolvable CBA limitations are not managed properly, decision makers might attribute an incorrect value to the CBA results (either too much or too little value). Furthermore, we can conclude that, although some of the proposed solutions have already been addressed in scientific literature, several of the proposed solutions, to our knowledge, add to the literature (solutions 1, 2, 8, 9, 11, 14 in table 5-1), and may inspire other CBA practices in the world to make improvements. Naturally, some proposed solutions might already be implemented in other countries. It is out of the scope of this study to scrutinize solutions to manage insolvable CBA limitations in other countries in an extensive way and relate these to the Dutch practice. However, this study could be a building block for 'the superior international CBA model', suggested by Hayashi and Morisugi (2000). They state (p. 87) that 'by conducting a careful study on the components of the different models, it would be possible to come up with a superior model by integrating all the good components of the existing models. This is a simple case of learning from each country's experience'. A suggestion for generating more building blocks is to replicate this research in other CBA practices and review the solutions implemented in other countries to manage insolvable CBA limitations.

The remainder of this section discusses the specific proposed solutions. We discuss, amongst other things, how the proposed solutions relate to solutions addressed in the literature. Moreover, we provide recommendations for further research and discuss policy recommendations that ensue from the results.

Key actors in the Dutch practice agree that 'incompleteness' is an insolvable CBA limitation. Whether incompleteness is truly insolvable is debatable because it is conceivable that knowledge developments in the more distant future will make it possible to take into account (far) more of the welfare effects in a spatial-infrastructure project compared to the current practice. However, nobody can foresee when and whether it will be possible to measure project effects on 'regional identity', for instance, with sufficient reliability in the distant future. Therefore, we think that the seemingly non-controversial solutions proposed for managing the incompleteness of welfare effects (such as: organizing effect survey meetings; providing high quality qualitative information about intangible effects) are interesting extensions to the existing literature. Nevertheless, for the proposed solution to 'enhance

\footnotetext{
${ }^{48}$ In Mouter et al. (2013, forthcoming) we discuss empirical results on which we sustain our claim that Dutch key actors perceive CBA as being a useful instrument in the decision-making process.
} 
communication of incompleteness in CBA reports', we recommend further research about the way incompleteness should be communicated in CBA reports in advance of an implementation decision, because - even though the key actors interviewed did not mention this - there might be a possible hazard that a too prominent communication of incompleteness would lead to 'the collapse' of the CBA - as would a too prominent communication of uncertainties. We believe that the proposed 'Effect Arena' solution can potentially add value to CBA practices. This solution will not necessarily lead to a situation where all the welfare effects of a project are included in the CBA study. However, the solution safeguards that all the welfare effects perceived by important stakeholders are discussed in the CBA study (in the CBA report, besides the effects that increase national welfare, CBA practitioners also discuss why effects which are perceived as welfare effects by stakeholders do not add to the welfare and, as a result, are excluded from the CBA score). An important benefit of conducting 'Effect Arenas' is that the probability that on-going (and often unclear) debates about a CBA study being complete or incomplete diminish. We think that this solution is transferable to other CBA practices as well because the incompleteness issue is raised in other countries that use CBA (see for instance, Barfod et al., 2011; Eliasson et al., 2013). Effect Arenas can help with reducing this issue.

Related to the incompleteness issue, it indeed seems very important to discuss distributional effects in the CBA report, as the respondents remarked. Respondents suggest displaying separate 'balance sheets' for relevant stakeholders. In the literature we find guiding principles, which in essence resemble this solution as proposed by Dutch actors. Nyborg (2012) and the review of the Norwegian CBA practice (Hagen et al., 2012) state that distributional consequences may be summarized as a list of winners and losers, supplementing the findings from a CBA. The goal of a distributional analysis is that decision makers should receive information about which conflicts of interest the project gives rise to, thus enabling them to evaluate for themselves how to address the resulting trade-offs. Martens (2011) argues that the substance of the distributional analysis should depend on the distributional concerns of decision makers and/or the wider public in a specific case. He states that, firstly, the distributive concerns in a case should be specified before developing an adequate methodology that can address these distributional concerns. In conclusion, the guiding principles mentioned by the respondents and stated in the literature for discussing distributional effects within or alongside the CBA report are essentially the same; however we observe minor differences. Respondents predominantly mentioned a specific distributive concern that should be addressed in CBA reports, such as distributions over regions or income classes, whereas Martens (2011) states that CBA practitioners should firstly scrutinize which distributive concerns are relevant in a specific case. We recommend future research, studying which specification works best in practice. Which solution rectifies the underexposure of distributional effects in a CBA study in the most efficient way? Besides the solutions to incorporate distributional effects in ex-ante evaluation mentioned by the respondents, we also advise including other solutions proposed by the scientific literature and other CBA practices in this study, such as 'Incorporating distributional effects in a CBA by distributive weights' (e.g. Boadway, 2006; Campbell and Brown, 2003; Mishan, 1976), 'Incorporating distributional effects in a hybrid model which combines CBA and Multi-criteria analysis' 
(e.g. Thomopoulos et al., 2009; Thomopoulos and Grant Muller, 2013; van Wee, 2012) and the UK Department for Transport's WebTAG guidance on Social and Distributional Impacts, see www.dft.gov.uk/webtag/). Subsequent to this study, we recommend considering the solution that minimizes the underexposure of distributional effects in the most efficient way in the Dutch practice, but also in other practices.

Many respondents stated that institutionalizing systematic 'ex-post' analyses in the Dutch planning and appraisal process for spatial-infrastructure projects might be an effective solution to minimize uncertainty in CBAs. Internationally, we see that in some countries 'expost' analyses are incorporated in the process (e.g. POPE Guidelines in the United Kingdom), whereas in other countries this is not the case (such as the Netherlands). We think it is interesting to study exactly how 'ex-post' analysis is institutionalized in different countries, and more importantly, what are the most important success and failure factors for institutionalizing systematic 'ex-post' analyses in the planning and decision-making process? Practitioners who aspire to institutionalize 'ex-post' analyses in their practice could use the results of this study.

Key actors in the Dutch appraisal practice for spatial-infrastructure projects agree that 'uncertainty' is an insolvable CBA limitation. However, there is controversy among respondents both in regard to 'the best solution' to enhance the communication of uncertainty in CBA reports and regarding the graduation in which uncertainty should be emphasized in CBA reports. We recommend further research that implies experimentation with the different solutions proposed by respondents and different graduations in which uncertainty is emphasized. We recommend including the solution 'display the uncertainty of effect estimations with Monte Carlo Analysis and interval results' in this experiment. This solution was not mentioned by Dutch respondents but is broadly discussed in recent literature (e.g. Ambrasaite et al., 2012; Barfod et al., 2011; Salling and Banister, 2009). From de Jong et al. (2007) we derive that it is already possible to scrutinize the uncertainty in traffic forecasts through Monte Carlo Analysis for the Dutch transport model, which is used to estimate a project's transport effects in a CBA. Mouter et al. (2013b) discuss that the controversy between Dutch key actors regarding the graduation in which uncertainty should be emphasized in the CBA report can be explained by the way their 'cognitive styles' diverge. Cognitive styles are defined as individuals' chronic motivations that principally determine the initiation, course, and cessation of information seeking and processing (e.g. Thompson et al., 2001). Mouter et al. (2013b), amongst other things, discuss that individuals who are prone to process information in a 'systematic' way are more prone to evaluate information that communicates an uncertain message as a useful input in the decision-making process than individuals who process information in a 'heuristic' way. We recommend a study of relevant findings from social psychological scientific literature in research programs that focus on an optimal way to communicate uncertainty in CBA reports.

The Dutch spatial-infrastructure planning practice focusses more and more on flexible investment strategies. We recommend assessing the advantages and disadvantages of scrutinizing both flexible investment strategies and non-flexible investment strategies in real- 
world CBAs through real option analysis in the near future. It would be interesting to monitor people's experiences with this method. Is this an effective and efficient solution to manage the insolvable limitation that project effect estimations in a CBA are uncertain? When the experiences are positive this solution could be promising for other countries as well.

Our empirical research shows that there is controversy in the Dutch practice regarding the insolvability of the relatively weak position of effects that are difficult to estimate and monetize. Respondents propose different solutions to minimize this limitation. Amongst others, a group of respondents state that the relatively weak position of effects that are difficult to monetize is not an insolvable limitation and CBA analysts should monetize project effects as much as possible. Another group of key actors believes that one should express effects that are difficult to monetize with indicators other than money because these effects are incommensurable with travel time savings, for instance. We do not have a final position in this debate and - although we are aware that this is a very pragmatic position - we suggest sustaining the extent to which effects that are difficult to monetize are monetized on two criteria. Firstly, the share of the effect that can be monetized. Although we do not propose a sharp threshold value, if, for instance, only $10 \%$ of the effects on biodiversity can be monetized, we would advise against the monetization of the effect because only a part of the effects on biodiversity are monetized and taken into account in the CBA report, whilst the reader might think that the total effect is included. Next, we think that the viewpoints of the relevant decision makers in a case should be decisive for the decision to monetize or not. This is in line with the argument of Nyborg (2012) who states that the more a Cost-Benefit Analysis contributes to the decision makers understanding of project consequences, the more successful it is. According to Nyborg monetary valuation may help in achieving this goal when reported numbers are understandable and clarifying, but hardly helps if monetary values are perceived as provocative and confusing. We recommend future research into the extent to which this pragmatic solution has a positive influence on the use of CBA in decision-making processes. Moreover, we recommend research to evaluate the merits of expressing effects that are difficult to monetize in indicators other than in monetary terms (such as the nature value indicator, Sijtsma et al. 2011). When monetizing is too problematic, these types of rigorous and informative indicators might be good substitutes. Currently, in the Netherlands an indicator for measuring landscape effects has been developed: the Hotspot Monitor (Sijtsma et al. 2013b; De Vries et al. 2013). We think that these methods are transferable to other countries and can be promising solutions to settle the debate between fierce proponents and opponents of monetization of biodiversity and landscape.

Overall, we conclude that Dutch key actors suggest two types of strategies to manage insolvable CBA limitations. The first type aspires to minimize insolvable CBA limitations, whereas the second type entirely focuses on the management of the insolvable CBA limitations. The leitmotif that can be distilled from the first type of proposed solutions is that they predominantly focus on providing more comprehensive information regarding project consequences compared to current Dutch CBA studies. This, in order to strengthen the usefulness of CBA in the decision-making process, for instance, by providing high quality information regarding intangible effects and distributional effects. Key actors agree that a 
CBA report should provide more comprehensive information regarding effects that are difficult to monetize but disagree about whether to monetize these effects with sophisticated valuation methods or providing alternative indicators (such as the nature value indicator) is the best route to take for finding a solution. As a result, the comprehensive CBA report provides high quality information regarding non-quantified effects, effects that are difficult to monetize and distributional effects alongside the monetized effects summarized in a final indicator.

The second type of solutions' leitmotif is to improve the communication of the existence of CBA limitations to non-expert users - for instance, decision makers who are important users of CBA reports - to enhance their understanding of the limitations. The proposed solutions urge CBA practitioners to be aware of the knowledge gap between them and non-expert users of CBA reports. The CBA practitioner should inform the non-expert user adequately in the CBA report about the incompleteness of the analysis, the uncertainties of effect estimations and the relatively weak position of effects that are difficult to estimate. An adequate communication of limitations means that CBA practitioners must be cautious about communicating CBA limitations in a too prominent way. Politicians will probably not consider CBA reports that endlessly emphasize the limitations of a study as useful information and certainly not as a solid basis for decision making. According to some respondents, this might eventually lead to a situation in which the use of CBA in the decisionmaking process will be abandoned. It is out of the scope of this paper to scrutinize what communicating CBA limitations adequately exactly means. We recommend studying this topic in further research. Based on this study we can conclude that the difficult task for CBA practitioners is to bridge the knowledge gap between them and the users of a CBA report in a 'subtle' way.

\section{Acknowledgment}

The authors wish to thank the 86 respondents for their open-heartedness. Moreover, we wish to thank four anonymous reviewers for their useful comments.

\section{References}

Ackerman, F., Heinzerling, L., 2004. Priceless: on knowing the price of everything and the value of nothing, New York: New Press.

Ambrasaite, I., Barfod, M. B., Salling, K.B., 2011. MCDA and Risk Analysis in Transport Infrastructure Appraisal: the Rail Baltica Case. Procedia Social and Behavioral Sciences 20, 944-953.

Atkinson, G., Mourato, S., 2008. Environmental Cost-Benefit Analysis. The annual Review of Environment and Resources 33. 317-344.

Barfod, M. B., Salling, K.B., Leleur, S., 2011. Composite Decision Support by Combining Cost-Benefit and Multi-Criteria Decision Analysis. Decision Support Systems 51, $167-$ 175.

Beattie, R. B., 1995. Everything you already know about EIA (but don't often admit). Environmental Impact Assessment Review 15 (2), 109-114. 
Börjesson, M., Eliasson, J., Lundberg, M., in press. Is CBA ranking for transport investment robust? Journal of Transport Economy and Policy

Buck Consultants International, 2002. Evaluatie OEEI-leidraad (In Dutch). The Hague. Buck Consultants.

Boadway, R., 2006. Principles of Cost-Benefit Analysis. Public Policy Review 2 (1), 1-42.

Campbell, H. F., Brown, R. P. C., 2003. Benefit-Cost Analysis: Financial and Economic Appraisal Using Spreadsheets. Cambridge University Press, Cambridge.

Eijgenraam, C. J. J., Koopmans, C.C., Tang, P.J.G., Verster, A.C.P., 2000. Evaluation of Infrastructural Projects; Guide for cost-benefit analysis, Sections I and II, CPB, The Hague, NEI (Changed Name to ECORYS), Rotterdam.

Eliasson, J. and Lundberg, M., 2012. Do Cost-Benefit Analyses Influence Transport Investment Decisions? Experiences from the Swedish Transport Investment Plan 201021. Transport reviews 32 (1), 29-48.

Flyvbjerg, B., Bruzelius, N., Rothengatter, W., 2003. Megaprojects and Risk - An Anatomy of Ambition. Cambridge University Press, Cambridge.

Flyvbjerg, B., Skamris Holm, M.K., Buhl, S.L., 2005b. How (in)accurate are demand forecasts in public works projects? The case of transportation. Journal of the American Planning Association 71, 131-146.

Grant-Muller, S., Mackie, P., Nellthorp, J., Pearman, A., 2001. Economic appraisal of European transport projects - The state of the art revisited. Transport Reviews 21 (2), 237-261.

Hagen, K. P., 2012. Official Norwegian Reports NOU 2012: 16. Review from a committee appointed by Royal Decree of 18 February 2011. Oslo.

Hajer, M. J., 1995. The Politics of Environmental Discourse: Ecological Modernisation and the Policy

Process, Oxford: Oxford University Press.

Hayashi, Y., and Morisugi, H., 2000. International comparison of background concept and methodology of transportation project appraisal. Transport Policy 7 (1), 73-88.

Jong, D.M., Geerlings, H., 2003. Exposing weaknesses in interactive planning: the remarkable return of comprehensive policy analysis in The Netherlands. Impact Assessment and Project Appraisal 21 (4), 281-291.

Jong, G.C., Daly, A.J., Pieters, M, Miller., Plasmeijer, R., Hofman, F., 2007. Uncertainty in traffic forecasts: literature review and new results for The Netherlands, Transportation 34, 375-395.

Kelman, S., 2002. Cost-benefit analysis: an ethical critique. In: Donaldson, T., Werhane, P.H., Cording, M. (eds.) Ethical Issues in Business: A Philosophical Approach, pp. 559-564. Prentice Hall, Upper Saddle River.

Mackie, P., 2010. Cost-Benefit Analysis in Transport: A UK Perspective. International Transport Forum, Mexico.

Mackie, P., Preston, J., 1998. Twenty-one sources of error and bias in transport project appraisal. Transport Policy 5 (1), 1-7.

Mackie, P., Worsley, T., 2013. International Comparisons of Transport Appraisal Practice. Overview Report. Institute for Transport Studies. University of Leeds. 
Martens, K., 2011. Substance precedes methodology: on cost-benefit analysis and equity. Transportation 38, 959-974.

Mishan, E.J., 1976. Elements of Cost-Benefit Analysis. George Allen and Unwin, London.

Mishan, E.J., 1988. Cost-Benefit Analysis, Allen and Unwin, London.

Mouter, N., Annema, J.A., Van Wee, B., 2012. Maatschappelijke Kosten- en Batenanalyse inhoudelijk geëvalueerd. NICIS: The Hague.

Mouter, N., Annema, J.A., Van Wee, B., 2013a. Ranking the substantive problems in the Dutch Cost-Benefit Analysis practice. Transportation Research Part A 49, 241-255.

Mouter, N., Holleman, M., Calvert, S., Annema, J.A., 2013b. A personality and social psychology perspective on communicating uncertainty in Cost-Benefit Analysis. Proceedings of International Conference on uncertainty in transport evaluation. 16-18 September, Copenhagen.

Mouter, N., Annema, J.A., van Wee, B., forthcoming. Attitudes towards the role of CostBenefit Analysis in the decision-making process for spatial-infrastructure projects: a Dutch case study. Transportation Research Part A

Naess, P., 2006. Cost-benefit analysis of transportation investments. Neither critical nor realistic. Journal of critical realism 5 (1), 32-60.

Naess, P., Strand., 2012. What kinds of traffic forecasts are possible? Journal of critical realism 11 (3), 277-295.

Nicolaisen, M. S., 2012. Forecasts: Fact or Fiction? Uncertainty and Inaccuracy in Transport Project Evaluation. Department of Develpment and Planning, Aalborg University.

Nyborg, K., 2012. The Ethics and Politics of Environmental Cost-Benefit Analysis. Routledge.

Odgaard, T., Kelly, C., Laird, J., 2005. Current practice in project appraisal in Europe, in: Proceedings of the European Transport Conference. 3-5 October, Strasbourg, Association for European Transport.

Page, J., 2006. Make it easy to your readers: ideas on environmental impact document focus, organization, and style. Impact Assessment and Project Appraisal, 24(3), 233-245.

Rietveld, P., Rouwendal, J., Vlist, A.J. van der, 2007. Equity issues in the evaluation of transport policies and transport infrastructure projects. In: Geenhuizen, M., van, A., Reggiani, Rietveld, P. (Eds.), Policy Analysis of Transport Networks. Ashgate, Aldershot, pp. 19-36.

Reuer, J. J., Tong, T. W., 2007. Real option theory. Advances in strategic management. Volume 22.

Salling, K.B., Banister, D., 2009. Assessment of large transport infrastructure project: the CBA-DK model. Transportation Research Part A 43 (9), 800-813.

Self, P., 1970. Nonsense on stilts: Cost-Benefit Analysis and the Roskill Commission. Political Quarterly 41 (3).

Sen, A.K., 2000. The discipline of cost-benefit analysis. The journal of Legal Studies 29 (2), 931-952.

Sijtsma, F. J., Heide, C. M., v.d. Hinsberg, A., v 2011. Biodiversity and decision-support: integrating CBA and MCA. In A. Hull, E. Alexander, A. Khakee \& J. Woltjer (Eds.), Evaluation for participation and sustainability in planning. London: Routledge. (Chapter 9; pp 197-218) 
Sijtsma, F. J., Heide, C. M., v.d. Hinsberg, A., v 2013a. Beyond monetary measurement: How to evaluate projects and policies using the ecosystem services framework. Environmental Science and Policy, Volume 32, October 2013, Pages 14-25.

Sijtsma, F. J., Farjon, H. S., van Tol, A., Hinsberg, A, v., Kampen, P, van., Buijs, A., 2013b. Evaluation of landscape changes - Enriching the economist's toolbox with the Hotspotindex. In: W. Heijman, \& C. M. J. v. d. Heide (Eds.), The Economic Value of Landscapes. Chapter 8, pp 136-164. London: Routledge.

Sijtsma, F. J., Heide, C. M. v. d., Hinsberg, A. v., 2011. Biodiversity and decision-support: integrating CBA and MCA. In A. Hull, E. Alexander, A. Khakee \& J. Woltjer (Eds.), Evaluation for participation and sustainability in planning. London: Routledge. (Chapter 9; pp 197-218)

Sijtsma, F.J., 2006. Project evaluation, sustainability and accountability - Combining CostBenefit Analysis (CBA) and Multi-Criteria Analysis (MCA). PhD Thesis, University of Groningen. Stichting REG, nr 27. Groningen.

Thomopoulos, N., Grant-Muller, S., Tight, M.R., 2009. Incorporating equity considerations in transport infrastructure evaluation: current practice and a proposed methodology. Evaluation and Program Planning 32 (4), 351-359.

Thomopoulos, N., Grant-Muller, S.,2013. Incorporating equity as part of the wider impacts in transport infrastructure assessment: an application of the SUMINI approach. Transportation 40 (2), 315-345.

Thompson, M.M., Naccarato, M.E., Parker, K.C.H., Moskowitz, G.B., 2001. The Personal Need for Structure (PNS) and Personal Fear of Invalidity (PFI) measures: Historical perspectives, present applications and future directions. In G. B. Moskowitz (Ed.), Cognitive social psychology: The Princeton symposium on the legacy and future of social cognition (pp. 19-39). Mahwah, NJ: Lawrence Erlbaum Associates, Inc.

Vries. S, de., Buijs, A., Langers, F., Farjon, H.S., Hinsberg, A, van., Sijtsma, F. J., in press. Measuring the attractiveness of Dutch landscapes: identifying national hotspots using Google Maps. Applied Geography.

Weber, R. P. (1990). Basic Content Analysis, 2nd ed. Newbury Park, CA.

Wee, V. B., 2012. How suitable is CBA for the ex-ante evaluation of transport projects and policies? A discussion from the perspective of ethics. Transport Policy 19 (1), 1-7.

Weiss, E, H., 1989. An unreadable EIS is an environmental hazard. The Environmental Professional 11, 236-240.

Welsh, M., Williams, H., 1997. The sensitivity of Transport investments benefits to the evaluation of small travel-time savings. Journal of Transport Economics and Policy. 


\section{Appendix 5.1: respondents and affiliation at the time of the interview}

1. Andre Belonje: Ministry of Infrastructure and the Environment

2. Kirsten van den Berg: Utrecht region

3. Peter van den Berg: Director, General Ministry of Finance

4. Luca Bertolini: Professor, University of Amsterdam

5. Luc Berris: Society for Preservation of Nature Monuments in the Netherlands (Natuurmonumenten)

6. Peter Blok: Private Consultant, Rebelgroup

7. Martijn Blom: Private Consultant, CE Delft

8. Lauri de Boer: Private Consultant, LPBL

9. Will Clerx: Municipality of Rotterdam

10. Jasper Dalhuisen: Ministry of Economic Affairs, Agriculture and Innovation

11. Karen van Dantzig: Ministry of Infrastructure and the Environment

12. Marc Davidson: Private Consultant, CE Delft

13. Adri Duivesteijn: Alderman, Municipality Almere

14. Carel Eijgenraam: Researcher, Netherlands Bureau of Economic Policy Analysis (CPB)

15. Klaas van Egmond: Professor, Utrecht University

16. Terri van Dijk: Researcher, University of Groningen

17. Henri Dijkman: Ministry of Finance

18. Rosemarie van den Eissen: Province of Gelderland

19. Paul Elhorst: Researcher, University of Groningen

20. Donne Engelen: The Netherlands Society for Nature and Environment

21. Koen Frenken: Professor, Eindhoven University of Technology

22. Karst Geurs: Researcher, Twente University

23. Jaron Haas: Rijkswaterstaat, Ministry of Infrastructure and the Environment

24. Niek van der Heiden: Ministry of Infrastructure and the Environment

25. Bart van der Heijden: Municipality of Amsterdam

26. Wim Heijman: Professor, Wageningen University

27. Hans Hilbers: Researcher, the Netherlands Environmental Assessment Agency (PBL)

28. Niels Hoefsloot: Private Consultant, Decisio

29. Arjen 't Hoen: Netherlands Institute for Transport Policy Analysis (KiM)

30. Edwin Huijsman: Rijkswaterstaat, Ministry of Infrastructure and the Environment

31. Toon van der Hoorn: Rijkswaterstaat, Ministry of Infrastructure and the Environment

32. Bert Hof: Ministry of Finance

33. Bas van Holst: Private Consultant, Drs. B

34. Walter Hulsker: Private Consultant, Ecorys

35. Ekko van Ierland: Professor, Wageningen University

36. Martin de Jong: Researcher, Delft University of Technology

37. Jarl Kind: Researcher, Deltares

38. Ursula Kirchholtes: Private Consultant, Witteveen \& Bos

39. Henk Klaassen: Researcher, Erasmus University Rotterdam

40. Jeroen Klooster: Private Consultant, Arcadis 
41. Maarten Koningsveld: Automobile Association (ANWB)

42. Carl Koopmans: Professor, University Amsterdam

43. Fokko Kuik: Municipality of Amsterdam

44. Wim Korver: Private Consultant, Goudappel/Coffeng

45. Sonja Kruitwagen: Researcher, the Netherlands Environmental Assessment Agency (PBL)

46. Robert van Leusden: Utrecht region

47. Ronald van der Meijs: Ministry of Infrastructure and the Environment

48. Coen Mekers: Province of Gelderland

49. August Mesker: Confederation of Netherlands Industry and Employers (VNO-NCW)

50. Henk Meurs: Professor, Radboud University Nijmegen / Private Consultant, Muconsult

51. Henk van Mourik: Ministry of Infrastructure and the Environment

52. Roland Nijssen: Researcher, Prorail

53. Michiel de Nooij: Private Consultant, SEO

54. Jan Oosterhaven: Professor, University of Groningen

55. Jan Peelen: Civil Servant, Ministry of Infrastructure and the Environment

56. Eric Pijnappels: Private Consultant, Goudappel/Coffeng

57. Paul Poppink: Transport and Logistics Association (TLN)

58. Bertus Postma: Municipality of Rotterdam

59. Aniel Ramawadh: Private Consultant, BCI Global

60. Emiel Reiding: Ministry of Infrastructure and the Environment

61. Gusta Renes: Researcher, the Netherlands Environmental Assessment Agency (PBL)

62. Piet Rietveld: Professor, University Amsterdam

63. Sytze Rienstra: Private Consultant, Syconomy

64. Gerbert Romijn: Researcher, Netherlands Bureau of Economic Policy Analysis (CPB)

65. Freddie Rosenberg: Private Consultant, RIGO

66. Elisabeth Ruijgrok: Private Consultant, Witteveen en Bos

67. Jan Sakko: Municipality of Rotterdam

68. Olaf Seinen: Private Consultant, Goudappel/Coffeng

69. Herman Stolwijk: Researcher, Netherlands Bureau of Economic Policy Analysis (CPB)

70. Wim Spit: Private Consultant, Ecorys

71. Edward Stigter: Ministry of Infrastructure and the Environment

72. Lori Tavasszy: Professor, Delft University of Technology

73. Bart Teulings: Municipality of Almere

74. Pieter Tordoir: Professor, University of Amsterdam

75. Bas Turpijn: Rijkswaterstaat, Ministry of Infrastructure and the Environment

76. Hans ten Velden: Ministry of Infrastructure and the Environment

77. Erik Verhoef: Professor, University Amsterdam

78. Erik Verroen: Private Consultant, Twynstra Gudde

79. Nol Verster: retired, former Private Consultant, Ecorys

80. Johan Visser: Netherlands Institute for Transport Policy Analysis (KiM)

81. Warren Walker: Professor, Delft University of Technology 
82. Pim Warffemius: Netherlands Institute for Transport Policy Analysis (KiM)

83. Bart Witmond: Private Consultant, Ecorys

84. Dik Wolfson: retired, former member of the Upper House

85. Pauline Wortelboer: Netherlands Institute for Transport Policy Analysis (KiM)

86. Peter Zwaneveld: Researcher, Netherlands Bureau of Economic Policy Analysis (CPB) 


\section{Appendix 5.2: number of respondents that mentioned a solution}

\begin{tabular}{|l|l|}
\hline Proposed solution to manage incorrect use of CBA & $\begin{array}{l}\text { Frequency of respondents } \\
\text { that mentioned a solution }\end{array}$ \\
\hline 1.Organize effect survey meetings & 4 \\
\hline 2.Provide high quality qualitative information regarding intangible effects & 9 \\
\hline 3.Carry out ex-post analyses & 9 \\
\hline 4.Monetize as much as possible & 17 \\
\hline $\begin{array}{l}\text { 5.Use indicators other than money to express effects that are difficult to } \\
\text { monetize }\end{array}$ & 15 \\
\hline $\begin{array}{l}\text { 6. Monetize effects in CBA studies when possible. However, when } \\
\text { monetizing leads to severe criticism and frustrations, one should not monetize }\end{array}$ & 6 \\
\hline $\begin{array}{l}\text { 7. Referent assesses the position of effects that are difficult to monetize in the } \\
\text { CBA report }\end{array}$ & 1 \\
\hline $\begin{array}{l}\text { 8. Explicitly discuss the way monetized and non-monetized effects relate to } \\
\text { each other in the summary of the CBA report }\end{array}$ & 1 \\
\hline $\begin{array}{l}\text { 9. Implement a 'showstopper' procedure in the CBA analysis for effects that } \\
\text { are difficult to monetize and that are irreversible }\end{array}$ & 1 \\
\hline $\begin{array}{l}\text { 10. CBA reports should be supplemented by an analysis of distributional } \\
\text { effects }\end{array}$ & 8 \\
\hline 11.Enhance communication of incompleteness in CBA reports & 9 \\
\hline 12.Enhance communication of uncertainty in CBA reports & 39 \\
\hline $\begin{array}{l}\text { 13. Estimate the project effects for at least one flexible investment strategy in } \\
\text { a CBA study }\end{array}$ & 8 \\
\hline $\begin{array}{l}\text { 14. Communicate that readers should also take effects that are difficult to } \\
\text { monetize into account }\end{array}$ & 5 \\
\hline
\end{tabular}




\section{Conclusions and reflections}

This chapter is organized as follows: section 6.1 presents the main conclusions of this thesis by answering the research questions. Section 6.2 discusses the methodological contribution of this thesis. Section 6.3 discusses the limitations of this study. Section 6.4 lists the most important policy recommendations that can be derived from the findings of this thesis. In section 6.5 I will discuss my views on possible implications the results of this thesis could have for the design of the planning and decision-making process for spatial-infrastructure projects in the Netherlands. Section 6.6 lists avenues for further research. Finally, section 6.7 provides reflections on this thesis.

\subsection{Answers to the research questions}

By investigating the perceptions of the 86 key individuals I aimed to answer the research questions postulated in the introduction. Below, the answers to the research questions are presented.

Research question 1: Which substantive problems with regard to appraising spatialinfrastructure projects using CBA do key individuals in the Dutch CBA practice for spatialinfrastructure projects perceive and what is the relative order of importance of substantive problems according to Dutch key individuals?

Key individuals in the Dutch CBA practice for spatial-infrastructure projects consider 'problems with the estimation of the non-monetized project effects' as the most important substantive problem cluster and 'problems with monetizing project effects' as the second most important substantive problem cluster. Also, key individuals consider the 'problem analysis' in a CBA to be a very important substantive problem. Moreover, there is, in a broad sense, consensus among the different groups in the Dutch CBA practice concerning their perception of the seriousness of problem clusters and the way they rank the problem clusters. The 'problem analysis' problem cluster is an interesting exception. Although key individuals on average perceive that the absence of high quality independent problem analyses in CBAs is 
a very important substantive problem, none of the 19 policy makers that filled out the questionnaire perceives that the quality of the 'problem analysis' problem cluster is problematic.

Research question 2: To which extent is there agreement among key individuals in the Dutch $C B A$ practice for spatial-infrastructure projects with regard to the role of the CBA in the decision-making process?

Key individuals in the Dutch CBA practice for spatial-infrastructure projects agree that CBA must have a role in the appraisal process of spatial-infrastructure projects. In the written questionnaire 73 out of 74 respondents stated that CBA must have 'a' role in the appraisal of spatial-infrastructure projects. However, there is a lot of controversy among economists and spatial planners in the Dutch practice concerning the value that is and should be assigned to CBA in the decision-making process. None of the 40 respondents that consider themselves economists think that, in the current practice, too much value is attributed to CBA, whereas $71 \%$ of the spatial planners think that too much value is attributed to CBA in the decisionmaking process. Ordinal logistic regressions reveal that the attitude of economists towards the value that is attributed to CBA in the decision-making process significantly differs from the attitude of spatial planners and transport specialists and that there is no significant relation between 'profession of a key individual' and 'attitude of a key individual towards the role of CBA'.

Research question 3: What are internationally relevant solutions for substantive CBA problems as identified by key individuals in the Dutch CBA practice for spatial-infrastructure projects?

Key individuals were able to provide a large variety of solutions for substantive CBA problems, which are discussed in-depth in chapter 4. They provide solutions on topics for which solutions are scarcely addressed in existing literature. I conclude that key individuals' perceptions of solutions for substantive CBA problems are very useful input for CBA research agendas. Firstly, because respondents provide solutions on topics for which solutions are scarcely addressed in existing literature. Secondly, Dutch key individuals propose some pragmatic solutions for practical substantive problems that add to existing scientific literature, which predominantly discusses theoretical solutions. When scientific literature is the only input for CBA research agendas, the risk is that the research agenda will only include solutions like the development of highbrow models, whereas key individuals that carry out CBAs especially need rules of thumb and temporary solutions to safeguard consistency, for example. Finally, an interesting result for an international audience is that Dutch key individuals mention as a solution that they are clearly in need of very clear and explicit instructions in CBA guidelines, which are enforced in a second opinion. Predominantly private consultants stated in the interviews that they can use the clear guidelines and the fact that the quality of the CBA will be assessed in a second opinion as a 'weapon' to convince the client to carry out a CBA that is as independent as possible. Although key individuals mentioned a large variety of interesting solutions, I conclude that key individuals' perceptions 
alone are insufficient input for CBA research agendas. Solutions discussed in the academic literature and solutions implemented in other countries provide very valuable input as well.

Research question 4: Which insolvable CBA limitations do key individuals in the Dutch CBA practice for spatial-infrastructure projects perceive? What are internationally relevant solutions to manage the insolvable CBA limitations as identified by Dutch key individuals?

Insolvable CBA limitations as perceived by key individuals in the Dutch CBA practice for spatial-infrastructure projects can be categorized in three groups: (1) CBA is always incomplete; (2) Effect estimations are always uncertain; (3) Effects that are difficult to estimate have a relatively weak position in the CBA. In the interviews, key individuals frequently mentioned that the fact that CBA is a tool with insolvable limitations is not problematic in itself. According to the key individuals, problems only arise when insolvable limitations are not managed properly. Key individuals perceive that, as a result of bad management, people might use or position the CBA as an instrument with too many or too few limitations and attribute an incorrect value to the CBA (either too much or too little value). An example of 'bad management' of insolvable CBA limitations discussed by key individuals is that as a result of a poor presentation of insolvable CBA limitations in the CBA report, it is difficult for users to understand the CBA limitations.

Key individuals mentioned fourteen categories of internationally relevant solutions to manage the insolvable CBA limitations they identified, which are discussed in-depth in chapter 5. Although some of the proposed solutions have already been addressed in scientific literature, several of the proposed solutions, to my knowledge, add to the literature an example being to organize effect survey meetings (Effect Arenas) preceding a CBA study to take into account as many welfare effects as possible in the CBA study. These solutions may inspire other CBA practices in the world to make improvements. Dutch key individuals suggest two types of strategies to manage insolvable CBA limitations. The first type aspires to minimize insolvable CBA limitations, whereas the second type entirely focuses on the management of the insolvable CBA limitations. The leitmotif that can be distilled from the first type of proposed solutions is that they predominantly focus on providing more comprehensive information regarding project consequences compared to current Dutch CBA studies. The second type of solutions' leitmotif is to improve the communication of the existence of insolvable CBA limitations to non-expert users - for instance, decision makers who are important users of CBA reports - to enhance their understanding of the limitations. An improved communication of limitations means that CBA practitioners must be cautious about communicating CBA limitations in too prominent a way. Politicians will probably not consider CBA reports that endlessly emphasize the limitations of a study as a solid basis for decision making. People that carry out CBA studies should communicate the limitations of the CBA report, but not in a way that is too prominent. 


\subsubsection{Contribution to problems addressed in section 1.2}

This thesis has studied the way Cost-Benefit Analysis is perceived by different key individuals in the Dutch CBA practice for spatial-infrastructure projects by answering the four research questions addressed above. A remaining question is: to which extent did answering the research questions contribute to solving the three problems of the scant attention in existing literature with regard to the way CBA is perceived by individuals that use or carry out CBA (section 1.2). Firstly, the way the merits of CBA are experienced by key individuals (who explicitly argue against the way CBA is used in the present) is important for the support for the instrument and the extent to which decision making in transport can be improved through CBA. By studying perceptions of key individuals who argue against the use of CBA with regard to $\mathrm{CBA}$ problems, $\mathrm{CBA}$ disadvantages and solutions for rectifying these perceived problems and disadvantages, this thesis provides clarity with regard to the problems and solutions perceived by this group. A next step might be to tackle the problems experienced by CBA antagonists to enhance their support for using CBA in the (Dutch) decision-making process for spatial-infrastructure projects.

Secondly, people that use or carry out CBA studies in practice might have additional - and maybe even better - suggestions for solutions to rectify CBA problems and for improving the way CBA is used in the decision-making process besides the solutions proposed by academics. Indeed, chapters 4 and 5 provide solutions perceived by key individuals that clearly add to the literature.

Thirdly, there is no contribution in existing literature that investigates the urgency of CBA problems, which can be used as a point of departure for researchers to prioritize problem areas for further research. This thesis provides guidance for researchers with regard to the urgency of CBA problems concluding that 'problems with the estimation of the non-monetized project effects', 'problems with monetizing project effects' and 'problem analysis' are the most urgent problem clusters from the perspective of Dutch key individuals. In chapters 2 and 4 I argued that key individuals' perceptions are useful but insufficient input for determining (the significance of) CBA problems. Solutions discussed in academic literature and solutions implemented in other countries are very valuable input as well. In all, this thesis provides a useful but not an indefinite input for determining the urgency of substantive problems.

\subsubsection{An analysis of individuals' perceptions or organizations' views?}

This thesis analyzes the perceptions of key individuals in the Dutch CBA practice of various CBA related topics. An interesting question which is not discussed in chapters 2-5 is 'to which extent did the responses of the key individuals represent their own perceptions with regard to $\mathrm{CBA}$ and to which extent did the individuals represent the opinions of the organizations they work for?' Let us assume, for instance, that 'organization A' sets up a meeting in which the director makes the following statement: 'I know you all like CBA very much but I do not, so from now on you should all tell people outside this organization that you detest CBA, otherwise you are fired.' In this extreme case, it is very likely that the respondents from this organization will answer that they do not think CBA should have a role in the appraisal process for spatial-infrastructure projects and that the opinion of the 
organization (or their superior) is measured via the respondent. To analyze this 'organization effect', I chose seven organizations (decentralized government agencies, central government agencies and knowledge institutes) and studied the extent to which employees of the organizations gave the same answers to the questions that were asked in the written questionnaire about their own perceptions of substantive problems and attitude towards the role of $\mathrm{CBA}$ in the decision-making process for spatial-infrastructure projects.

Table 6-1 describes the answers of respondents from the seven organizations to the question, to select the most important substantive problem cluster out of the nine problem clusters (column 3), the second most important problem cluster (column 4) and the third most important problem cluster (column 5). Through a lack of sufficient observations per organization, testing the effect with statistical analysis is impossible. Because I assured the respondents that I would report the results in a way that the statements they made during the interview would be unidentifiable, the names of the organizations are not mentioned. The nine problem clusters are - in order of sequence - 'problem analysis (1)', 'reference case (2)', 'project alternative (3)', 'estimating non-monetized effects (4)', 'monetizing (5)', 'discounting (6)', 'presentation (7)', 'distributional effects (8)' and 'uncertainty (9)'.

Table 6-1 Problem clusters mentioned by employees

\begin{tabular}{|c|c|c|c|c|}
\hline Organization & Employee & Problem cluster 1 & Problem cluster 2 & Problem cluster 3 \\
\hline \multirow[t]{3}{*}{ Organization A } & I & 5 & 4 & 6 \\
\hline & II & 3 & 9 & 4 \\
\hline & III & 1 & 4 & 9 \\
\hline \multirow[t]{4}{*}{ Organization B } & I & 7 & 1 & 9 \\
\hline & II & 2 & 3 & 4 \\
\hline & III & 2 & 5 & 9 \\
\hline & IV & 1 & 7 & 9 \\
\hline \multirow[t]{3}{*}{ Organization C } & I & 3 & 2 & 7 \\
\hline & II & 9 & 4 & 5 \\
\hline & III & 1 & 4 & 7 \\
\hline \multirow[t]{3}{*}{ Organization D } & I & 1 & 9 & 5 \\
\hline & II & 5 & 7 & 1 \\
\hline & III & 4 & 5 & 9 \\
\hline \multirow[t]{4}{*}{ Organization E } & I & 4 & 2 & 7 \\
\hline & II & 2 & 7 & 8 \\
\hline & III & 4 & 99 & 1 \\
\hline & IV & 4 & 1 & 2 \\
\hline \multirow{2}{*}{ Organization F } & I & 3 & 2 & 4 \\
\hline & II & 4 & 5 & 3 \\
\hline \multirow[t]{3}{*}{ Organization G } & I & 4 & 9 & 2 \\
\hline & II & 1 & 8 & 4 \\
\hline & III & 4 & 2 & 5 \\
\hline
\end{tabular}


Table 6-1 shows that key individuals in the Dutch CBA practice that work in the same organization gave different answers to the question about the most important substantive problem clusters they experience. It occurred only once (Organization B) that two members of the same organization selected the same problem clusters in their 'Top 3'. Hence, I conclude that the 'organization effect' is limited for this topic.

Also, I analyzed the respondents' answers from the seven organizations on the question 'how do you evaluate the value that is attributed to CBA in the decision-making process for spatialinfrastructure projects nowadays?' I have not described the results in a table per organization because I think that the respondents could potentially be identified. The leitmotiv is that in organizations in which mainly economists work, the respondents think that too little value is attributed to the CBA; in organizations in which mainly spatial planners work, the respondents think that too much value is attributed to the CBA; and in organizations in which spatial planners, transport experts and economists work, the views on the role of CBA are mixed. It can be concluded that with regard to the attitudes of respondents towards the role of CBA in the decision-making process for spatial-infrastructure projects the 'specialization effect' is stronger than the 'organization effect'. Because of a lack of observations it is not possible to test whether the 'organization effect' exists to some extent. More specifically, do economists who work in an organization with spatial planners think that less value should be attributed to CBA in the decision-making process than economists who work in an organization with solely economists? And, do spatial planners who work in an organization with economists think that more value should be attributed to CBA in the decision-making process than spatial planners who work in an economist-free organization? I think that this is an interesting question for further research.

Another method for studying the extent to which the 'organization effect' exists is to ask the same question to the respondents who were surveyed for this thesis ten years from now, for example. Possibly a share of the respondents will switch jobs and it would be interesting to analyze whether their view on the role of CBA also switches. Although I can see the problem with the fact that a respondent's switched views can definitely be caused by factors other than a job change, I think this would still be an interesting analysis should this study is repeated in the future.

\section{Discussion of results}

My stance on the question of whether or not an 'organization effect' exists is that, although I believe that an 'organization effect' does exist, there is still some evidence in the Dutch practice that it is more likely that a 'collaboration effect' is stronger than an 'organization effect'. With a 'collaboration effect' I mean that if an economist (intensively) works or worked together with spatial planners on a CBA related project, the probability is higher that he or she is able to use CBA in a 'subtle way' (not assigning an absolute or marginal value to the $\mathrm{CBA}$ and thus using $\mathrm{CBA}$ as an instrument with advantages and limitations) than an economist who never collaborated with spatial planners. To underpin my position I use the statements made by people that worked on the 'Plans for the City' (Romijn and Renes, 2013a; 
in Dutch: Plannen voor de Stad) project, a co-production of the Netherlands Bureau for Economic Policy Analysis (mainly economists) and the Netherlands Environmental Assessment Agency (mainly spatial planners and ecologists) after finishing the project in personal communication, and the presentations of the project at 'Nieuwe Werkpraktijken MKBA' (March 12th, 2013), 'Ontwikkelagenda MKBA' (October 2nd, 2013) and 'Colloquium Vervoersplanologisch Speurwerk' (November 23th, 2013): 'an important added value of this project was that the economists of the Netherlands Environmental Assessment Agency learned about the limitations of CBA while working intensively together with spatial planners and that the spatial planners from the Netherlands Environmental Assessment Agency learned about the strong points of CBA while working intensively together with economists'. Hence, my hypothesis is that the effect that economists learn about limitations of CBA and spatial planners about advantages of CBA is not so much the result of an 'organization effect' (both disciplines work in the same organization) but is the result of a 'collaboration effect' (both disciplines work together on a project in which CBA plays a role) and this 'collaboration effect' can also be realized by working with someone from the other discipline who is affiliated with another organization. I think it is interesting to test this hypothesis in future research. If research supports this hypothesis, I think that the collaborative approach, which was used in 'Plans for the City' (Romijn and Renes, 2013a) and the Dutch General Guidelines for Cost-Benefit Analysis - in which both economists and spatial planners were involved in the design and supervision of the guideline (Romijn and Renes, 2013b) - can be recommended to other countries who use CBA.

\subsection{Methodological contribution}

Although the primary aim of this thesis is to generate empirical knowledge concerning the way CBA is perceived by key individuals, I think that, also, a methodological finding can be derived from this thesis. The reliability of the content analysis carried out in this thesis was assessed through an intercoder reliability test. It was found that, especially in the field of transport, it is uncommon to explicitly discuss the reliability of the analysis of interviews and literature reviews (Mouter and Vonk Noordegraaf, 2012). Together with Ardic et al. (2013) and Vonk-Noordegraaf et al. (2014) the intercoder reliability test carried out in this thesis can be seen as an example for academics that wish to explicitly assess the reliability of their data analysis in order to enhance the research quality of their work. Mouter and Vonk Noordegraaf (2012) list lessons learned by carrying out intercoder reliability testing and give some practical recommendations based on the hands-on experiences of the two authors.

\subsection{Limitations}

In each chapter, notion is given to limitations. This section summarizes the main limitations and adds some additional thoughts on limitations and directions for future research.

\subsubsection{Non-response bias}

One of the strong points of this thesis is that the response rate is high. $85 \%$ of the respondents who were invited for an interview accepted the invitation. Of the respondents that were interviewed, $86 \%$ completed the written questionnaire. Despite these high response rates, it 
should be noted that the fact that some individuals did not participate is a limitation of this thesis. Whether or not the non-response is problematic depends on the extent to which the overall results would have substantially changed had the non-respondents actually responded, which is labeled as 'non-response bias' (Creswell, 2009). When non-response bias is severe, it is not possible to generalize the results of the study to the non-respondents and the population (Berg, 2005). The next question is: 'how to determine the extent to which non-response bias is severe?' The only way to answer this question with certainty is to interview the nonrespondents and determine the extent to which the answers differ from the answers of the people who already participated. Because this solution is practically unfeasible for almost every study, the 'second-best option' is to assess the possibility of 'non-response bias'.

The first indicator for assessing whether a study suffers from non-response bias is the response rate (Mundy, 2002). The lower the response rate, the higher the risk of non-response bias. Experts consulted by Mundy (2002) agree that there is no magic number for which it can be guaranteed that non-response bias is insignificant but a practical rule of thumb that can be used is: ' $70 \%$ is reasonable, $80 \%$ is good, $90 \%$ is excellent'. The US Office of Management and Budget uses the following rule of thumb: 'if the response rate is below $80 \%$, a nonresponse analysis is demanded' (Fowler jr., 2009). A second indicator is to compare characteristics of non-respondents with those of respondents and assess the extent to which the characteristics differ. When the characteristics of both groups are similar, this is an indication that non-response bias is marginal (Davidoff in Mundy, 2002). A third indicator is a comparison of the answers of 'early responders' with 'late responders'. The assumption is that 'late responders' are more similar to the non-respondents than the 'early responders'. When the answers of the 'late responders' significantly differ from the answers of the 'early responders', this is an indication of potential non-response bias (Armstrong and Overton (1977). To illustrate: when the 'early responders' answer a question with 'six' and the 'late responders' answer a question with 'twelve' it is plausible that the non-respondents will answer this question with 'eighteen' which affects the mean. A fourth way to verify the extent to which a study suffers from non-response bias is to ask the non-respondents a few key questions that were also discussed with the respondents. When the non-respondents give approximately the same answers as the respondents, this is an indication that non-response bias is marginal. For instance, Chorus et al. (2011) called all non-respondents who refused to participate in their study and asked them about their opinion in general about road pricing to test whether their sample was representative with respect to this general attitude. A fifth indicator I would like to add is 'reason for non-response'. My intuition is that the probability of non-response bias is relatively high when non-respondents mention 'I detest CBA thus I don't want to talk about it' as a reason and the probability of non-response bias is relatively low when 'I am not an expert so I don't have a clear opinion on CBA' as a reason for nonresponse. A downside of this indicator is that it is possible that non-respondents strategically do not mention their genuine reason for not participating.

With respect to the first indicator it can be concluded that the response rates of this study are higher than $80 \%$ which is an indication that the non-response bias is marginal. In addition, sensitivity for non-response bias was assessed using the second and the fifth indicator for the 
people who did not accept the invitation for the interview. I do not see the third indicator as feasible to analyze non-response bias as it is difficult to distinguish 'early responders' and 'late responders' because the invitations for the interview were not sent on the same day. With the benefit of hindsight, it would have been interesting to also assess the fourth indicator by asking a few questions to the non-respondents.

Sensitivity for non-response bias for the individuals who did not complete the questionnaire was assessed using the fourth indicator. The reason for choosing this indicator is that data on the perceptions with regard to CBA of these twelve individuals was available because they participated in the interview study. The results of both non-response bias assessments are discussed below.

Non-response bias for interview results

Table 6-2 depicts both the explanations for non-response and the characteristics of the nonrespondents.

Table 6-2 Explanations and characteristics non-response interview results

\begin{tabular}{|l|l|l|l|l|}
\hline & Specialization & & & \\
\hline & Economy & Spatial Planning & Transport & Unknown \\
\hline Profession & & & & \\
\hline Civil servant & $1(\mathrm{~B})$ & $2(\mathrm{C}, \mathrm{D})$ & $2(\mathrm{D}, \mathrm{C})$ & \\
\hline Politician & $1(\mathrm{~A})$ & & & $1(\mathrm{~B})$ \\
\hline Lobbyist & & $1(\mathrm{C})$ & & \\
\hline Scientist / Researcher & $2(\mathrm{~B}, \mathrm{~B})$ & $2(\mathrm{C}, \mathrm{C})$ & & \\
\hline Consultant & $2(\mathrm{~B}, \mathrm{~B})$ & $1(\mathrm{~B})$ & & \\
\hline
\end{tabular}

$\mathrm{A}=$ Did not respond on invitation.

$\mathrm{B}=$ Only used 'lack of time' as argument.

$\mathrm{C}=$ 'Lack of time' and 'it is better to interview the expert from our organization' (who was eventually interviewed for this research).

$\mathrm{D}=$ 'Lack of time' and 'you already interviewed enough key experts in my organization with regard to CBA, so I have nothing to add'.

An observation that can be derived from table 6-2 is that for seven respondents it is questionable whether they should be classified as non-response. The individuals classified in 'category $\mathrm{C}$ ' all had a leading position in their organization and told me that for CBA related issues they consulted the CBA expert in their organization to prepare their response and that it was better to interview this expert. In all five cases this expert accepted my request for an interview. I think it is defendable to argue that the five individuals classified in category $\mathrm{C}$ do not count as non-response because they responded via their experts. I also argue that it is questionable whether the two individuals classified in 'category D' should be labeled as nonresponse. Both were civil servants from the Ministry of Infrastructure and the Environment and I had already interviewed eleven individuals from this institution when I invited these individuals for an interview. On the one hand, I believe it is plausible that after interviewing a certain number of individuals from an organization the ratio of 'valuable new insights / time' is rather negative. On the other hand, table 6-1 shows that people from the same organization give very different answers on one of the most important questions in the questionnaire. My 
judgment is that the latter argument outweighs the former and the two individuals should be labeled as non-response.

Table 6-2 shows that the split of non-participants to participants is fairly similar for economists (12\%), spatial planners $(6 \%)$ and transport experts $(7 \%)$ when the categories $\mathrm{A}, \mathrm{B}$ and $\mathrm{D}$ of non-response are considered. Hence, I conclude that it is not the case that individuals with a specific characteristic are overrepresented in the non-response which is an indicator that the probability of 'non-response bias' is rather low.

\section{Non-response bias for questionnaire results}

To analyze the extent to which the results derived from the written questionnaire are affected by non-response bias a selection of statements made in the interviews by the non-respondents and the respondents were compared. Firstly, I analyzed the answers about the question how respondents outweigh the advantages and disadvantages of using CBA for spatialinfrastructure projects. Respondents were asked to choose between three options ('advantages are larger', 'disadvantages are larger' or 'neutral'). The hypothesis is that if the people who did not complete the written questionnaire answered this question in the interviews in a significantly different way than the people who did complete the written questionnaire, the probability is high that the questionnaire results presented in chapter 3 (attitudes towards the role of CBA) suffer from non-response bias. For instance, the result from the written questionnaire that 73 out of the 74 respondents who completed the questionnaire think that CBA should have a role in the appraisal process for spatial-infrastructure projects might be flawed if all 12 of the non-participants stated in the interviews that they think that the disadvantages of CBA are greater than the advantages. The results of this analysis are presented in table 6-3.

Table 6-3 Respondents and non-respondents' judgment on CBA's advantages versus disadvantages

\begin{tabular}{|l|l|l|l|l|}
\hline & Greater advantages & Greater disadvantages & Neutral & No answer \\
\hline Non-Respondents & $10(83 \%)$ & $1(8 \%)$ & $0(0 \%)$ & $1(8 \%)$ \\
\hline Respondents & $61(82 \%)$ & $6(8 \%)$ & $5(7 \%)$ & $2(3 \%)$ \\
\hline
\end{tabular}

Table 6-3 shows that non-respondents and respondents find that advantages outweigh disadvantages in approximately the same way. My hypothesis is that as a result of this observation it can be concluded that the probability of non-response bias with regard to this topic is low. However, I want to emphasize that I cannot prove that this hypothesis is true. Theoretically, it is possible that the 10 non-respondents who stated in the interview that 'advantages of CBA outperform disadvantages' would have stated in the questionnaire that they think CBA should have no role in the appraisal process for spatial-infrastructure projects. Then, as a consequence, the conclusion of this thesis - that there is consensus in the Dutch practice that CBA should have a role - is flawed. The only way to test this hypothesis is to force the non-respondents to fill out the questionnaire. 
Secondly, I analyzed the answers to the question that was asked in the interviews: 'what are the five most important substantive problems of evaluating spatial-infrastructure projects using CBA?' The hypothesis is that if non-respondents and respondents answer this question in a significantly different way, there is a high probability that the questionnaire results presented in chapter 2 (ranking the substantive problems of CBA) suffer from non-response bias. For instance, if the 12 respondents who did not complete the questionnaire all labeled 'problems with discounting' as the most important substantive CBA problem in the interviews, the result of the questionnaire - that only 5 out of 74 respondents labeled 'discounting' as a 'top 3 CBA problem' - might be flawed. This analysis was only carried out for the three problem clusters that were clearly ranked differently in the interviews and the written questionnaire, which were 'discounting', 'problem analysis' and 'presentation'. The results of this analysis are presented in table 6-4.

Table 6-4 Number of times problem clusters were mentioned by respondents and nonrespondents

\begin{tabular}{|l|l|l|l|}
\hline & Discounting & Problem analysis & Presentation \\
\hline $\begin{array}{l}\text { Mentioned as a problem by } \\
\text { non-respondents }\end{array}$ & $4(33 \%)$ & $0(0 \%)$ & $4(33 \%)$ \\
\hline $\begin{array}{l}\text { Mentioned as a problem by } \\
\text { respondents }\end{array}$ & $28(38 \%)$ & $10(14 \%)$ & $28(38 \%)$ \\
\hline
\end{tabular}

Table 6-4 shows that non-respondents and respondents mentioned a substantive problem that can be categorized in the problem clusters 'discounting' and 'presentation' approximately the same number of times. My hypothesis is that, as a result of this observation, it can be concluded that the probability of non-response bias with regard to both problem clusters is low and that the ranking of both problem clusters in the questionnaire analysis (see section 2.4.4) would not shift had the 12 non-respondents actually completed the questionnaire. A second observation that can be derived from table 6-3 is that none of the non-respondents mentioned 'problem analysis' as a problem cluster in the interviews. Hence, my hypothesis is that there is a possibility for non-response bias and as a result it is plausible that the problem cluster 'problem analysis' would have dropped from position three to position four or five in the questionnaire analysis. Again, the only way to test this hypothesis is to force the nonrespondents to fill out the questionnaire.

In conclusion, my view with regard to the non-response bias limitation would be that it is defendable to conclude that non-response bias exists in this thesis, but in a very limited way. Although I believe that the reader should keep this limitation in mind while using the results, my judgment would be that only the ranking of the 'problem analysis' problem cluster in the written questionnaire might be biased to a limited extent. The next question is whether or not it is actually a problem that the ranking of the 'problem analysis' problem cluster is biased to some extent? My answer would be that this is not a significant problem. The result that 19 key individuals in the Dutch CBA practice consider 'problem analysis' as the most important problem cluster is not affected. 


\subsubsection{Interviewer bias}

In section 1.4.4 I discussed which actions were taken to minimize 'interviewer bias' (Christiaans et al., 2004; Sarantakos, 2005) in this study. For instance, I decided that when starting a new topic in the interview, the first question should be the most important one for the data collection and after asking this question, I only started to ask clarifying questions when the respondent stopped speaking. This was done to make sure that the most important data that was generated from the interview was influenced (biased) as marginally as possible by the interviewer. Although attempts were made to minimize 'interviewer bias', I see different sources of potential 'interview bias'.

Firstly, all the statements made by the respondents after the interviewer asked the clarifying and the confronting questions can potentially be influenced by the questions asked by the interviewer and the way that the questions were asked. My hypothesis is, however, that the results of this thesis are not, or are only marginally, affected by this type of 'interviewer bias'. As discussed in section 1.4.4 the purpose of the starting question of each topic in the interview was 'to gather data' (for instance: 'what are the five most important substantive problems you perceive with the appraisal of spatial-infrastructure projects using CBA?'). The purpose of the clarifying and confronting questions was to understand the data. Some respondents did not mention any new substantive problems after this question and some did. To provide the reader with a feeling for the severity of this type of potential interviewer bias, for ten of the interviews (same interviews that were used for the intercoder reliability test, see 2.4.3) I analyzed which problem clusters were mentioned before the clarifying and confronting questions and which new problem clusters were mentioned after these questions. The results are presented in table 6-5.

Table 6-5: Problem clusters mentioned before and after clarifying and confronting questions

\begin{tabular}{|l|l|l|}
\hline & $\begin{array}{l}\text { Mentioned before additional } \\
\text { questions }\end{array}$ & $\begin{array}{l}\text { Mentioned as new problem after } \\
\text { additional questions }\end{array}$ \\
\hline Problem analysis & 1 & 0 \\
\hline Reference case & 3 & 1 \\
\hline Project alternative & 3 & 0 \\
\hline $\begin{array}{l}\text { Estimating non-monetized } \\
\text { effects }\end{array}$ & 8 & 2 \\
\hline Monetizing & 5 & 3 \\
\hline Discounting & 6 & 0 \\
\hline Presentation & 1 & 5 \\
\hline Distributional effects & 2 & 1 \\
\hline Uncertainty & 1 & 1 \\
\hline Total & $\mathbf{3 0}(\mathbf{7 0 \% )}$ & $\mathbf{1 3 ( 3 0 \% )}$ \\
\hline
\end{tabular}

Table 6-5 shows that the lion's share (70\%) of problem clusters mentioned in the interviews by respondents were already addressed before the clarifying and confronting questions were asked. Only $30 \%$ of the problem clusters mentioned could potentially be influenced by the interviewer's questions. One interesting outlier is the 'presentation' problem cluster. In 50\% of the interviews analyzed, a problem that can be categorized in this cluster was mentioned by 
the respondents after clarifying and confronting questions were asked and hence it is possible to conclude that this problem cluster potentially suffers from 'interviewer bias'. It is interesting to note that in section 2.4.3 it was concluded that this problem cluster also scored as relatively low on the intercoder reliability test and in section 2.4.4 it was concluded that this cluster scored as relatively low in the 'questionnaire analysis' compared to the 'interview analysis'. As a result of these two observations, I think it is possible to conclude that the results of the 'questionnaire analysis' should be considered to be more reliable for this cluster because the results of the 'interview analysis' for this cluster are potentially biased. For the other problem clusters I think that, based on the results of table 6-5, it is possible to defend the fact that interviewer bias is limited. However, potential interviewer bias might still exist to some extent for the problem clusters mentioned, after the clarifying and confronting questions were asked. Hence, it is interesting to analyze this in more depth.

Firstly, the respondents' answers after the clarifying and confronting questions were asked could have been influenced by the characteristics of the interviewer (see section 1.4.3 for characteristics). For instance, it is plausible that respondents - while preparing for the interview - found out on the internet that I am an economist and, as a consequence, would be more prone to mention 'technical economical topics' such as issues with the risk premium in the discount rate as substantive problems in the interview. Should this be the case, this effect might be one of the causes why the 'discounting' problem cluster ranked higher in the 'interview analysis' compared to in the 'questionnaire analysis'. To scrutinize this, it might be interesting to repeat the whole study under the condition that all of the interviews are carried out by a person with very different characteristics. A research question could be 'would the respondents mention more problems with monetizing environmental effects if the interviewer is a person with an educational background in ecology?'. Although carrying out this exercise is interesting from an academic perspective, it is questionable whether this would be practically feasible because many respondents might not be willing to spend time on an interview with exactly the same format. My stance is that it is very difficult to make a final judgment on the extent to which the results of this thesis are influenced by my characteristics when I interviewed the respondents. I believe that there are two indications for arriving at the conclusion that the influence was limited. Firstly, since the financiers of my project and other members of the consortium considered 'synergy effects' and 'reference case' as key CBA problems (see section 6.7.1), and these topics were discussed at the first meetings, my expectation was that the result of my research would be that these topics would receive the most 'votes' from the key individuals interviewed. I consider the fact that the results of this thesis were not in line with these expectations (see chapter 2) as a good indication that 'interview bias' is marginal. If the lion's share of the respondents would have mentioned 'reference case' and 'synergy effects' as key substantive problems, I would have been more suspicious. Secondly, I would not argue that I started the interviews without any knowledge and opinions about CBA, but it is safe to say that, when I started the interviews I had a lot of questions and basically no answers on the subject of CBA. When people asked me questions about the topic at that time, my answer was frequently: 'sorry, I do not have an answer'. Because I did not have a lot of opinions myself, I do not think that I influenced the answers of the respondents in a significant way. I believe that this would be very different today (June, 
2014). I have formed clear opinions about CBA related topics and also disseminate these opinions via various media. Hence, I think it is very likely that the 'interviewer bias' would be significant if I were to repeat the research again today. From this last observation, my hypothesis would be that the more the interviewer formed and disseminated his opinion with regard to a topic, the higher the probability that 'interviewer bias' occurs. If this hypothesis is true, the recommendation would be to select a person to carry out the interviews who is relatively ignorant about the topic .

Another type of potential 'interviewer bias' that I would like to address is that the knowledge of the interviewer with regard to the CBA topic and with regard to interviewing skills differed between the $1^{\text {st }}$ and the $86^{\text {th }}$ interview. In the period between the $1^{\text {st }}$ and the $86^{\text {th }}$ interview I read a lot of books and literature about CBA and also I learned a lot from the respondents. Hence, the quality of the clarifying questions and the confronting questions enhanced along the way and this might have influenced the results. Although I had a lot of experience with short interviews before I started this research, I did not have a lot of experience with longer interviews, which were carried out for this thesis. Along the way I noticed that my interview skills' improved (for instance, I improved the skill of waiting for a few seconds when the respondent stops talking before asking a clarifying question in order to see whether the respondent continues with sharing information. Also, I learned that the clarity of the data improved when I asked the question 'could you summarize your view on this topic in one sentence' as a closing question for a topic). As a result of this 'learning effect for the interviewer', the answers of the respondents could have been different had the respondents been interviewed in reversed order. The extent to which this effect is substantial and would influence the results is - in my opinion - difficult to determine. Comparing the characteristics and the answers of the first ten respondents and the last ten respondents, I did not see any clear patterns. However, I am aware of the fact that this does not mean that the effect is nonexistent.

A final source of potential 'interviewer bias' is that the 74 key individuals who completed the questionnaire might be influenced by the discussion that they had with the interviewer during their interview while filling out the questionnaire. For instance, when a respondent mentioned 'presentation' as an important substantive problem during the interview, subsequently the interviewer confronted the respondent with contradicting statements from respondents who had previously been interviewed. Unmistakably, some of these contradicting statements will have influenced the respondents' perceptions of the substantive problems they mentioned and this might have influenced their responses with regard to substantive problems in the written questionnaire and thus the results of this thesis. My hypothesis is that this source of 'interviewer bias' has a temporal component. More specifically, when the written questionnaire is filled out right after the interview, this source of 'interviewer bias' is more problematic than when it is filled out a year later. The questionnaire was filled out by 63 of the 74 respondents between half a year and one year after their interview and 11 of the 74 respondents filled out the questionnaire between two weeks and six weeks after their interview. My hypothesis is that the perceptions of these last 11 respondents could have been influenced by the discussion with the interviewer and this might be a source of 'interviewer 
bias' in the results of the written questionnaire. In addition, I believe that this source of 'interviewer bias' is limited or non-existent for the 63 respondents who were interviewed more than half a year before they filled out the written questionnaire. If this source of 'interviewer bias' is high it can be expected that it holds true that the interviewer confronted the respondents with contradicting statements, especially for the problem clusters that scored as relatively low in the 'questionnaire analysis' compared to the 'interviewer analysis' ('discounting' and 'presentation'). To provide the reader with information to help determine whether or not this is the case, for ten of the interviews (same interviews as table 6-5) I analyzed which problem clusters mentioned by the respondents were confronted with contradicting statements. The results are presented in table 6-6.

Table 6-6: Problem clusters confronted with contradicting statements

\begin{tabular}{|l|l|l|}
\hline & $\begin{array}{l}\text { Problem cluster confronted with } \\
\text { contradicting statement }\end{array}$ & $\begin{array}{l}\text { Problem cluster not confronted } \\
\text { with contradicting statement }\end{array}$ \\
\hline Problem analysis & 0 & 1 \\
\hline Reference case & 2 & 2 \\
\hline Project alternative & 1 & 2 \\
\hline $\begin{array}{l}\text { Estimating non-monetized } \\
\text { effects }\end{array}$ & 6 & 4 \\
\hline Monetizing & 6 & 2 \\
\hline Discounting & 2 & 4 \\
\hline Presentation & 1 & 5 \\
\hline Distributional effects & 2 & 1 \\
\hline Uncertainty & 2 & 0 \\
\hline Total & $\mathbf{3 0}$ & $\mathbf{1 3}$ \\
\hline
\end{tabular}

An interesting result of table 6-6 is that, although it was expected that 'discounting' and 'presentation' would have been more prone to contradicting statements because they ranked lower in the 'questionnaire analysis' compared to the 'interview analysis', this was not at all the case for the ten interviews analyzed. Hence, I think this is a strong indication that this source of 'interviewer bias' is limited or non-existent.

\subsubsection{Politicians underrepresented in this thesis}

An interesting observation regarding the methodology of this study is that although politicians are actors in the decision-making process regarding spatial-infrastructure projects, and they have to make a decision - informed by a CBA - about the development of a spatialinfrastructure project, only four (ex) politicians were mentioned by respondents as people that needed to be interviewed in order to make sure that the entire population of key actors in the Dutch CBA practice for spatial-infrastructure projects was interviewed (only two of the four politicians were interviewed). This is a limitation of this thesis. Further research may study the perceptions of (Dutch) politicians regarding the topics investigated in this thesis (or other topics).

\subsubsection{Low intercoder reliability}

I regard the low scores of the first phase of the intercoder reliability test in chapter 3 as a fourth limitation of this thesis. The most important reason for the low intercoder reliability 
score was that the coding task was complex. Parts of the 'coding and categorizing protocol' were very difficult to understand for the independent coder, leading to coding errors. For more details regarding the explanations for the low intercoder reliability scores, I refer to Mouter and Vonk Noordegraaf (2012). In all, I regard the 'ranking of CBA advantages and CBA disadvantages' by key individuals in a CBA practice for spatial-infrastructure projects as an interesting topic for further research.

\subsubsection{Limited geographical and temporal transferability}

A fifth limitation is the limited geographical transferability of the findings to other practices. Because CBA guidelines and the way CBA is embedded in the decision-making process differs in place and time (e.g. Hayashi and Morisugi; Mackie, 2010; Turner, 1979 2000), the findings are not necessarily applicable to CBA practices in other countries. Hence, I think that the findings of this thesis should be considered as a building block for 'the superior international CBA model', suggested by Hayashi and Morisugi (2000). Hayashi and Morisugi (2000, p 87) state that 'by conducting a careful study on the components of the different models, it would be possible to come up with a superior model by integrating all the good components of the existing models. This is a simple case of learning from each country's experience'. A suggestion for generating more building blocks is to replicate this study in other CBA practices and compare the results with this study.

Besides the limited geographical transferability of the results of this thesis, I think it is possible to argue that the temporal transferability of the results, especially those in chapter 2 (substantive problems), is limited in the Netherlands. When a large research project is started in the Netherlands to iron out several problems perceived by key individuals, it is possible that the ranking of substantive CBA problems shifts as a result of this research project. For example, in the past few years several research projects were undertaken in the Netherlands to operationalize the external effects of spatial-infrastructure projects (e.g. Romijn and Renes, 2013a; Wever and Rosenberg, 2012). Hence, it is possible that key individuals who considered 'problems with operationalizing external effects' as an important substantive problem at the time they were interviewed (2010-2011), no longer consider this a problem today (June, 2014).

Also, CBA practice in the Netherlands is subject to change and therefore the answer to the question of which people are considered to be 'key individuals' is subject to change. A recent trend in the Netherlands is that - besides the National Government - decentralized governments started to use CBA as an input in the decision-making process. Larger municipalities like Eindhoven, Amsterdam and The Hague and smaller municipalities like Tholen (7,600 inhabitants) all used a CBA as ex-ante information in the past few years. Hence, it is possible that controllers at these municipalities should be included in the population of key individuals in the present-day (June 2014). Another recent trend is that Dutch politicians actively started to use CBA results in debates on the Dutch spatialinfrastructure investment program. To illustrate, in the debate on November $25^{\text {th }}, 2013$ (Houses of Representatives, 2013) the term 'CBA' was used 53 times (the transcription of the debate was 104 pages long) whereas in the debate on December $11^{\text {th }}, 2011$ (Houses of 
Representatives, 2011) the term 'CBA' was used 4 times (the transcription of the debate was 109 pages long). Probably as a result of political attention to CBA in the status quo (2014), the media also increasingly uses the results of CBA reports. Hence, I think that if this study was repeated in the present-day 'journalists that frequently use CBA reports for writing articles' should be included in the population. Also, the underrepresentation of politicians would be more problematic. The limited temporal transferability of this thesis for the Netherlands could be taken as an argument to repeat this research when it is noticeable that the Dutch CBA practice has significantly altered compared to the Dutch CBA practice in $2010-2011$.

\subsubsection{Time constraint in the interviews}

I can't emphasize enough how grateful I am that 86 people with busy agendas were willing to schedule one hour of their time for an interview and that 74 people were willing to fill out an additional questionnaire. However, the limited amount of topics that were touched upon in the interviews (and the written questionnaire) should be considered as a limitation of this thesis. The topics scrutinized were relatively general (e.g. what are the (solutions) for substantive CBA problems?). It was not possible to systematically ask the respondents questions such as: 'how do you think uncertainties surrounding effect estimations should be communicated in CBA reports and why?'; 'What do you consider to be the criteria of a high-quality problem analysis?' etc. I think that it would be interesting to study a selection of these more specific topics in further research.

\subsubsection{Solutions are not tested in practice}

The main objective of this thesis is acquiring a thorough understanding of the way CBA is perceived by different key individuals that use, carry out or study CBAs. Amongst other things, perceptions of key individuals with regard to substantive CBA problems, CBA (dis)advantages and the role of CBA in the decision-making process are surveyed. Also, key individuals proposed solutions to rectify substantive CBA problems and solutions to manage inherent CBA limitations. In my opinion, some of the proposed solutions can be labeled as 'no regret', which I conceptualize as solutions that have no or little costs in terms of time, money and potential adverse effects. These solutions can be implemented without any further research. However, as already discussed in chapters 4 and 5, for the majority of the proposed solutions it holds true that the extent to which the solution is promising is currently uncertain. In my opinion, it is important to evaluate, test and refine these solutions in practice (in section 6.6.4 I will discuss this more in-depth). I consider the fact that the proposed solutions have not been evaluated, tested and refined in practice at present as a limitation of this thesis.

\subsection{Policy recommendations}

In this section I will list the most important recommendations for (especially Dutch) policy makers that can be derived from the findings of this thesis. ${ }^{49}$

\footnotetext{
${ }^{49}$ In this section, I only discuss policy recommendations that can directly be deduced from the perceptions of the 86 key individuals presented in chapters 2-5. Because, for some topics, it holds true that the recommendations are relatively generic (for instance 'ex-post analysis' and 'problem analysis'), I will discuss more specific recommendations with regard to these topics in section 6.5 .
} 
Seven topics are distinguished within the recommendations. Each sub-section discusses one topic.

\subsubsection{Maintain CBA in the appraisal process for spatial-infrastructure projects and use it in a 'subtle way'}

The first and foremost policy recommendation is to maintain a role for CBA in the planning and decision-making process for spatial-infrastructure projects. An important result of this thesis is that key individuals agree that CBA must have a role in the appraisal process of spatial-infrastructure projects. I did not a priori expect such a wide support for CBA among the key individuals interviewed for this thesis. Before I started gathering data I often heard the following statement at conferences and workshops: 'you are either a CBA Believer or a nonBeliever'. Also influential scholars use this dichotomy in their publications (e.g. Sen, 2000). Based on the findings of this thesis it is possible to conclude that - with respect to the Netherlands - this dichotomy does not exist. I recommend emphasizing this when the 'Believer/non-Believer myth' is raised in discussions. Emphasizing that there is broad consensus among key individuals in the Dutch CBA practice that CBA is indeed a useful tool in the planning and decision-making process for spatial-infrastructure projects might improve the acceptability of using CBA.

From this thesis it can be deduced that economists and spatial planners perceive that individuals other than themselves in the Dutch CBA practice assign a value that is too absolute or too marginal to $\mathrm{CBA}$ results in the decision-making process regarding spatialinfrastructure projects and that this is problematic.

In chapters 3, 4 and 5 I conclude that a 'subtle' use of CBA (not assigning an absolute or marginal value to the $\mathrm{CBA}$ and thus using $\mathrm{CBA}$ as an instrument with advantages and limitations) is desirable. How could policy makers be helped to use CBA in a 'subtle' way? Below, I present recommendations that were deduced from the statements of key individuals.

Firstly, although I am aware of the fact that politicians are prone to use the CBA in a strategic way (if the CBA outcome does not support the political interest the politician emphasizes the limitations of the method, and when the CBA outcome supports the political interest the politician ignores the limitations of the CBA) I recommend that politicians should communicate - more than they do at present - that they will assign an important but, at the same time, not too absolute a value to the CBA in the decision-making process for a specific spatial-infrastructure project (see also chapter 3).

A second recommendation for improving 'subtle use' - discussed in chapter 4 - is that the intelligibility and verifiability of CBA reports should be enhanced. A poor intelligibility and verifiability of effect estimations in CBA reports might lead to distrust and rejection of the results of the CBA study. According to the key individuals very few examples of CBA studies exist that provide sufficient data to make it possible for readers to verify the effect 
estimations. In chapter 4 key individuals mention different solutions to enhance the intelligibility and verifiability of CBA reports. However, the proposed solutions that aspire to enhance the verifiability and intelligibility of CBA reports point in opposite directions (solutions to enhance intelligibility advocate a simplification of the CBA report, whereas solutions to enhance the verifiability of effect estimations lead to more complexity). The 'digital multi-layered CBA' seems to be a solution which is able to reconcile both objectives (intelligibility and verifiability). This 'digital multi-layered CBA' aims to fulfill both the need of the group of readers that want to find relevant information as soon as possible and the need of readers that want to know in detail how every effect is estimated in the CBA study.

Finally, chapter 5 discusses fourteen solutions that aspire to enhance the subtle use of CBA by minimizing or managing insolvable CBA limitations. The solutions that aim to minimize limitations predominantly focus on providing more comprehensive information regarding project consequences compared to current Dutch CBA studies. This, in order to strengthen the usefulness of CBA in the decision-making process, for instance, by taking into account more welfare effects using 'Effect Arenas ${ }^{, 50}$ and by providing high quality information regarding intangible effects and distributional effects. As a result, the comprehensive CBA report provides high quality information regarding non-quantified effects, effects that are difficult to monetize and distributional effects alongside the monetized effects summarized in a final indicator. I think it is interesting for developers of CBA Guidelines and CBA practitioners to contemplate whether these solutions enhance the comprehensiveness of CBA reports. The solutions that aim to manage limitations predominantly focus on the communication of the existence of CBA limitations to non-expert users - for instance, decision makers who are important users of CBA reports - to enhance their understanding of the limitations. The CBA practitioner should inform the non-expert user adequately in the CBA report about the incompleteness of the analysis, the uncertainties of effect estimations and the relatively weak position of effects that are difficult to quantify/monetize. An adequate communication of limitations means that CBA practitioners communicate limitations in a more prominent way than they do at present, but at the same time, must be cautious about communicating CBA limitations in too prominent a way. Politicians will probably not consider CBA reports that endlessly emphasize the limitations of a study as a solid basis for decision making. A remaining question is: 'what is exactly an adequate communication of limitations?' The paper included in Appendix I provides building blocks for an answer to this question on which further research with regard to this topic can build.

\subsubsection{Design CBA research agendas based on different inputs}

In chapter 4 I recommend using three types of input as a guiding principle for designing CBA research agendas: 1) Key individuals' perceptions of solutions; 2) Solutions discussed in scientific literature; 3) Solutions implemented in other countries.

\footnotetext{
${ }^{50}$ I am aware of the fact that the concept 'Effect Arena' is not unambiguously defined in the Dutch appraisal practice. In this thesis 'Effect Arena' is defined as: a meeting with the aim to give all relevant actors the opportunity to articulate which effects they think will accrue as a result of the project. To be clear, only effects that increase national welfare are included in the CBA (the idea of the Effect Arena is that the CBA analyst can clarify to other actors why the non-welfare effects will not be included in the CBA report).
} 
Key individuals' perceptions should be considered because key individuals provide solutions on topics for which solutions are scarcely addressed in existing literature. Solutions discussed in academic literature and solutions implemented in other countries are very valuable input as well, for instance when key individuals in the practice under scrutiny are relatively unaware of solutions for CBA problems discussed in other countries or in existing literature. In the Netherlands, for instance, it seems that - in the status quo - there is an unawareness of stateof-the-art developments in literature regarding discounting. From chapter 2 it can be derived that Dutch key individuals perceive 'problems with discounting' as the least important problem category and none of the respondents mentioned solutions to this topic that are prevailing in current literature (see for instance, Atkinson and Mourato 2008; Arrow et al., 2012; Gollier, 2012; Groom et al., 2005).

\subsubsection{Prescribe clearly what a high-quality problem analysis should entail}

Another policy recommendation for developers of (Dutch) CBA guidelines that can be derived from this thesis is that CBA guidelines should clearly prescribe what a high-quality problem analysis entails. In the (Dutch) status quo, the criteria for determining the extent to which a problem analysis is 'high-quality' are not clear. The new Dutch CBA Guideline (Romijn and Renes, 2013b) states that criteria for developing high-quality problem analyses should be conceptualized in the domain-specific CBA guidelines (such as the domain-specific CBA Guideline for spatial-infrastructure projects). An important challenge for the developers of domain-specific CBA guidelines is to decide whether the problem analysis is a copy of the problem that is perceived by politicians and stakeholders or that CBA practitioners should be urged to reflect in a critical way on the problems (and solutions) perceived by the politicians and stakeholders.

\subsubsection{Identify whether or not a problem is a specific CBA problem}

An interesting conclusion of this thesis is that a large part of the substantive problems mentioned by the key individuals in Dutch CBA practice are not specifically CBA related (see chapter 2). If people experience problems with the estimation of the non-monetized project effects (the problem cluster most mentioned) or other non-specific CBA problems, they would face the same problem when using other ex-ante impact studies (e.g. multi-criteria analysis, cost-effectiveness analysis, environmental impact analysis). Because of this, a policy recommendation is that it would be wise to identify whether or not a specific or a non-specific CBA problem is emphasized when the use of CBA in a particular decision-making process regarding spatial-infrastructure projects is criticized. When a non-specific CBA problem is used as an argument to criticize the use of CBA in the decision-making process, one should emphasize that other ex-ante impact evaluation studies have to face the non-specific CBA problems as well. This might improve the acceptability of CBA as an ex-ante evaluation method and the usage of CBA in the decision-making process regarding spatial-infrastructure projects.

\subsubsection{Institutionalize 'ex-post analyses'}

A policy recommendation that is brought forward in almost every thesis that studies the appraisal of infrastructure projects is that 'ex-post analyses' - in which ex-ante estimations of 
CBA studies are verified - should be carried out on a systematic basis (e.g. Cantarelli, 2011; Nicolaisen, 2012). Institutionalizing 'ex-post analyses' is also a recommendation that can be derived from this thesis. Key individuals believe that 'ex-post analyses' might help by improving models, rules of thumb and standard national numbers that are used to estimate project effects for specific CBA studies. As a result of 'ex-post analyses' uncertainty with regard to effect estimations can be diminished when ex-ante effect estimations are verified.

\subsubsection{Make sure that CBA studies are reviewed in a second opinion}

Another policy recommendation that can be derived from this thesis is that the quality of CBA studies should be reviewed with a second opinion. Key individuals consider second opinions of CBA studies as very advantageous. Predominantly private consultants stated in the interviews that they can use the fact that the quality of the CBA will be assessed in a second opinion as a 'weapon' to convince the client to carry out a CBA that can be considered to be 'as independent as possible'. Hence, my recommendation is to make sure that CBA studies are reviewed with a second opinion.

\subsubsection{Disseminate new CBA insights in the Dutch CBA practice via experts}

An interesting finding from this thesis is that five individuals invited for this study who had a leading position within their organization told me that for CBA related issues they consulted the CBA expert in their organization when preparing their response (see section 6.3.1). Moreover, several respondents made the following remark during their interview: 'if I do not know the answer I always go to 'Person $A$ ' because he/she is the CBA expert in our organization'. Based on these statements, my hypothesis is that the most effective way to disseminate new CBA insights in the Dutch CBA practice is to identify 'the CBA expert' in each relevant organization and make sure that this expert is familiar with the new insights. Subsequently, it is very likely that these new insights will be distributed through the organization via these CBA experts.

CBA experts in Dutch organizations who read this recommendation might be interested in the 'new CBA insights' that I see as 'need to know'. My aim is not to provide an exhaustive list of foreign publications and the remark should be made that another academic will probably come up with another list:

- Arrow et al. (2012); Gollier (2012); Weitzman (2012) with regard to 'discounting';

- Börjesson and Eliasson (2014); Daly et al. (2011) with regard to the value of time and the value of small time savings in CBA;

- Nicolaisen (2012) with regard to uncertainty in effect estimations for transport projects;

- Eliasson and Lundberg (2012) with regard to the role of CBA in the decision-making process;

- Nyborg (2012) with regard to the concept 'welfare' and distributional effects. 


\subsection{Possible implications for the design of a planning model for spatial- infrastructure projects}

During the past few years I have presented the conclusions and recommendations listed in the previous sections on many occasions. One comment I frequently received was: 'you interviewed 86 key individuals and then these are your only conclusions and recommendations? You should be able to draw a stronger set of conclusions and provide more specific recommendations for the design of spatial-infrastructure planning models and the role of CBA therein' (also reviewers of chapters 2-5 made this remark). My answer usually was: 'my role as a scientist is to present the results of my study and it is up to policy makers to decide about the implications'. As Pielke jr. (2007) coins it, I took the 'pure scientist' role. However, during one presentation, an attendee made the following remark: 'you owe it to the tax payer to express the views you developed during your study with respect to ideas for adjusting the design of the planning and decision-making model and then we can always decide whether we are inspired by your views or if we disagree with you'. After this presentation I realized that the result of taking the 'pure scientist' role was that I had a clean pair of hands but that I left the attendees empty-handed. To rectify this, I will give my views on the possible implications for the design of the Dutch planning and decision-making process for spatial-infrastructure and the role of CBA therein.

Besides complying with the demand of reviewers and attendees at presentations, I think there are two additional arguments for elaborating on the recommendations presented in the previous section. Firstly, between submitting chapters 2-5 for publication in scientific journals and the publication of this thesis, I read contributions in literature which - in my view - can enrich the policy recommendations presented in section 6.4. Hence, I will sustain my argument with respect to the possible implications for the Dutch planning and decisionmaking process not only on the results presented in chapters 2-5, but also on these contributions in current literature. Secondly, some of the recommendations discussed in section 6.4 might be too generic to be of any use for Dutch practitioners. For instance, when reading the recommendation 'carrying out 'ex-post analysis' in a systematic way' it might be difficult for Dutch practitioners to know what to do because many questions are unanswered (should we carry out simple or comprehensive 'ex-post analyses'? For all projects or only for very large projects?). To make these recommendations more specific, I will discuss my views on possible specifications in this section.

My aim is to take the role of the 'Honest Broker of Policy Alternatives' instead of the 'Issue Advocate', which means that my aim is to provide several options when discussing implications with respect to the design of the Dutch planning model without aligning myself with one specific option (Pielke jr., 2007). Naturally, the reader is invited to disagree with the options I propose and draw their own set of conclusions.

\subsubsection{The importance of connecting CBA to interactive phases in the planning process} Analyzing the recommendations listed in section 6.4, I think it is striking that the majority of the recommendations resulting from a study that focuses on substantive CBA problems, CBA 
(dis)advantages and the role of CBA point at the interface between the CBA and other phases of the Dutch planning and decision-making process for spatial-infrastructure projects. I think it can be concluded that the key individuals are in need of a situation in which the CBA is smoothly connected with phases before and after the study. On the other hand, I think this result is not surprizing because the main result from a dissertation that studied the use of analytical information in the Dutch planning process (van de Riet, 2003) was that in a multiactor policy setting knowledge can only become useful when it smoothly connects to the policy process. In the next subsections (6.5.2 and 6.5.3) I will list ideas for enhancing the connection of the CBA with the planning processes before and after the CBA. Finally, I will argue in section 6.5.4 that preserving credibility of CBA studies is important for safeguarding the useful role of the instrument in the planning process and discuss lines of solutions for preserving credibility.

Although the way the 'rational planning perspective' and the 'interactive planning perspective' are blended into the Dutch planning and decision-making model for spatialinfrastructure is discussed in depth in section 1.5, I think a short recap of the main characteristics is worthwhile before I embark on the discussion. In the first years of the planning and decision-making process, the 'interactive planning perspective' dominates 'the rational planning perspective'. The output from this first phase provides three potentially favorable alternatives. After selecting these three alternatives, the 'interactive planning perspective' is put on hold for a while and 'the rational planning perspective' enters the scene. The effects of the three alternatives are evaluated in a Cost-Benefit Analysis. After the CBA results are reported, the 'interactive planning perspective' informed by the results of the CostBenefit Analysis, starts up again and continues to be the dominant perspective until the final decision is made.

\subsubsection{Recommendations for connecting CBA with the early planning process}

\subsubsection{Problem analysis as a bridge between CBA and the interactive process}

In the Dutch planning and decision-making process for spatial-infrastructure projects the problem analysis could be regarded as the bridge between the Cost-Benefit Analysis and the planning process preceding the CBA. As discussed in section 1.5 the 'problem analysis' in the first year of the 'exploration phase' of the Dutch planning and decision making model is highly influenced by the 'interactive planning perspective'. Politicians, civil servants, stakeholders and the public are invited to share and discuss their views on problems, ambitions and challenges and at the end of the day a joint vision on the problems, ambitions and challenges is formulated (Ministry of Infrastructure and the Environment, 2010). Based on this problem analysis, three potentially favorable alternatives are selected.

One of the findings of this thesis is that especially academics, consultants and other researchers do not believe that a CBA practitioner should uncritically accept the problem definition that results from the interactive process. Hence, the authors of the first CBA guideline in the Netherlands (Eijgenraam et al., 2000, p. 10) labeled the 'problem analysis' as the first phase of a CBA in which the political problem definition should be assessed in a 
critical way. Many key individuals interviewed in the context of this thesis emphasized that it is worrying that the lion's share of problem analyses carried out in CBAs are - only - copies of the political problem definition. One of their arguments is that the added value of the CBA is suboptimal if the problem definition is 'analytically incorrect'. In the following textbox, I will give a fictive example of a political problem definition that can be considered as 'analytically incorrect'.

\section{Textbox: an 'analytically incorrect' problem definition}

Politicians and stakeholders agree that the public transport accessibility of 'City A' is a problem that has a very negative effect on the business climate of 'City A'. As a solution for this problem the construction of a High Speed Railway between 'City A' and 'City B' is proposed. Many consultants and researchers interviewed for this thesis believe that it is not sensible to uncritically accept this political problem definition and verify the problem perception by asking companies located in 'City A' (or companies who are considering moving to 'City A') to elaborate on the pros and cons of the business climate in 'City A', for instance. Let us assume that the result of this survey is that companies evaluate 'public transport accessibility' as 'sufficient' and also state that it is an insignificant variable in their evaluation of the business climate. Moreover, companies state that the business climate is negatively affected by other factors, such as the level of education of the people living in or around 'City A'. In this case, the political problem definition 'public transport accessibility of 'City $A$ ' is a problem because it harms the business climate' can be evaluated as 'analytically incorrect' or even worse 'negotiated-nonsense' (van de Riet, 2003).

\section{What is the problem?}

At present, both the interactive process, which leads to the political problem definition and the analytical verification of this political problem definition are coined as 'problem analysis'. Hence, it is not clear what a 'problem analysis' exactly entails. The result is that at the moment when participants in a discussion use the term 'problem analysis', it is highly probable that people will talk around each other for the next couple of minutes ending up in Babel-like confusion or - even worse - in 'dialogues of the deaf' (van Eeten, 1999). The result is that the connection between the 'interactive planning process' and the Cost-Benefit Analysis (rooted in the rational planning model) is far from smooth. In contrast, discussions about 'what is a good quality problem analysis' held between people who participated in the interactive process and CBA practitioners might end up in frustration (Mouter, 2013a).

\section{What are the solutions?}

To my knowledge, two solutions for rectifying this issue are discussed in the Netherlands. Baarsma et al. (2010), Hajer et al. (2010), Romijn and Renes (2013b) and Mouter and Pelzer (2013) mention the involvement of CBA practitioners in the early planning phase as a key solution. The result is that - besides politicians, stakeholders and citizens - CBA practitioners also participate in the interactive planning process, during which problems and solutions are jointly formulated. Although none of the publications strictly defines the role of the CBA practitioner in the interactive planning process, the main idea is that the CBA practitioner asks 
questions to encourage the other practitioners to examine the problems they perceive in more detail with empirical information (For how many people is this a problem? How severe is the problem? Will there still be a problem ten years from now?); he encourages the other practitioners to test the claims they make with regard to the effects of the solutions and he provides the other participants with 'back of the envelope' estimations of costs and benefits of the project proposals. As a result, the other participants in the multi-actor policy setting are already familiar with the 'CBA way of thinking' early in the process, which might diminish the 'cold feet experience' when a CBA is carried out to evaluate the welfare effects of the three favorable alternatives.

A second solution that I discussed in Mouter (2013a) is to separate the 'political problem definition' from the 'analytical problem analysis' and accept that the outcome of both exercises can differ. Politicians and stakeholders can, of course, decide to neglect the 'analytical problem analysis'. However, my hypothesis is that the 'analytical problem analysis' might at least lead to 'stop and think' (Christensen, 2009), which means that politicians and stakeholders are urged to think whether or not they have to redefine their 'political problem definition' if it significantly deviates from the 'analytical problem analysis'. I consider the question 'which of the two solutions helps the smooth connection between the pre-CBA interactive planning process and the CBA in the best way?' as an interesting topic for further research. Also, I recommend surveying whether other solutions are available in current literature or in other CBA practices that could be included in this study.

\subsubsection{The Effect Arena as a method for involving stakeholders in the preparation of a CBA}

A solution discussed in section 5.5 is organizing 'effect survey meetings' (Effect Arenas) preceding a CBA study. In this meeting all actors who participated in the interactive planning process preceding the CBA get the opportunity to articulate which effects they think will accrue from the project. The purpose of this meeting is fourfold. Firstly, project effects that would be overlooked without an Effect Arena will now be included in the CBA study. Secondly, support for the use of CBA to appraise spatial-infrastructure projects might increase when stakeholders who participated in the interactive planning process are actively involved in the preparation of the CBA study (e.g. Enserink, 2000). Thirdly, the CBA practitioner has an opportunity to discuss with stakeholders why the effects they perceive are non-welfare effects and will not be included in the CBA study. My hypothesis is that this can diminish the probability that stakeholders consider the CBA as an 'invalid study' which does not consider effects from which they had high expectations. Fourthly, if CBA practitioners and other participants in the interactive planning process did not discuss the problem analysis earlier in the process - which I think is recommendable - the Effect Arena can be an occasion to discuss this topic.

A concluding remark that I want to make is that in the CBA processes I personally witnessed, Dutch CBA practitioners already spontaneously organized kick-off meetings with stakeholders in which they discussed the rationale of the project, perceived effects and the 
basics of CBA methodology. Hence, this recommendation is especially useful for CBA practitioners who have not incorporated this in their practices already.

\subsubsection{Recommendations for connecting CBA to the planning process after the CBA}

Analyzing the results of this thesis, I think two things are key for ensuring that participants in the interactive planning and decision-making process can fruitfully use the information. Firstly, the way the information is presented should be in line with the capabilities, needs and timetables of the people who aspire to use the information in the planning and decisionmaking process. Secondly, the results of a CBA report can only be used in a fruitful way in a multi-actor setting when participants in the discussion are aware of the advantages and the limitations of the method. Just as it is sensible to read the leaflet before one uses heavy medication, it is also sensible to get acquainted with the key advantages and limitations of CBA before one uses its information in a multi-actor policy setting. In this section I will discuss both topics. Also, I will discuss two other solutions related to the connection of CBA with the planning phase after the CBA.

\subsubsection{Dissemination of results should be fine-tuned with the users of information}

A first solution for enhancing the extent to which people who aspire to use the information in a CBA understand the results is by presenting information in a 'digital multi-layered CBA', which might enhance the intelligibility and verifiability of the results of the CBA and, as a consequence, improve trust in the instrument. In my opinion, cost-efficiency is of key importance for the design of the 'digital multi-layered CBA' because CBA practitioners have to compete for a CBA tender in the Dutch CBA practice. To win a tender the price-quality ratio of their offer must outperform the offers of the competing CBA practitioners. Hence, I believe that an important characteristic of the 'digital multi-layered CBA' should be that it does not enhance the price of the tender. Moreover, I think that sharing the lump sum development costs for the software of the 'digital multi-layered CBA' between various CBA practitioners will contribute to the feasibility of this solution.

Secondly, I think the smoothness of the connection between the CBA and the policy process after the CBA can be improved when the CBA practitioner discusses the results of the CBA report with the people who are going to use the CBA report. This is an excellent opportunity for the CBA practitioner to answer the questions raised by the people who are going to use the CBA in the interactive process. Thirdly, I believe that it is sensible to communicate to the people who attended the Effect Arena (which are probably the same people who are going to use the CBA in the policy process) where in the report they can find the effects they raised during the meeting.

\subsubsection{Enhance the 'subtle use' of CBA in the planning and decision-making process}

One of the results of this thesis - discussed in chapters 3 and 5 - is that CBA should be used in a 'subtle way' (not assigning an absolute or marginal value to the CBA and thus using CBA as an instrument with advantages and limitations) to ensure a fruitful contribution to the planning and decision-making process. To attain a 'subtle use of CBA' I think it is essential to make people who aspire to use CBA aware of CBA advantages and limitations. I see multiple solutions to attain this goal. Firstly, a fact sheet discussing the key advantages of the method, 
its key limitations and the purposes for which one can use CBA can provide participants in a meeting in which CBA plays a role with this key information. Secondly, policy makers should explicitly discuss the advantages and limitations of the CBA method as a first point on the agenda in meetings in which CBA plays a role. My hypothesis is that the probability that people will assign a value that is too absolute or too marginal to CBA in a discussion, diminishes when the participants in a discussion are fully aware of both CBA advantages and CBA limitations. Thirdly, I think that guidelines, publications and CBA reports should not only explain what a CBA is, but also discuss CBA advantages and CBA limitations. In chapter 5 I discussed a variety of solutions with respect to adequately informing the nonexpert users of a CBA study in the CBA report about the incompleteness of the analysis, the uncertainties of effect estimations and the relatively weak position of effects that are difficult to quantify/monetize.

\subsubsection{Other solutions focusing on the connection between $C B A$ and the planning phase after}

\section{$\underline{C B A}$}

A first additional solution for smoothing the connection between CBA and the phase after the CBA is that it is important to make it explicit exactly which purpose(s) the participants in a multi-actor policy process will use the CBA for. In chapter 3, I discussed the fact that key individuals perceive that the CBA can be used for various purposes. In the status quo, situations in which different participants in a planning process agree that it is useful to carry out a CBA but implicitly disagree about 'the' role (for instance, the spatial planner to use the CBA as a discussion platform and the economist to support the final decision) could lead to confusion and frustration. Hence, I recommend starting a meeting in which CBA plays a role with an inventory of the perceptions of the various actors that are participating in the discussion with regard to the role they think the results of the CBA study should play in the decision-making process. Explicit communication of any differences of opinion with respect to this topic might lead to mutual understanding (agree to disagree) which could iron out any frustration.

A second potentially interesting solution for enhancing the extent to which CBA information contributes to multi-actor policy settings, proposed by Nyborg (2012), is that CBA should provide policy makers with objective information instead of normative information. The essence of Nyborg's argument is that CBA measures aggregate net willingness to pay for a project and does not measure the 'social welfare effect' of a project. If the sum of everyone's willingness to pay for a project exceeds the project's total costs, this does not automatically imply that the 'social welfare effect' of the project is positive. According to Nyborg the concept 'social welfare' is a normative concept. What is 'good for society' is a normative question and thus cannot be answered objectively. When one would ask actors participating in a discussion to define 'social welfare' they will probably give different answers. If the CBA practitioner decides that only one definition of 'social welfare' is valid this may lead to a situation in which actors who disagree with this definition will rightfully disregard the analysis altogether because it is based on normative views that they do not share (Nyborg, 2012). Hence, Nyborg's recommendation is to leave normative judgments on 'the social welfare effect of the project' to actors in a decision-making process and to interpret the 
outcome of a CBA study as an estimation of aggregate net willingness to pay for a project, which is an objective (ethically and politically neutral) criterion and makes the conclusions of the report acceptable for participants with different ethical and political views.

\section{Textbox: specific recommendations when CBA is used within and between organizations}

I believe that the recommendations listed above are particularly interesting for using CBA $\underline{\text { within }}$ an organization in which both economists and spatial planners are employed. When the extreme positions of economists and spatial planners with regard to the role CBA should play in the decision-making process lead to severe controversy, the recommendations might attribute to arriving at a more 'subtle use' of CBA, which may possibly rectify the controversy. The Secretary General of the Ministry of Infrastructure and the Environment, Siebe Riedstra, labeled this issue as the most important issue he experienced with CBA within the organization, when speaking at the Young Scientist meeting (June 23th, 2011 at the Ministry of Infrastructure and the Environment, Impression Ymkje de Boer). He said that since the merger between the Ministry of Housing, Spatial Planning and the Environment with the Ministry of Transport, Public Works and Water Management the main issue with respect to CBA is that there are 'Believers' and 'Non-Believers' and that his goal was to bridge the gap between the two camps'.

I think that - based on this statement by the Secretary General - it can safely be concluded that the recommendations discussed in this section were extremely relevant for applying CBA within the Ministry of Infrastructure and the Environment in 2011 (a few years after the merger). However, I think it is interesting to analyze the extent to which these recommendations are 'extremely relevant' in the present-day (June, 2014). When we assume that the 'collaborative effect (when an economist and a spatial planner work together on a project in which CBA plays a role, the former learns about CBA limitations and the latter learns about CBA advantages, as explained in section 6.1.2) is strong, it is possible that the economists and spatial planners within the Ministry of Infrastructure and the Environment learned 'by trial and error' to apply CBA in a subtle way and the controversy between 'Believers' and 'Non-Believers' is not 'extremely relevant' anymore. I think it is interesting to analyze this in further research. Should the outcome of this research show that 'the gap between CBA Believers and Non-Believers still exists', a recommendation would be to start a CBA-related project with economists and spatial planners working together. An interesting project could be the implementation of the recommendations from the Dutch General CBA Guidelines (Romijn and Renes, 2013b) into the framework for applying CBA for spatialinfrastructure projects (Ministry of Infrastructure and the Environment, 2012), which needs to be carried out anyway. Also, I think that the outcomes of analysis on the way that the controversy developed between economists and spatial planners with respect to CBA in the Ministry of Infrastructure and the Environment after the merger in 2009 can be used in countries like Sweden, Norway and Denmark, where several transport-related organizations have recently merged.

I also believe that the recommendations listed in this section are interesting for using CBA $\underline{\text { in }}$ a context in which both organizations where mainly spatial planners are employed and 
organizations where mainly economists are employed have to use the information of a CBA study in a discussion about a specific project. My hypothesis is that by not taking these recommendations seriously, with regard to the use of CBA, it could easily lead to a situation in which frustrations about the perceived incorrect use of CBA could dominate the debate and the discussion on the usefulness, necessity and design of a spatial-infrastructure project would deteriorate (instead of improve) as a result of using a CBA (see section 5.4.2 for the underpinning of this hypothesis).

\subsubsection{Usefulness of CBA in multi-actor policy settings enhances when credibility is safeguarded}

Bozeman and Landbergen (1989) discuss the idea that because participants in a multi-actor policy setting can have different belief systems and values, searching for the 'objective truth' is frequently too ambitious. As an alternative for the 'truth-seeking approach', Bozeman and Landbergen (1989) argue that it is important to seek for a study which is considered by participants in a multi-actor policy process to be 'credible', which means that the different actors can follow (yet not necessary agree with) the logic of the study. When important stakeholders have doubts about the credibility of a study, this can easily lead to knowledge fights (van Buuren and Edelenbos, 2004). Also, it is difficult for stakeholders to accept decisions that are based on a study which is, in their view, dodgy. Kørnøv and Thissen (2000) state that improving the scientific quality of a study may not necessarily enhance the extent to which participants in a multi-actor policy setting perceive the study as credible and useful. Hence, my hypothesis is that not only the quality of CBA studies but also the credibility is important to ensure a positive contribution to the policy process.

Compared to other decision-support tools used in the Dutch planning and decision-making process for spatial-infrastructure projects, the credibility with regard to the quality and independence of CBA results is safeguarded because the CBA practitioner has to follow standardized guidelines when estimating the effects of the project, and the extent to which this guideline is followed is often checked through a second opinion (Mouter, 2013b). As a result of this credibility - but also as a result of the other perceived advantages discussed in chapter 3 - the popularity of Cost-Benefit Analysis increased in the past few years in the Netherlands. In the most recent debates on the Dutch spatial-infrastructure investment program (House of Representatives, April $8^{\text {th }}, 2013$; November $25^{\text {th }}, 2013$ ), politicians frequently used the CBA result as an important argument for proceeding or not proceeding with a project.

Based on the results of this thesis, I conclude that it is positive that politicians use the information derived from an instrument which enjoys wide support from key individuals who use, study and carry out CBAs. On the other hand, I think that the importance of CBA in debates about large spatial-infrastructure projects also enhances the vulnerability of the instrument. Firstly, I believe that the importance of CBA creates an incentive for politicians and stakeholders for whom the outcome of the CBA is not desirable to produce information which brings the CBA study into discredit. That this is not unimaginable follows from the study of van Buuren and Edelenbos (2004) about the use of knowledge in the Betuweline case 
(a freight-transport railway line linking the Port of Rotterdam with the European hinterland): 'actors spend most of their time deconstructing each other's research, trying to prove that suppositions are contestable, a database inadequate and so on'. Secondly, I believe that the importance of CBAs in the political debate creates an incentive for stakeholders to influence the results of a CBA study. Christensen (2009) concluded that enhancing the importance of the reports produced by pre-qualified consultants about the desirability of National Government projects in Norway created an incentive for lobbyists to influence the outcomes using creative strategies. See Huijs (2011) for a discussion of creative strategies that were used to influence outcomes of research reports in the Netherlands. Hence, my hypothesis is as follows: 'the more politicians coin a study as decisive information in the decision-making process, the higher the vulnerability of the study and the more important it is to safeguard the credibility of the study'. In this thesis key individuals discussed four lines of solutions for enhancing the credibility of CBA studies.

6.5.4.1 Safeguard credibility through reviews of CBA studies that are 'as independent as possible'

Key individuals interviewed for this thesis mentioned 'second opinions' as a solution to enhance the quality and credibility of CBA reports. Predominantly private consultants stated in the interviews that they can use the fact that the quality of the CBA will be assessed in a second opinion as a 'weapon' to convince the client to carry out a CBA that can be considered as independent as possible, which can enhance the extent to which a CBA study is considered as 'credible' by other stakeholders. In the Netherlands, a lively review culture exists for CBAs that are carried out. In the first few years after the introduction of the Dutch CBA Guidelines (Leidraad-OEI, Eijgenraam et al., 2000), the quality of CBA studies was reviewed by the Netherlands Bureau for Economic Policy Analysis. Currently, the quality of the lion's share of CBA studies for spatial-infrastructure projects is reviewed by institutes that are part of or affiliated with the Ministry of Infrastructure and the Environment.

In a recent interview - as part of another research project (Mouter, 2013b) - I realized that participants in a multi-actor policy setting are not only in need of 'a second opinion' but desire 'a second opinion that is as independent as possible' before they consider the results of a CBA study to be credible information. A respondent expressed the following opinion about the status quo: 'the minister and the alderman wanted to push this project through the system. So the alderman carried out a CBA and the ministry gave a second opinion. Then it is a foregone conclusion what the outcome will be'. Although I personally believe that the CBA in question was carried out well and that the second opinion was made honestly, I can imagine that the respondent does not consider a 'second opinion' carried out by the ministry as an 'independent second opinion' and that this can harm the extent to which a CBA is perceived as credible information. In two Dutch language publications van Holst $(2010,2013)$ also argued against the practice that institutes affiliated with the Ministry of Infrastructure and the Environment carry out second opinions for projects in which the minister has a direct interest: 'the butcher should not inspect his own meat or determine who is going to inspect his meat' (van Holst, 2013). 
The next question is: what is the alternative? I see three different alternatives. Firstly, survey key individuals in the Dutch planning and decision-making process with regard to spatialinfrastructure projects about which institutes they consider to be independent, and increase the capacity of the institutes that are selected by the key individuals to make it possible that these institutes are able to carry out second opinions. Secondly, set up an independent CBA committee (van Holst, 2010 and 2013) - a group of CBA experts who, just like the Dutch Environmental Impact Assessment Committee, deals with methodology developments, advice and carry out second opinions. In the supplement to the OEI Guidelines 'OEI in the decisionmaking process' (2004), research was done into whether or not such a committee was wanted. In 2004 it was decided that it was not necessary because expectations were that there would not be an increase in the number of CBAs that would be carried out. Now that there has in fact been a strong increase in the number of CBAs carried out, this argument no longer stands. A third solution would be to copy an element of the British CBA practice (discussed in Mouter, 2013b). In the UK a 'scheme promoter' has the responsibility for a project to make sure that it is assessed in accordance with the guidelines (Webtag). After that, 'objectors' have the opportunity to challenge the assessment of the 'scheme promoter' during a meeting with an 'inspector'. 'Objectors' could be residents, companies and lobby groups. The 'objector' can call on 'witnesses' who could then also be questioned by the 'scheme promoter'. It is the job of the witness to make critical remarks about the assumptions that have been made when estimating the welfare effects of the project in the CBA. In the end it is the 'inspector' who decides which parts of the assessment have to be amended (so the inspector is a sort of judge), after which he reports on the assessment to the minister. The 'scheme promoter' has the incentive to produce the CBA in a neutral way. If he makes use of rose-coloured assumptions he runs the risk of being exposed by the witnesses who are called up and this would not make a good impression on the 'inspector'.

A final remark that I wish to make with regard to this topic is that, in my opinion, carrying out a comprehensive second opinion for all CBAs - in which every assumption and estimation is verified in detail - might not be cost-efficient. Hence, I recommend carrying out comprehensive second opinions for CBAs for multi-billion projects and 'quick scan second opinions' for CBAs of smaller projects, which means that a person, other than the CBA practitioner, reads the report, verifies the key assumptions and swiftly checks the calculations in the underlying Excel spreadsheet. The essence of these 'quick scan second opinions' is that another pair of eyes looks at the CBA report, which the CBA practitioner can use as a 'weapon' to say to his client 'we can make this assumption, however I know that 'the reviewer' will definitely disagree and this might potentially harm the credibility of the CBA'.

\subsubsection{Safeguard credibility through 'ex-post analyses'}

As discussed in section 6.4.5, key individuals mention institutionalizing 'ex-post analyses' as a solution for reducing the uncertainty with regard to effect estimations. They perceive that information generated from 'ex-post analyses' can be used to improve models, rules of thumb and standard national numbers that are used to estimate project effects for specific CBA studies. As well as mentioning this advantage of carrying out 'ex-post analyses', key individuals also stated that an additional benefit of institutionalizing 'ex-post analyses' might 
be that the fact that the quality of CBA studies are checked afterwards, would enhance trust in the method.

A problem with the 'institutionalizing ex-post analyses' recommendation is that it might be too generic to be of any use for Dutch practitioners. I think that two research projects carried out in the Netherlands with regard to this topic provide useful building blocks for specifying this recommendation. Below, I will discuss the key recommendations of the two studies. The first study (Berveling et al., 2009) recommends enclosing all effects of the project into 'expost analysis' to make a comparison with the 'ex-ante' effect estimations of the CBA possible. To enhance the feasibility of 'ex-post analyses', the study recommends scrutinizing important effects in more depth than relatively insignificant effects. Berveling et al. (2009) also argue for scrutinizing the causality of the results of specific 'ex-post analyses'. More specifically, the practitioner who carries out the 'ex-post analyses' should verify the extent to which the outcomes of the 'ex-post analysis' deviate from the estimations of the 'ex-ante' CBA due to incorrect estimations in the CBA or due to changing circumstances (for instance, structural changes in economic growth). Also, they argue in favor of 'ex-post analyses light' in which effects are studied in a cost-efficient, simple and feasible way. Finally, the study recommends investing in documentation of effect estimations in the CBA to enhance the feasibility of carrying out an 'ex-post analysis'. The second study (Nijland et al., 2010) by and large repeats the recommendations of Berveling et al. (2009) and emphasizes that a successful 'ex-post analysis' starts with the documentation of the effect estimations of the 'ex-ante' CBA study. Because in some cases the period between the CBA study and the actual procurement of the project can be more than ten years, Nijland et al. (2010) recommend verifying the extent to which the key assumptions of the CBA study are still valid at the moment the project is procured.

Despite the useful recommendations of the two studies, 'ex-post analysis' is still not successfully implemented in the Netherlands. Hence, my recommendation is to learn from countries in which systematic 'ex-post analyses' is (to a certain extent) successfully implemented. For instance, in Norway, every year one 'ex-post analysis' is carried out for a large infrastructure project. Five years after an infrastructure project is opened, the construction costs, traffic demand, travel times and the number of accidents are evaluated. Hence, not all effects are included and no 'causality analysis' is carried out. Of course, this is not the institutionalization of systematic 'ex-post analysis', but it might be an interesting first step for the Netherlands. A first lesson that the Netherlands can learn from Norway with regard to this topic is that effect estimations for large infrastructure projects are centrally documented at the Transport Administration and civil servants of this Administration verify the documentation. The systematic documentation might save valuable time when one wishes to collect data for carrying out an 'ex-post analysis'. Secondly, the Norwegian approach is less ambitious compared to the approach proposed in Berveling et al. (2009). In my opinion, the advantage of the Norwegian approach is its feasibility and the advantage of the approach discussed by Berveling et al. (2009) is that the learning potential is higher. Hence, I recommend combining the two approaches. For all infrastructure projects for which a CBA is carried out an 'ex-post analysis' based on the Norwegian approach should be conducted. 
Subsequently, further analysis, based on the approach discussed in Berveling et al. (2009), should be carried out if policy makers think that the benefits of this 'extended ex-post analysis' outperform its costs.

\subsubsection{Safeguard credibility by making CBAs and 'ex-post analyses' publically available}

Four key individuals interviewed for this thesis discussed the importance of making all CBA studies publically available. According to the key individuals the credibility of a CBA study that is publically available is higher than a 'secret CBA'. One of the four respondents stated that not only CBAs, but also 'ex-post analyses' should be made available. Another respondent thinks that not only the CBA report but also the underlying calculations should be available to the public. This respondent states that this gives other CBA experts the opportunity to recalculate the effect estimations and discuss differences of opinion which might lead to learning effects and, as a consequence, improve the quality of CBA studies. Because the Dutch Minister of Finance (Dijselbloem) recently stated in a letter to the House of Representatives (House of Representatives December $6^{\text {th }}$, 2013) that: 'to enhance the transparency and quality of CBAs, all CBAs that are (partly) initiated by the National Government, should be send to the House of Representatives. Also, all CBAs should be published on the website of the National Government', I think that the probability is high that the wish of these four key individuals will be met.

\subsubsection{Safeguard credibility through improving CBA methodology}

My hypothesis is that the 'quality of a CBA study' is a necessary, but not a sufficient, condition for the 'credibility of the CBA studies'. The fact that 'high quality' is not a sufficient condition for 'high credibility' was discussed in section 6.5.4.1. The credibility of a 'high quality' CBA study can be low when the second opinion is carried out by an institute that is not considered to be independent by individuals who participate in multi-actor policy settings. An argument for the hypothesis that the 'high quality' of CBA studies is a prerequisite for 'high credibility' can be found in Kørnøv and Thissen (2000) who state that the vulnerability of a study increases when the results cannot be supported in a scientific debate. Although I think that 'surviving a scientific debate' may be too demanding a requirement, I believe that the credibility of CBA studies can be harmed when CBA innovations (in literature and in other countries) are not taken into account in Dutch CBA Guidelines and studies. When an actor - for whom the outcome of a CBA report is not politically desirable - finds out that new insights with regard to 'variable A' are not taken into account in Dutch CBA Guidelines, this can harm the credibility of the CBA and thus the use of CBA in the planning and decision-making process for spatial-infrastructure projects. Hence, my recommendation is to frequently monitor new insights with regard to CBA that emerge in other countries and literature and to take these insights into account in the Guidelines. In my view, 'taking into account' can also mean discussing why these new insights should not be or are not included in Dutch CBA Guidelines.

In section 6.4.2 I discussed the fact that 'key individuals' perceptions of solutions' should be considered as an input for research agendas as well as the two inputs discussed above (solutions discussed in scientific literature and solutions implemented in other countries) - not 
only because key individuals can provide solutions that add to existing literature - but also because this might enhance support for the method. When many key individuals perceive that a CBA-related topic is a problem (or that they have found a solution), I think it is important for ensuring the credibility of the instrument, that these views are taken seriously. In my opinion there are two lines of solution. Firstly, it is possible to set up research projects in which perceived problems and solutions are scrutinized. This is a strategy frequently used in the Netherlands (see, for instance, Zwaneveld and Bakker, 2009) and by the Dutch CBA development agenda (Ministry of Infrastructure and the Environment, 2011-2013). Secondly, I think organizing workshops or seminars (or webinars) for all key individuals who mentioned a certain problem or solution, in which literature is discussed related to this topic, can be a very efficient way to handle problems and solutions that are perceived by many individuals as worthwhile for including in CBA guidelines or research projects. For example, relatively many key individuals in the Dutch practice felt that one solution for improving the CBA practice would be that 'one should take into account smaller time savings to a proportionally lesser extent than larger time savings'. However, to my knowledge, good arguments for using a continuous unit value can be found in existing literature (Daly, 2011; Fowkes, 1999; Hjorth and Fosgerau, 2012; Mackie et al., 2001). I believe it would be a good idea to organize a workshop (or webinar) on this topic with key individuals interested in this issue and to publish the results online. A good example might be the 'Benefit/Cost Analysis for Transportation Infrastructure' workshop held in the United States, for which a transcription of the discussions held during the workshop can be found online (Transportation Economics Centre, 2010).

\subsection{Further research}

The main objective of this thesis is acquiring a thorough understanding of the way CBA is perceived by different key individuals that use, carry out or study CBAs. Amongst other things, perceptions of key individuals with regard to substantive CBA problems, CBA (dis)advantages, the role of CBA in the decision-making process, solutions to rectify substantive CBA problems and solutions to manage inherent CBA limitations were surveyed. In my opinion, some of the proposed solutions can be labeled as 'no regret', which I conceptualize as solutions that have no or little costs in terms of time, money and potential adverse effects. Perhaps some of the solutions which aspire to catalyze 'subtle use' of the CBA can be labeled as 'no regret'. For instance, I consider starting meetings in which CBA plays a role with a brief discussion of advantages and limitations of CBA as a 'no regret' solution, which can be implemented without any further research. However, as already discussed in chapters 4 and 5, for the majority of the proposed solutions it holds true that the extent to which the solution is promising is currently uncertain. The next question is: do academics have a role (and if yes, which role) in scrutinizing the extent to which solutions are promising and further refining solutions, or should practitioners take it from here? In this section, I will discuss five different categories for further research in which I believe that academics can play a role. Before I embark on this discussion, I wish to emphasize that in this section I am only outlining my views on this topic and I am aware of the fact that other academics might disagree with me. 


\subsubsection{Enhance the quality of effect estimations}

The backbone of each CBA study is the estimation of the non-monetized project effects. How many hours of travel time are saved? What is the long term effect of the project on biodiversity? Since Dutch key individuals experience problems with the estimation of the non-monetized project effects as the most important substantive CBA problem, I recommend focusing on enhancing the quality of effect estimations of spatial-infrastructure projects in further research. Carrying out 'ex-post analyses' in which the non-monetized effects estimated in CBAs are verified is - in my opinion - an excellent type of research to attain better effect estimations (see section 6.5.3.2 for a more in-depth discussion).

\subsubsection{Search for more solutions}

In chapter 4 and section 6.4.2 I have already outlined the fact that solutions implemented in other countries can be used as input for research agendas alongside solutions discussed by Dutch key individuals and solutions discussed in existing literature. Cost-Benefit Analysis is used in many countries all over the world and, in my opinion, key individuals in the Dutch CBA practice do not know a lot about solutions - successfully or unsuccessfully implemented in other countries. Because I think that comprehending the intricacies of the way CBA is embedded in foreign planning and decision-making processes and discussing merits of implemented solutions with key individuals in foreign practices can be a challenging activity, I believe that there is a role for academics to carry out this research.

I think that it is interesting to study the research question: 'Which solutions are implemented in other countries using CBA and how do academics and practitioners evaluate the merits of these solutions?' with regard to the following topics:

- Connecting the Cost-Benefit Analysis with other phases in the planning and decisionmaking process;

- Communicating uncertainty in the CBA report;

- Enhancing intelligibility and verifiability of CBA reports;

- Ensuring a strong position for non-monetized effects and distributional effects in the CBA report;

- Improving the quality of effect estimations in CBA studies (for instance, can we learn from other countries with regard to determining the discount rate, estimating the value of time and improving transport models?);

- How is 'ex-post' analysis institutionalized in different countries and what are the most important success and failure factors for institutionalizing systematic 'ex-post' analyses in the planning and decision-making process?

- How do other countries aim to guarantee the quality and credibility of CBA studies? Are second opinions obligatory or do other countries use alternative methods?

\subsubsection{Further understanding of problems and solutions}

For some of the solutions proposed by key individuals it holds true that there is a broad consensus that a solution will bring advantages to the Dutch CBA practice and that only the costs of implementing the solution could impede implementation. An example of such a 
solution is implementing systematic 'ex-post analyses'. However, there were also examples of proposed solutions on which key individuals disagreed with regard to the extent to which the benefits of the solution outweighed the adverse effects, such as communicating uncertainties with regard to effect estimations in a CBA report in a more prominent way. In chapter 3, I discussed the fact that some respondents claimed that a more prominent communication of uncertainties is 'the salvation' of the CBA in the Netherlands because it will effectively reduce absolute use of the method, whereas others believe that a too prominent communication of uncertainties eventually leads to 'the collapse' of the instrument in the decision-making process. In my opinion, academics can have a role in enhancing the understanding of dilemmas and controversies with regard to problems and solutions, for instance, by applying insights from other disciplines. I will discuss in Appendix I a research project that I carried out with other scholars in which we scrutinize the dilemma mentioned above from a social-psychological perspective.

I believe that carrying out additional scientific research is not only interesting when solutions are controversial, but also when a solution can be characterized as 'clearly unfeasible in the short run and high potential in the future'. An example of such a solution, discussed in section 4.2.2, is the use of social media for deriving the willingness to pay for specific projects, which might severely diminish the costs for willingness to pay studies. At present, this solution is clearly unfeasible because social media is mainly used by young people (selectiveness), and many people tend to make extreme statements when using social media (strategic answers or exaggerated answers). But it is not unthinkable that scientists will find solutions to rectify these issues in research projects.

In addition, research carried out in this thesis generated some new hypotheses with regard to the use of CBA in the decision-making process in a multi-actor setting. I think it is interesting to scrutinize these hypotheses in order to improve our understanding with regard to this topic. Below, the hypotheses generated are listed:

- Both spatial planners and economists perceive that CBA is a more appropriate method than MCA for facilitating roles in the decision-making process, other than supporting 'go' or 'no go' decisions;

- Spatial planners believe that CBA is predominantly a useful design tool in the early planning phase and do not think CBA is an appropriate tool in later phases of the decision-making process;

- Economists who work in an organization with spatial planners think that less value should be attributed to CBA in the decision-making process than economists who work in an organization with solely economists;

- Spatial planners who work in an organization with economists think that more value should be attributed to CBA in the decision-making process than spatial planners who do work in an economist-free organization; 
- Participants in a discussion will be less prone to assign a value that is too absolute or too marginal to CBA in a discussion when the participants in a discussion are fully aware of both CBA advantages and CBA limitations;

- It is not the quality of CBA studies but the credibility of CBA studies that is important to ensure a positive contribution to the policy process;

- The more politicians coin a study as decisive information in the decision-making process, the higher the vulnerability of the study and the more important it is to safeguard the credibility of the study.

\subsubsection{Evaluate, develop and refine solutions}

In section 6.5.2.1, I discussed two solutions that might enhance the smooth connection between the pre-CBA interactive planning process and the CBA via the problem analysis. Because I think that a lot of questions are unanswered at present with regard to these solutions (for instance, which of the two solutions is most effective with regard to smoothing the connection between CBA and the pre-CBA phase? Are there any adverse effects?) and the solutions are not very concrete at the moment, I believe that carrying out further research with regard to these solutions would be interesting. The next question is: how to evaluate, develop and refine these solutions? I believe that 'experiential learning', which was introduced by Straatemeier et al. (2010), amongst others, for planning research is an interesting method to consider. The essence of this method is that academics develop solutions in co-production, together with the intended users. A reciprocal learning process between research and practice is activated in which the original hypotheses about possible planning innovations are developed through iterative testing, reflection and adaptation. Another feature of this method is that academics and practitioners both participate in the research by experiencing the solution and critically reflect upon the practices after the experience.

Although, I consider this method to be promising, I also acknowledge the limitations of the method as discussed in Straatemeier et al. (2010) and te Brömmelstroet et al. (2008), amongst others. Firstly, the method can suffer from 'confirmation bias'. Because the researcher aims to design a solution that works in practice, he or she may be tempted to defend his or her solution even when it actually does not work, or blame this on other aspects (Straatemeier et al., 2010, p. 588). Also, both publications emphasize the problems with 'generalizability'. If one draws the conclusion that the solution 'works' in a specific case, this does not mean that the solution will 'work' in every case. Besides the limitations discussed by Straatemeier et al. (2010) and te Brömmelstroet et al. (2008) I can see two other limitations. Firstly, I think there is a problem with 'causality' because it is very difficult to determine the extent to which a goal is achieved (for instance, the smooth connection between CBA and pre-CBA) as a result of the solution or as a result of a 'friendly moderator', 'low complexity of the case', 'CBA practitioners and stakeholders know each other from previous cases', 'the first sunny day in spring' or other variables. A second problem I see is that researchers use 'to which extent are the goals achieved?' as the main criterion for evaluating the extent to which the solution 'works' and do not explicitly take the costs of the solution into consideration. In my opinion, it is highly probable that a solution does not 'work' in practice when the benefits of a solution do not outweigh the costs. 
To iron out the limitations of 'experiential learning' as discussed above, I think it would be interesting to consider actively involving private consultants in the research team and making them 'the owners of the solution'. In my opinion, private consultants - more than academics possess specific 'tacit knowledge' (Nonaka and Takeuchi, 1995) to make judgments on 'the business case' for the solution (are the benefits higher than the cost?) and the 'generalizability' of the solution (can I sell this solution to other potential clients?). In this model the academics still actively participate in the workshop (or take the observing role), provide the consultants with useful insights from literature and critically reflect on the pros of the cons of the solution, together with the practitioners. In my opinion, another advantage of this model is that the 'confirmation bias' of the academics is diminished since they are not the 'owners' of the solution anymore. In my opinion, potential candidate solutions that can be evaluated, developed and refined using this method are:

- What should a problem analysis contain when one aspires for a smooth connection between the pre-CBA interactive planning process and the CBA? The solutions discussed in section 6.5.2.1 can be evaluated, developed and refined using the 'experiential learning' method;

- 'The multi-layered digital CBA report'. Currently, this idea is very abstract. Using 'experiential learning' this solution can be evaluated, developed and refined;

- 'How can 'subtle use' of CBA effectively be encouraged?' In section 6.5.3.2 many solutions to 'enhance subtle use' are listed. Especially the solutions that have potential adverse effects, such as 'communication of uncertainty' can be evaluated, developed and refined using the 'experiential learning' method;

- What is the best solution to manage the insolvable limitation of CBA that "effects that are difficult to quantify and monetize have a relatively weak position in the CBA report' (using measures such as the nature value indicator; using a hybrid model which combines MCA and CBA or monetize the effects?) I think it is interesting to evaluate, develop and refine the different solutions.

\subsubsection{Organizing 'practitioners meet academics' workshops}

In section 6.5.3.4 I discussed that when the problems and solutions with regard to a specific CBA-related topic mentioned by the respondents are not in line with the problems and solutions that are discussed in literature, organizing workshops or seminars (or webinars) with all key individuals who mentioned these problems/solutions, in which the literature related to this topic is discussed, can be very useful. I have not yet taken a final stance on the question of whether academics should take the lead in organizing these workshops. On the one hand, one could argue that academics have a role in disseminating knowledge and organizing workshops is a way to fulfill this role. On the other hand, consultants and policy makers might have a better sense for judging the extent to which a workshop is useful and necessary.

\subsection{Reflection on this thesis}

In this section I will address two topics. Firstly, I reflect on the process of this thesis. With the benefit of hindsight, what would I have done differently and why? Secondly, there is some 
reflection on scientific research in the social sciences. Although I am still a junior researcher, I have worked for 4.5 years in this field and think that I am indebted to share some thoughts on this branch of academia and maybe provide some useful input for the debate.

\subsubsection{This thesis in retrospective}

In the last couple of months, some people who recently started their Ph.D. research asked me what I considered to be the most important missed opportunity or error I made during my Ph.D. research. My answer to this question was that with the benefit of hindsight the start of my Ph.D. research could have been better because I spent too much time on distilling the research questions that I studied in this thesis from the initial research proposal. To underpin this answer I will briefly elaborate on the first year of my Ph.D. project.

When I started my Ph.D., a research proposal had already been written. In this initial research proposal I found that substantive problems with Cost-Benefit Analysis should be studied from a broad perspective in the early phase of the Ph.D. research. Also, I found in the proposal that 'estimating synergy effects between spatial projects and infrastructure projects', 'constructing reference cases', 'distributional effects' and 'difficult to monetize effects' were topics labeled as 'interesting topics that should be considered during the Ph.D. project'. In the first month of my contract we had already a meeting with the financiers of the project. In a workshop the financiers emphasized that they considered 'synergy effects' and 'constructing references cases' as topics with the highest priority. In first instance, I considered the outcome of this meeting as being a strictly-defined roadmap for the rest of my Ph.D. project. All the financiers and the other members of the consortium were by far more experienced than I was on the 'CBA' topic so they must be right that these two topics were paramount to study. Over the next four years I would do research on 'synergy effects' and 'the reference case'.

However, after a few months of work I noticed that it was very hard to find a sub-topic to study within the two topics. Amongst other things, I considered conducting 'ex-post analyses' of reference cases. However, some experts in the field warned me that this could be a very difficult and probably not a very fruitful research direction. Moreover, I wrote a short Dutch paper on the way synergy effects between the spatial and the infrastructural part of a specific project were estimated (Mouter and Annema, 2010). The discussion of this paper with Jan Anne Annema (co-promotor) and Bert van Wee (promotor) was very enlightening. Bert was very pleased with the paper. However, he asked me whether I thought this paper was interesting for an academic journal. "I don't know. What are the criteria for a scientific journal to accept a paper?" was my answer. Bert told me that for a scientific journal it is important that the problem you study and the outcome of your research is relevant for an international audience, for instance. Bert asked me again if I thought this was the case. I answered that I had not found a contribution in existing literature which could provide any guidance for answering the question about what CBA problem areas are relatively important. Hence, we ascertained that carrying out research to provide guidance for researchers with regard to the question about what problem areas to prioritize for further research should be the main topic of this Ph.D. project. However, I was a bit worried if this change of direction was in line with the initial research proposal, because a conclusion of the study could be that none 
of the topics proposed by the financiers are 'high priority topics'. On the other hand the research proposal entailed that substantive problems with Cost-Benefit Analysis should be studied from a broad perspective in the early phase of the Ph.D. research.

Next, we determined that 'in-depth interviews' would be the most auspicious method for conducting this research and I started with the first interview in July 2010. Fifteen months after I started my research I was finally on track. The error I made was that in the first year of my $\mathrm{Ph} . \mathrm{D}$. I took the problem statement, the research questions and the research goals that were stated in the initial research proposal for granted. With the benefit of hindsight I recommend that other Ph.D.s critically reflect on these topics or ask other people for feedback. Why are research questions stated in the initial proposal important? Is the problem stated in the research proposal actually a problem? In my case, this would have probably saved me a lot of time. Perhaps the introduction of the Graduate School will assist TU Delft Ph.D.s with asking these vital questions.

A second topic that deserves some reflection is 'in-depth interviews' as a key method, which I used to gather the data. The most important reason for using interviews was that I had no a priori idea about the perceptions of respondents and considered interviews to be the most auspicious method for exploring the perceptions of key actors. In retrospect, I think this was a very good choice. Respondents provided me with a very wide range of interesting perceptions with regard to CBA problems, advantages, disadvantages and solutions. Even in the 86th interview I collected new perceptions on the topics. Moreover, I think I cannot claim that including more people in the sample would not have led to new or relevant data, which is one of the criteria for determining that 'theoretical saturation' emerges (e.g. Thomson, 2011). The conclusion that in the 86th interview I still had not attained 'saturation' was surprising because the literature (e.g. Thomsom, 2011) concludes that saturation normally occurs between 10 and 30 interviews.

Another reason for choosing 'in-depth interviews' was that I considered it necessary to challenge the statements of the respondents because I thought it was likely that respondents would be prone to make strategic statements (see section 1.4). In retrospect, I must conclude that - without any exceptions - the attitude of the respondents seemed to be genuine and authentic instead of strategic. I think that there are two possible causes for this. Firstly, the interviews were anonymous. I assured respondents that they would in no way be referred to regarding the statements they made in the interviews. Secondly, at the time when I interviewed the key actors, I did not have any position in debates with regard to the planning and decision-making process for spatial-infrastructure projects. The lion's share of the interviewees did not know me and the interviewees that I had already met only knew me as a Ph.D. who was in the first phase of his research, making himself familiar with the basics of CBA. I think that many respondents presumed that the statements they made in an interview with me would not have any effect on debates with regard to the planning and decisionmaking process for spatial-infrastructure projects. As a result, I think that respondents were prone to share genuine perceptions with me. 
In the last couple of months I have found out that it is more difficult for me to generate fully genuine perceptions of actors in the Dutch decision-making process for spatial-infrastructure projects. Because I recently wrote articles in newspapers and my website about CBA is a well-used medium (see the next section), people I recently spoke to explicitly stated that they wanted to influence the debate via the website or tried to convince me that I should argue pro or against a specific project in the media. Hence, my hypothesis is that the level of genuineness of perceptions that respondents share with an interviewer may be influenced by the position of the interviewee in the public debate and that it might be recommendable to ask young researchers to carry out the type of research that was carried out in this thesis.

Moreover, I think it is interesting to reflect on the 'content analysis' method that I used to analyze the interviews and the quality of the content analysis that was assessed with an intercoder reliability test by two other researchers. Firstly, I think that I can conclude from this thesis that carrying out an intercoder reliability test has several benefits. The most important benefit is that it makes clear which (preliminary) conclusions can be drawn from the data and - perhaps more importantly - which conclusions can no longer be supported. To give an example: after I completed the content analysis, I thought that it was possible to rank the CBA (dis)advantages that were mentioned. The result from the intercoder reliability test was that the first independent coder and I found more or less the same (dis)advantage categories in the 10 interviews that were tested by the independent coder. However, the number of times advantage and disadvantage categories coded varied greatly, so this was, thus, unreliable and I concluded that it was not responsible to rank CBA (dis)advantages based on the data derived from the interviews. One of the causes of the low intercoder reliability score was that I did not ask enough clarifying questions in the interviews. The result was that it was very difficult for the coders to decide which (dis)advantage category was discussed by the respondent. A question like: "do you mean advantage A or B?" would have severely reduced the ambiguity of the data. I consider this as a missed opportunity. On the other hand, I would like to emphasize that I am really pleased that the intercoder reliability test was carried out. It helped me to draw modest but reliable conclusions and prevented me from 'over-icing the pudding'.

Another missed opportunity in this thesis is that, although key actors distinguish multiple (positive) roles that the CBA can play in the decision-making process for spatialinfrastructure projects (for instance: for contemplating the design of the project, for being a discussion platform and for supporting 'go' or 'no go' decisions), I only asked respondents in the written questionnaire to outweigh advantages and disadvantages of CBA compared to MCA to support 'go' or 'no go' decisions. In retrospect it would be very helpful to know how key actors assess the (dis)advantages of CBA compared to MCA for all roles of CBA or MCA. The reason why I did not include additional questions in the written questionnaire is that at the time I sent out the written questionnaire I had not yet discovered in the data that many of the advantages of CBA mentioned by the key actors can be interpreted as 'positive roles of CBA.' In fact, I sent out the written questionnaire right after I completed the last interview. In conclusion, a missed opportunity was that I sent out the questionnaire too swiftly after the last interviews and, as a consequence, did not included some interesting questions. 
On the other hand, I consider the high response rate (74 out of 86 respondents) as a benefit of sending out a questionnaire rapidly after the interviews.

Finally, I think that it is useful to reflect on the fact that all the chapters of this thesis are based on 'only' one single dataset. An alternative option would have been to collect four datasets and to write four chapters with each chapter based on the results derived from one dataset. So why did I choose for the former and not for the latter option? My answer is that I used 'how can I maximize the reliability and validity of the results?' as a guiding principle for making methodological choices. Below, I will discuss some illustrations of the way I applied this principle:

- To enhance validity, I interviewed more individuals: 86 key individuals instead of, say, 30 key individuals;

- To enhance reliability, I transcribed the interviews and used content analysis to analyze the data instead of listing the key statements of a respondent and using this as data, for instance;

- To enhance reliability and validity, I recoded the interviews three times. During the first two rounds of coding I realized that the 'coding and categorizing protocol' needed revision. Existing categories needed to be split up or merged and it was necessary to add new categories.

A clear disadvantage of using this guiding principle is that enhancing the reliability and validity of a study takes time, which implies that there is less time to conduct other studies and, as a consequence, diminishes the productivity of the researcher. I believe that using another guiding principle - for instance, 'publish as many papers as possible' - would have saved a lot of time. Perhaps, following this principle, interviewing ten key individuals would have been sufficient and transcribing the interviews would not have been necessary. One result of the lower productivity that I experienced is that it raises eyebrows among practitioners: 'is this the only study you undertook?'

Although I acknowledge the disadvantages of the guiding principle I used, I personally believe that the advantages are greater. I think a first key advantage is that, if a policy maker aspires to make a decision based on the information provided by the results of a scientific study, it enhances the probability that the quality of the decision is improved as a consequence of using the results when the reliability and validity of the results of the study is high. In my view, a second key advantage is that, when the reliability and validity of the results of the study is high, there is a high probability that the results of the study will guide scientific research in the right direction. On a contrary, when the results of a study are invalid, this might guide a new research project in the wrong direction when the new research project uses the results of the invalid study as a starting point.

A key solution for ironing out the disadvantages of my approach I currently apply is to combine a large research project, in which I aspire to maximize reliability and validity, with (several) smaller research projects. Based on the data derived from the smaller research 
projects, I mainly write Dutch language discussion papers in which I raise questions that - in my opinion - should be raised (and that have not been raised yet). Naturally, I emphasize the limitations with regard to the reliability and validity of the results in these papers.

\subsubsection{Reflection on scientific research in the social sciences}

In the status quo a very important measurement for the success of a scientist is the number of papers published in highly prestigious journals. This is also known as the 'publish or perish' paradigm. After one of my papers was accepted for a high-ranked journal (chapter 2) and another paper was conditionally accepted for this journal (chapter 3), I asked myself the question: does having two papers from my thesis accepted by high-ranked journals make me a successful scientist? My answer was that being published in high-ranked journals is a necessary but not a sufficient condition for being a successful social scientist. I think that dissemination of results in society and criticizing 'the status quo' (for instance, current paradigms in society or policies) are equally important activities to perform for a successful social scientist, especially when the scientist conducts research on a topic that is relevant for (Dutch) citizens, enterprises or the Government, such as CBA. ${ }^{51}$ In the last years of my Ph.D. I aimed to attain both goals.

\subsubsection{Website as vehicle to disseminate scientific findings}

Although the term 'publishing' is derived from the word 'public', the consensus in the status quo is that publications in scientific journals are difficult for the public to access. Firstly, many high-ranked journals are not open-access. Secondly, many journal articles are written in a way which is difficult for lay people to understand. Hence, I decided that I must start two activities to disseminate my research in (Dutch) society. Firstly, I needed to produce easy-toread, Dutch publications. Secondly, I needed to give easy-to-follow presentations. In the last year, especially, I have produced many Dutch publications and have given many presentations. However, I noticed that this was not enough to disseminate the findings of my research, and also the findings of other interesting studies with regard to CBA, in a sustainable way. I found that some people who attended my presentations for the third time made the same remarks or asked the same questions as the first time they attended my presentation. One of the possible causes for this phenomenon could be my presentation skills. Another cause could be that I overestimated the knowledge that people generated from a presentation. It might be true that the lion's share of the attendees of a presentation only remember some of the issues you presented - and maybe even only remember things for a very short period of time. Also, I noticed that the readership of my Dutch publications was not very high. From these experiences I concluded that developing a website so that my research findings and the findings of other CBA related studies, guidelines and reports could be presented in piecemeal would be a good idea. The website www.mkba-informatie.nl was launched in March 26th 2013. The main objective of this website is to provide direct access to 'basic information' concerning Cost-Benefit Analysis. In addition, www.mkba-informatie.nl offers extensive background information about this ex-ante evaluation instrument for experts and interested non-experts (for instance, publications, guidelines and 'best practices'). As at

\footnotetext{
${ }^{51}$ Of course it is very difficult to demarcate social scientists from non-social scientists. I think that scientists that see themselves as social scientists can at least be identified as social scientists.
} 
January $18^{\text {th }}$, 2013, 15,000 people had visited the website. The website is visited by universities, municipalities, ministries and the Dutch Parliament, amongst others. More than 1000 people downloaded the documents that were specially written for the website ('Eerste Hulp bij MKBA' and 'Fact sheet MKBA').

\subsubsection{Criticizing the current decision-making process}

Especially in the last months of my Ph.D. I aimed criticizing the current decision-making process for spatial-infrastructure projects in the Netherlands. I think that a social scientist is obliged to think about the questions that should be raised (and that haven't been raised yet) in the domain in which he or she is active, and also to raise these questions in public debate. Who else would raise these questions? To attain this objective, I wrote a newspaper articles for the newspapers, Trouw and Financieel Dagblad. Moreover, I wrote a blog for www.ruimtevolk.nl and wrote two discussion papers. Although I am not sure whether I attained my goal of raising important questions with regard to the current decision-making process, I do think that I made a good start and hope to further develop this part of my academic skills in my future career.

\subsubsection{Criticizing the integrity debate}

One of the elements of the scientific debate that triggered my attention during my Ph.D. was the 'integrity debate'. The fraud committed by Diederik Stapel was a catalyst for a discussion on integrity in the social sciences, especially in the Netherlands. The committees that researched Stapel's fraud (e.g. the Levelt Commission) concluded that, although Stapel was fully and solely responsible for this extensive case of academic fraud, the research culture in which this academic misconduct occurred was unhealthy. The committees describe this as "a general culture of careless, selective and uncritical handling of research and data." They conclude that "...from the bottom to the top there was a general neglect of fundamental scientific standards and methodological requirements." The committees point the finger not only at Stapels peers, but also at editors and reviewers of international journals. The key question is: how to prevent fraud (in the social sciences)? Some measures suggested by the committees are: improving education on research integrity, data storage, carrying out replication, making researchers aware of ethical codes (such as the VSNU code).

Although I support all these measures, I am missing one interesting measure to positively influence a culture of integrity in the social sciences, which encourages (young) scientists to be transparent about the dilemmas they faced during their Ph.D. I see virtue in open-hearted discussions about the dilemmas that scientists face in practice alongside urging Ph.Ds. and other scientists to swear that they have integrity. By facilitating open discussions, 'integrity' will become a topic from which scientists can learn from each other. I think that one way to catalyze transparency is to challenge Ph.Ds. to discuss a few dilemmas they faced during their research, preferably dilemmas in which they did not know for sure whether or not they had made the right choice. Below, I will present four dilemmas that I faced during my Ph.D. 


\section{Which projects to use as an illustration?}

A few months ago, I was writing an article for a Dutch newspaper about the poor quality of problem analyses for spatial-infrastructure projects in the Netherlands. In the leader of the article I decided to mention five example projects with a poor problem analysis as an illustration for the reader. To select these five projects, I made a shortlist of ten projects. For two of the ten projects from this shortlist I knew in advance that mentioning the project in the newspaper might be disadvantageous for me. A few weeks before I decided to write a newspaper article a Government agency that co-financed one of these ten projects asked me if I could give a presentation about the findings of my research, amongst other things. For the second project I expected, a priori, that one of the financiers of my website might not like it if I mentioned the project in the article.

The dilemma was: should I mention these two projects in the newspaper article? A scientist with lots of integrity would mention both projects to make sure that his/her integrity could never be questioned. A scientist that did not care about integrity at all would not mention either of the two projects. Hindered by an approaching deadline for the article, I selected five projects, including one of the two projects discussed above. From these five projects, two were unambiguously failure projects, one of the projects was hotly debated in the media at the time I was writing the article, one of the projects was not an infrastructure project and could contribute to the argument "poor problem analysis is not a problem specific for infrastructure projects' and for the fifth project I scrutinized the problem analysis in-depth. So there were good arguments for the selection I made. However, it was of course possible to make another defendable selection. I claim that, because I only included one of the two 'doubt' projects in the newspaper article, the integrity of my decision mediocre. With hindsight I think maybe a better method for selecting the five projects would have been putting pieces of paper with the names of the projects in a basket and taking five out of the basket, letting chance decide which projects are noted down in the article.

\section{Who should be the first author?}

One of the findings of chapter 3 was that key actors in the Dutch appraisal practice for spatialinfrastructure projects disagree on the way the uncertainty of effect estimations should be communicated in (the summary of) the CBA report. Chapter 5 concludes that to understand and explain the controversy with regard to communicating uncertainties, cognitive psychological theory may provide the right perspectives. To get a feeling for the extent to which scrutinizing cognitive psychological literature would be a fruitful research project, I contacted two researchers from the faculty of social psychology at the University of Amsterdam and they provided me with relevant scientific literature. After reading some papers I concluded that this was an interesting avenue for further research.

Because I did not have sufficient time to study all the relevant social psychological literature, Jan Anne Annema (co-promotor) and I decided to recruit a Masters student to undertake this work. Marc Holleman was interested in carrying out this project for his Masters' thesis. I made an appointment with the two researchers from the University of Amsterdam to refine the research questions for the project. In the first few months Marc read an impressive number 
of social-psychological papers. Once or twice a month we had a meeting in which we discussed his findings and the next steps to take. Also, I considered the findings promising enough for a journal paper. My idea was to write a conference paper for the UNITE conference in Copenhagen in September 2013. I asked Marc and the other supervisors (Simeon Calvert and Jan Anne Annema) if they thought this was a good idea and they agreed.

However, the question was: who was going to be the first author of the paper? On the one hand the project was a spin-off of my Ph.D., I initiated the project and would take the lead in writing the paper. On the other hand, Marc spent more hours than I did on the project and developed conceptual ideas for the paper based on his literature review. I decided to discuss the issue with Marc. Marc said that he was already very pleased that I would write a paper for a conference and a journal. He would not have written a paper, based on his Master's thesis, on his own. Concluding, there were legitimate reasons to make Marc the first author and there were legitimate reasons to make myself the first author. I chose for the second option, whereas others might favour the first option. It is definitely valuable to discuss such choices openly with a Masters student: 'as Marc and I did'. Furthermore, I think it is valuable for the scientific community to make such important practical issues debatable.

\section{To vote or not to vote?}

A project financed by the Knowledge Platform for Transport and Traffic (KPVV) to design a tool that makes Cost-Benefit Analysis methodology more applicable for decentralized Governments was started in January 2013. KPVV asked me to take a place on the supervising committee of the project. The first step of the project was the selection of a private consultant who would carry out the project. The selection was based on the votes of the members of the supervising committee, amongst other things. The dilemma was that the private consultants that financed my website all tendered for the project, which was an argument for abstaining from voting. On the other hand, the tool might be very important for informing decentralized Governments ex-ante about the welfare effects of their policy options and I had an opinion about which consultants were better-equipped to successfully carry out the project. I decided to abstain from voting because I thought that influencing which commercial entity should carry out a project was not a scientist's task.

\section{Identifying the weaknesses in my research}

After I completed the content analysis of the interviews I discussed the idea about assessing the reliability through an intercoder reliability test with my supervisors. We were all very enthusiastic about this idea. However, I had one reservation. Would it be possible to publish the papers in a high-ranked journal if the reliability of my content analysis turned out to be low? After the intercoder reliability task was completed, the reliability of the number of times (dis)advantage categories were coded turned out to be unreliable and I concluded that it was not responsible to rank CBA (dis)advantages based on the data derived from the interviews. Hence, I reported the low intercoder reliability scores in the paper 'Attitudes towards the role of Cost-Benefit Analysis in the decision-making process for spatial-infrastructure projects: a Dutch case study' (chapter 3) hoping that the reviewers would not reject the paper based on the low scores. I expected that there was a substantial chance that reviewers would take the 
low scores as an argument to reject the paper because I had heard stories of other researchers whose papers were by and large always rejected if they honestly discussed the limitations of their data in their paper. Eventually, none of the reviewers did make a strong point about the low scores. One of the reviewers asked me to provide the reader with a short justification of the low intercoder reliability scores. In the end, I am sure that I made the right decision to carry out (and report the results of) the intercoder reliability test. However, to be honest, I am not sure whether I would have taken the same stand had all my papers been rejected, based on the reviewers' comment regarding the low scores of the intercoder reliability test.

\section{References}

Ardic, O., Annema, J.A., van Wee, B., 2013. Has the Dutch news media acted as a policy actor in the road pricing policy debate? Transportation Research Part A 57, 47-63.

Atkinson, G., Mourato, S., 2008. Environmental Cost-Benefit Analysis. The annual Review of Environment and Resources 33. 317-344.

Armstrong, J.S., Overton, T., 1977. Estimating nonresponse bias in Mail Surveys. Journal of Marketing Research 15. Page 396-402.

Arrow, K.J., Cropper, M.L., Gollier, C., Groom, B., Heal, G.M., Newell, R.G., Nordhaus, W.D., Pindyck, R.S., Pizer, W.A., Portney, P.R., Sterner, T., Tol, R.J.S., Weitzman, M.L., 2012. How should benefits and costs be discounted in an intergenerational context?

Baarsma, B., Koopmans, C., Theeuwes, J., 2010. Beleidseconomie. Een rationele onderbouwing van overheidsingrijpen, Amsterdam.

Berg, Nathan (2005): Non-response bias. Published in: In Kempf-Leonard, K. (ed.), Encyclopedia of Social Measure, Vol. 2, (2005): pp. 865-873.

Berveling, J., Groot, W., Lijsen, M., Savelberg, F., van der Werf, E., 2009. Na het knippen van het lint. Netherlands Institute for Transport Policy Analysis. The Hague.

Börjesson, M., Eliasson, J., 2014. Experiences from the Swedish Value of Time study, 59. P. 144-158.

Bozeman, B., Landsbergen, D., 1989. Truth and credibility in sincere policy analysis: alternative approaches for the production of policy-relevant knowledge evaluation review. Evaluation Review 13: 355.

Cantarelli, C.C., 2011. Cost Overruns in Large-Scale Transport Infrastructure Project: A theoretical and empirial exploration for the Netherlands and worldwide. Dissertation. Delft University of Technology.

Chorus, C.G., Annema, J.A., Mouter, N., van Wee., 2011. Modeling politicians' preferences for road pricing policies: a regret-based and utilitarian perspective. Transport Policy 18 (6). Pp 856-861.

Christiaans, H. H. C. M., Fraaij, A. L. A., de Graaf, E., Hendriks, C. F., 2004. Methodologie van technisch-wetenschappelijk onderzoek. Lemma B.V. Utrecht.

Creswell, J.H., 2009. Research Design. Qualitative, Quantitative and Mixed Methods Approaches. 3rd edition. SAGE Publications inc. Eijgenraam, C.J.J, Koopmans, C.C., Tang, P.J.G., Verster, A.C.P., 2000. Evaluatie van infrastructuurprojecten; Leidraad voor kosten-batenanalyse, Sdu, Den Haag. 
Berveling, J., Groot, W., Lijsen, M., Savelberg, F., van der Werf, E., 2009. Na het knippen van het lint. Netherlands Institute for Transport Policy Analysis. The Hague.

Christensen, T., 2009. The Norwegian Front-End Governance Regime of Major Public Projects - a Theoretically Based Analysis. Concept rapport nr. 23. Conceptprogrammet.

Daly, A., Tsang, F., Rohr. C., 2011. The value of small time savings for non-business travel. Contribution to ETC 2011.

Eijgenraam, C.J.J., Koopmans, C.C., Tang, P.J.G., Verster, A.C.P., 2000. Evaluation of Infrastructural Projects; Guide for cost-benefit analysis, Sections I and II, CPB, The Hague, NEI (Changed Name to ECORYS), Rotterdam.

Eliasson, J., Lundberg, M., 2012. Do Cost-Benefit Analyses Influence Transport Investment Decisions? Experiences from the Swedish Transport Investment Plan 2010-21. Transport reviews 32 (1), 29-48.

Enserink, B., 2000. A quick scan for infrastructure planning: screening alternatives through interactive stakeholder analysis. Impact Assessment and Project Appraisal, 18(1), March, pages 15-22.

Fowler jr. F.J., 2009 Survey Research Methods (Applied Social Research Methods Series, No. 1).

Fowkes, A.S., 1999. Issues in evaluation. A justification for awarding all time savings and losses, both small and large, Equal Unit Value in scheme evaluation. In: Accent/Hague, 341-359.

Groom, B., Hepburn, C., Koundouri, P., Pearce, D.W., 2005. Declining discount rates: the long and the short of it. Environ. Resour. Econ. 33, 445-93.

Gollier, C. (2012) Evaluation of long-dated investments under uncertain growth trend, volatility and catastrophes. CESifo Working paper: Industrial organization no. 4052.

Hajer, M., van 't Klooster, S., Grijzen, J., eds. 2010, Strong Stories. How the Dutch are reinventing spatial planning, (010 Publishers, Rotterdam).

Hayashi, Y., Morisugi, H., 2000. International comparison of background concept and methodology of transportation project appraisal. Transport Policy 7 (1), 73-88.

Hjorth, K., Fosgerau, M., 2012. Using prospect theory to investigate the low marginal value of travel time for small time changes. Transportation Research Part B 46 (2012) 917932

House of Representatives, 2011. Debates on the Dutch spatial-infrastructure investment program December 11th 2011 (In Dutch: Notaoverleg MIRT, 11 December, 2011). The Hague.

House of Representatives, 2013. Debates on the Dutch spatial-infrastructure investment program April 8th 2013 (In Dutch: Notaoverleg MIRT, 8 April, 2013). The Hague.

House of Representatives, 2013. Debates on the Dutch spatial-infrastructure investment program November 25th 2013 (In Dutch: Notaoverleg MIRT, 25 November, 2013). The Hague.

House of Representatives, 2013. Letter to the Cabinet with regard to the New Dutch CBA Guideline. December 6th, 2013. The Hague.

Huijs, M., 2011. Building Castles in the (Dutch) Air: Understanding the Policy Deadlock of Amsterdam Airport Schiphol 1989 - 2009. Ph.D. Dissertation, TU Delft. 
Kørnøv, L., Thissen, W.A.H., 2000. Rationality in decision- and policy-making: implications for strategic environmental assessment, Impact Assessment and Project Appraisal, 18:3, 191-200.

Mackie, P., Jara-Diaz, S., Fowkes, A.S., 2001. The value of travel time savings in evaluation. Transportation Research Part E. 37 (2-3), 91-106.

Mackie, P., 2010. Cost-Benefit Analysis in Transport: A UK Perspective, International Transport Forum Discussion Paper 2010-16.

Ministry of Infrastructure and the Environment, 2010. Handreiking MIRT-Verkenning. The Hague.

Ministry of Infrastructure and the Environment, 2010. Manual for exploration phase spatialinfrastructure projects (In Dutch: Handreiking MIRT-Verkenning). The Hague.

Ministry of Infrastructure and the Environment, 2012. Kader 'KBA bij MIRT-Verkenningen'. The Hague.

Ministry of Infrastructure and the Environment., 2011-2013. Research Agenda Cost-Benefit Analysis (In Dutch: Ontwikkelagenda OEI). The Hague, December 2011.

Ministry of Transport, Public Works and Water Management, 2004. Supplement to the OEI Guideline, OEI in the Decision-making process. The Hague.

Mouter, N., 2013a. De Advocaat van de Duivel maakt besluitvorming Sneller en Beter. Contribution to MKBA symposium 'hoe de MKBA inhoudelijk en procesmatig te verbeteren'. Amsterdam, september 12, 2013

Mouter, N., 2013b. De Donkere kant van het gebruik van kennis, modellen en de MKBA in de besluitvorming. Contribution to the Colloquium Vervoersplanologisch speurwerk. November 22th Rotterdam.

Mouter, N., Annema, J.A., 2010. Synergie-effecten van ruimtelijk-infrastructurele projecten. Contribution to 'Colloquium Vervoersplanologisch Speurwerk'. Roermond, November 2010.

Mouter, N., Pelzer, P., 2013. 'Zwemles voor Planners'. Contribution to 'de Plandag 2013'. Antwerps 23 mei 2013.

Mouter, N., Vonk Noordegraaf, D., 2012 Intercoder reliability for qualitative research. You win some, but do you lose some as well? TRAIL Conference 2012. TRAIL Research School.

Mundy, 2002. A question of response rates. Council of science editors. January - February 2002. Vol 25 (1)

Nicolaisen, M. S., 2012. Forecasts: Fact or Fiction? Uncertainty and Inaccuracy in Transport Project Evaluation. Department of Develpment and Planning, Aalborg University.

Nijland, H., Snellen, D., Wortelboer-van Donselaar, P., Korteweg, J.A., 2010. With current hindsight. Learning from evaluation. the Netherlands Environmental Assessment Agency and Netherlands Institute for Transport Policy Analysis

Nonaka, I., Takeuchi, H., 1995. The Knowledge-Creating Company: How Japanese Companies Create the Dynamics of Innovation. Oxford University Press, New York.

Nyborg, K., 2012. The Ethics and Politics of Environmental Cost-Benefit Analysis. Routledge.

Pielke jr., R., 2007. The Honest Broker of Policy Alternatives. Making sense of science in policy and politics. Cambridge University Press. 
Romijn, G., Renes, G., 2013a. Plans for the city. In Dutch: Plannen voor de Stad. the Netherlands Environmental Assessment Agency and the Netherlands Bureau of Economic Policy Analysis

Romijn, G., Renes, G., 2013b. Dutch General CBA Guideline. In Dutch: Algemene Leidraad voor maatschappelijke kosten-batenanalyse. Centraal Planbureau en Planbureau voor de Leefomgeving.

Sarantakos, S., 2005. Social Research 3rd Edition. Palgrave Mac Millan. New York.

Straatemeier, T., Te Brömmenstroet, M. C. G., Bertolini, L., Hoetjes, P., 2010. An experiential approach to research in planning. Environment and Planning B: Planning and Design 2010, volume 37, pages 578- 591.

Te Brömmenstroet, M. C. G., Bertolini, L., 2008. Developing land use and transport PSS: Meaningful information through a dialogue between modelers and planners. Transport Policy 15 251-259.

Thomson, S. B., 2011. Sample Size and Grounded Theory. JOAAG, Vol. 5. No. 1

Transportation Economics Centre, 2010. Benefit/Cost Analysis for Transportation Infrastructure: A practitioner's workshop. May 17, 2010. Washington, D.C.

Turner, R.K., 1979. Cost-Benefit analysis - a critique. Omega 7 (5), 411-419.

Van Buuren, A., Edelenbos, J., 2004. Why is joint knowledge production such a problem? Science and Public Policy, volume 31 (4), p. 289-299.

Van Eeten, M., 1999. Dialogues of the Deaf; defining New Agendas for Environmental Deadlocks (Eburon Publishers, Delft).

Van Holst, B., 2010. Kosten-batenanalyse verwordt tot invuloefening. Me Judice

Van Holst, B., 2013. Naar een vaste Commissie Beleidsanalyses kosten-batenanalyses. www.mkba-informatie.nl

Van de Riet, O., 2003. Policy Analysis in a Multi-Actor Setting (Eburon Publishers, Delft).

Vonk Noordegraaf, D., Annema, J.A., van Wee, G.P., 2014. Policy implementation lessons from six road pricing cases. Transportation Research Part A 49, 172-191.

Wever, E., Rosenberg, F., 2012. Omgevingskwaliteiten bij MIRT-projecten. Overzicht van methoden voor het meten en waarderen van welvaartseffecten in een MKBA. Juni 2012.

Weitzman, M. L., 2012. On the risk-adjusted discount rate for long-term public investments.

Zwaneveld, P., Bakker, P., 2009. Het belang van openbaar vervoer: de maatschappelijke effecten op een rij. Netherlands Bureau of Economic Policy Analysis and the Netherlands Institute for Transport Policy Analysis. 


\section{Summary}

\section{Background}

In transport planning governments often have to outweigh negative and positive effects. For instance, development of a new highway leads to positive effects such as travel time savings for users, but also to negative effects like noise hindrance for residents and construction costs. It is up to politicians to outweigh these effects. Hence, they frequently want to be informed ex-ante about the positive and negative effects of the policy option(s) considered. Often, they would also like to have information about the positive and negative effects of different alternatives to the policy option(s) (different alignments of a highway, for instance). Research shows that in most OECD countries Cost-Benefit Analysis (CBA) is often used to inform decision makers about positive and negative effects for society of transport policy options, at least at some stage of the decision-making process (Hayashi and Morisugi, 2000; Mackie and Worsley, 2013; Odgaard et al., 2005).

Basically, a CBA is an overview of all the positive effects (benefits) and negative effects (costs) of a project. The costs and benefits are quantified as far as possible and valued in monetary terms. Results are expressed in one or more indicators, such as the difference between costs and benefits or the benefit-cost ratio.

\section{Aims and scope of this thesis}

Despite the existence of a wide range of scholarly literature arrayed across a variety of CBA related topics, the way CBA is perceived by different key individuals that use, carry out or study CBAs has received scant attention in existing literature. This thesis aims to fill four knowledge gaps at the interface of CBA and practice for the Netherlands (each chapter focuses on one knowledge gap). Foremost, this implies that insights from this thesis are potentially very interesting for improving the Dutch practice. Still, the Dutch practice can also give useful international insights for other CBA practices because of the extensive use of CBA in the Netherlands over the last 13 years. Moreover, this thesis only presents the findings which are considered as potentially relevant for an international audience. Findings that are only relevant for the Dutch practice are presented in a Dutch language report (Mouter et al., 2012).

\section{Results}

This section presents the main results for the chapters 2 to 5. Also, the methods that were used are discussed in brief.

Chapter 2: Ranking the substantive problems in the Dutch Cost-Benefit Analysis practice This chapter investigates the perceptions of key individuals in the Dutch CBA practice for spatial-infrastructure projects ${ }^{52}$ regarding substantive problems when appraising spatial-

\footnotetext{
${ }^{52}$ Because in the Netherlands ex-ante evaluation using CBA is obligatory for all spatial-infrastructure projects (and not only transport projects) applying for co-funding by the Dutch Government, I decided to adjust my aim to this obligation.
} 
infrastructure projects with CBA. Two research methods were applied. Firstly, 86 key individuals in the Dutch CBA practice (consultants, academics, policy makers) were interviewed in-depth in order to obtain an overview and a ranking of perceived substantive problems with CBA in the Netherlands. Secondly, the people interviewed were also asked to fill out a written questionnaire in which they were asked to rank the substantive problems once again, in order to validate the ranking; 74 of the 86 key individuals completed this questionnaire. The most important conclusions of this chapter are:

- Key individuals consider 'problems with the estimation of the non-monetized project effects' as the most important substantive problem cluster and 'problems with monetizing project effects' as the second most important substantive problem cluster;

- Key individuals consider the 'problem analysis' in a CBA to be a very important substantive problem;

- There is, in a broad sense, consensus among the different groups in the Dutch CBA practice concerning their perception of the seriousness of problem clusters and the way they rank the problem clusters. The 'problem analysis' problem cluster is an interesting exception. Policy makers evaluate the quality of this problem cluster more positively than consultants and scientists/researchers;

- The lion's share of the substantive problems mentioned by the key individuals in the Dutch CBA practice are non-specific CBA problems.

Chapter 3: Attitudes towards the role of Cost-Benefit Analysis in the decision-making process for spatial-infrastructure projects: a Dutch case study

This chapter provides a systematic overview of the attitudes of key individuals in the Dutch CBA practice for spatial-infrastructure projects towards the role of CBA in the decisionmaking process for spatial-infrastructure projects. The main aim of this chapter is to scrutinize the extent to which there is agreement among key individuals in regard to the role of the CBA in the decision-making process. The same research methods used for chapter 2 were applied, these being in-depth interviews and a written questionnaire. The most important conclusions of this chapter are:

- Key individuals in the Dutch CBA practice for spatial-infrastructure projects agree that CBA must have a role in the appraisal process of spatial-infrastructure projects. In the written questionnaire, 73 out of 74 respondents stated that CBA must have ' $a$ ' role in the appraisal of spatial-infrastructure projects.

- There is a lot of controversy among economists and spatial planners in the Dutch practice concerning the value that is and should be assigned to CBA in the decisionmaking process. None of the 40 respondents that consider themselves economists think that, in the current practice, too much value is attributed to CBA, whereas $71 \%$ of the spatial planners think that too much value is attributed to CBA in the decisionmaking process;

- Both economists and spatial planners believe that this controversy is problematic as it results in debates about the pros and cons of CBA instead of the pros and cons of the spatial-infrastructure projects; 
- Respondents do not oppose the use of CBA, but oppose a situation in which other participants in the decision-making process assign an incorrect value to the results of the study in the decision-making process;

- Individuals with different professions (researchers, policy makers, consultants) do not have significantly different attitudes towards the role of CBA.

This chapter also analyzes some solutions to overcome the controversy between economists and spatial planners, which are discussed below in the policy recommendations.

Chapter 4: Solutions for substantive Cost-Benefit Analysis problems: results of an interview based study

This chapter provides internationally relevant solutions proposed by key individuals in the Dutch CBA practice for spatial-infrastructure projects that aim to solve (perceived) substantive CBA problems. In 55 of the 86 interviews carried out for this thesis, key individuals discussed solutions which I considered potentially relevant for an international audience. The most important conclusions of this chapter are:

- Key individuals were able to provide a large variety of solutions for substantive CBA problems;

- Key individuals provide solutions on topics for which solutions are scarcely addressed in existing literature;

- There is a gap between the scientific literature, which predominantly discusses theoretical solutions, and the ideas of the 55 key individuals who predominantly propose pragmatic solutions for practical substantive problems;

- Dutch key individuals are clearly in need of very clear and explicit instructions in CBA guidelines, which are enforced in a second opinion;

- Key individuals' perceptions of solutions for substantive CBA problems are very useful input for CBA research agendas. However, key individuals' perceptions alone provide insufficient input for CBA research agendas. Solutions discussed in academic literature provide very valuable input as well. This chapter shows that the ideal situation for a CBA practice seems to be to use a mixture of inputs for designing CBA research agendas.

Chapter 5: Managing the insolvable limitations of Cost-Benefit Analysis: results of an interview based study

This chapter scrutinizes the perceptions of key individuals in the Dutch CBA practice for spatial-infrastructure projects with regard to insolvable CBA limitations and solutions to manage the insolvable CBA limitations by analyzing the 86 interviews with key individuals carried out for this thesis. The most important conclusions of this chapter are:

- Insolvable CBA limitations as perceived by key individuals in the Dutch appraisal practice for spatial-infrastructure projects can be categorized into three groups: (1) CBA is always incomplete; (2) Effect estimations are always uncertain; (3) Effects that are difficult to estimate have a relatively weak position in the CBA; 
- Key individuals frequently perceive that the fact that CBA is a tool with insolvable limitations is not problematic in itself. According to the key individuals, problems only arise when insolvable limitations are not managed properly;

- Key individuals mentioned fourteen categories of internationally relevant solutions to manage the insolvable CBA limitations which can be categorized into two groups. The first group aspires to minimize insolvable CBA limitations, whereas the second type entirely focuses on the management of the insolvable CBA limitations.

This chapter also discusses how the proposed solutions by key individuals relate to solutions addressed in existing literature.

\section{Policy recommendations}

This section lists the most important recommendations for policy makers (especially Dutch policy makers) that can be derived from the findings of this thesis.

1 The most important policy recommendation is to maintain a role for CBA in the planning and decision-making process for spatial-infrastructure projects. An important result of this thesis is that key individuals in the Dutch CBA practice agree that CBA must have a role in the appraisal process of spatial-infrastructure projects. In the Netherlands, there is no such thing as a camp of 'CBA-Believers' who promote CBA and a camp of 'Non-Believers' who oppose CBA. I recommend emphasizing this when the 'Believer/non-Believer myth' is put forward in discussions.

2 Although key individuals agree that CBA must have a role in the appraisal practice for spatial-infrastructure projects there is a lot of controversy among economists and spatial planners in the Dutch CBA practice concerning the value that is and should be assigned to CBA in the decision-making process. This thesis concludes that to overcome the controversy between economists and spatial planners concerning the value that is and should be assigned to CBA in the decision-making process, a 'subtle' use of CBA (not assigning an absolute or marginal value to the $\mathrm{CBA}$ and thus using $\mathrm{CBA}$ as an instrument with advantages and limitations) is a promising solution. How could policy makers be helped to use CBA in a 'subtle' way? Based on the statements made by key individuals I distinguish three key solutions:

- Politicians should communicate - more than they do at present - that they will assign an important but, at the same time, not too absolute value to the CBA in the decisionmaking process;

- The intelligibility and verifiability of CBA reports should be enhanced;

- The CBA practitioner should inform the non-expert user adequately in the CBA report about CBA limitations. An adequate communication of limitations means that CBA practitioners communicate limitations in a more prominent way than they do at present, but at the same time, must be cautious about communicating CBA limitations in a way that is too prominent. 
3 For the design of a CBA research agenda, I recommend using three types of input as a guiding principle: 1) Key individuals' perceptions of solutions; 2) Solutions discussed in scientific literature; 3) Solutions implemented in other countries.

4 I recommend that developers of CBA guidelines prescribe clearly what a high-quality problem analysis should entail. In the (Dutch) status quo, the criteria for determining the extent to which a problem analysis is 'high-quality' are not clear.

5 A policy recommendation that follows from this thesis is that it would be wise to identify whether or not a specific or a non-specific CBA problem is emphasized when the use of CBA in a particular decision-making process regarding spatial-infrastructure projects is criticized. When a non-specific CBA problem is used as an argument to criticize the use of CBA in the decision-making process, one should emphasize that other ex-ante impact evaluation studies have to face the non-specific CBA problems as well.

6 I recommend institutionalizing systematic 'ex-post analyses' in the planning and decisionmaking process for spatial-infrastructure projects. Uncertainty with regard to effect estimations can be diminished when 'ex-ante' effect estimations are verified. Also, key individuals state that an additional benefit of institutionalizing 'ex-post analyses' might be that the trust in government decision making would be enhanced because the government shows that it really does check the quality of the information it uses in decision-making processes. The next question is: how could institutionalization of (systematic) 'ex-post analyses' be achieved? I recommend learning from countries in which systematic 'ex-post analysis' is - to some extent - institutionalized (for instance, Norway).

7 A final recommendation is to make sure that CBA studies are reviewed in a second opinion. Key individuals consider second opinions of CBA studies as very advantageous. Predominantly private consultants stated in the interviews that they can use the fact that the quality of the CBA will be assessed in a second opinion as a 'weapon' to convince the client to carry out a CBA that can be considered to be 'as independent as possible'.

\section{References}

Hayashi, Y., Morisugi, H., 2000. International comparison of background concept and methodology of transportation project appraisal. Transport Policy 7 (1), 73-88.

Mackie, P., Worsley, T., 2013. International Comparisons of Transport Appraisal Practice. Overview Report. Institute for Transport Studies. University of Leeds.

Mouter, N., Annema, J.A., Van Wee, B., 2012. Maatschappelijke Kosten- en Batenanalyse inhoudelijk geëvalueerd. NICIS: Den Haag.

Odgaard, T., Kelly, C., Laird, J., 2005. Current practice in project appraisal in Europe, in: Proceedings of the European Transport Conference. 3-5 October, Strasbourg, Association for European Transport. 


\section{Samenvatting}

\section{Achtergrond}

Bij het maken van beleidskeuzes in het ruimtelijk-infrastructurele domein moeten overheden vaak negatieve en positieve effecten van beleid afwegen. Het aanleggen van een nieuwe weg leidt bijvoorbeeld tot positieve effecten als reistijdwinst, maar ook tot negatieve effecten als geluidsoverlast en constructiekosten. Politici willen meestal voorafgaande aan de beslissing goed geïnformeerd worden over de positieve en negatieve effecten van de beleidsopties die voorliggen. In de meeste gevallen willen zij per beleidsoptie ook informatie hebben over verschillende alternatieven (bijvoorbeeld, verschillende alternatieven voor een nieuwe weg en verschillende alternatieven voor het verbeteren van bestaande wegen). Uit onderzoek volgt dat in de meeste OECD landen een maatschappelijke kosten-batenanalyse (MKBA) op enig moment in het besluitvormingsproces wordt gebruikt om beleidsmakers te informeren over de positieve en negatieve effecten van beleidsopties (o.a. Hayashi en Morisugi, 2000; Mackie en Worsley, 2013; Odgaard et al., 2005).

Een MKBA probeert de (positieve en negatieve) effecten van een project (of beleidsmaatregel) op de welvaart van Nederland in te schatten. Het gaat hier niet alleen om financiële kosten en baten, maar ook om maatschappelijke effecten zoals effecten van een project op geluidsoverlast of de natuur die inwoners van Nederland van waarde vinden. Deze effecten worden zo goed als mogelijk uitgedrukt in geld. De resultaten van een MKBA worden vaak geaggregeerd in één indicator, zoals de netto contante waarde of de baten-kosten ratio.

\section{Doel en reikwijdte van deze thesis}

Ondanks het de beschikbaarheid van een grote hoeveelheid literatuur over verschillende MKBA-gerelateerde onderwerpen, is er in de literatuur nog weinig aandacht besteed aan percepties van hoofdrolspelers die de MKBA gebruiken, uitvoeren of bestuderen. Deze thesis besteedt aandacht aan vier onderwerpen op het snijvlak van MKBA en praktijk in Nederland (ieder hoofdstuk besteedt aandacht aan één onderwerp). Dit impliceert dat de inzichten die voortvloeien uit deze thesis voornamelijk interessant zijn voor (de verbetering van) de Nederlandse MKBA-praktijk. Echter, het bestuderen van de Nederlandse praktijk levert ook interessante resultaten op voor andere praktijken, omdat het instrument de laatste dertien jaar in Nederland intensief is gebruikt. Daarbij beschrijft deze thesis alleen de resultaten die potentieel interessant kunnen zijn voor een internationaal publiek. Resultaten die louter interessant zijn voor de Nederlandse praktijk worden beschreven in 'MKBA inhoudelijk geëvalueerd' (Mouter et al., 2012).

\section{Resultaten}

Deze sectie beschrijft de resultaten van hoofdstuk 2 tot en met 5. Daarbij passeren ook de methoden die in deze hoofdstukken zijn gebruikt kort de revue. 
Hoofdstuk 2: Rangschikking van inhoudelijke problemen in de Nederlandse MKBA-praktijk Dit hoofdstuk beschrijft de percepties van hoofdrolspelers in de Nederlandse beoordelingspraktijk van ruimtelijk-infrastructurele projecten (verder: hoofdrolspelers in de Nederlandse beoordelingspraktijk) op inhoudelijke problemen bij het beoordelen van ruimtelijk-infrastructurele projecten met een MKBA. Deze percepties zijn onderzocht door 86 hoofdrolspelers in de Nederlandse beoordelingspraktijk (politici, consultants, beleidsambtenaren, lobbyisten, academici) te interviewen over inhoudelijke problemen. Deze percepties zijn gebruikt om een overzicht van ervaren inhoudelijke problemen te krijgen en om deze te kunnen rangschikken. Vervolgens hebben 74 van de 86 respondenten een schriftelijke enquête ingevuld, waarin aan hen werd gevraagd om de inhoudelijke problemen nogmaals te rangschikken. De belangrijkste conclusies van dit hoofdstuk zijn:

- Hoofdrolspelers zien het probleemcluster 'inschatten nog niet gemonetariseerde (in geld uitgedrukte) projecteffecten' als het belangrijkste probleemcluster en 'monetariseren van projecteffecten' als het op één na belangrijkste probleemcluster;

- Hoofdrolspelers zien 'het uitvoeren van een probleemanalyse voorafgaande aan de MKBA' als een zeer belangrijk MKBA-probleem;

- $\mathrm{Er}$ is onder verschillende groepen respondenten relatieve consensus over de urgentie van de verschillende problemen. 'Het uitvoeren van een probleemanalyse

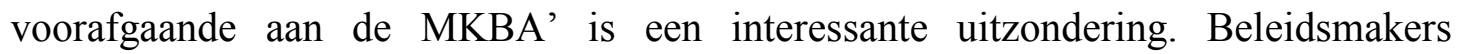
beoordelen de kwaliteit van probleemanalyses een stuk positiever dan consultants en academici;

- Een groot deel van de in de interviews genoemde inhoudelijke problemen, zijn problemen waar andere 'ex ante' evaluatiemethoden ook mee te maken hebben. Dit zijn niet-specifieke MKBA-problemen.

Hoofdstuk 3: Percepties op de rol van de MKBA in het besluitvormingsproces rondom ruimtelijk-infrastructurele projecten: Nederland als case study

Dit hoofdstuk geeft een systematisch overzicht van percepties van hoofdrolspelers in de Nederlandse beoordelingspraktijk op de rol van de MKBA in het besluitvormingsproces rondom ruimtelijk-infrastructurele projecten. Net als in hoofdstuk 2 is gebruik gemaakt van een combinatie van interviews en enquêtes om dit onderwerp te bestuderen. De belangrijkste conclusies van dit hoofdstuk zijn:

- Uit de schriftelijke enquête blijkt dat 73 van de 74 respondenten vinden dat de MKBA een rol moet spelen in het besluitvormingsproces rondom ruimtelijk-infrastructurele projecten. Hier is dus nagenoeg consensus over;

- Respondenten zijn het niet eens over de waarde die aan de MKBA in dit besluitvormingsproces moet worden toegekend. Economen vinden dat andere betrokkenen te weinig waarde toekennen. Ruimtelijk ordenaars vinden dat andere betrokkenen te veel waarde toekennen;

- Zowel economen als ruimtelijk ordenaars vinden deze controverse problematisch, omdat de controverse leidt tot een discussie over de voor- en nadelen van de MKBA in plaats van een discussie over de voor- en nadelen van een project; 
- Respondenten zijn niet tegen het gebruik van de MKBA, maar tegen het toekennen van een - in hun ogen - onjuiste waarde aan de resultaten van een MKBA-studie;

- Wetenschappers, beleidsmakers en consultants kijken niet verschillend aan tegen de waarde die aan de MKBA in het besluitvormingsproces moet worden toegekend.

Dit hoofdstuk besteedt ook aandacht aan oplossingsrichtingen om deze controverse te doorbreken. Deze oplossingen komen verderop in de samenvatting aan bod bij de beleidsaanbevelingen.

Hoofdstuk 4: Oplossingen voor inhoudelijke MKBA-problemen: resultaten van een op interviews gebaseerde studie

Dit hoofdstuk beschrijft de internationaal relevante oplossingen voor inhoudelijke MKBAproblemen die door hoofdrolspelers in de Nederlandse beoordelingspraktijk zijn voorgesteld. In 55 van de 86 interviews die zijn uitgevoerd voor dit onderzoek bespraken respondenten oplossingsrichtingen die ik zie als internationaal relevant. De belangrijkste conclusies die volgen uit dit hoofdstuk zijn:

- Hoofdrolspelers noemen een grote variëteit aan oplossingsrichtingen voor inhoudelijke problemen;

- Hoofdrolspelers noemen oplossingsrichtingen op onderwerpen die nauwelijks zijn geadresseerd in de literatuur;

- Er is sprake van een kloof tussen de internationale literatuur die voornamelijk theoretische oplossingen aandraagt en de oplossingen van hoofdrolspelers die voornamelijk pragmatische oplossingen voor praktische problemen noemen;

- Hoofdrolspelers hebben over het algemeen behoefte aan duidelijke richtlijnen die worden afgedwongen in second opinions;

- De percepties van hoofdrolspelers in de Nederlandse beoordelingspraktijk op oplossingen voor inhoudelijke problemen zijn een nuttige input voor onderzoeksagendas. Echter, ook oplossingen die de literatuur aandraagt en oplossingen die zijn geïmplementeerd in het buitenland kunnen worden gezien als relevante input voor onderzoeksagendas. Dit hoofdstuk laat zien dat onderzoeksagendas idealiter worden vastgesteld aan de hand van een mix van deze drie inputs.

Hoofdstuk 5: Hoe de onoplosbare beperkingen van de MKBA te managen? Resultaten van een op interviews gebaseerde studie

Dit hoofdstuk beschrijft voorstellen die hoofdrolspelers in de Nederlandse beoordelingspraktijk doen om onoplosbare beperkingen van de MKBA te managen. De belangrijkste conclusies van dit hoofdstuk zijn:

- Onoplosbare MKBA-beperkingen kunnen in drie categorieën worden ingedeeld: 1) De MKBA is altijd onvolledig; 2) Inschattingen van effecten van een MKBA zijn altijd 
onzeker; 3) Lastig in geld uit te drukken effecten hebben altijd een relatief zwakke positie in de MKBA;

- Hoofdrolspelers vinden het feit dat de MKBA een instrument met (onoplosbare) beperkingen is op zichzelf niet problematisch. Er ontstaan pas problemen indien deze beperkingen onvoldoende worden gemanaged;

- Hoofdrolspelers noemen veertien categorieën internationaal relevante oplossingsrichtingen om onoplosbare beperkingen van de MKBA te managen. Deze veertien categorieën zijn in twee groepen onder te verdelen. De eerste groep bestaat uit oplossingsrichtingen die gericht zijn op het minimaliseren van de MKBAbeperkingen. De tweede groep bestaat uit oplossingsrichtingen die alleen gericht zijn op het managen van MKBA-beperkingen.

Dit hoofdstuk bespreekt ook hoe de oplossingen die door respondenten zijn genoemd zich verhouden tot de oplossingen die in de literatuur worden besproken.

\section{Beleidsaanbevelingen}

Deze sectie bespreekt de belangrijkste beleidsaanbevelingen die voortvloeien uit deze thesis (deze zijn voornamelijk bestemd voor Nederlandse beleidsmakers):

1 De belangrijkste beleidsaanbeveling is dat de positie van de MKBA in het plan- en besluitvormingsproces voor ruimtelijk-infrastructurele projecten behouden moet blijven. Hier is brede consensus over in de Nederlandse beoordelingspraktijk voor ruimtelijkinfrastructurele projecten. De mythe dat er in Nederland een onderscheid kan worden gemaakt tussen 'MKBA-gelovigen' en 'niet-MKBA gelovigen' klopt niet. Ik beveel aan om dit te benadrukken, indien deze mythe naar voren wordt gebracht in politieke discussies.

2 Deze thesis concludeert dat subtiel gebruik van de MKBA (ook wel deugdzaam gebruik genoemd) een kansrijke oplossing is om de controverse tussen economen en ruimtelijk ordenaars over de waarde die aan de MKBA moet worden toegekend in het besluitvormingsproces rondom ruimtelijk-infrastructurele projecten te doorbreken. Met subtiel gebruik wordt bedoeld dat geen absolute waarde en ook geen marginale waarde aan de MKBA wordt toegekend en dat de MKBA dus wordt gebruikt als een instrument met zowel sterke punten als beperkingen.

Respondenten noemen onder meer de volgende drie belangrijke acties die kunnen worden ondernomen om subtiel gebruik van de MKBA te realiseren:

- Politici moeten - meer dan in de status quo - communiceren dat zij een belangrijke maar geen absolute waarde toekennen aan de MKBA in het besluitvormingsproces;

- De begrijpelijkheid en navolgbaarheid van MKBA-rapporten moet verbeteren;

- De uitvoerders van een MKBA moeten gebruikers van de MKBA (die vaak geen MKBA-expert zijn) in het rapport op een adequate manier informeren over de beperkingen van de MKBA. Dit betekent dat MKBA-beperkingen op een 
prominentere manier in het MKBA-rapport moeten worden gecommuniceerd dan in de status quo. Tegelijkertijd moet men de beperkingen ook weer niet te prominent communiceren, anders bestaat het risico dat beleidsmakers de MKBA niet meer zien als een goede basis voor besluitvorming.

3 Het is verstandig om bij het opzetten van MKBA-onderzoeksagendas gebruik te maken van drie verschillende inputs, te weten: percepties van hoofdrolspelers uit de praktijk over oplossingen; oplossingen die aan de orde komen in de literatuur; oplossingen die zijn geïmplementeerd in het buitenland.

4 De eerste stap die een MKBA-analist maakt bij het uitvoeren van een MKBA is het maken van een probleemanalyse. Een resultaat van deze thesis is dat een groot deel van de geïnterviewde hoofdrolspelers vindt dat de kwaliteit van deze eerste stap te wensen overlaat. Uit deze thesis volgt de aanbeveling dat MKBA-leidraden veel beter moeten beschrijven aan welke criteria een goede probleemanalyse moet voldoen. Door een gebrek aan criteria in de status quo, is het nu onvoldoende duidelijk wat men onder 'een goede probleemanalyse' precies moet verstaan.

5 Een groot deel van de inhoudelijke problemen die hoofdrolspelers ervaren bij het uitvoeren en gebruiken van een MKBA zijn problemen waar andere 'ex ante' evaluatiemethoden (zoals de multicriteria-analyse) ook mee te maken hebben. Dit zijn niet-specifieke MKBAproblemen. Een aanbeveling die volgt uit deze thesis is dat men bij discussies over de kwaliteit van de MKBA bij een project snel moet identificeren of de discussie gaat over een specifiek MKBA-probleem dan wel over een niet-specifiek MKBA-probleem. Als de discussie gaat over een niet-specifiek MKBA-probleem dan beveel ik aan om dit in de praktijk snel te benadrukken. Dit kan frustraties over het gebruik van MKBA bij het evalueren van ruimtelijk-infrastructurele projecten voorkomen.

6 Een aanbeveling die volgt uit deze thesis is om vaker effectinschattingen van MKBAstudies achteraf met een 'ex-post analyse' te controleren en dit te institutionaliseren in het Nederlandse plan- en besluitvormingsproces rondom ruimtelijk-infrastructurele projecten. Het achteraf systematisch controleren van de inschattingen van projecteffecten kan grote leereffecten met zich meebrengen. Men krijgt een beter zicht op de daadwerkelijke effecten van ruimtelijk-infrastructurele projecten en dit kan de onzekerheid rondom effectinschattingen op termijn verkleinen. Een bijeffect van de introductie van 'ex-post analyses' kan zijn dat het vertrouwen in de overheid toeneemt, doordat de overheid laat zien dat zij de studies waarop beleidsbeslissingen steunen achteraf controleert. Ik beveel aan om te leren van landen waar men 'ex-post analyses' heeft geïmplementeerd in het proces (bijvoorbeeld Noorwegen).

7 Een laatste aanbeveling die volgt uit de thesis is dat verplicht moet worden gesteld dat de kwaliteit van MKBA-studies wordt gecontroleerd in second opinions. Met name consultants gaven in de interviews aan dat het feit dat bekend is dat een second opinion zal worden uitgevoerd, door hen als 'wapen' kan worden ingezet om de opdrachtgever van een MKBA ervan te overtuigen om een zo onafhankelijk mogelijke MKBA uit te laten voeren. 


\section{Referenties}

Hayashi, Y., Morisugi, H., 2000. International comparison of background concept and methodology of transportation project appraisal. Transport Policy 7 (1), 73-88.

Mackie, P., Worsley, T., 2013. International Comparisons of Transport Appraisal Practice. Overview Report. Institute for Transport Studies. University of Leeds.

Mouter, N., Annema, J.A., Van Wee, B., 2012. Maatschappelijke Kosten- en Batenanalyse inhoudelijk geëvalueerd. NICIS: Den Haag.

Odgaard, T., Kelly, C., Laird, J., 2005. Current practice in project appraisal in Europe, in: Proceedings of the European Transport Conference. 3-5 October, Strasbourg, Association for European Transport. 


\section{Appendix I: Towards improved handling of uncertainty in Cost-Benefit Analysis: addressing the 'price-quality' and 'communication' dilemmas}

This paper is currently under review as: Mouter, N., Holleman, M., Calvert, S., Annema, J.A., Towards improved handling of uncertainty in Cost-Benefit Analysis: addressing the 'pricequality' and 'communication' dillemas

\section{Introduction}

Cost-Benefit Analysis (CBA) has been an important tool for transport planners for several decades, in particular for evaluating and ranking transport infrastructure investments (e.g. Eliasson and Lundberg, 2012; Grant-Muller et al., 2001). Despite its popularity, CBA has often been criticised for several reasons, most of them related to the insolvable limitations when it is applied in practice. One important insolvable limitation is that estimations of future project effects are inherently very uncertain (e.g. Flyvbjerg et al., 2003; Naess, 2006; Naess and Strand, 2012). The topic of uncertain impact estimations in CBA is addressed in recent literature. For example, Nicolaisen (2012) states that a systematic ex-post evaluation programme needs to be established to facilitate a better learning process from experiences in past projects, which should result in more accurate effect estimations. Salling and Banister (2009) suggest to present interval results to decision makers instead of single point results to enhance decision makers' understanding of uncertainties. In this paper we take a different view on handling uncertainty in CBA. We argue that two dilemmas - the 'price-quality dilemma' and the 'communication dilemma' - impede a proper handling of uncertainty in current CBA practices. In this paper, we discuss both dilemmas and - more importantly - for each dilemma we propose a solution that aspires to be a first step towards solving the dilemmas. The paper is organised as follows: section II discusses both dilemmas in more depth. Sections III-V discuss the solutions. Section VI provides concluding remarks. 


\section{Problem definition}

We label the first dilemma as the 'price-quality dilemma'. CBA practitioners make a trade-off between the quality of the estimation of welfare effects and the costs in time and money of providing these estimates. Cost-Benefit Analyses are used in the decision-making process to provide decision makers with high quality information with regard to the welfare effects of infrastructure projects. CBA practitioners aspire to provide effect estimations that are as accurate as possible sustaining their estimations on empirical information, for instance. However, in most CBA practices, private consultants have to compete for a CBA tender. To win a tender the price-quality ratio of their offer must outperform the offers of the competing private consultants. Hence, it is important that their offer is not too expensive. Moreover, CBA Guidelines emphasise that costs of the appraisal should be proportionate to the costs of the infrastructure project under scrutiny in the CBA study. See for instance the UK WebTag (www.dft.gov.uk/webtag/) 1.4.2: 'it is expected that appraisals will be comprehensive but proportionate.' And WebTag 2.1 'careful consideration should be given, before resources are committed to data collection and model building.' Also, supplements to the Official Dutch CBA Guidelines (e.g. Ministry of Transport, Public Works and Water Management, 2004) emphasise that the resources that would have to be devoted to preparing estimates of welfare effects should not be disproportionate. This results in gathering data of varying degrees of quality, applying causal explanations with varying degrees of validity and robustness, making assumptions and selecting certain approaches, all to limit the inquiry (e.g. Beattie, 1995).

A group of scholars argues that the accumulation of assumptions and shortcuts leads to biased results and take this as an argument to oppose the use of CBA in the decision-making process at all (e.g. Ackerman and Heinzerling, 2004; Naess, 2006). We define the "price-quality dilemma' as follows: on the one hand CBA practitioners want to produce high-quality unbiased effect estimates. However, because instruments to produce accurate effect estimates can be expensive, CBA practitioners are not inclined to produce accurate results, because this could make their tender too expensive to win.

We label the second dilemma as the 'communication dilemma'. There is much literature on the poor communication of uncertainties in CBA reports. Naess and Strand (2012) state that the high degrees of uncertainty are often not displayed in reports. According to Welch and Williams (1997), CBA outcomes are usually presented as if they are endowed with considerable accuracy, although estimations of traffic models, for instance, are very uncertain. From an analysis of decision-support documents of 78 Norwegian and Danish projects, Nicolaisen (2012, p.7) finds that: 'uncertainties are often toned down or ignored in the decision support prepared for policy makers.' Annema et al. (2013) have analysed 106 Dutch transport CBAs published in the period 2000 - 2012 and found, amongst other things, that in only $25 \%$ of the projects evaluated the CBA results were presented with a clear bandwidth to the decision-makers, in the other $75 \%$ just point estimates were given in the main results. To which extent is a poor communication of uncertainties problematic? Nicolaisen (2012) finds that improper communication makes impact appraisals appear more accurate than warranted, which causes distrust towards the results among policy makers. Based on a survey of 86 key 
actors in the Dutch appraisal practice for spatial-infrastructure projects Mouter et al. (2013) discuss that a poor communication of uncertainties leads to two problems. On the one hand politicians, civil servants and other stakeholders that use CBA assign too much value to the CBA because they are not aware of the uncertainties in CBAs and, as a result, use it as a holy grail ("we decide positively only if the benefit-cost ratio is above 1"). On the other hand poor communication of uncertainties enhances suspicion by sceptical actors, which leads to a situation where these actors assign too little value to the CBA ("I don't trust instruments that produce false certainties and are not honest about the limitations of the results"). Some Dutch key actors even consider a poor communication of uncertainties so hazardous, that they think it can lead to the 'collapse' of the CBA in the decision-making process.

Is a very prominent communication of uncertainties then the solution? Mouter et al. (2013) find that a group of key actors in the Dutch appraisal practice for spatial-infrastructure projects perceives that a too prominent communication of uncertainties eventually leads to 'the collapse' of the instrument in the decision-making process. These key actors perceive that politicians will not use a CBA report that communicates an uncertain message because politicians will not consider this as useful information and certainly not as a solid basis for decision making. In addition, a Review of the Norwegian Cost-Benefit Analysis Guideline (Hagen et al., 2012, p. 85) advises against the use of more than one estimate of welfare effects: 'since the approach will not provide one estimate, but several different estimates, for net economic benefits for the entire lifespan of the project, this approach may result in a more complex and equivocal basis for making decisions.' Therefore, the dilemma is that both a poor communication and a too prominent communication of uncertainties cause problems. As long as this dilemma is not solved, uncertainty in CBA will probably be handled poorly because practitioners just do not know a best way between 'poor' and 'too prominent' way of communicating.

\section{A first step towards solving the 'price-quality dilemma'}

In this section we propose a solution that aspires to be a first step towards solving the 'pricequality dilemma'. The general idea is to develop models or calculation tools which practitioners can use in order to make more accurate estimations without substantial extra costs (time and money) compared to current models and tools. Below, we discuss the probabilistic dynamic traffic model INDY-MonteCarlo as a promising example of how the 'price-quality dilemma' can be solved. This model applies efficient Monte Carlo sampling which makes it possible to estimate welfare effects more accurately against approximately the same time and costs (approximately 4 extra man-days, and 10 days extra running time for computers)

We state that research agendas for an improved CBA practice should focus on these types of solutions and not only on solutions that lead to more accurate effect estimations but which are too costly (in terms of time, effort and money) to apply in practice. For instance, Spatial Computable General Equilibrium (SCGE) models (e.g. Knaap and Oosterhaven, 2011) that were developed to estimate indirect effects of transport projects more accurately is an 
example of such a solution. Another example is determining case-specific risk surcharges for welfare effects, which is prescribed in Dutch CBA Guidelines (Ministry of Transport, Public Works and Water Management et al., 2004) but turned out to be too costly to apply in practice resulting in CBAs still being conducted based on the inaccurate assumptions.

In CBAs for infrastructure projects the transport effects (such as travel time gains) are for financial reasons estimated based on a model simulation of a representative day, almost without exception. The representative day contains the average of the applicable capacity and traffic demand values for a scenario. The underlying assumption made is that even though traffic demand and capacity vary over the year - for instance, as a result of weather, lane closures, special events and incidents - the outcomes for the representative day can be extrapolated to a yearly value, presuming that the capacity and demand in the representative day are good averages. Conducting a CBA applying this assumption is obviously far less expensive than conducting a CBA for which the transport effects for all days in a year are estimated separately. The question is to which extent this assumption makes the estimation less accurate.

In a real-world case study, we investigate this topic by applying an advanced Monte Carlo traffic model, called INDY-MonteCarlo (see Calvert et al., 2014) for new rush-hour lanes on the A9 highway in Amsterdam (the Netherlands). As a result of the new rush-hour lanes the 2x2-lane road was expanded to a 2x3-lane road during peak hours (see figure 1). It was one of the thirty projects in the Dutch Roadworks Priority Program. Supplying extra road capacity was expected to relieve congestion on these critical motorway stretches. The lack of capacity typically caused congestion at the Diemen junction going in the direction of Amstelveen/Schiphol in the morning, and in the opposite direction in the evening.

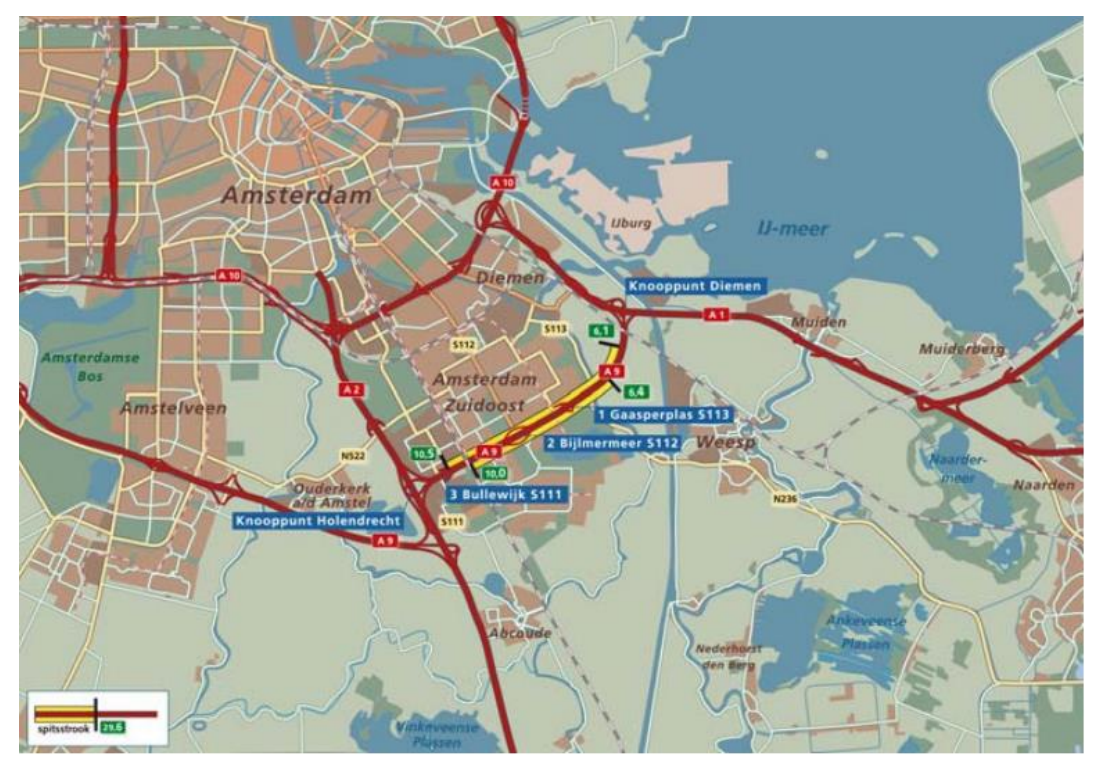

Figure 1: South East Amsterdam (the Diemen - Holendrecht stretch is colored yellow)

Application of stochastic variation in modeling the case study's travel time savings 
In our case study we consider the stochasticity of road capacity and traffic demand while modeling the traffic effects of the project. Applying variation in the modeling process using stochastic input through Monte Carlo simulation is performed in this study through the approach that is introduced by Calvert et al. (2014). Firstly, in this approach, the traffic network is constructed with associated empirical information about road capacity and traffic demand. These distributions of stochastic variations of capacity and demand ${ }^{53}$ result in probability distributions of capacity and demand. The underlying information for the probability distributions is derived from real traffic data from the A4 and A12 highways in the Netherlands during weekdays. Calvert et al. (2014) further indicate that the distributions found can be generically applied to most highways, "as the distributions are constructed as a relative factor rather than absolute capacity values." The resulting cumulative distribution functions of the road capacity and traffic demand factor are presented in figure 2 .
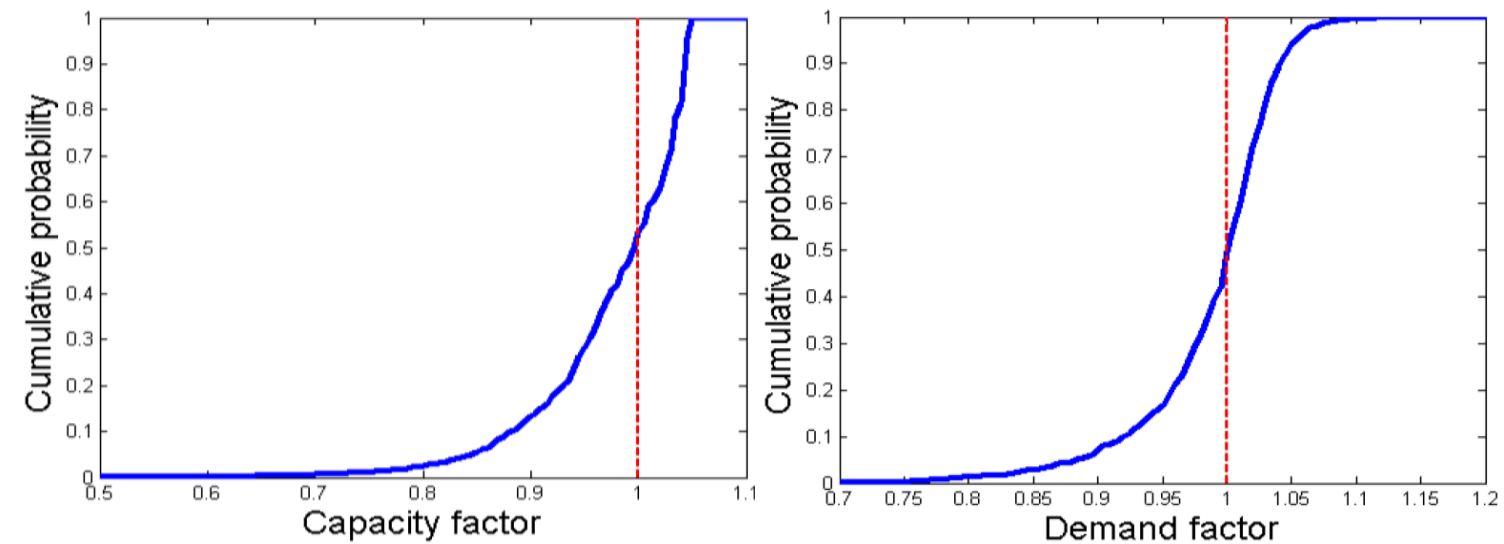

Figure 2: Cumulative distribution function of the road capactity and traffic demand factor

Secondly, from these distributions a random sample is taken using Monte Carlo simulation, which is applied as input for the traffic model. In this study, 100 values are drawn for capacity and 100 values for demand. One important aspect in this study is that, in order to reduce the variance between individual samples and thereby to reduce the number of required sample iterations before an adequate level of performance is reached, Latin Hypercube Sampling (LHS) is applied in the Monte Carlo simulations in this study, in line with Calvert et al. (2014) and Salling and Banister (2009).

Thirdly, a traffic model simulation is run with 100 iterations for both the project situation and the reference situation in 2010, 2020, 2030 and 2040 for two social-economic development scenarios that differ in traffic demand development (Global Economy or Regional Communities; Huizinga \& Smid, 2004), in which the samples drawn are applied as adjustment factors over base capacity and demand. The traffic model applied in this study is

\footnotetext{
${ }^{53}$ Stochastic variation in traffic is a result of weather, lane closures, special events, incidents, and shifting demand patterns, for example. In this study, stochasticity is applied by using probability distributions indicating variations in road capacity and in traffic demand (i.e. adjustments from the average). For example, if the average ('base') demand for a particular road section is 1800 vehicles/hour, then an adjustment factor of 1.05 yields a demand of 1890 vehicles/hour, and a factor of 0.80 yields a demand of 1440 vehicles/hour.
} 
INDY. INDY is a dynamic macroscopic traffic model (Bliemer et al., 2004), which uses the Link Transmission Model (LTM) implementation by Yperman (2007) for traffic propagation.

The 100 outcomes of the simulation are expressed as a reduction in the total network delay of traffic in the project situation compared to the reference situation for each year of the time horizon using linear interpolation. Furthermore an assumption is made of the number of relevant days that the situation applies to per year of 210 days a year. These are generally the non-holiday weekdays in which congestion usually occurs. The result of the model simulation is multiplied with this number of days to give a yearly value, presuming that the given capacity and demand values are valid on all days. Finally, the travel time savings are expressed in monetary terms and are discounted to the base year (in this case 2010; discount rate is $5.5 \%$ in the Netherlands) in order to estimate the Net Present Value (NPV).

\section{Resulting distributions and conclusions}

The steps described in the previous section result in outcomes for the whole time horizon, in both scenarios. In the Global Economy scenario, the mean value of travel time benefits as approximated by INDY-MonteCarlo is 133 million euro, with a standard deviation of approximately 0.7 million euro. The deterministic mean, in which a single simulation is performed with a representative day, returns a considerably higher value of 141 million euro. In this scenario the mean is therefore overestimated by six percent if deterministic traffic model input is used. Figure 3 shows the distribution and the means in the GE scenario.

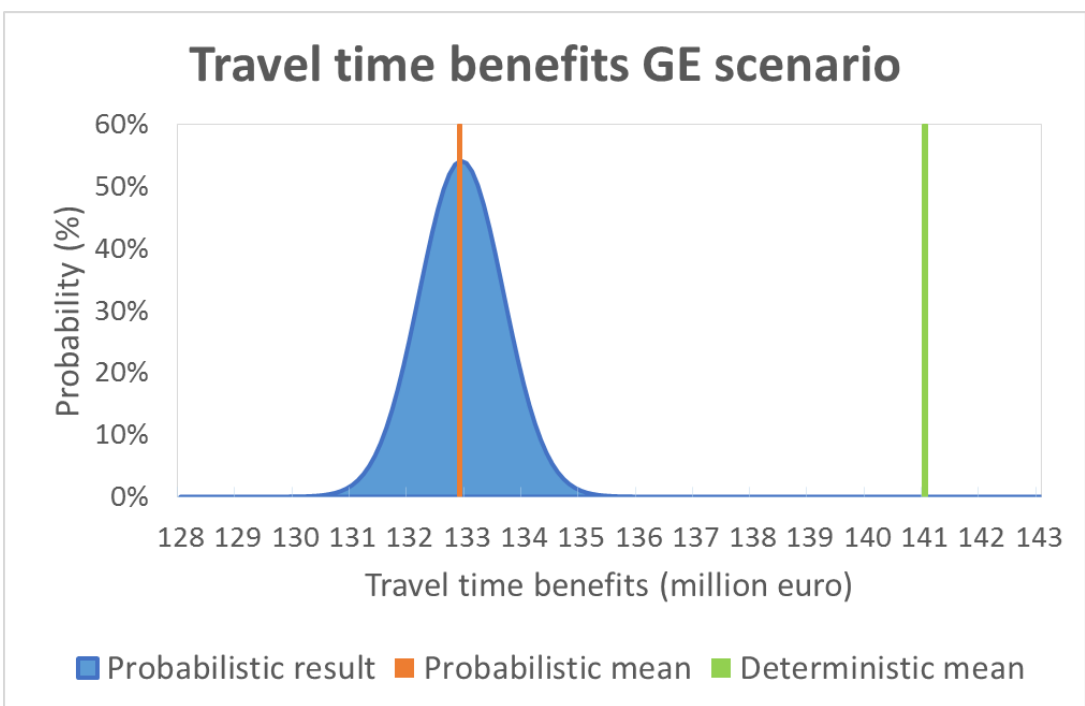

Figure 3: Uncertainty in estimations of travel time savings in the GE scenario

In the Regional Communities scenario, the mean value of travel time benefits is 73 million euro, with a standard deviation of approximately 0.8 million euro. The deterministic mean, in which a single simulation is performed, returns a much lower value of 60 million euro. In this scenario the mean is therefore underestimated by seventeen percent if deterministic traffic model input is used. Figure 4 shows the distribution and the means in the RC scenario. 


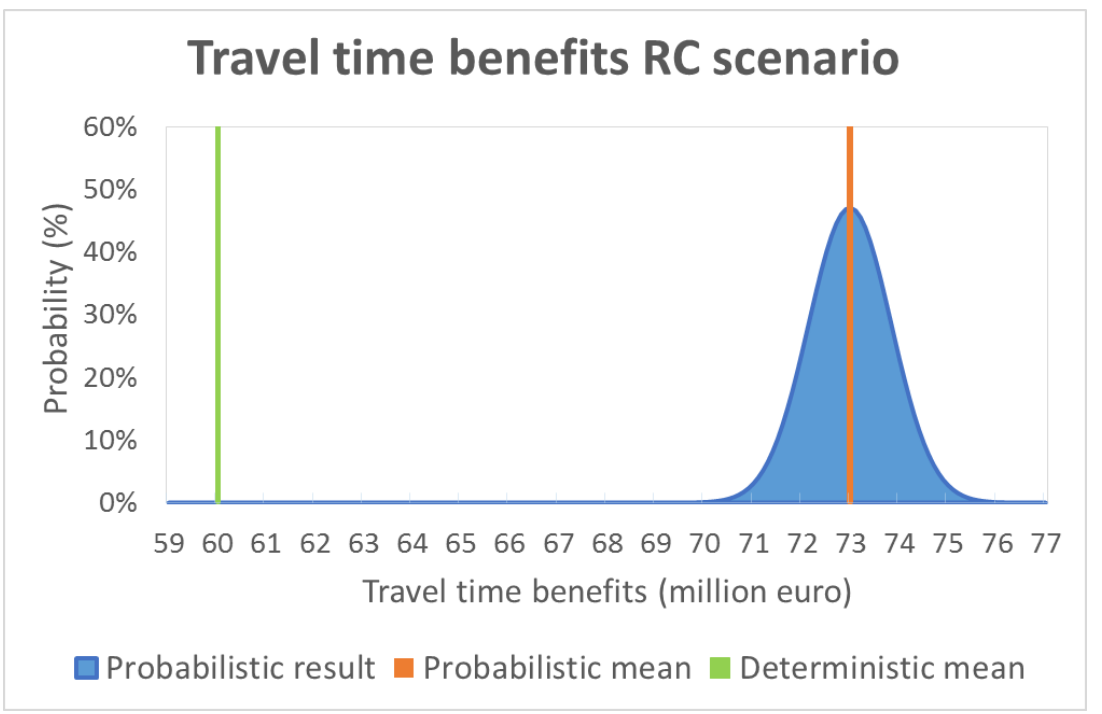

Figure 4: Uncertainty in estimations of travel time savings in the RC scenario

Figures 3 and 4 demonstrate that modeling traffic with the assumption that the capacity and demand in the representative day are good averages will lead to biased CBA outcomes. The results show that considering uncertainty with regard to demand and capacity over the year results in deviations from $6 \%$ and $17 \%$ compared to merely considering a 'representative day' for the model simulation in this test case. These values are also comparable with deviations found elsewhere in literature (van Lint et al, 2012; Calvert et al, 2012). A second notable observation is that the bandwidths that were found around the probabilistic mean are small. Moreover, figures 3 and 4 show that uncertainty which originates from estimating effects with two social-economic development scenarios is much larger than uncertainty that results from estimating traffic effects with a probabilistic traffic model for demand and capacity. Hence, we conclude that - when CBA practitioners aspire to effectively communicate uncertainty surrounding effect estimations in the CBA report - it is paramount to estimate welfare effects with two economic development scenarios. Furthermore, these estimations will be more accurate if a model such as INDY-MonteCarlo is used, which makes it possible to estimate these welfare effects more accurately compared to estimating the effects assuming a representative day.

Now that we have more information with regard to the level and shape of uncertainty surrounding effect estimations the question is: how to communicate uncertainty in the CBA report? For instance, it is not yet clear how prominently uncertainties should be communicated in the CBA report, such that different types of individuals have a better understanding of the uncertainty. This topic is addressed in the next chapters.

\section{Explanations for controversy about communication of uncertainty from a psychological perspective}

As discussed in section II the dilemma is that both a poor communication and a too prominent communication of uncertainties are mentioned as potential causes for 'the collapse' of CBA in the decision-making process for spatial-infrastructure projects. We argue in this and the next 
section that cognitive psychology may provide a promising perspective to solve this dilemma. Based on insights from cognitive psychology, we scrutinise the extent to which individuals have different attitudes towards uncertainty. Based on this, a cognitive psychological theory is developed that helps to explain the controversy about the communication of uncertainty in CBA reports. This theory also provides insight into how uncertainty should be communicated, based on individuals' reactions towards the communication of uncertainty in CBA reports. Furthermore, based on cognitive psychological theory measures arise that may stimulate the motivation of CBA users whose attitude towards the communication of uncertainty in CBA reports is expected to be problematic. Although the results of this study may not necessarily provide a final answer to the question of how uncertainty should be communicated in CBA reports in an appropriate manner, the results may enhance insights into the question of how and most of all how prominently - uncertainty in welfare effect estimations should be communicated in CBA reports so that users with different personality and social psychological characteristics are able to understand the information and still evaluate the information as useful input in the decision-making process.

To address this topic, this section first discusses the dual-process theory of reasoning. This widely recognised theory clarifies how individuals receive and process information and explains that individuals can process information systematically or heuristically. Secondly, we discuss the fact that one result of a heuristic way of processing a CBA report that prominently presents point estimations is that uncertainties are poorly understood and argue that one should present uncertainty in a very prominent way.

\section{The dual-process theory of reasoning}

The dual-process theory of reasoning basically argues that individuals may theoretically employ two modes of thinking when processing information: individuals can process messages via 'System 1' or via 'System 2,54. System 1 is characterised by the reliance on simple inquiries and environmental characteristics of the message (O'Keefe, 2008), such as credibility of the author, appearance of the text or clarity of illustrations, whereas System 2 is characterised by accurate balancing of all specific information before judging, extensively relating the information to knowledge already possessed (O'Keefe, 2008). In other words, System 1 tends to process information heuristically, via subconscious cognitive 'shortcuts' that act as automatic programs to reduce complex decision tasks to simpler judgmental information, whereas System 2 tends to process information systematically (Kahneman et al., 1982; Shah and Oppenheimer, 2008). System 1 is always active (unintentionally) and is influenced by experiences, emotions and memories, whereas System 2, which is influenced by facts, logic, and evidence, is only active if an individual perceives that System 1 does not reach realistic conclusions and intentionally chooses to employ System 2 (Kahneman, 2011). Furthermore, literature indicates that individuals will only choose to employ System 2 if they

\footnotetext{
${ }^{54}$ See e.g. Stanovich and West (2000), Kahneman (2011). Other labels for this theory and the associated modes of thinking are 'Elaboration Likelihood Model' (ELM; Petty and Cacioppo, 1986) and 'Heuristic-Systematic Model of Information Processing' (HSM).These theories refer to the same phenomenon and are conceptualised in similar terms (Evans, 2009). Therefore, it seems justified to assume that findings that apply to ELM, HSM or System 1 and 2 are also applicable to the others.
} 
are sufficiently motivated to assign cognitive resources to the task of information processing, if they have the ability, i.e. the competences or skills, to accurately interpret and understand a message, and if they have the opportunity to do so (e.g. Andrews, 1998).

Meyers-Levy and Maheswaran (2004) suggest that if decision-makers process a message systematically (typical of System 2), there will still always be some heuristic processing, to some extent (typical of System 1). In other words, even if individuals are highly motivated to thoroughly assess information in a systematic way, heuristic processing will always occur to a certain degree. Based on this observation and the occurrence of heuristic processing in other fields of research and policy making, it is considered likely that the use of heuristics in the processing of CBA reports is common, even if individuals are highly motivated to thoroughly assess all the information in a systematic way. Letson et al. (2001) state that before risks, uncertainties and limitations can be effectively communicated, scientists need to comprehend the 'mental models', which essentially refers to actors' use of framing and heuristics when they evaluate the information. Therefore, the next passage focuses on the most important heuristics that are relevant to the present study.

\section{When point estimations are presented prominently, individuals will not consider the uncertainty}

In this section, the relationship between the use of heuristics and the communication of CBA uncertainty is discussed. The heuristics that are taken into consideration explain why individuals are not able to understand uncertainties sufficiently when point estimations are presented in a prominent way.

\section{Availability and anchoring-and-adjustment heuristics}

There are various types of heuristics. Two of the most common and important heuristics are the availability heuristic and the anchoring-and-adjustment heuristic (e.g. Tversky and Kahneman, 1974).

The availability heuristic makes it more likely that people will consider the events which are easier to recall or bring to mind. For example, Tversky and Kahneman (1974) indicate that people tend to overrate the danger of air travel (relative to car travel), because of the dramatic nature of aircraft calamities and the subsequent lasting impressions of these accidents. Next, the anchoring-and-adjustment heuristic is the fundamental decision-making heuristic in events where values need to be estimated (Epley and Gilovich, 2006). In essence, this heuristic refers to starting from an initial value - the 'anchor' - which is based on a simple feature and then to adjust this number to arrive at the final answer (Tversky and Kahneman, 1974). But typically, the adjustments made to these anchors are insufficient (Lichtenstein and Slovic, 1971; Epley and Gilovich, 2006), meaning that different initial values lead to different estimates that are biased towards the initial values. For example, when asked to estimate the percentage of African countries in the United Nations, the median estimations were 25 and 45 for two distinct groups that had 10 and 65, respectively, as suggested initial values (Tversky and Kahneman, 1974). The anchor biased their final estimate. Furthermore, Yamagishi (1994) 
suggested that anchoring-and-adjustment also leads to biases in evaluations of risk and uncertainty, the same as the other heuristics and biases.

The availability heuristic and the anchoring-and-adjustment heuristic may be important causes for ineffective communication of uncertainties when CBA practitioners prominently present 'point estimates'. Considering the availability heuristic; this heuristic leads individuals to relate the numbers presented to the ease with which they can imagine such outcomes. Since individuals have far less difficulty in imagining a single number as the outcome than in imagining a range or a probability distribution as the outcome, presenting a single number results in an overconfidence in this number. In other words, as soon as individuals are given a single number as the outcome, they are likely to put so much emphasis on this number that they will subconsciously accept that number as decisive, irrespective of the presentation of uncertainties surrounding the estimation. For the anchoring-and-adjustment heuristic: this heuristic leads individuals to assume that the actual effect cannot differ that much from the starting estimation, or the 'best estimate'. So, individuals would subconsciously underestimate the possibility of different outcomes (outliers) and overestimate the confidence with which outcomes are likely to be close to the initial single point estimation. In other words, if a CBA report communicates a specific value for a social benefit or a social cost of a project, the report may still present uncertainties surrounding the estimations, but CBA users remain relatively unaffected by this 'late' presentation of uncertainties.

Hence, we suggest that the goal that CBA users understand uncertainty can only be attained when CBA practitioners first communicate the uncertainty surrounding welfare effect estimations, such as bandwidths, ranges, and chances of outliers, and only then carefully give some hints as to what could be plausible outcomes. So, a prominent presentation is a first step of solving the dilemma. In essence, by presenting welfare effect estimations in this typical order individuals' tendency to make use of heuristic inquiries is used against itself: when confronted with uncertainty first, it subconsciously becomes less likely that the outcome can be expressed in a single number. This effective communication of uncertainties might result in a better understanding of the uncertainties of effect estimations in CBA studies. However, although communicating uncertainty very prominently may result in more understanding of the uncertainty, it should not be expected that all CBA users perceive this as positive (also prominent presentation can lead to the collapse of the instrument as our dilemma states). Problems are expected for at least two types of individuals. In the next chapter these problems are discussed, and solutions are proposed, again from a cognitive psychological perspective.

\section{Prominent communication of uncertainties: problems and solutions}

A report that prominently communicates all uncertainties and limitations, does not serve heuristic message processing. Actors are not enabled to reach conclusions immediately, but will have to consider the uncertainties and ambiguous clues. In this study we distinguish two 
possible types of 'heuristic individuals' who we think will have trouble with processing information on uncertainty. ${ }^{55}$

Firstly, we believe that the communication of an uncertain and equivocal message will be problematic for the 'flamboyant heuristic individual'. By making decisions, this type of individual will heavily rely on his intuition. Hence, this individual is a priori relatively sceptical towards the added value of research reports. This type of individual will almost exclusively use System 1 to process information. If this individual decides to process the information of a report at all, he will process the information in an extremely heuristic way. When a research report communicates an uncertain message this commands the flamboyant individual to activate System 2. Chances are high that the individual will not decide to activate System 2 and will just focus on information that is possible to grasp using System 1 solely or will rely on his intuition. In conclusion, if a CBA report first communicates point estimations, a 'flamboyant heuristic individual' will probably consider the point estimations and not the uncertainties. However, when uncertainties are presented first, it is likely that this individual will not consider the information of the CBA report at all. Hence, prominent communication of uncertainties results in diminishing use of information.

Secondly, we think it is likely that a prominent communication of uncertainties is ineffective for the 'stubborn heuristic individual'. In spite of the prominent warning that effect estimations are uncertain, this individual still wants to find a definite and unambiguous conclusion in the CBA report. This type of individual will consider a report that conveys an equivocal message useful. However, this individual will ignore the uncertainty and eventually believe to have found conclusive evidence in the report to support or not support the project.

To enhance our understanding of the two types of individuals' difficulties to process ambiguous messages, we first need to discuss the relationship between individual differences and motivations to use the CBA report. Moreover, we will discuss psychological characteristics of the so-called 'stubborn heuristic individuals' and the 'flamboyant heuristic individual' and provide solutions for managing their problems of processing uncertain messages.

\section{Different Motivations (orientations)}

Individuals can have different motivations for using a CBA report in the decision-making process (Mouter et al., 2013). For instance, individuals use the CBA to contemplate the usefulness, necessity and design of a project, use it strategically (either to kill or support the project), use it in an Absolute way ("if the score is positive we decide positively and vice versa). The first three motivations will from now on be called (1) Challenge orientation, (2) Strategic orientation and (3) Absolute orientation. We have conceptualised Challenge

\footnotetext{
${ }^{55}$ We are aware of the fact that considering a report that communicates an uncertain message can be troublesome for other types of individuals as well. Hence, the two possible types of heuristic individuals should be seen as examples of individuals for whom we consider it certain that possible drawbacks of prominently communicating uncertainty can arise. Further research should clarify which other types of individuals may have trouble with processing information on uncertainty.
} 
orientation as the tendency to view information as being useful or needed to think about the usefulness, necessity and design of the project, and to be likely to question assumptions in the CBA, for the sake of making better decisions. Strategic orientation has been conceptualised as individuals' tendency to value and apply information according to their own liking, for the sake of serving their political or personal interests. Absolute orientation has been conceptualised as the tendency to overrate or absolutise information because of a conviction that it is imperative to base the final decision on this information. Within this orientation, the accent is not on searching out the limitations and assumptions of the research, which is the case in the Challenge orientation, but on 'simply' trusting that the information provides the right (final) answer. ${ }^{56}$

\section{Cognitive styles}

Before we discuss a conceptual model for the hypothesised relationships between cognitive styles and the three motivations for processing CBA reports we need to explain the cognitive styles that are relevant, related to the processing of uncertainty-related CBA report content.

Cognitive styles are defined as individuals' "chronic motivations that principally determine the initiation, course, and cessation of information seeking and processing" (Thompson, 2008; Thompson et al., 2001). In other words, cognitive styles are individual differences that directly influence information seeking and processing preferences. Individual differences are defined as psychological traits or chronic tendencies that "convey a sense of consistency, internal causality and personal distinctiveness" (Carver and Scheier, 2000). These individual differences are assumed and demonstrated to be relatively unrelated to situational induced differences: individual differences are considered to "play an elemental role in how people generally react across the situations they encounter" (e.g. Thompson, 2008). In other words, individual differences, as they are understood in psychology, are presumed to describe individuals' general orientations and motivations across domains.

Three cognitive style variables are discussed which can be related to the processing of uncertainty-related CBA report content. These are: Need for Cognition (NC; Cacioppo and Petty, 1982), Personal Need for Structure (PNS; Thompson et al., 1989, 1992), and Personal Fear of Invalidity (PFI; Thompson et al., 1989, 1992).

\section{Characteristics of Need for Cognition (NC)}

Cacioppo \& Petty (1982) conceptualised Need for Cognition (NC) as "an individual's chronic tendency to engage in and enjoy effortful cognitive activities." To measure individuals' NC, generally, the scale validated by Cacioppo et al. (1984) is used. This scale consists of 18 items, such as "I would prefer complex to simple problems"; "I find satisfaction in deliberating hard and for long hours"; "I only think as hard as I have to" (reverse scored).

\footnotetext{
${ }^{56}$ Strong support for these conceptualisations is found in the study of three distinct motivations in the field of religion: it was found that Challenge, Strategic and Absolute orientation are highly similar to 'Quest', 'Means' and 'End' orientation in religion (see e.g. Barrett et al., 2005). It is, however, beyond the scope of this research to discuss the convincing similarities between the motivation to be involved in religion and the motivation to use the CBA report.
} 
Positive correlations have been found, amongst other things, between NC and Objectivism (the tendency to base one's judgements and beliefs on empirical information and rational considerations, Leary et al., 1986; see Cacioppo et al., 1996, for a review of studies concerning NC).

Hypothesised relationships between NC and the motivations in the processing of CBA reports Challenge orientation clearly indicates individuals' inclination to systematic processing of the more cognitively complex and less explicit content. Consequently, it is hypothesised that there is a positive relationship between $\mathrm{NC}$ and Challenge orientation.

Since NC was found to be positively related to Objectivism, indicating that individuals high in $\mathrm{NC}$ are more open to change their opinion - perhaps even their strategic (self-centred or political) opinion - if empirical or rational information demands so, it is to be expected that $\mathrm{NC}$ and Strategic orientation are inversely related.

Absolute orientation has been conceptualised as the tendency to overrate or absolutise the CBA because of a conviction that it is imperative to 'simply' trust the outcomes of the CBA report and base the final decision on its results. Nicolaisen (2012) found that individuals with a higher education tend to perceive results of a research report with more skepticism than people with a low education. From the findings of Spotts (1994) we derive that level of education and Need for Closure are positively related as well. Consequently, it is hypothesised that there is a negative relationship between NC and Absolute (vs. Relative) orientation.

\section{Characteristics of Personal Need for Structure (PNS)}

PNS is designed to "assess preferences for structure and clarity in most situations, with ambiguity and grey areas proving troublesome and annoying" (Thompson et al., 1989) and was indicated by Neuberg et al. (1997) to serve "to capture the chronic preference for cognitive simplicity and structure". Thompson et al. (1992) furthermore indicate that PNS "reflects individual differences in preferences for structure and clarity in one's thinking and one's life". To measure individuals' PNS, generally the scale validated by Thompson et al. (1989) is used. This scale consists of items (such as "I become uncomfortable when the rules in a situation are not clear" "I hate to be with people who are unpredictable"; "I don't like situations that are uncertain." Negative correlations have been found, amongst other things, between PNS and Openness to experience, and Need for Cognition (Neuberg and Newsom, 1993). Furthermore, it should be expected that people high in PNS prefer simple informational messages over complex ones, which require more cognitive effort to understand (e.g. Van Hiel and Mervielde, 2003).

Hypothesised relationships between PNS and the motivations in the processing of CBA $\underline{\text { reports }}$

PNS is expected to be negatively related to Challenge orientation. Basically, this is because high PNS is indicative of rigid or inflexible thought, whereas Challenge orientation is conceptualised as showing flexibility in changing one's thoughts for the sake of making better 
decisions. Individuals high in Challenge orientation are likely to start processing a CBA report in an open-minded way.

Strategic orientation is hypothesised to be positively related to PNS. The reason is that highPNS individuals will need to act strategically more than low-PNS individuals in order to be able to maintain their more circumscribed convictions.

Absolute orientation is hypothesised to be positively associated with PNS. It may be expected that absolutising a message in the context of a decision-making process requires people to freeze their judgments and then to remain relatively uncritical about their opinions, which are characteristic of high PNS.

\section{Characteristics of Personal Fear of Invalidity (PFI)}

Personal Fear of Invalidity (PFI) refers to the tendency of individuals to seek alternatives and avoid making an explicit choice between them because of a fear of being incorrect (Thompson et al., 1992), and to the extent to which individuals are concerned with the cost of committing errors (Thompson et al., 1989). To measure an individual's PFI, typically, the scale validated by Thompson et al. (1989) is used. This scale consists of 14 items, such as "I prefer situations where I don't have to decide immediately"; "I rarely doubt that the course of action I have selected will be correct" (reverse scored). Thompson et al. (1992) indicate that individuals high in PFI were found to be concerned about the possible consequences of a choice, that they are indecisive, that they were found to be likely to feel discomfort when they receive feedback indicating that they have made a mistake, and that they are likely to embrace cognitive structures to reduce ambiguity. It can be suggested that there are positive relations between PFI and the amount of information acquired prior to making decisions (Wichary et al., 2008). Negative relations may be expected between PFI and reliance on incomplete information and confidence in one's own judgment (Kruglanski and Fishman, 2009).

Hypothesised relationships between PFI and the motivations in the processing of CBA reports It is conceivable that PFI is positively associated with Challenge orientation. Whereas Challenge orientation refers to a motivation to study the CBA exhaustively, individuals high in PFI are likely to study reports exhaustively as a result of a fear of making an error harmful to themselves or harmful to society.

Strategic orientation is hypothesised to be unrelated to PFI. Whether individuals have a high or low fear of making errors seems to be orthogonal to using the CBA outcomes strategically in order to serve their personal or political interests.

The relationship between PFI and Absolute orientation is expected to be positive. It might be expected that individuals high in PFI will want to minimise their personal responsibility of being wrong, whereby they are conceivably more likely to rely on the outcomes of underlying research reports. By doing so, in a sense, they absolve themselves of their personal responsibility. 


\section{Conceptual framework}

Overall, the previous section provides support for the hypothesis that broader cognitive orientations might have a systematic influence on actors' motivations in the processing and use of CBA reports in decision-making processes. We display the hypothesised relationships between NC, PNS, PFI and Strategic, Absolute, and Challenge orientation discussed in the previous section in a conceptual framework (figure 5). These relationships have not been examined by researchers before. This study contains the first exploration of these relationships.

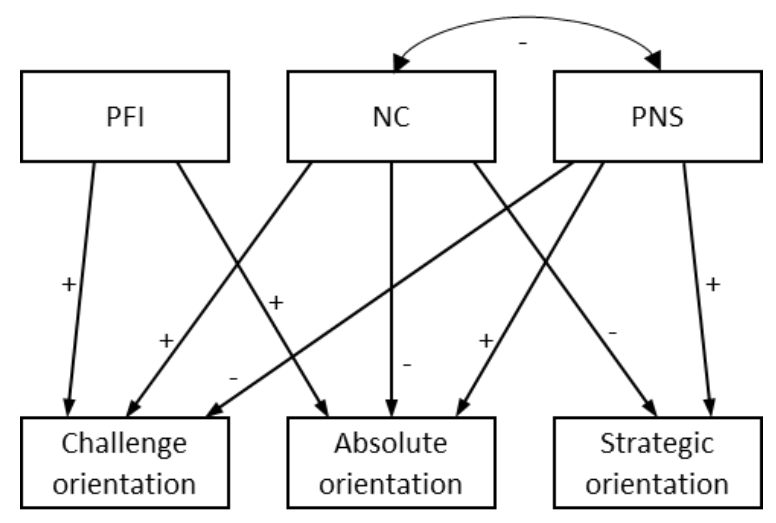

Figure 5: A conceptual framework of the hypothesised relationships between Personal Need for Structure, Need for Cognition, Personal Fear of Invalidity and Strategic, Absolute and Challenge orientation in the processing of CBA reports

The conceptual framework results in the following observations ${ }^{57}$ :

- Individuals who are high on Strategic orientation should be expected to be low on NC, high on PNS, and either high or low on PFI;

- Individuals high on Absolute orientation should demonstrate high PNS, high PFI and low NC;

- Individuals who are high on Challenge orientation are expected to show high NC, high PFI and low PNS.

\section{Relate psychological characteristics of flamboyant heurist and stubborn heurist}

Looking at the conceptual framework (figure 5) we assume that the 'flamboyant heuristic individual' will have a low NC and low PFI. The flamboyant individual tends to rely on intuition. For this individual it is not necessary to process research findings to come to a decision. Hence, his NC is low. Moreover, the PFI of a flamboyant individual can assumed to be low. This individual will trust that his intuition is right, even when the outcomes of a research report contrast his intuition. At best, this type of individual will read the top page of a research report and will use the results of the CBA report in a strategic way. When the report supports his intuition, he considers the information in the report as valid. When the report does not support his opinion he might marginalise the validity of the report.

\footnotetext{
${ }^{57}$ We would like to emphasise that the assumed relationships in the conceptual framework need to be tested in further research.
} 
It is likely that the 'stubborn heuristic individual' is high on PNS. Although the CBA report prominently communicates that the welfare effect of the project is highly uncertain, this individual wants to know if the outcomes mean that the project should or shouldn't be supported. It is either black or white. This type of individual will not consider it problematic to process the report systematically (use System 2), as long as he can find conclusive evidence for a 'go' or 'no go' decision. Although uncertainty is communicated prominently, this individual will not consider the uncertainty.

We hypothesise that the result of the prominent communication of uncertainties is that the 'flamboyant individual' will not use the CBA report at all, whereas the 'stubborn heuristic individual' is likely to ignore the uncertainty, even though the uncertainty is communicated in a prominent way.

\section{Solutions to enhance systematic processing}

In this section we discuss some possible remedies to enhance motivation of the flamboyant heurist and the stubborn heurist to simultaneously understand uncertainty and perceive the CBA report as useful input for the decision-making process (thus, some remedies for solving the dilemma). For both individuals it is not easy to achieve our double objective. However, our theory indicates that increasing the Personal Fear of Invalidity might help both individuals to consider the results of the CBA report in a more in-depth way. Accordingly, a solution could be that decision makers are held personally accountable for their decisions (e.g. Bruzelius et al., 2002). When these individuals know in advance that the consequences of a wrong decision will be severe (for their income or reputation), this might be an incentive to process the CBA report more systematically, even though the main conclusion of the CBA report is that the welfare effect of the project is uncertain. Flyvbjerg et al. (2003) propose a number of instruments to improve accountability. There are, however, a number of dangers with the introduction of such a measure, moral hazard being the most important (Cantarelli, 2011).

Another remedy to enhance systematic processing of information of a CBA report is to enhance the Ability and Opportunity of individuals, by training, for instance. It may be assumed that the Ability of individuals to work with research reports that communicate an uncertain message will be enhanced anyhow when all CBA reports communicate uncertainty. Eventually individuals get more used to it. Opportunity of individuals may be enhanced by customising the environmental characteristics of the message (O'Keefe, 2008), such as credibility of the author, appearance of the text or clarity of illustrations. This means that it is more likely that the flamboyant individual will process the information of the CBA report in a systematic way when the report (that presents uncertain results) is presented by THE expert in the field and the lay-out of the report is very persuasive. Because the flamboyant individual is forced to use System 2 to process the uncertain message of the CBA report it is paramount to make sure that the individual solely needs to use System 1 to process the rest of the information. More specifically, jargon should be avoided at all cost, the report should be very easy to read, persuasive info graphics should be used etc. 
Although we do not necessarily provide a definitive answer to the question of how the 'communication dilemma' can be solved, we conclude that uncertainty should be communicated very prominently before point estimates in order to make sure that CBA users understand the uncertainty. However, one simultaneously should apply the actions that are discussed in this section to make sure that decision makers still perceive the CBA as useful information. We recommend scrutinising which of these actions is most effective in future research.

\section{Concluding remarks}

In this paper we discuss solutions that aspire to be a first step towards solving two dilemmas with respect to handling uncertainty in the CBA and the decision-making process in which the CBA is used. The 'price-quality dilemma' and the 'communication dilemma'.

Regarding the handling of uncertainty in CBA studies, we derive three main conclusions. Firstly, in addressing the 'price-quality' dilemma there is a need for models in CBA which can more accurately estimate project impacts without substantially increasing time and monetary costs compared to the current models. The INDY-MonteCarlo method is an example of such a model. Secondly, if uncertainty is considered in CBA studies, and if it is desirable that different types of users are given a better understanding of the uncertainty, the uncertainty should be presented very prominently. Cognitive theory shows that the negative consequences of using heuristics when processing the CBA report (i.e. using outcomes strategically or absolutise or marginalise the report) can be diminished when CBA practitioners first communicate the uncertainty surrounding welfare effect estimations, such as bandwidths, ranges, and chances of outliers, and only then carefully give some indications to what could be plausible outcomes. Thirdly, if uncertainty is considered in CBA studies, CBA practitioners should be aware that communicating uncertainty (and, thus, even very large uncertainty) in a prominent way can lead to problems for individuals that process information heuristically. In this study, we developed a cognitive psychological conceptual framework of motivation to use the CBA report in the decision-making process. Based on this conceptual framework we identify remedies for the problems caused by a prominent communication of uncertainties. We argue that increasing heuristic individuals' Personal Fear of Invalidity might stimulate them to consider the results of the CBA report in a more in-depth way. One way of achieving this is by increasing personal accountability for a negative outcome of a decision. Another remedy is to enhance the presentation of the results. It is important that 'the expert in the field' presents research reports that communicate an equivocal message to heuristic individuals. Likewise, optimising environmental characteristics of the message, such as appearance of the text, clarity of illustrations, less jargon, etc., increases the chance that individuals will make the cognitive effort to understand the uncertainty. Lastly, training that enhances the ability of individuals to process CBA reports that communicate an uncertain message might result in a more systematic way of processing the information.

We would like to emphasise that the aim of this contribution was to contribute to our insight into handling uncertainty in CBA in a more optimal way. This was done by considering the 
result of giving uncertainty a more prominent place in the analysis and in the communication of results in a CBA report. Several items in this study have not been empirically demonstrated. This study contains the first exploration of these relationships and further research is needed to test the validity of the hypothesised relationships. We distinguish three relationships that need further research. Firstly, the fact that CBA users make use of heuristics in the processing of CBA reports has not been tested. Theoretically, it may be expected that this is indeed the case, but the extent to which this is the case for decision makers processing CBA reports remains unclear. Secondly, based on existing literature regarding cognitive psychology, we suggest that uncertainty is better understood if communicated very prominently in the CBA report, but the extent to which the understanding increases has not been tested. Thirdly, the relationships between broader cognitive motivations and motivations in the processing of CBA reports have not been examined before.

Other possible avenues for future research based on the results of this study include the following. Firstly, which format communicates uncertainty in an optimal way? In this study we found that - based on cognitive theory - CBA users understand uncertainty better if uncertainty is presented prior to point estimations. However, we did not analyse which format is the most appropriate to present uncertainty in CBA reports so that users with different personality and social psychological characteristics are able to understand the information and evaluate the information as useful input in the decision-making process. Secondly, which social-psychological factors explain the position of CBA in a group decision-making process, and what does this mean for the way uncertainties should be communicated in CBA reports? The background of this question is that decisions with regard to spatial-infrastructure projects are usually made in group process, not by individuals. This study, - at least, in the discussion of the 'communication' dilemma - is focused on individuals. Thirdly, in practice CBA reports are 'translated' by senior civil servants to politicians. Hence, one can argue that not the politicians but the senior civil servants should be encouraged to process and communicate uncertainty. Does the fact that results - and uncertainties - are usually communicated via a senior civil servant to a politician have any effect on the way uncertainties should be communicated in CBA reports?

\section{References}

Ackerman, F., Heinzerling, L. (2004). Priceless: on knowing the price of everything and the value of nothing, New York: New Press.

Andrews, J.C. (1988). Motivation, ability, and opportunity to process information: Conceptual and experimental manipulation issues. In Bettman, J.R. (Ed.), Advances in Consumer Research 15, 219-225.

Annema, J.A., Frenken, K., Koopmans, C.C. (2013). Twaalf jaar maatschappelijke kostenbatenanalyse van transportprojecten: 106 rapporten geanalyseerd. Colloquium Vervoersplanologisch Speurwerk, 22 November 2013. Rotterdam.

Barrett, D.W., Patock-Peckham, J.A., Hutchinson, G.T., Nagoshi, C.T. (2005). Religious orientation and social cognitive motivation. Personality and Individual Differences, 38(2), 461-474. 
Beattie, R. B. (1995). Everything you already know about EIA (but don't often admit). Environmental Impact Assessment Review 15 (2), 109-114.

Bliemer, M.E. Versteegt, Castenmiller, R. (2004). INDY: A New Analytical Multiclass Dynamic Traffic Assignment Model. In: Proceedings of the TRISTAN V conference, pp. 1-8. Montreal: CRT.

Bruzelius, N., B. Flyvbjerg, and W. Rothengatter. (2002) Big decision, big risks. Improving accountability in mega projects, in: Transport Policy, 9(2), 143-154.

Cacioppo, J.T., Petty, R.E. (1982). The need for cognition. Journal of Personality and Social Psychology, 42(1), 116-131.

Cacioppo, J.T., Petty, R.E., Kao, C.F. (1984). The efficient assessment of need for cognition. Journal of Personality Assessment, 48, 306-307.

Cacioppo, J.T., Petty, R.E., Feinstein, J.A., Jarvis, W.B.G. (1996). Dispositional differences in cognitive motivation: The life and times of individuals varying in need for cognition. Psychological bulletin, 119, 197-253.

Calvert, S.C., Taale, H., Snelder, M., \& Hoogendoorn, S.P. (2012) Probability in traffic: a challenge for modeling. Proceedings of the $4^{\text {th }}$ International Symposium on Dynamic Traffic Assignment (DTA2012). Martha's Vineyard, MA, USA.

Calvert, S.C., Taale, H., Snelder, M., \& Hoogendoorn, S.P. (2014) Application of Advanced Sampling for efficient Probabilistic Traffic Modeling. Manuscript submitted for publication.

Cantarelli, C.C. (2011). Cost Overruns in Large-Scale Transport Infrastructure Projects: A Theoretical and Empirical Exploration for the Netherlands and Worldwide. Delft: TU Delft.

Carver, C.S., \& Scheier, M.F. (2000). On the structure of behavioral self-regulation. In M. Boekaerts, P. R. Pintrich, \& M. Zeidner (Eds.), Handbook of Self-Regulation, 42-80. San Diego: Academic Press.

Eliasson, J., \& Lundberg, M. (2012). Do Cost-Benefit Analyses influence transport investment decisions? Transport Reviews, 32(1), $29-48$.

Epley, N., \& Gilovich, T. (2006). The anchoring and adjustment heuristic: why adjustments are insufficient. Psychological Science, 17, 311-318.

Evans, J.S.B.T., \& Frankish, K. (2009). In two minds: Dual processes and beyond. New York: Oxford University Press.

Flyvbjerg, B., Skamris Holm, M.K., Buhl, S.L. (2003). How Common and How Large Are Cost Overruns in Transport Infrastructure Projects? Transport Reviews, 23(1), 71-88.

Grant-Muller, S., Mackie, P., Nellthorp, J., Pearman, A. (2001). Economic appraisal of European transport projects - the state of the art revisited. Transport Reviews, 21 (2), 237-261.

Hagen, K.P., S. Berntsen, B. Bye, L. Hultkrantz, K. Nyborg, K.R. Pedersen, M. Sandsmark, G.H. Volden, G. Avitsland, 2012, Cost-Benefit Analysis, Official Norwegian Report NOU 2012:16.

Huizinga, F.H., \& Smid, B.C. (2004). Vier Vergezichten op Nederland: Productie, arbeid en sectorstructuur in vier scenario's tot 2040. Den Haag: Centraal Planbureau.

Kahneman, D., Slovic, P., Tversky, A. (1982) Judgment Under Uncertainty: Heuristics and Biases. New York: Cambridge University Press. 
Kahneman, D. (2011). Thinking, fast and slow. New York: Farrar, Straus and Giroux.

Knaap, T., Oosterhaven, J., 2011. Measuring the welfare effects of infrastructure: a simple spatial equilibrium evaluation of Dutch railway proposals. Research in Transportation Economics. 31, 19-28.

Kruglanski, A.W., Fishman, S. (2009). The need for cognitive closure. In: M.R. Leary, \& R.H. Hoyle (Eds.), Handbook of individual differences in social behaviour (pp. 343353). New York: Guilford Press.

Leary, M.R., Sheppard, J.A., McNeil, M.S., Jenkins, T.B., Barnes, B.D. (1986). Objectivism in information utilization: Theory and measurement. Journal of Personality Assessment, $50,32-43$.

Letson, D., Llovet, I., Podestá, G., Royce, F., Brescia V., Lema, D., Parellada, G. (2001). User perspectives of climate forecasts: crop producers in Pergamino, Argentina. Climate Research, 19(1), 57-67.

Lichtenstein, S., Slovic, P. (1971). Reversal of preferences between bids and choices in gambling decisions. Journal of Experimental Psychology, 89, 46-55.

Meyers-Levy, J., Maheswaran, D. (2004). Exploring Message Framing Outcomes When Systematic, Heuristic or Both Types of Processing Occur. Journal of Consumer Psychology, 14(1\&2), 159-166.

Ministry of Transport, Public Works and Water Management (2004) Aanvullingen op de Leidraad Overzicht Effecten Infrastructuur [Supplements to the Dutch CBA Guide] (The Hague: Ministry of Transport, Public Works and Water Management).

Mouter, N., Annema, J.A., van Wee, B. (2013). Attitudes towards the role of Cost-Benefit Analysis in the decision-making process for spatial-infrastructure projects: a Dutch case study. Transportation Research Part A (58). P. 1-14.

Naess, P. (2006). Cost-benefit analysis of transportation investments. Neither critical nor realistic. Journal of critical realism 5 (1), 32-60.

Naess, P., Strand., 2012. What kinds of traffic forecasts are possible? Journal of critical realism 11 (3), 277-295.

Neuberg, S.L., Judice, T.N., West, S.G. (1997). What the Need for Closure Scale measures and what it does not: Toward differentiating among related epistemic motives. Journal of Personality and Social Psychology, 72, 1396-1412.

Neuberg, S.L., \& Newsom, J.T. (1993). Personal Need for Structure: Individual differences in the desire for simple structure. Journal of Personality and Social Psychology, 65, 113131.

Nicolaisen, M. S. (2012). Forecasts: Fact or Fiction? Uncertainty and Inaccuracy in Transport Project Evaluation. Department of Development and Planning, Aalborg University

O'Keefe, D. J. (2008). Elaboration likelihood model. In W. Donsbach (Ed.), International encyclopedia of communication, 4, 1475-1480. Oxford, UK, and Malden, MA: WileyBlackwell.

Petty. R.E., Cacciopa, J.T., 1986 The Elaboration Likelihood Model of Persuasion. Central and peripheral routes to attitudes change. Springer Series in Social Psychology 1986, 124.

Salling, K.B., Banister, D. (2009). Assessment of large transport infrastructure projects: the CBA-DK model. Transportation Research Part A, 43, 800-813. 
Shah, A. K., \& Oppenheimer, D. M. (2008). Heuristics made easy: An effort-reduction framework. Psychological Bulletin, 134(2), 207-222.

Spotts, H. (1994). Evidence of a relationship between need for cognition and chronological age: Implications for persuasion in consumer research. Advances in Consumer Research, 21, 238-243.

Stanovich, K.E., West, R.F. (2000). Individual differences in reasoning: Implications for the rationality debate? Behavioral and Brain Sciences, 23, 645-665.

Thompson, M.M. (2008). Individual Difference Theory and Research: Application to Multinational Coalition Teamwork. Paper presented at the HFM-142 Symposium: Adaptability in Coalition Teamwork (NATO RTO-HFM-142), pp. KN2-1 - KN2-28.

Thompson, M.M., Naccarato, M.E., Parker, K.C.H., Moskowitz, G.B. (2001). The Personal Need for Structure (PNS) and Personal Fear of Invalidity (PFI) measures: Historical perspectives, present applications and future directions. In G. B. Moskowitz (Ed.), Cognitive social psychology: The Princeton symposium on the legacy and future of social cognition, 19-39). Mahwah, NJ: Lawrence Erlbaum Associates, Inc.

Thompson, M.M., Naccarato, M.E., Parker, K.E. (1989). Assessing cognitive need: The development of the Personal Need for Structure and Personal Fear of Invalidity scales. Paper presented at the annual meeting of the Canadian Psychological Association, Halifax, Nova Scotia.

Thompson, M.M., Naccarato, M.E., Parker, K.E. (1992). Measuring cognitive needs: The development and validation of the Personal Need for Structure (PNS) and Personal Fear of Invalidity (PFI) measures. Unpublished manuscript.

Tversky, A., \& Kahneman, D. (1974). Judgment under uncertainty: Heuristics and biases. Science 185 (4157), 1124-1131.

Van Hiel, A., \& Mervielde, I. (2003) The Need for closure and the Spontaneous Use of Complex and Simple Cognitive Structures. The Journal of Social Psychology, 14, 559568.

van Lint, H., Miete, O., Taale, H., \& Hoogendoorn, S. (2012). Systematic Framework for Assessing Traffic Measures and Policies on Reliability of Traffic Operations and Travel Time. Transportation Research Record: Journal of the Transportation Research Board, 2302(1), 92-101.

Welch, M., \& Williams, H. (1997). 'The Sensitivity of Transport Investment Benefits to the Evaluation of Small Travel-Time Savings. Journal of Transport Economics and Policy, 31, 231-254.

Yamagishi, K. (1994). Consistencies and biases in risk perception: I. Anchoring process and response-range effect. Perceptual and Motor Skills, 79, 651-656.

Yperman, I., (2007). The Link Transmission Model for dynamic network loading. Catholic University of Leuven. 


\section{TRAIL Thesis Series}

The following list contains the most recent dissertations in the TRAIL Thesis Series. For a complete overview of more than 100 titles see the TRAIL website: www.rsTRAIL.nl.

The TRAIL Thesis Series is a series of the Netherlands TRAIL Research School on transport, infrastructure and logistics.

Mouter, N., Cost-Benefit Analysis in Practice: A study of the way Cost-Benefit Analysis is perceived by key individuals in the Dutch CBA practice for spatial-infrastructure projects, T2014/2, June 2014, TRAIL Thesis Series, the Netherlands

Ohazulike, A., Road Pricing mechanism: A game theoretic and multi-level approach, T2014/1, January 2014, TRAIL Thesis Series, the Netherlands

Cranenburgh, S. van, Vacation Travel Behaviour in a Very Different Future, T2013/12, November 2013, TRAIL Thesis Series, the Netherlands

Samsura, D.A.A., Games and the City: Applying game-theoretical approaches to land and property development analysis, T2013/11, November 2013, TRAIL Thesis Series, the Netherlands

Huijts, N., Sustainable Energy Technology Acceptance: A psychological perspective, T2013/10, September 2013, TRAIL Thesis Series, the Netherlands

Zhang, Mo, A Freight Transport Model for Integrated Network, Service, and Policy Design, T2013/9, August 2013, TRAIL Thesis Series, the Netherlands

Wijnen, R., Decision Support for Collaborative Airport Planning, T2013/8, April 2013, TRAIL Thesis Series, the Netherlands

Wageningen-Kessels, F.L.M. van, Multi-Class Continuum Traffic Flow Models: Analysis and simulation methods, T2013/7, March 2013, TRAIL Thesis Series, the Netherlands

Taneja, P., The Flexible Port, T2013/6, March 2013, TRAIL Thesis Series, the Netherlands

Yuan, Y., Lagrangian Multi-Class Traffic State Estimation, T2013/5, March 2013, TRAIL Thesis Series, the Netherlands

Schreiter, Th., Vehicle-Class Specific Control of Freeway Traffic, T2013/4, March 2013, TRAIL Thesis Series, the Netherlands 
Zaerpour, N., Efficient Management of Compact Storage Systems, T2013/3, February 2013, TRAIL Thesis Series, the Netherlands

Huibregtse, O.L., Robust Model-Based Optimization of Evacuation Guidance, T2013/2, February 2013, TRAIL Thesis Series, the Netherlands

Fortuijn, L.G.H., Turborotonde en turboplein: ontwerp, capaciteit en veiligheid, T2013/1, January 2013, TRAIL Thesis Series, the Netherlands

Gharehgozli, A.H., Developing New Methods for Efficient Container Stacking Operations, T2012/7, November 2012, TRAIL Thesis Series, the Netherlands

Duin, R. van, Logistics Concept Development in Multi-Actor Environments: Aligning stakeholders for successful development of public/private logistics systems by increased awareness of multi-actor objectives and perceptions, T2012/6, October 2012, TRAIL Thesis Series, the Netherlands

Dicke-Ogenia, M., Psychological Aspects of Travel Information Presentation: A psychological and ergonomic view on travellers' response to travel information, T2012/5, October 2012, TRAIL Thesis Series, the Netherlands

Wismans, L.J.J., Towards Sustainable Dynamic Traffic Management, T2012/4, September 2012, TRAIL Thesis Series, the Netherlands

Hoogendoorn, R.G., Swiftly before the World Collapses: Empirics and Modeling of Longitudinal Driving Behavior under Adverse Conditions, T2012/3, July 2012, TRAIL Thesis Series, the Netherlands

Carmona Benitez, R., The Design of a Large Scale Airline Network, T2012/2, June 2012, TRAIL Thesis Series, the Netherlands

Schaap, T.W., Driving Behaviour in Unexpected Situations: A study into the effects of drivers' compensation behaviour to safety-critical situations and the effects of mental workload, event urgency and task prioritization, T2012/1, February 2012, TRAIL Thesis Series, the Netherlands

Muizelaar, T.J., Non-recurrent Traffic Situations and Traffic Information: Determining preferences and effects on route choice, T2011/16, December 2011, TRAIL Thesis Series, the Netherlands

Cantarelli, C.C., Cost Overruns in Large-Scale Transportation Infrastructure Projects: A theoretical and empirical exploration for the Netherlands and Worldwide, T2011/15, November 2011, TRAIL Thesis Series, the Netherlands 